\title{
Diversidad de Rotíferos Monogononta en la cuenca del Bajo Paraná
}

\section{José de Paggi, Susana B.}

Doctor en Ciencias Naturales

Dirección: Schnack, Juan Alberto

Facultad de Ciencias Naturales y Museo

2004

Acceso en:

http://naturalis.fcnym.unlp.edu.ar/id/20120126000112

\section{(c) (1) (2) (2) \\ BY NC SA}

Esta obra está bajo una Licencia Creative Commons

Atribución-NoComercial-Compartirlgual 4.0 Internacional

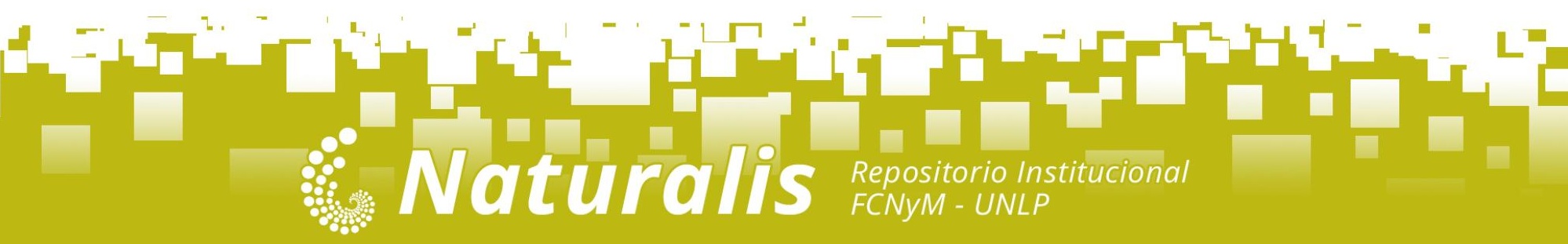




\section{RESUMEN}

El objetivo de este trabajo es analizar la composición y riqueza, en niveles gamma, beta y alfa, de la fauna de Rotíferos de la cuenca del Río Paraná desde su confluencia con el río Paraguay hasta su desembocadura en el río de la Plata. Se consideraron el curso principal del río, cauces secundarios, principales tributarios y 79 ambientes lénticos de la llanura de inundación. El estudio se basó en la colección de muestras existentes en el Instituto Nacional de Limnología tomadas entre los años 1968-2000. El análisis incluyó la distribución espacial y temporal de la riqueza.

La diversidad gamma fue de 241 especies, lo que constituye poco más de un tercio de los rotíferos hallados hasta el presente en Sudamérica. Los géneros Brachionus, Lecane y Trichocerca presentaron la mayor diversidad, a pesar de no ser típicamente planctónicos. En los ambientes lóticos se hallaron 145 especies, mientras que en los lénticos el total fue de 226.

El valor más bajo de riqueza de especies se registró en el curso principal (113), lo cual se asocia a que éste representa un ambiente estructuralmente más simple, con condiciones físicas rigurosas para la supervivencia de los rotíferos del plancton. El análisis de la distribución temporal de la riqueza y composición de especies en una sección del curso principal( km 603) durante el período 1976 - 2000 mostró una clara tendencia a la disminución del número de especies. La mayor diversidad anual se observó en 1977 y la menor en 1998. Las variaciones en la riqueza instántanea de rotiferos en los ambientes lóticos fueron reguladas en gran medida por el pulso de inundación. En general, durante las fases de aguas altas el número de especies fue mayor que en las de aguas bajas, ello se relaciona a la acción del pulso de inundación que activa la conectividad entre los ambientes de todo el sistema, favoreciendo el intercambio de agua y organismos. Las inundaciones extraordinarias, como la de 1982, incorporaron al curso principal un importante número de especies no registradas en los años previos de estudio, evidenciando el efecto de arrastre de las aguas desde otros sectores de la cuenca. El análisis de la afinidad faunística entre la composición de distintos tramos del curso principal mostró pocas especies en común. Por el número de especies litorales de presencia ocasional en el río puede inferirse que el mayor aporte proviene de los ambientes de la planicie de inundación, predominando el efecto de la dimensión lateral sobre la longitudinal. La riqueza acumulativa de especies o diversidad temporal de rotíferos en el curso principal del sistema sería una expresión indirecta de la riqueza de la llanura.

El mayor número de especies y géneros se encontró en las lagunas, observándose diversidades alfa mayores de 40 para un momento dado. No se registró un gradiente de 
riqueza en las lagunas ubicadas de $\mathrm{N}$ a $\mathrm{S}$, es decir en el sentido del eje de escurrimiento; sin embargo, la afinidad faunística entre ellas fue baja evidenciando particularidades en la composición de cada una. El régimen pulsátil del Paraná y la complejidad estructural de las lagunas son factores determinantes de la riqueza de las mismas. La incidencia de la entrada de las aguas de inundación en la diversidad de rotíferos se evidenció tanto en un análisis temporal del área limnética de una laguna en particular, muestreada cada siete días, como en un estudio de varias de ellas con muestreos pre y pos-inundación. La conectividad activada por la inundación generó una mayor comunicación entre las lagunas de la planicie y contribuyó a homogeneizar la composición, lo cual fue analizado mediante la diversidad beta.

La riqueza más alta se encontró en las lagunas con mayor heterogeneidad ambiental. Incluso dentro de una misma laguna el área litoral con vegetación presentó mayor diversidad de rotíferos que el área limnética. Los ambientes sin vegetación, independientemente de su tamaño, presentaron, a su vez, una menor diversidad alfa.

La microfauna de rotíferos del Paraná se caracteriza por la dominancia de elementos de distribución cosmopolita y cosmotropicales, presenta similitudes con la de otros ríos sudamericanos y algunos africanos en cuanto a la mayor riqueza de Brachionus, Lecane y Trichocerca. Comparte con los primeros un número de especies endémicas de la región Neotropical, algunas de ellas consideradas inicialmente como exclusivamente amazónicas. Este sector del Paraná presenta una riqueza mayor que la de los tramos superiores, lo cual puede asociarse al mayor desarrollo de su planicie lateral de inundación. El número total de especies es similar al hallado en otros ríos con planicie aluvial, sin embargo es menor que el del Amazonas, probablemente debido a que este último presenta una diversidad química de sus aguas incrementada por numerosos ambientes de $\mathrm{pH}$ ácido propicias para la mayor diversidad de rotíferos. La composición muestra similitud con la del Pantanal del río Paraguay, el $50 \%$ de las especies registradas en esa región estuvo presente en el Bajo Paraná.

En este trabajo se efectuó también un análisis taxonómico de los componentes de las tres familias de rotíferos mejor representadas en el río Paraná. Se citan doce nuevos registros para Argentina correspondientes a los géneros, Dicranophoroides, Dicranophorus, Eosphora, Euchlanis, Gastropus y Trichocerca. Se propone el cambio de estatus taxonómico en taxones infraespecíficos del género Brachionus. 


\section{AGRADECIMIENTOS}

Al Dr. Juan A. Schnack por la valiosa dirección de este trabajo, la crítica y paciente lectura de los borradores del mismo.

A Juan César Paggi por su siempre incondicional apoyo, incentivo y sugerencias en la realización de este trabajo. A Mariana y César L. Paggi por el auxilio en la preparación de figuras e inserción en el texto. A Gabriela Paggi por su cálido estímulo, tan útil en muchas circunstancias.

A los eficientes técnicos del INALI: Cristian De Bonis por su apoyo en trabajos de campo, Lucrecia Valdeneus y Gabriel Tour por su colaboración en tareas de la edición del texto. A Pablo Collins por la obtención de algunas muestras en campo. A todos los compañeros del INALI que de distinta manera contribuyeron a que pudiera realizar esta tesis. 


\section{INDICE}

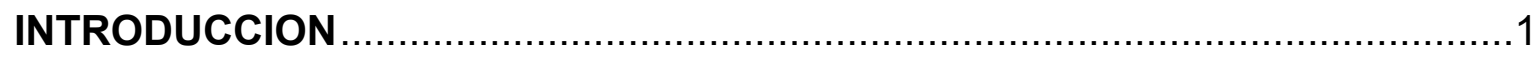

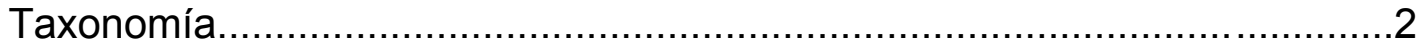

Biodiversidad y su manifestación en ríos con planicie de inundación.............3

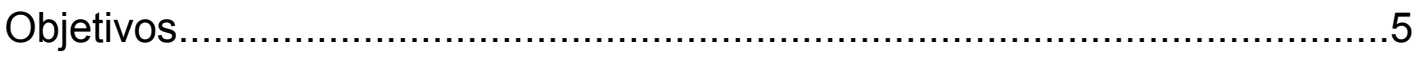

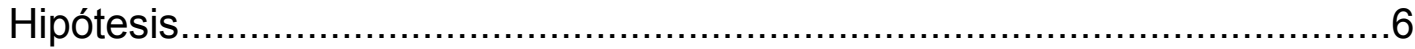

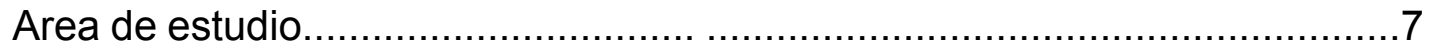

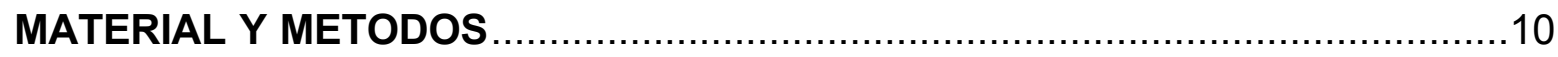

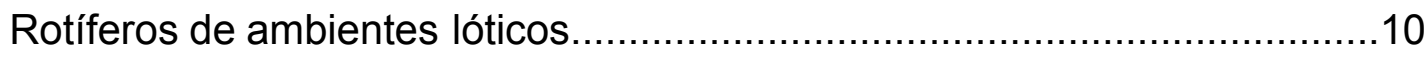

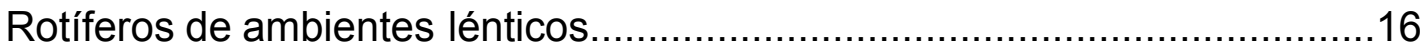

Algunas consideraciones sobre la riqueza de especies y su estimación......26

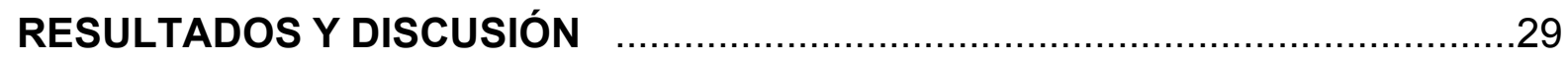

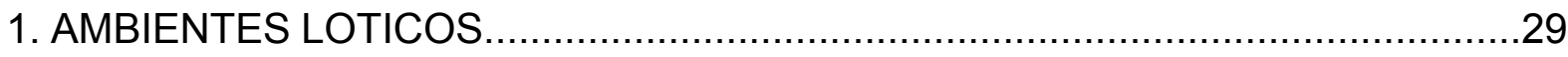

Fauna de rotíferos en cursos fluviales de distinta jerarquía .........................29

Consideraciones generales sobre la diversidad de rotíferos en los ambientes

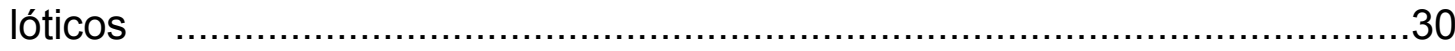

Variaciones espaciales en la diversidad de rotíferos en el curso principal......35 Variaciones temporales en la diversidad de rotíferos en el curso

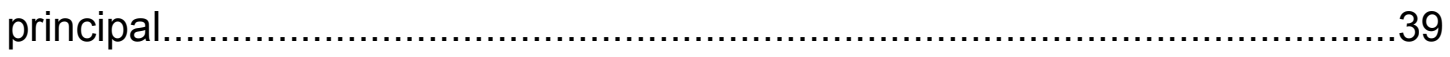

Diversidad temporal de los rotíferos y fluctuaciones de nivel.........................46

Riqueza específica, turbiedad y velocidad de la corriente...............................50

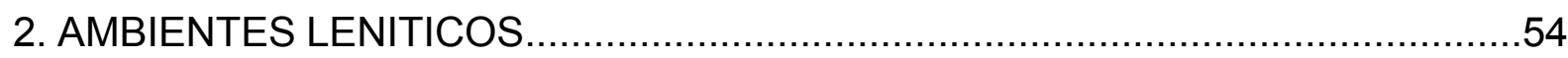

Diversidad general de los rotíferos en ambientes de la planicie de inundación

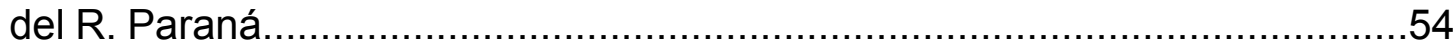

Riqueza y composición de rotíferos en lagunas ubicadas a lo largo del eje de

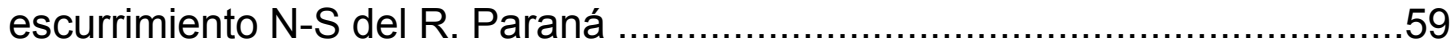

Diversidad de rotíferos y complejidad ambiental ...........................................63 
Variaciones espaciales y temporales en la diversidad de rotíferos en relación

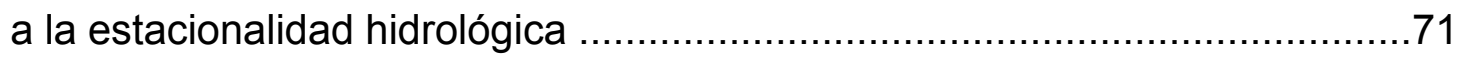

Diversidad de rotíferos y conectividad de los ambientes .............................84

3. LA ROTIFEROFAUNA DEL SISTEMA RIO-LLANURA DEL PARANA Y CONSIDERACIONES SOBRE LOS FACTORES QUE DETERMINAN SU DIVERSIDAD...88

La riqueza de rotíferos del río Paraná respecto de la de otros ríos ................99

Aspectos biogeográficos en la composición de rotíferos del Paraná ............101

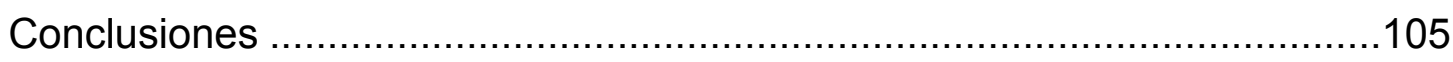

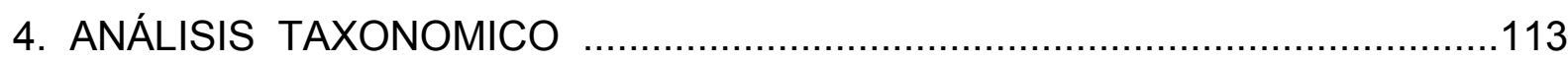

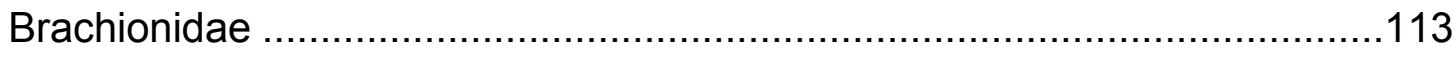

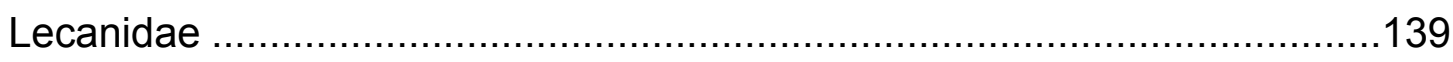

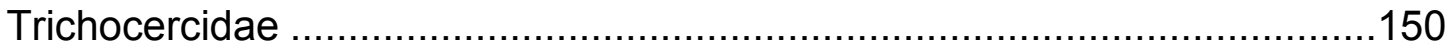

Nuevos registros para la fauna Argentina .............................................172

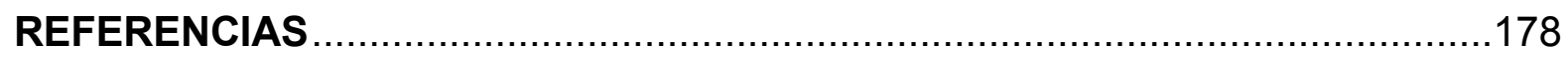


Con amor a mi esposo

Juan C. Paggi

y nuestros hijos

Gabriela, César L.

y Mariana 


\section{INTRODUCCION}

Entre los invertebrados acuáticos, el phylum Rotifera reúne unas 2000 especies, de un tamaño que varía entre poco menos de $100 \mu \mathrm{m}$ y $2 \mathrm{~mm}$, aunque muy pocas superan $1 \mathrm{~mm}$. Incluye las clases Monogononta, Bdelloidea y Seisonidea, aunque el análisis de algunas características que aportan las técnicas moleculares y la taxonomía cladística sugieren que los dos primeras podrían reunirse en una única clase (en Ricci et al. 2000).

Los rotíferos se encuentran en musgos terrestres, microlimnótopos (huecos en árboles, axilas foliares) y, principalmente, en los ambientes acuáticos continentales, aún en los más pequeños y temporarios. Forman parte de las comunidades del plancton, del bentos y litorales. La mayor diversidad de especies se registra en las zonas litorales con vegetación acuática.

Son organismos metazoos, pseudocelomados, eutélicos; su patrón corporal presenta una gran diversidad de formas, a veces recubiertos de una loriga elástica o rígida; presentan dos elementos característicos: una corona de cilios sobre su cabeza, que cumple una importante función locomotora en los organismos de vida libre y una estructura masticatoria denominada trophi. Posen quimioreceptores que les permiten discriminar partículas de alimento o las presas, en el caso de los carnívoros; algunos depredadores también producen señales químicas que les permite a las potenciales presas desarrollar espinas corporales de carácter defensivo (Snell 1998).

La reproducción es partenogenética en Bdelloideos y partenogenética y anfigónica, aunque en menor grado, en los Monogononta. En los primeros, este tipo de reproducción sería muy primitiva como lo atestigua el hecho de que aunque diploides, no poseen cromosomas homólogos, con lo cual se refuerza la hipótesis de una antigua supresión de la recombinación (Ricci et al. 2000). En la actualidad se conoce la existencia probada de machos en algunas especies de Mononongonta. En tal sentido, algunos estudios han aportado valiosos datos sobre los mecanismos químicos de reconocimiento específico entre machos y hembras (Snell et al. 1995, Rico Martínez \& Snell 1997a entre otros). La estrategia reproductiva de producción de huevos de resistencia o de diapausa por hembras mícticas asegura su supervivencia en el medio natural. En Synchaeta pectinata Ehrenberg incluso se observó la producción de huevos en diapausa por parte de hembras amícticas (Gilbert 1995). Los huevos de resistencia producidos por anfigonia pueden conservar su viabilidad durante mucho tiempo, existiendo registros de hasta 65 años ( Ricci et al. 2000). La eclosión experimental de estos huevos depositados en los sedimentos secos es una excelente herramienta para la evaluación 
complementaria de la diversidad de una región y localización de taxa de dispersión pasiva (Langley et al. 2001).

Los rotíferos tienen importancia en el reciclado de nutrientes y en la producción secundaria de los ambientes acuáticos, siendo fundamentales en la transferencia de energía de los productores primarios a los restantes niveles tróficos. Constituyen también el primer alimento de la gran mayoria de las larvas de peces, por lo tanto son uno de los alimentos más empleados en la larvicultura tanto de especies de agua dulce como marinas, lo que llevó al desarrollo de técnicas eficientes de cría masiva (Dhert et al. 2001).

Como fuente de alimento, los rotíferos pueden utilizar una amplia variedad de recursos, entre los que se encuentran las algas, bacterias, protozoos y detritus. Algunas especies de los géneros Asplanchna, Synchaeta y Ploesoma entre los planctónicos y Cupelopagis vorax entre los sésiles son depredadores. Tradicionalmente, se ha destacado su importancia en la cadena autotrófica de los lagos; sin embargo, su importancia no es menor en la cadena del detritus, ya que muchos de ellos son detritívoros y bacteriófagos (Nogrady et al. 1993). El rol de los mismos en la transferencia del carbono entre ambas cadenas troficas es muy importante (Ardnt 1993). Son muy abundantes en ambientes expuestos a eutroficación cultural (Walz et al. 1987) pero pueden serlo también en lagos no afectados por acción antrópica, donde los peces planctívoros al consumir zooplanctontes de cuerpo grande promueven, indirectamente, una producción mayor de los rotíferos al eliminar a sus competidores y depredadores invertebrados (Lynch \& Shapiro 1981).

Por sus cortos ciclos de vida responden rápidamente a los cambios en el ambiente constituyendo muy buenos indicadores de alteraciones ambientales (Gannon \& Stemberg 1978). Por otro lado, en la última década han sido objeto de estudios toxicológicos que señalan su sensibilidad frente a distintas sustancias xenobióticas pero también muestran mayor resiliencia respecto de los otros componentes del plancton (José de Paggi 1997).

\section{Taxonomía}

En los rotíferos Monogononta, considerando la prevalencia de la reproducción partenogenética, es difícil aplicar el concepto de especie biológica (Ruttner- Kolisko 1974, Koste \& Shiel 1989a). El estudio taxonómico de rotíferos se basa, principalmente, en el análisis de caracteres morfológicos externos, evaluados según distintos métodos o técnicas, entre los que se incluyen la microscopia electrónica de barrido y los análisis biométricos. Desde hace pocos años, estos análisis han comenzado gradualmente a completarse con estudios de cariotipos, empleo de electroforesis para el examen de las proteínas, y secuenciación de ADN (Gómez 1998, 
Welch \& Meselson 1998, entre otros). Recientemente, los estudios de mecanismos de reconocimiento de las hembras han comenzado a utilizarse como herramientas para la separación efectiva entre especies de un grupo (Rico Martinez \& Snell 1995, 1997). Sin embargo, estas herramientas metodológicas no son aprovechadas en la medida esperada .

La taxonomía de los rotíferos presenta diversos problemas, extensamente discutidos (Pejler 1977, Koste \& Shiel 1989a, Ruttner-Kolisko 1989, Nogrady et al. 1993) cuyas causas son diversas, aunque debidas, fundamentalmente, a las siguientes particularidades de este taxon:

1. La partenogénesis facultativa u obligada: este tipo de reproducción implica transferencia de genotipos completos de padres a hijos, no existiendo diferencias genéticas entre ellos; por lo tanto, las mutaciones cuando no son letales se pueden fijar rápidamente en la población pudiendo generar un alto grado de variabilidad.

2. Corto tiempo generacional : se estima que, bajo condiciones favorables podrían producirse unas 100 generaciones por año potenciando los efectos de un determinado cambio genético.

3. Reducido número de caracteres morfológicos útiles: esta limitación, sumada a la variabilidad que exhibe este taxon dificulta su tratamiento taxonómico.

La alta variabilidad fenotípica (inducida por la dieta, la depredación y eclosión de huevos de resistencia) constituye una importante limitación para la taxonomía basada en la morfología externa. Además, los rotíferos monogononta parecen encontrar condiciones para mantener un activo proceso de especiación, el que puede ser particularmente promovido por la especialización estacional y los períodos de reproducción bisexual (Serra et al. 1997). En los Monogononta es común observar alta variabilidad intraespecifica, con un promedio de 1.4 taxa subespecíficos por especie no habiendo, aún entre cladóceros y copépodos un nivel comparable de diversidad intraespecifica (Serra et al. 1997), aunque se desconoce si tales diferencias se deben a causas biológicas o son más aparentes que reales, dadas las particularidades del desarrollo de la taxonomía de cada grupo.

Otra cuestión no menos importante es la existencia, en los rotíferos, de especies gemelas. Los estudios genéticos y moleculares realizados en la última década sobre la base de morfotipos diferentes de Brachionus plicatilis, han demostrado que se trata de un complejo de especies biológicas (Fu et al.1991, Gomez \& Serra 1995, Ciros-Perez et al. 2001) La dificultad de establecer los límites entre las especies gemelas le resta rigurosidad a los estudios de biodiversidad (Gomez \& Snell 1996).

\section{Biodiversidad y su manifestación en ríos con planicie de inundación}


La diversidad biológica puede ser medida en tres niveles diferentes: a nivel de la variabilidad genética , como medida de la diversidad del complemento genético dentro de una población, a nivel de especies, en términos de riqueza de especies o número de especies por unidad de área y a nivel de ecosistema, es decir, de diversidad de hábitats de un paisaje (Solbrig 1991).

El concepto más simple de diversidad es la riqueza de especies. La estimación de la riqueza para la elaboración de inventarios de especies es, sin duda, el punto de partida para todos los otros niveles de análisis. Es una herramienta necesaria para la evaluación de la magnitud de impactos futuros y la toma de decisiones en la biología de la conservación ; permite también identificar hábitats inusuales o únicos para futuros estudios científicos (Stemberger 1990). El inventario no significa solo un número de especies, sino quienes, con nombre y apellido determinan ese número. Naturalmente, aquí adquiere fundamental importancia la taxonomía como herramienta que permite la determinación correcta de las entidades biológicas. La primera Misión de la Systematics Agenda 2000 (1994) es precisamente: "to discover, describe and inventory global species diversity".

La diversidad tiene varios componentes, la diversidad alfa o diversidad local dentro de una comunidad o un sitio determinado, diversidad gamma o diversidad regional, entendiendo como región un área sin barreras significativas para la dispersión de los organismos y la diversidad beta en relación al recambio espacial en la composición de especies entre sitios (Ricklefs 1998). La diversidad gamma como número total de especies en una región es función de la diversidad alfa, la diversidad beta y la diversidad de hábitats, pudiendo ser la “región” definida en diferentes escalas (cuenca, planicie,etc.) (Whittaker 1960,1972).

Desde el punto de vista de los recursos acuáticos continentales el rasgo distintivo de Sudamérica es sin duda, la existencia de grandes humedales, individual y globalmente los más extensos de la biosfera, donde en comparación con otros continentes escurre superficialmente mayor cantidad de agua respecto de la superficie continental (Neiff 1997). Hay una prevalencia de ambientes fluviales sobre otros tipos de humedales. El mayor volumen de agua dulce lo reúnen las cuencas del Amazonas, Orinoco y del Plata, cuyos caudales combinados representan más de dos tercios del escurrimiento total del continente que fluye hacia el Atlántico (Morello 1984).

El régimen hidrológico de estos ríos presenta en síntesis cuatro fases, una de aguas bajas, cuando el río está contenido en su canal principal, cauces secundarios y lagunas de la llanura, una fase de aguas en ascenso, una fase de aguas altas, en la cual el río desborda 
su cauce e invade la llanura y una última fase de aguas en descenso hasta que la masa de agua se encauza nuevamente en sus canales.

Los ríos con planicie de inundación desarrollada constituyen ambientes particulares, donde la dinámica fluvial, entendida como la energía del agua en movimiento, es una fuerza modeladora que opera tanto a una escala amplia, de planicie de inundación favoreciendo la diversidad de hábitats, como a una más localizada sobre cada ambiente en particular. Como consecuencia de esta caracterización espacial y del régimen de pulsos de inundación, estos sistemas generan una gran heterogeneidad temporal y espacial. Son, precisamente, estos factores los responsables de la elevada biodiversidad que exhiben estos sistemas (Pianka 1966, Ward 1995, Shiel et al. 1998, Wetzel 2001, Ward \& Tockner 2001).

Debe considerarse que estos humedales, por su complejidad, requieren un enfoque metodológico y conceptual adecuado a la idea de que planicie y curso principal constituyen una unidad funcional y de paisaje. La estimación de la biodiversidad al nivel de inventarios de especies es una herramienta necesaria para el entendimiento de los procesos que operan en estos ríos con planicies de inundación (Ward \& Tockner 2001). La riqueza específica, calculada a través de distintas colecciones y durante un tiempo no necesariamente comparable para los distintos sitios, permite obtener un indicador de la complejidad biótica potencial de los humedales (Neiff 1999). Por otro lado, se ha señalado que la escasez de datos de biodiversidad a nivel de riqueza de especies en los ríos tropicales impide o dificulta hacer análisis de otro tipo, tales como comparaciones entre la diversidad de ambientes tropicales y templados (Wantzen \& Junk 2000).

Los estudios realizados en ambientes tropicales y subtropicales han señalado que los mismos sustentan una elevada diversidad biológica en general y a nivel de distintos grupos taxonómicos en particular (Moss 2000). Para el caso de los rotíferos es conocida la riqueza de especies de ríos con planicie de inundación, tales como el Orinoco Nasquez \& Rey 1989, 1992 ) Amazonas (Hardy et al. 1984), en Sudamérica, ríos Murray (Shiel et al.1998) en Australia, Niger (Segers et al. 1993) en Africa, y Brahmaputra (Sharma \& Sharma 2001) en India. Segers et al. (1993) han postulado que las planicies de inundación de ríos subtropicales y tropicales constituyen los hábitas de mayor riqueza de rotíferos.

\section{OBJETIVOS}

Este trabajo tiene como objetivos rectores: 
1.- Efectuar un relevamiento de la fauna de rotíferos Monogononta de la cuenca del río Paraná aguas abajo de su confluencia con el río Paraguay, hasta su desembocadura en el río de la Plata, considerando los siguientes ambientes: 1) curso principal; 2) cauces secundarios; 3) cauces tributarios 4) lagunas de la llanura de inundación.

2.- Analizar la diversidad temporal de los rotíferos de una sección del curso principal y de una laguna de su planicie de inundación.

3.-Realizar un estudio comparativo de la rotiferofauna de cada uno de los ambientes estudiados en particular a nivel del familias, géneros y especies.

4.-Efectuar un análisis comparativo de la riqueza de especies y composición de las faunas de las comunidades pelágica y litoral (excluyendo las especies fijadas a substratos).

5.- Realizar estudios taxonómicos de los grupos mejor representados (estudios morfológicos y biométricos de las especies más importantes)

6.- Analizar la rotiferofauna registrada en comparación con la de otros ríos de planicie de inundación.

\section{HIPOTESIS}

* Los diversos ecosistemas acuáticos de la cuenca del Paraná pueden ser caracterizados por la composición de su rotiferofauna .

* La riqueza de especies de los distintos ambientes estudiados es función su grado de heterogeneidad espacial.

* La riqueza de especies de rotíferos está en relación con el gradiente físico transversal que se registra en el río Paraná, determinado por la secuencia creciente: cauce principal-cursos secundarios y tributarios-lagunas del valle de inundación.

* La calidad química de las aguas y diversidad de hábitats favorecen la mayor importancia relativa de las familias Brachionidae, Lecanidae y Trichocercidae. 


\section{AREA DE ESTUDIO}

El gran sistema del Plata está formado por las cuencas de los ríos Paraguay, Paraná y Uruguay, originando la unión de estos últimos el río de La Plata. El Paraná con su principal tributario el río Paraguay, aporta al sistema el $77 \%$ del caudal.

El río Paraná por la longitud y extensión de su área tributaria es el río más importante del sistema hidrográfico del Plata. Tuvo su origen en el Plioceno por levantamientos tectónicos que formaron la Serra do Mar junto al Atlántico (Paoli et al. 2000). Presenta una longitud total de $3.780 \mathrm{~km}$, a partir de su nacimiento por la confluencia de los ríos Paranaiba y Grande. La cuenca del Paraná está compuesta por varias provincias geológicas :Escudo brasileño, Cordillera de los Andes, Provincia jurásico-cretácica del Alto Paraná, Provincia Carbonífera del Alto Paraná, Llanura Chaco-pampeana y Planicies orientales (Iriondo 1992, fide Paoli et al. 2000).

La clasificación por tramos, posiblemente la más usada, considera cuatro de éstos (Bonetto \& Drago 1968, Bonetto \& Wais 1995): El Paraná Superior que corresponde a la alta cuenca desde las cabeceras hasta las cataratas del Guayrá, actualmente cubiertos por el embalse de la represa de Itaipú, el Alto Paraná, desde Itaipú a la confluencia con el río Paraguay; en este sector se emplaza la represa de Yacyretá, el Paraná medio desde la confluencia con el río Paraguay hasta Diamante, y el Paraná inferior desde allí hasta su desembocadura en el río de la Plata. Tossini (1959) (fide Bonetto \& Drago, 1968) divide el río Paraná en dos únicos tramos, el Superior hasta la confluencia con el Paraguay, discurriendo por planaltos, y caracterizado por márgenes altos y el Inferior desde allí hasta la desembocadura en el río de la Plata. A a partir de la confluencia el paisaje se torna diferente y la planicie de inundación se ensancha. Neiff (1990) también considera esta separación con las denominaciones de Alto y Bajo Paraná.

Desde la confluencia con el río Paraguay el río Paraná ocupa una franja de clima subtropical, sin estación seca que llega hasta el límite entre las Provincias de Corrientes y Entre Ríos y una franja de clima templado pampeano hasta el río de la Plata (Drago 1973). A partir de la confluencia el río desciende con pendiente muy leve, 0,036 m/km. Este tramo se caracteriza por presentar una extensa llanura aluvial lateral que se extiende por más de $20.000 \mathrm{~km} 2$. En el tramo medio del río la planicie de inundación tiene un ancho que varía entre $13 \mathrm{~km}$ frente a Corrientes y $56 \mathrm{~km}$ en la sección Rosario-Victoria (Paoli et al. 2000). En la planicie se distinguen varias unidades geomorfológicas: planicies de bancos de arena, planicies de avenamiento o drenaje impedido y planicies de espiras de meandro (riondo 
1972). Alojan una gran variedad de ambientes lóticos y lénticos incluyendo cauces secundarios, tributarios, segmentos de cauces abandonados, lagunas originados por una variedad de procesos dinámicos, diversas en grado de temporalidad, tamaño, forma ( redondas, semilunares, madrejones).

Hay ambientes más o menos estables y otros que permanecen secos algunos meses del año, durante los períodos de aguas bajas. Las planicies de bancos de arena generalmente tienen lagunas extensas, de conformación irregular, mientras que las de drenaje impedido son redondeadas y someras y las de las planicies de espiras de meandro son lagunas semilunares (“oxbow lakes").

El río Paraná es un curso de llanura con lecho de fondo movible (Soldano 1947). La planta del mismo es una sucesión de tramos ensanchados separados por otros más estrechos, de canal más profundo. Los tramos ensanchados presentan como elementos geomorfológicos característicos las islas y los bancos de arena. El diseño del cauce es entrelazado de thalweg meandriforme (Ramonell et al. 2000). La margen izquierda del tramo medio es bien definida, incluso de altas barrancas y la derecha es más baja, de límites fluctuantes e inundables; en el tramo inferior se invierten las características de las márgenes, siendo la derecha alta y definida y la izquierda fácilmente inundable.

Una característica importante del sector medio es que el río recibe una gran carga de sedimentos suspendidos a través del sistema Bermejo-Paraguay. En el alto Paraná las concentraciones medias en los períodos de mayor aporte son $114 \mathrm{mg} / \mathrm{l}$ y luego de la descarga del río Paraguay (576 mg/l) los valores medios son de 250 mg/l. (Drago 1990). Las aguas del Paraná en los tramos superiores se caracterizan por una baja salinidad, relativamente bajas concentraciones de calcio y altas concentraciones de sílice. A partir de la confluencia con el Paraguay, la conductividad promedio se duplica (90 uS/cm), el sodio es dominante entre los cationes y entre los aniones domina el bicarbonato (Bonetto 1986).

El curso principal del bajo Paraná se divide en varios cursos secundarios y recibe a lo largo de su recorrido un gran número de cauces tributarios. A partir de la confluencia con el río Paraguay, sobre la margen derecha del valle aluvial, corren diversos cauces secundarios como los ríos San Jerónimo, San Javier, Colastiné y Coronda. Sobre esta margen encontramos también tributarios o afluentes como el Río Negro, arroyos Los Amores , El Rey, Malabrigo , el Toba, Saladillo, Río Juramento-Salado, Río Carcarañá entre los principales. 
Es de destacar la subcuenca del río Saladillo, ubicada en la antigua planicie del Paraná, separada del valle actual por una angosta franja elevada de $300 \mathrm{~km}$ de longitud. Esta incluye dos sistemas lóticos: El Garabato-El Toba-Caraguatay- Saladillo Dulce de 600 km y El Espín-Saladillo Amargo de $490 \mathrm{~km}$. Ambos sistemas confluyen en el río Saladillo. Químicamente, se diferencian Saladillo Dulce- arroyo Amargo- arroyo El Espín-canal Pájaro Blanco por aguas cloruradas y El Toba-El Yacaré-El Rabón con aguas carbonatadas (García de Emiliani \& Manavella 1989).

Sobre la margen izquierda, el curso principal del Paraná recibe otros tributarios como los ríos Santa Lucia, Corrientes, Guayquiraró, Feliciano, Gualeguay, entre los principales.

El delta terminal del Paraná se inicia a $320 \mathrm{~km}$. de la desembocadura y cubre un área de $14.100 \mathrm{~km} 2$. El derrame de la cuenca del Paraná se descarga al río de la Plata por los numerosos brazos tales como Paraná Bravo, Paraná Guazú, Barca Grande, Barca Chica, Paraná Miní y Paraná de las Palmas.

El régimen hidrológico del Paraná, en lo que es el tramo medio, históricamente incluye períodos de aguas bajas a fines del invierno y comienzos de primavera y aguas altas en el verano, principalmente febrero-marzo (Soldano 1947). En el Paraná Inferior los máximos ocurren generalmente en marzo-mayo ( Paoli \& Cacik 2000). Sin embargo, la regularidad de los eventos hidrológicos es decreciente desde el Pantanal al Delta del Paraná (Neiff 1997) y el nivel de predicibilidad no es siempre alto. A partir de las décadas del 60-70 las inundaciones fueron más frecuentes y severas, aumentó el derrame anual total, se incrementaron las medias anuales, y cambió la distribución estacional (Paoli \& Cacik 2000).

Anderson et al. (1993) (fide Giacosa et al. 2000) señalan que ocurrieron tres cambios importantes que podrían haber afectado la hidrometeorología de la cuenca: cambios en el uso de la tierra que habrían aumentado el nivel de escurrimiento, precipitaciones durante la estación húmeda que han sido más altas por lo menos desde 1960 y harían suponer cambios climáticos inducidos por el hombre y el desarrollo hidroeléctrico en el Alto Paraná. Quirós (1990) también señala la posible incidencia del aumento de la construcción de represas en los tramos superiores del Paraná a partir de 1973, en los cambios señalados. 


\section{MATERIAL Y METODOS}

Para la realización de este trabajo se dispuso de muestras colectadas tanto del curso principal como de ambientes de la planicie (ambientes lóticos y leníticos), obtenidas, con frecuencia variable, durante varios ciclos anuales (1968-2000) y pertenecientes a la colección del Laboratorio de Zooplancton del Instituto Nacional de Limnología. El total de muestras analizadas fue de aproximadamente 650 .

En el curso principal del río Paraná las muestras fueron obtenidas subsuperficialmente y en profundidad, con bomba centrífuga (100 litros) y filtradas en redes de $53 \mu \mathrm{m}$ de apertura de malla. En los cauces de menor jerarquía, se obtuvieron muestras subsuperficiales con baldes hasta reunir también 100 litros, las que fueron filtradas por los mismos tipos de redes empleadas en el curso principal. Estudios metodológicos previos determinaron que el utilizado es el volumen adecuado para la obtención de muestras representativas de estos ambientes, tanto en sentido cuali como cuantitativo (José de Paggi 1978 a e inédito). En las lagunas, las muestras se obtuvieron mediante el empleo de redes de arrastre de $30 \mu \mathrm{m}$ de apertura de malla y trampa tipo SchindlerPatalas de 20 litros, equipada con red de $53 \mu \mathrm{m}$, siendo el tamaño de las muestras de 40 litros, o mayor. Cuando solo se tomaron muestras cualitativas, éstas se obtuvieron con redes de igual tamaño de abertura de malla, las que fueron pasadas repetidamente por el área pelágica o por el litoral, entre la vegetación.

Las identificaciones taxonómicas de los rotíferos se efectuaron siguiendo los criterios de varios autores, según los géneros considerados (Ruttner-Kolisko 1974, Koste 1978, Koste \& Shiel 1989 b y c, 1990, 1991,1992, Segers 1995 b, Nogrady \& Pourriot 1995, De Smet \& Pourriot 1997, José de Paggi 2002 a).

\section{Rotíferos de ambientes lóticos}

Para el análisis de la diversidad faunística general y aspectos de la distribución espacial se dispuso de muestreos realizados en los cursos fluviales de distinta jerarquía (Figs.l,II) que se detallan más adelante.

El análisis de las variaciones temporales en relación al ciclo hidrológico del río se efectúo sobre la base de los muestreos realizados en el canal principal y referenciados del 1 al 3 . 
FIG. I 
La numeración empleada corresponde a la asignada también en la tabla de registros de especies.

\section{Curso principa!}

1.- Sección Paraná-Santa Fe (1 estación centro, frecuencia mensual de muestreo ): Septiembre 71-Enero 1973.

2.- Sección Paraná- Santa Fe (3 estaciones: centro y riberas, frecuencia quincenal y mensual; semanal durante el período de El Niño) :Enero 1977- Marzo de 1983.

3.- Idem, Diciembre de 1997- Diciembre de 1998 ; Noviembre de 1999- Abril de 2000 (frecuencias semanales, quincenales y mensuales).

4.- Tramo Confluencia-Diamante, $700 \mathrm{~km}, 49$ estaciones en el centro del canal y desembocadura de tributarios y 11 perfiles transversales, año 1975, aguas bajas.

5.- Tramo Goya-Diamante, 440 km, 6 estaciones. Diciembre de 1981, aguas medias en creciente.

6.- Idem marzo de 1983, aguas altas.

7.- Tramo Paraná- Río de la Plata, 580 km, 60 estaciones, año 1972, aguas medias.

8.- Tramo Paraná- Río de la Plata, 580 km,17 estaciones en el curso principal, año 1990, aguas en proceso de bajante.

9.- Tramo Diamante -Río de la Plata, 9 estaciones, septiembre de 1995, aguas bajas .

\section{Cauces secundarios}

1.- Ríos San Javier (7 estaciones), Santa Rosa ( 1) y Coronda (1) San Jerónimo (1): Diciembre de 1981, aguas medias en creciente.

2.- Idem, marzo de 1983, aguas altas. 
3.- Ríos: Correntoso, Santa Fe y Coronda, arroyo El cordobés (1 estación en el centro de los cauces): junio de 1974- noviembre de 1975, muestreo mensual.

4.- Río Correntoso (1 estación central): febrero de 1987- abril de 1988 (muestreo quincenal) .

5.-Ríos Santa Fe- Coronda ( 7 estaciones): septiembre y diciembre de 1993.

Cauces tributarios margen izquierda

1.- Ríos Santa Lucía, Corriente, Guayquiraró, Feliciano (1 estación en cada cauce): Diciembre de 1981, aguas medias en creciente.

2.- Idem, marzo de 1983, aguas altas. Río Santa Lucía, Arroyo Sarandí, Arroyo Abalos, Arroyo próximo a Mercedes, Arroyo en Curuzú Cuatía, Río Guayquiraró, Río en Feliciano, diciembre de 1992 .

3.-Arroyo Las Pencas, febrero de 2000.

Cauces tributarios margen derecha

1.- Ríos Salado, Los Amores, Arroyo del Ombu, Malabrigo, del Rey (1 estación en cada río ): Diciembre de 1981, aguas medias en creciente .

2.- Idem, marzo de 1983, aguas altas.

3.- Río Salado. (10 estaciones): septiembre y diciembre de 1993. Marzo y septiembre de 1996.

4.- Arroyo San Lorenzo ( 5 estaciones): octubre de 1992 y noviembre de 1996.

5.-Ríos Saladillo dulce y Saladillo amargo. ( 19 estaciones ): octubre de 1984.

6.- Arroyos próximos a Resistencia: Río Negro y $A^{\circ}$ Salto la Vieja (4 estaciones), mayo de 1987. 
FIG II 
FIG. III 
7.- Arroyo Las Garzas, Hardy y Arroyo próximos a Villa Guillermina, Río Carcarañá, Río del Sauce (4 estaciones). Febrero 2000.

Para el análisis de las variaciones temporales de la riqueza de rotíferos en el curso principal se consideró una sección ubicada en el km 603 , 2,7 km aguas arriba de la

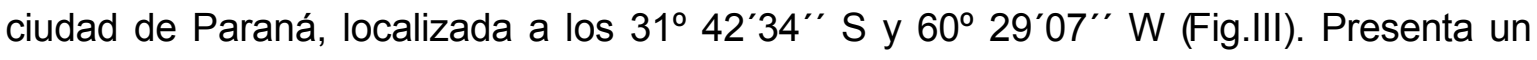
ancho de $600 \mathrm{~m}$ y una profundidad máxima de $22 \mathrm{~m}$ en aguas medias. Está alejada de influencia de tributarios y constituye un "punto de control primario" característico de ríos con diseño anastomosado, sin grandes embancamientos, perfil en $U \circ \mathrm{V}$ asimétrica (Drago 1984). Esta sección en el cuerpo de la tesis se denomina también Sección Paraná-Santa Fe.

El período de estudio incluyó los dos eventos del Niño registrados entre 1977-2000. Para el primero de ellos se dispuso de un muestreo desde noviembre 1982 a marzo de 1983 con una alta frecuencia de muestreo entre 4 y 8 días. Para el segundo evento de 19971998, se dispuso de un muestreo mensual entre noviembre de 1997 a diciembre de 1998.

La crecida registrada en 1982-1983 fue la mayor del siglo XX, presentó caudales del orden de $60.000 \mathrm{~m} 3$ / s en Corrientes y Santa Fe-Paraná. La escorrentía durante esos dos años fue sensiblemente superior a la escorrentía media del período 1901-1982. El volumen escurrido hasta Posadas en el período noviembre 1982-marzo 1983 fue de $373,0 \mathrm{~km} 3$, mientras que el valor medio del periodo noviembre1901-marzo 1982 fue de 170,7 km3 (Paoli \& Cacik 2000).

\section{Rotíferos de ambientes leníticos}

1.-Para el análisis de la riqueza y composición general de rotíferos, como así también de aspectos de su distribución, se analizaron muestreos efectuados en varias lagunas a lo largo del valle de inundación e islas del cauce (Fig.IV). Las mismas se listan a continuación, indicadas en el orden de su ubicación geográfica en un eje norte a sur.

1. Laguna en isla Nogueras (1)

2. Madrejón Pelón, Isla Pelón (1)

3. Laguna Pelón, Isla Pelón

4. Sombrero, Isla Sombrero (1)

5. La Bella, Isla sobre costa Chaqueña (1) 
6. Ñatiú, Isla Ñatiú (1)

7. Yuruhatá (1)

8. Madrejón San Jerónimo, Isla San Jerónimo * (1)

9. Madrejón Mal abrigo, Isla Mal abrigo * (1)

10. Cartagena * (1)

11. Gabriela, Isla Cambá Nupá * (1)

12. Ingá, Isla Retaguardia (1)

13. Curuzú Chalí, Isla Curuzú Chalí (1)

14. Pago de los deseos (2)

15. La Mula(2)

16. Soto (2)

17. La Cruz (2)

18. Duna (2)

19. El varillar (2)

20. Caraguatay (2)

21. Pista (2)

22. Junco (2)

23. El Pacú (2)

24. Timbocito (2)

25. Concepción (2)

26. Laguna en Sauce (2)

27. Otra laguna en Sauce (2)

28. Laguna Palo Pelado * (6)

29. Laguna Tembleque * $(6)$

30. Ocho lagunas del sistema Saladillo

31. Seis lagunas en islas Los Mellados (3) (corresponden a $N^{0} 1,2,3,4,6,7$ )

32. Ocho lagunas en isla Carabajal, (3) (corresp. A No $5,15,16,17,18,19,20,21$ )

33. Cuatro lagunas en isla Timbó (3) (corresp. $\left.A N^{\circ} 22,23,24,25\right)$

34. Siete lagunas en isla Sirgadero (3) (corresp. A No 8-14)

35. Don Felipe (4)

36. Los Espejos (4)

37. El Alemán (4)

38. La Cuarentena (4)

39. Los Matadores (4)

40. El tigre (4)

41. Dos lagunas en Isla frente a Rosario (5)

42. Dos lagunas en Isla de las Lechiguanas, frente a San Nicolás de los Arroyos (5) 
43. Dos lagunas en Isla Catáneo, frente a San Nicolás de los Arroyos (5)

44. Una laguna en Isla frente a Villa Constitución (5)

En las lagunas señaladas con un asterisco solo se obtuvo una muestra en el centro, en las restantes entre dos y cuatro muestras.

(1) Fecha de muestreo septiembre de 1975.

(2) Fecha de muestreo diciembre de 1992

(3) Fecha de muestreo 11 al 27 de febrero de 1972- 6 al 16 de abril de 1972.

(4) Muestreos de 1 año o más de duración, en más de dos estaciones, desde 1968 a 1988 , según las lagunas. Estos son ambientes ubicados en la planicie, próxima a la localidad de Santa Fe (Don Felipe), en las Islas Sirgadero (Los Espejos), EI Vado (EI alemán), Carabajal (La Cuarentena) Clucellas (Los matadores), islote el Tigre (El Tigre).

(5) Fecha de muestreo julio de 1972.

(6) Fecha de muestreo febrero de 2000.

Total de lagunas estudiadas 79

Referencias de Lagunas (L) y Madrejones (M) de la Fig. IV

1. L.en Isla Nogueras.

2. L. Pelón

3. M. Pelón

4. L. Nogueras

5. L.La Bella

6. L.Sombrero

7. L.Yuruatha

8. L.Ñatiú

9. M. San Jerónimo

10. L. Malabrigo

11. L. Gabriela

12. L. Ingá

13. L. Curuzu Chalí

14. L. La Cuarentena

15. L.1.en isla frente Rosario

16. L. 2.en isla frente Rosario

17. L.1. en isla Lechiguana

18. L.2. en isla Lechiguana

19. L.1. en isla Cataneo

20. 2 Lagunas en isla Cataneo y frente a V. Constitución

A. 7 Lagunas próximas al río Santa Lucia

B. 6 Lagunas próximas al río Corrientes

C. 8 Lagunas del sistema Saladillos

D. 2 Lagunas próximas al Río Guayquiraró

E. 30 Lagunas en islas próximas a Santa Fe 
FIGURA IV. AMB.LENITICOS 
2.-Para el análisis comparativo de la composición de rotíferos de las zonas pelágicas y litorales vegetadas de una misma laguna, se consideraron 6 de ellas distribuidas a lo largo del valle aluvial del Paraná, en el tramo comprendido entre los km 1216 y 820 . En general las lagunas muestreadas se ubican en llanura de adosamiento de bancos, que son las de más fácil acceso desde el río.

3.-Para analizar comparativamente la riqueza de rotíferos de lagunas con y sin vegetación, se consideró un grupo de 25 lagunas isleñas de diferente tamaño y forma, ubicadas en la proximidad de la ciudad de Santa Fe, en cuatro islas correspondientes a distintas unidades geomorfológicas: Timbó, Carabajal, Los Mellados y Sirgadero (Fig.V). Por carecer algunas de nombre regional se optó por numerarlas del 1 al 25 . Estos ambientes fueron muestreados casi simultáneamente durante un día, pues se realizaron con el auxilio de un helicóptero. La isla Timbó corresponde a planicie de espiras de meandro, con lagunas semilunares, la isla Carabajal a llanura de bancos originada más recientemente por adosamientos de islas y bancos del cauce, caracterizándose por su proximidad al curso principal, reuniendo cuerpos de agua de gran superficie y profundidades del orden de 5- $6 \mathrm{~m}$. En esta isla se muestrearon madrejones, espiras de meandro y lagunas dendríticas. Las islas Los Mellados y Sirgadero corresponden a llanura de avenamiento impedido, de mayor antigüedad, más apartadas del curso principal, con cuerpos de agua generalmente menores, casi circulares, y de escasa profundidad, hasta $3,5 \mathrm{~m}$, presentando albardones altos con vegetación arbórea (Drago 1973, Iriondo \& Drago 1972).

4.-Para analizar las variaciones espaciales de los rotíferos en un mismo cuerpo de agua bajo diferentes condiciones hidrométricas, se seleccionó la Laguna La Cuarentena, ubicada en el centro de la isla Carabajal, frente a la ciudad de Santa Fe $\left(31^{\circ} 42^{\prime} \mathrm{S}\right.$ $60^{\circ} 37^{\prime} \mathrm{W}$ ) (Fig.VI). Esta laguna es del tipo de "adosamiento" (Drago 1976). Tiene espejo de agua articulado en forma de brazos y de gran superficie, y se ha originado por la unión de varios segmentos de cauces abandonados (Drago 1972). Fue elegida para el análisis de la distribución espacial de rotíferos, por presentar considerable heterogeneidad ambiental debido a su forma dendrítica, con un cuerpo y un brazo principal, los que a su vez tienen brazos menores con áreas de distinta profundidad y cobertura vegetal. Para un 


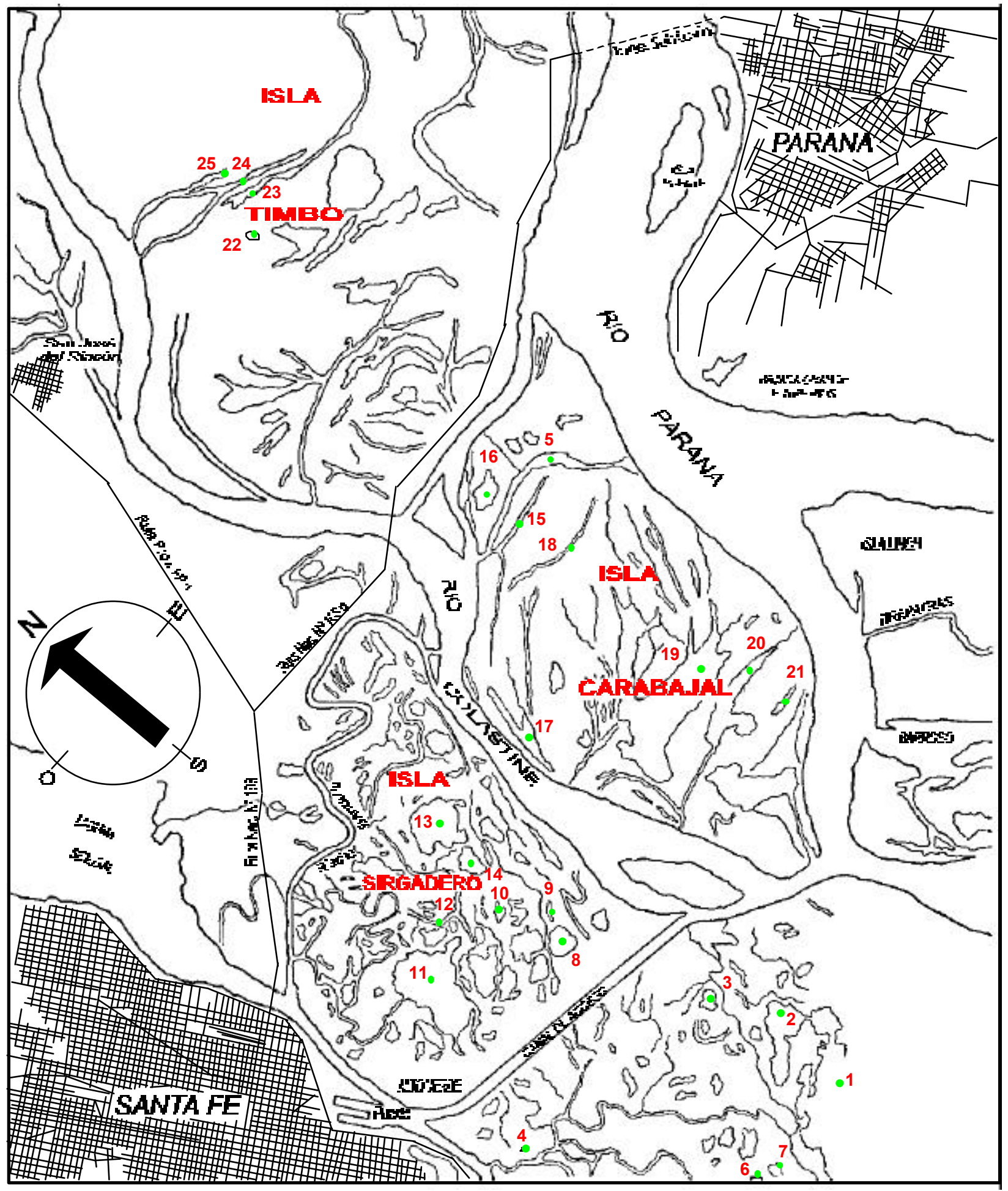

Fig. V. Localización de 25 lagunas isleñas. 


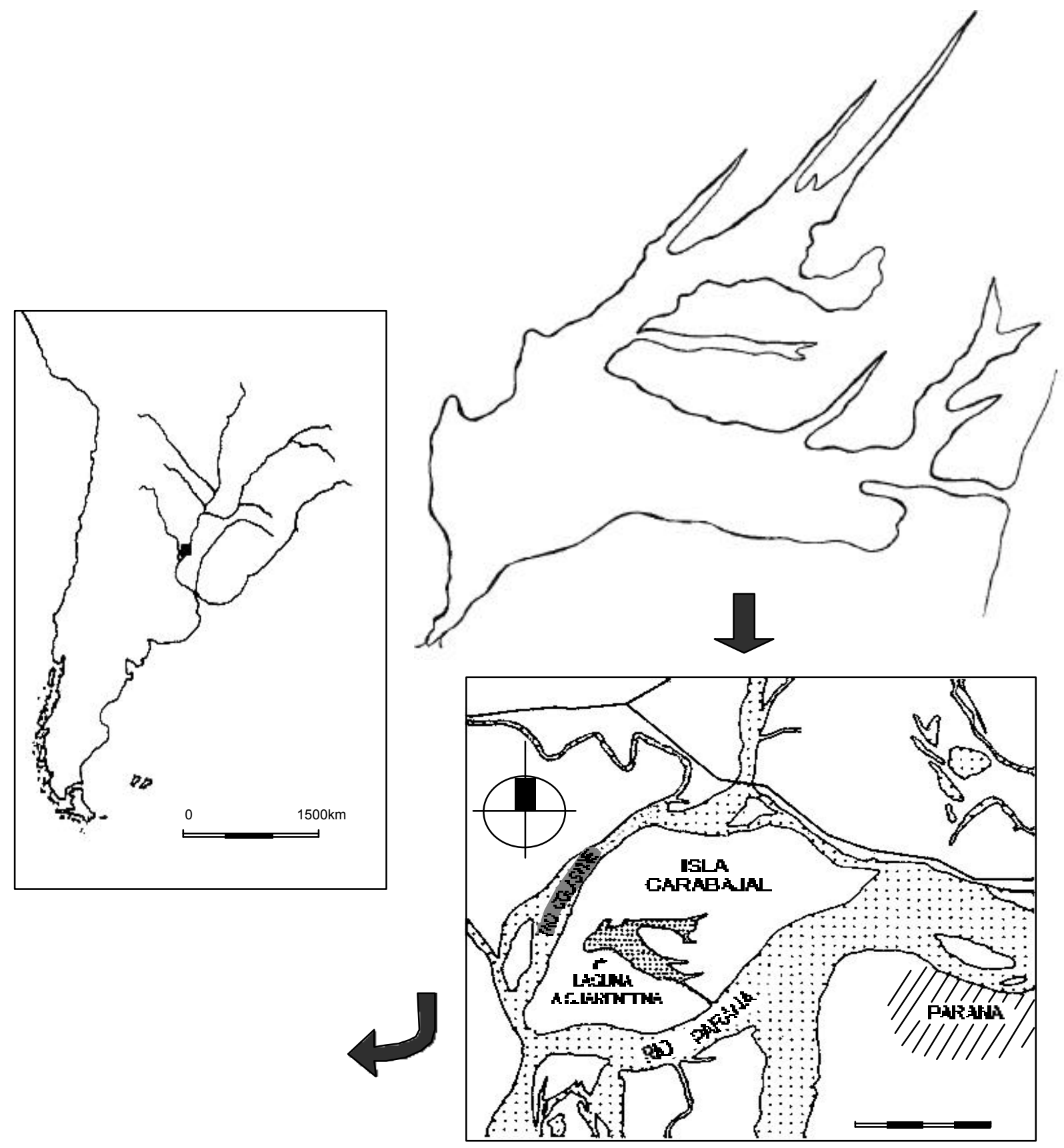

Fig. VI. Laguna La Cuarentena, su localización en Isla Carabajal.

nivel de 3,32 del Puerto de Paraná, la extensión del área sin vegetar fue de 274,5 ha (Oldani \& Tablado 1985). En su extremo sudeste se comunica directamente con el curso principal del Paraná, a través de un canal estrecho y poco profundo, por el extremo norte recibe agua de ambientes anegables durante la inundación. Se analizaron muestras tomadas en varias estaciones del año, ubicadas en las zonas pelágicas y litorales, en el período 1980-1981. 
5. El análisis de las variaciones temporales de la riqueza y composición en relación a las variaciones de nivel hidrométrico, se efectuó sobre material de la laguna Los Matadores, ubicada en la isla Clucellas, (31 $\left.41^{\prime} \mathrm{S}-60^{\circ} 42^{\prime} \mathrm{W}\right)$ (Fig.VII). Es de "expansión lateral" y ha

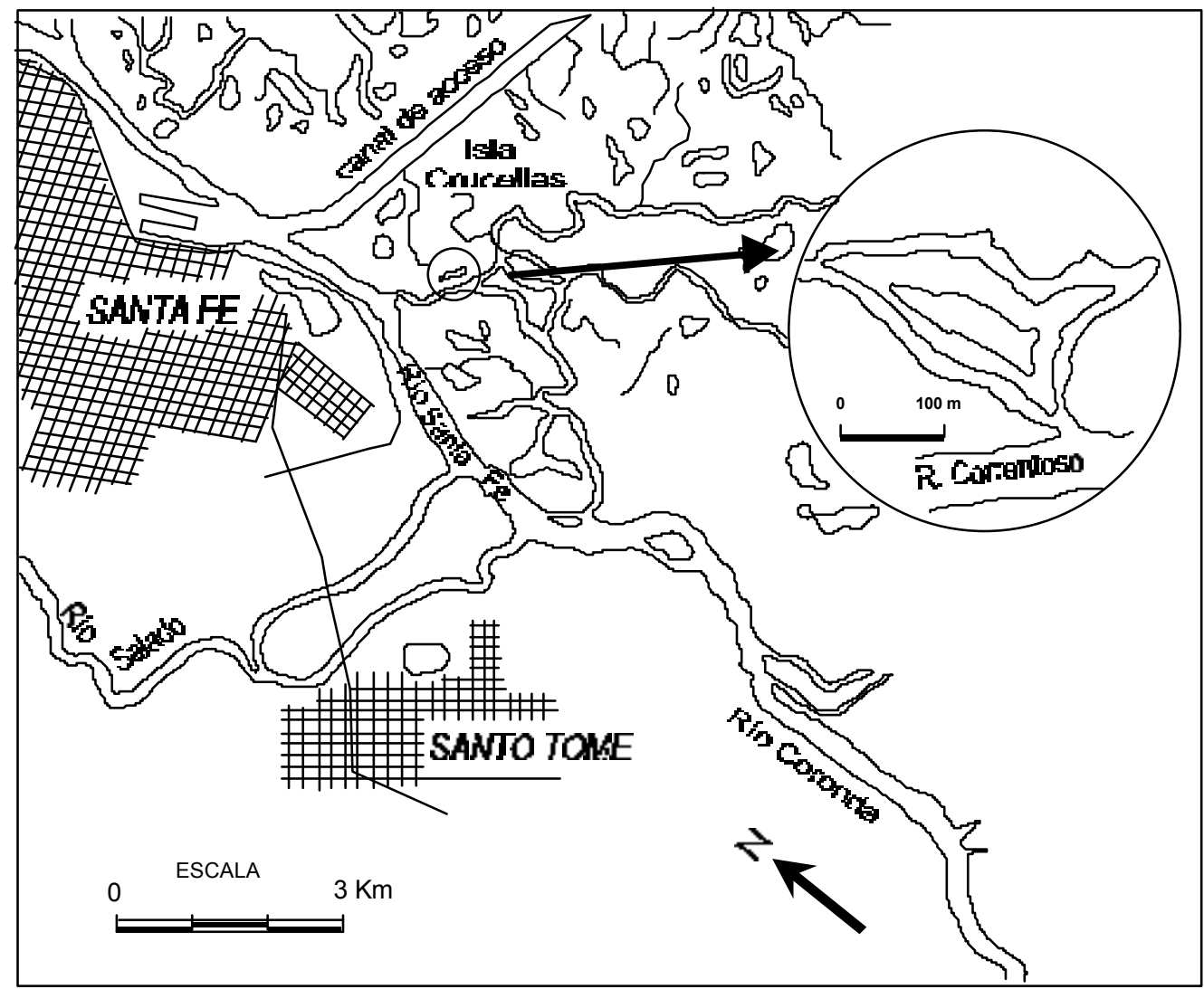

Fig.VI. Laguna los Matadores.

sido originada por cegamiento de un cauce secundario y posterior erosión de albardones (Drago 1980). Tiene un área aproximada de 3,29 ha. Tiene conexión directa con el río Correntoso, el que, a su vez, se comunica con el río Santa Fe. La comunicación se establece a través de un corto canal de unos $10 \mathrm{~m}$ de ancho en aguas medias. La diferenciación entre conexiones indirectas y directas en las lagunas de la planicie se refiere al tipo de ubicación de la misma, la cual determina la presencia o ausencia de algún otro cuerpo de agua intermedio (bañados, otras lagunas, etc.) entre los regímenes lótico y el lenítico. En las lagunas de conexión directa es donde la acción modificadora del cuerpo de agua lótico sobre el lenítico se observa con mayor claridad, a través de una sucesión de variaciones en el tiempo de residencia del agua, dado que no existe otro cuerpo de agua intermedio que se interponga en el flujo de agua que ingresa como consecuencia del desborde del canal y que pudiera constituir un factor de interferencia. 
Se dispuso de muestreos semanales en el área pelágica para una fase de conexión y posterior aislamiento con el río durante el año 1977 , cuando el Paraná presentara un comportamiento hidrológico similar al patrón medio anual descripto por Soldano (1947) para un período de más de 50 años.

6.-Para analizar el efecto inmediato de la inundación en la composición de rotíferos, se analizaron muestras correspondientes a períodos pre-inundación (enero de 1972) y pos-inundación (abril de 1972) en 11 lagunas de diferentes tamaños y características (ausencia-presencia de vegetación), ubicadas en las islas Los Mellados, Carabajal, Timbó y Sirgadero, próximas a la ciudad de Santa Fe. Estas lagunas corresponden a la serie de 25 lagunas muestreadas con el auxilio de un helicóptero.

La relación entre dos variables se expresó gráficamente a través de un diagrama de dispersión o diagrama cartesiano. Se calculó el coeficiente de correlación productomomento (Pearson), el valor de $\mathrm{p}$, indicando con la sigla NS cuando este no es significativo.

En algunos casos, se calculó la ecuación de la recta de regresión, estimándose las constantes de ordenada al origen y la pendiente de la recta.

Las diferencias entre medias fueron analizadas mediante el test $t \quad o$ el análisis de la varianza. Cuando los datos no cumplieron el requisito de la distribución normal, se utilizó el test no paramétrico de Kruskal-Wallis (Zar 1996).

Para estimar la afinidad faunística entre dos inventarios se utilizó el coeficiente de Jaccard ( fide Odum 1982)

$J=a /(a+b+c)$

$a=n^{\circ}$ de taxa comunes a ambos inventarios

$\mathrm{b}=$ taxa presentes solo en el inventario 1

$\mathrm{c}=$ taxa presentes solo en el inventario 2

Para analizar la afinidad faunística entre varias lagunas de una región o área se utilizó el índice de dispersión biótica o índice de Koch (1957)

$\mathrm{IBD}=\underline{\mathrm{T}-\mathrm{S} / \mathrm{n}-1} \times 100$

$S$

$\mathrm{n}=$ número de lagunas en una región o área determinada

$\mathrm{S}=$ número de especies presentes en la región o área 
$\mathrm{T}=$ suma aritmética de $\mathrm{S}_{1}, \mathrm{~S}_{2}, \mathrm{~S}_{3} \ldots \mathrm{S}_{\mathrm{n}}$

$\mathrm{S}_{1}, \mathrm{~S}_{2}, \mathrm{~S}_{3} \ldots \mathrm{S}_{\mathrm{n}}=$ número de especies en lagunas $1,2,3 \ldots \mathrm{n}$

Las afinidades faunísticas determinadas mediante el coeficiente de Jaccard fueron expresadas gráficamente mediante dendrogramas. Los enlaces de estos fueron establecidos mediante la técnica aglomerativa de pares no ponderados usando medias aritméticas "UPGMA" (Sokal \& Michener 1958).

Para analizar el recambio aparente de rotíferos en el curso principal del río entre dos años se utilizó la siguiente fórmula (Arnott et al. 1999)

$\mathrm{T}=100(\mathrm{I}+\mathrm{E}) /((\mathrm{S} 1+\mathrm{S} 2) \mathrm{t})$

$\mathrm{I}=\mathrm{n}^{\circ}$ de taxa presentes en el segundo año

$E=n^{\circ}$ de taxa perdidos entre los censos

$\mathrm{S} 1=\mathrm{n}^{\circ}$ de taxa en el año $1 ; \mathrm{S} 2=$ idem año 2

$\mathrm{T}=\mathrm{n}^{0}$ de años entre los censos

El término diversidad se utiliza en el sentido dado por Whitaker $(1960,1972)$ ("riqueza de especies"). En este estudio se calculó la diversidad alfa, la gamma y la beta. La primera es la diversidad local y se refiere al número de especies en un cuerpo de agua (Harrison et al, 1992, Amoros \& Bornette 2002), la gamma o diversidad regional es el número total de especies en un área o región. La beta es la diversidad entre comunidades y se relaciona a la tasa de recambio espacial, se calculó de acuerdo a la siguiente ecuación (Harrison et al. (1992)

$ß=((y / \bar{x})-1) /(N-1) \cdot 100$

y= número total de especies en un área o región, o diversidad regional.

$\bar{x}=$ promedio de las diversidades locales

$\mathrm{N}=$ número de ambientes muestreados

Esta medida resulta conveniente para comparar diversidades entre transectas de desigual tamaño. La diversidad beta variará entre 0 , cuando todas las especies de la región ocurren en todas las lagunas, es decir similitud total y 100 cuando cada especie ocurre en un solo hábitat o laguna, es decir la mas completa disimilitud.

Harrison et al. (1992) proponen también otra medida de la diversidad beta, la ß2 donde en lugar de considerar la diversidad alfa media se considera el máximo valor de la 
diversidad alfa en la colección de $\mathrm{N}$ sitios o hábitats. Varia también entre 0 y 100 y converge con la primer medida de $ß$ cuando la variabilidad en la diversidad alfa es pequeña.

ß2: $\left(\mathrm{S} / \mathrm{a}_{\max }\right)-1 /(\mathrm{N}-1) \times 100$

$\mathrm{a}_{\max }=$ es el valor máximo de diversidad alfa en la colección de $\mathrm{N}$ sitios.

Como estimador de la riqueza basada en la presencia de especies raras se utilizó la metodología del "jackknife " ( Baltanas 1992 , Kreb 1999)

$S=s+(n-1 / n) k$

$\mathrm{s}=$ número total de especies presentes en $\mathrm{n}$ unidades $\mathrm{o}$ cuadrados

$\mathrm{n}=$ número total de unidades muestreadas

k= número total de especies halladas una sola vez

También para datos de riqueza se empleó el estimador de Chao \& Lee 1992 (Fide Dumont \& Segers 1996)

$S=S . o b s+\left(L^{2} / 2 M+1\right)$

S. obs= número total de especies registradas

$\mathrm{L}=$ número de especies presentes en una sola muestra

$\mathrm{M}=$ número de especies presentes en dos muestras

La riqueza asintótica de especies se obtuvo a partir del método gráfico de Walford, basado en la construcción de un diagrama de dispersión de riqueza acumulativa (Ricker 1958). Un valor de riqueza asintótica mayor que la acumulativa indica que es necesario un mayor número de muestras para detectar todas las que ocurrirían.

\section{Algunas consideraciones sobre la riqueza de especies y su estimación}

Todas las mediciones de riqueza de especies son altamente dependientes de la escala espacial de muestreo, intensidad del análisis y competencia taxonómica del investigador (Brown 1990, Kalff 2002). Por otro lado, la representatividad de las muestras es la piedra angular en la evaluación de la riqueza, dado que la confiabilidad se relaciona directamente a la proporción de la comunidad muestreada (Baltanas 1992). Así es que el 
registro de especies raras es fuertemente dependiente del tamaño de la muestra (Lampert \& Sommer 1997). Considerando el tamaño de la escala espacial y temporal de un sistema como el del río Paraná, es más que importante considerar estas variables en las mediciones de la riqueza.

Interesa particularmente saber si en los ambientes estudiados un período determinado de tiempo que cubra diferentes niveles hidrométricos es adecuado para estimar la riqueza de rotíferos. Para este análisis, entre los ambientes descriptos precedentemente, se consideraron los siguientes: Laguna los Matadores, de conexión directa con el río, con una sola estación pelágica, en la que se realizaron muestreos semanales en el período de aguas altas-bajante; Laguna La Cuarentena, de conexión directa con el río y forma compleja por la articulación de varios brazos, donde se muestrearon entre 4 y 12 estaciones durante 6 fechas, representativas de distintos niveles hidrométricos; Canal Principal del río Paraná durante el evento de El Niño , periodo noviembre de 1982 -marzo 1983 en el cual se tomaron muestras durante 18 ocasiones.

Para conocer el grado de representatividad de la riqueza observada respecto de la esperada en los casos señalados, se tuvieron en cuenta dos tipos de estimadores: el del "jackknife" (Kreb 1999), donde se incluyen la especies encontradas solo una vez y el estimador de Chao \& Lee (1992) (fide Dumont \& Segers 1996), donde se consideran especies encontradas una y dos veces.

Según los datos de la Tabla I en la laguna Los Matadores, un periodo de estudio de 7 meses con muestreos semanales permite obtener entre el 82 y $87 \%$ de la riqueza esperada en su área limnética. En la Laguna La Cuarentena los seis muestreos realizados permiten obtener entre un 75 y $79 \%$ del valor esperado de riqueza, es decir menor que en la laguna anterior, pero aquí se trata de toda la laguna (área limnética + área litoral). La estimación más cercana a la esperada se obtuvo en los Matadores, con mayor frecuencia de muestreo. En cambio, durante el período que coincidiera con el fenómeno de El Niño, el muestreo realizado en el canal principal, pese a tener una frecuencia entre tres y siete días, resulta poco eficiente para ser representativo, seguramente por la magnitud del evento hidrológico.

Probablemente, la información más completa sobre diversidad de rotíferos es la existente sobre el canal principal ( $\mathrm{km} \mathrm{603)}$ donde los muestreos cubren un período continuo de varios años (1977-1983), período cuya extensión posibilitaría una mejor aproximación 
al conocimiento de la riqueza de un biotopo a través de muestreos a lo largo de ciclos anuales.

\begin{tabular}{|c|c|c|c|}
\hline & L. Los Matadores & .L. La Cuarentena & $\begin{array}{l}\text { Curso Principal (km 603) } \\
\text { Evento El Niño 1982-1983 }\end{array}$ \\
\hline $\mathrm{N}^{\circ}$ observado & 94 & 84 & 44 \\
\hline \multicolumn{4}{|l|}{$N^{\circ}$ esperado } \\
\hline Jacknife & 114 & 112 & 69 \\
\hline Chao \& Lee & 108 & 107 & 78 \\
\hline & & & \\
\hline
\end{tabular}

Tabla I. Riqueza específica de rotíferos observada y esperada en tres ambientes. 


\section{MATERIAL Y METODOS}

Para la realización de este trabajo se dispuso de muestras colectadas tanto del curso principal como de ambientes de la planicie (ambientes lóticos y leníticos), obtenidas, con frecuencia variable, durante varios ciclos anuales (1968-2000) y pertenecientes a la colección del Laboratorio de Zooplancton del Instituto Nacional de Limnología. El total de muestras analizadas fue de aproximadamente 650 .

En el curso principal del río Paraná las muestras fueron obtenidas subsuperficialmente y en profundidad, con bomba centrífuga (100 litros) y filtradas en redes de $53 \mu \mathrm{m}$ de apertura de malla. En los cauces de menor jerarquía, se obtuvieron muestras subsuperficiales con baldes hasta reunir también 100 litros, las que fueron filtradas por los mismos tipos de redes empleadas en el curso principal. Estudios metodológicos previos determinaron que el utilizado es el volumen adecuado para la obtención de muestras representativas de estos ambientes, tanto en sentido cuali como cuantitativo (José de Paggi 1978 a e inédito). En las lagunas, las muestras se obtuvieron mediante el empleo de redes de arrastre de $30 \mu \mathrm{m}$ de apertura de malla y trampa tipo SchindlerPatalas de 20 litros, equipada con red de $53 \mu \mathrm{m}$, siendo el tamaño de las muestras de 40 litros, o mayor. Cuando solo se tomaron muestras cualitativas, éstas se obtuvieron con redes de igual tamaño de abertura de malla, las que fueron pasadas repetidamente por el área pelágica o por el litoral, entre la vegetación.

Las identificaciones taxonómicas de los rotíferos se efectuaron siguiendo los criterios de varios autores, según los géneros considerados (Ruttner-Kolisko 1974, Koste 1978, Koste \& Shiel 1989 b y c, 1990, 1991,1992, Segers 1995 b, Nogrady \& Pourriot 1995, De Smet \& Pourriot 1997, José de Paggi 2002 a).

\section{Rotíferos de ambientes lóticos}

Para el análisis de la diversidad faunística general y aspectos de la distribución espacial se dispuso de muestreos realizados en los cursos fluviales de distinta jerarquía (Figs.l,II) que se detallan más adelante.

El análisis de las variaciones temporales en relación al ciclo hidrológico del río se efectúo sobre la base de los muestreos realizados en el canal principal y referenciados del 1 al 3 . 
FIG. I 
La numeración empleada corresponde a la asignada también en la tabla de registros de especies.

\section{Curso principa!}

1.- Sección Paraná-Santa Fe (1 estación centro, frecuencia mensual de muestreo ): Septiembre 71-Enero 1973.

2.- Sección Paraná- Santa Fe (3 estaciones: centro y riberas, frecuencia quincenal y mensual; semanal durante el período de El Niño) :Enero 1977- Marzo de 1983.

3.- Idem, Diciembre de 1997- Diciembre de 1998 ; Noviembre de 1999- Abril de 2000 (frecuencias semanales, quincenales y mensuales).

4.- Tramo Confluencia-Diamante, $700 \mathrm{~km}, 49$ estaciones en el centro del canal y desembocadura de tributarios y 11 perfiles transversales, año 1975, aguas bajas.

5.- Tramo Goya-Diamante, 440 km, 6 estaciones. Diciembre de 1981, aguas medias en creciente.

6.- Idem marzo de 1983, aguas altas.

7.- Tramo Paraná- Río de la Plata, 580 km, 60 estaciones, año 1972, aguas medias.

8.- Tramo Paraná- Río de la Plata, 580 km,17 estaciones en el curso principal, año 1990, aguas en proceso de bajante.

9.- Tramo Diamante -Río de la Plata, 9 estaciones, septiembre de 1995, aguas bajas .

\section{Cauces secundarios}

1.- Ríos San Javier (7 estaciones), Santa Rosa ( 1) y Coronda (1) San Jerónimo (1): Diciembre de 1981, aguas medias en creciente.

2.- Idem, marzo de 1983, aguas altas. 
3.- Ríos: Correntoso, Santa Fe y Coronda, arroyo El cordobés (1 estación en el centro de los cauces): junio de 1974- noviembre de 1975, muestreo mensual.

4.- Río Correntoso (1 estación central): febrero de 1987- abril de 1988 (muestreo quincenal) .

5.-Ríos Santa Fe- Coronda ( 7 estaciones): septiembre y diciembre de 1993.

Cauces tributarios margen izquierda

1.- Ríos Santa Lucía, Corriente, Guayquiraró, Feliciano (1 estación en cada cauce): Diciembre de 1981, aguas medias en creciente.

2.- Idem, marzo de 1983, aguas altas. Río Santa Lucía, Arroyo Sarandí, Arroyo Abalos, Arroyo próximo a Mercedes, Arroyo en Curuzú Cuatía, Río Guayquiraró, Río en Feliciano, diciembre de 1992 .

3.-Arroyo Las Pencas, febrero de 2000.

Cauces tributarios margen derecha

1.- Ríos Salado, Los Amores, Arroyo del Ombu, Malabrigo, del Rey (1 estación en cada río ): Diciembre de 1981, aguas medias en creciente .

2.- Idem, marzo de 1983, aguas altas.

3.- Río Salado. (10 estaciones): septiembre y diciembre de 1993. Marzo y septiembre de 1996.

4.- Arroyo San Lorenzo ( 5 estaciones): octubre de 1992 y noviembre de 1996.

5.-Ríos Saladillo dulce y Saladillo amargo. ( 19 estaciones ): octubre de 1984.

6.- Arroyos próximos a Resistencia: Río Negro y $A^{\circ}$ Salto la Vieja (4 estaciones), mayo de 1987. 
FIG II 
FIG. III 
7.- Arroyo Las Garzas, Hardy y Arroyo próximos a Villa Guillermina, Río Carcarañá, Río del Sauce (4 estaciones). Febrero 2000.

Para el análisis de las variaciones temporales de la riqueza de rotíferos en el curso principal se consideró una sección ubicada en el km 603 , 2,7 km aguas arriba de la

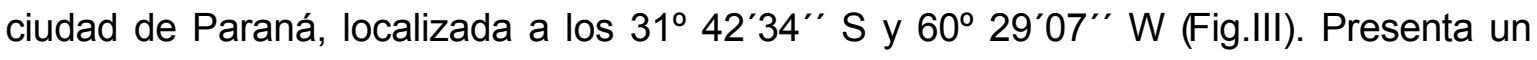
ancho de $600 \mathrm{~m}$ y una profundidad máxima de $22 \mathrm{~m}$ en aguas medias. Está alejada de influencia de tributarios y constituye un "punto de control primario" característico de ríos con diseño anastomosado, sin grandes embancamientos, perfil en $U \circ \mathrm{V}$ asimétrica (Drago 1984). Esta sección en el cuerpo de la tesis se denomina también Sección Paraná-Santa Fe.

El período de estudio incluyó los dos eventos del Niño registrados entre 1977-2000. Para el primero de ellos se dispuso de un muestreo desde noviembre 1982 a marzo de 1983 con una alta frecuencia de muestreo entre 4 y 8 días. Para el segundo evento de 19971998, se dispuso de un muestreo mensual entre noviembre de 1997 a diciembre de 1998.

La crecida registrada en 1982-1983 fue la mayor del siglo XX, presentó caudales del orden de $60.000 \mathrm{~m} 3$ / s en Corrientes y Santa Fe-Paraná. La escorrentía durante esos dos años fue sensiblemente superior a la escorrentía media del período 1901-1982. El volumen escurrido hasta Posadas en el período noviembre 1982-marzo 1983 fue de $373,0 \mathrm{~km} 3$, mientras que el valor medio del periodo noviembre1901-marzo 1982 fue de 170,7 km3 (Paoli \& Cacik 2000).

\section{Rotíferos de ambientes leníticos}

1.-Para el análisis de la riqueza y composición general de rotíferos, como así también de aspectos de su distribución, se analizaron muestreos efectuados en varias lagunas a lo largo del valle de inundación e islas del cauce (Fig.IV). Las mismas se listan a continuación, indicadas en el orden de su ubicación geográfica en un eje norte a sur.

1. Laguna en isla Nogueras (1)

2. Madrejón Pelón, Isla Pelón (1)

3. Laguna Pelón, Isla Pelón

4. Sombrero, Isla Sombrero (1)

5. La Bella, Isla sobre costa Chaqueña (1) 
6. Ñatiú, Isla Ñatiú (1)

7. Yuruhatá (1)

8. Madrejón San Jerónimo, Isla San Jerónimo * (1)

9. Madrejón Mal abrigo, Isla Mal abrigo * (1)

10. Cartagena * (1)

11. Gabriela, Isla Cambá Nupá * (1)

12. Ingá, Isla Retaguardia (1)

13. Curuzú Chalí, Isla Curuzú Chalí (1)

14. Pago de los deseos (2)

15. La Mula(2)

16. Soto (2)

17. La Cruz (2)

18. Duna (2)

19. El varillar (2)

20. Caraguatay (2)

21. Pista (2)

22. Junco (2)

23. El Pacú (2)

24. Timbocito (2)

25. Concepción (2)

26. Laguna en Sauce (2)

27. Otra laguna en Sauce (2)

28. Laguna Palo Pelado * (6)

29. Laguna Tembleque * $(6)$

30. Ocho lagunas del sistema Saladillo

31. Seis lagunas en islas Los Mellados (3) (corresponden a $N^{0} 1,2,3,4,6,7$ )

32. Ocho lagunas en isla Carabajal, (3) (corresp. A No $5,15,16,17,18,19,20,21$ )

33. Cuatro lagunas en isla Timbó (3) (corresp. $\left.A N^{\circ} 22,23,24,25\right)$

34. Siete lagunas en isla Sirgadero (3) (corresp. A No 8-14)

35. Don Felipe (4)

36. Los Espejos (4)

37. El Alemán (4)

38. La Cuarentena (4)

39. Los Matadores (4)

40. El tigre (4)

41. Dos lagunas en Isla frente a Rosario (5)

42. Dos lagunas en Isla de las Lechiguanas, frente a San Nicolás de los Arroyos (5) 
43. Dos lagunas en Isla Catáneo, frente a San Nicolás de los Arroyos (5)

44. Una laguna en Isla frente a Villa Constitución (5)

En las lagunas señaladas con un asterisco solo se obtuvo una muestra en el centro, en las restantes entre dos y cuatro muestras.

(1) Fecha de muestreo septiembre de 1975.

(2) Fecha de muestreo diciembre de 1992

(3) Fecha de muestreo 11 al 27 de febrero de 1972- 6 al 16 de abril de 1972.

(4) Muestreos de 1 año o más de duración, en más de dos estaciones, desde 1968 a 1988 , según las lagunas. Estos son ambientes ubicados en la planicie, próxima a la localidad de Santa Fe (Don Felipe), en las Islas Sirgadero (Los Espejos), EI Vado (EI alemán), Carabajal (La Cuarentena) Clucellas (Los matadores), islote el Tigre (El Tigre).

(5) Fecha de muestreo julio de 1972.

(6) Fecha de muestreo febrero de 2000.

Total de lagunas estudiadas 79

Referencias de Lagunas (L) y Madrejones (M) de la Fig. IV

1. L.en Isla Nogueras.

2. L. Pelón

3. M. Pelón

4. L. Nogueras

5. L.La Bella

6. L.Sombrero

7. L.Yuruatha

8. L.Ñatiú

9. M. San Jerónimo

10. L. Malabrigo

11. L. Gabriela

12. L. Ingá

13. L. Curuzu Chalí

14. L. La Cuarentena

15. L.1.en isla frente Rosario

16. L. 2.en isla frente Rosario

17. L.1. en isla Lechiguana

18. L.2. en isla Lechiguana

19. L.1. en isla Cataneo

20. 2 Lagunas en isla Cataneo y frente a V. Constitución

A. 7 Lagunas próximas al río Santa Lucia

B. 6 Lagunas próximas al río Corrientes

C. 8 Lagunas del sistema Saladillos

D. 2 Lagunas próximas al Río Guayquiraró

E. 30 Lagunas en islas próximas a Santa Fe 
FIGURA IV. AMB.LENITICOS 
2.-Para el análisis comparativo de la composición de rotíferos de las zonas pelágicas y litorales vegetadas de una misma laguna, se consideraron 6 de ellas distribuidas a lo largo del valle aluvial del Paraná, en el tramo comprendido entre los km 1216 y 820 . En general las lagunas muestreadas se ubican en llanura de adosamiento de bancos, que son las de más fácil acceso desde el río.

3.-Para analizar comparativamente la riqueza de rotíferos de lagunas con y sin vegetación, se consideró un grupo de 25 lagunas isleñas de diferente tamaño y forma, ubicadas en la proximidad de la ciudad de Santa Fe, en cuatro islas correspondientes a distintas unidades geomorfológicas: Timbó, Carabajal, Los Mellados y Sirgadero (Fig.V). Por carecer algunas de nombre regional se optó por numerarlas del 1 al 25 . Estos ambientes fueron muestreados casi simultáneamente durante un día, pues se realizaron con el auxilio de un helicóptero. La isla Timbó corresponde a planicie de espiras de meandro, con lagunas semilunares, la isla Carabajal a llanura de bancos originada más recientemente por adosamientos de islas y bancos del cauce, caracterizándose por su proximidad al curso principal, reuniendo cuerpos de agua de gran superficie y profundidades del orden de 5- $6 \mathrm{~m}$. En esta isla se muestrearon madrejones, espiras de meandro y lagunas dendríticas. Las islas Los Mellados y Sirgadero corresponden a llanura de avenamiento impedido, de mayor antigüedad, más apartadas del curso principal, con cuerpos de agua generalmente menores, casi circulares, y de escasa profundidad, hasta $3,5 \mathrm{~m}$, presentando albardones altos con vegetación arbórea (Drago 1973, Iriondo \& Drago 1972).

4.-Para analizar las variaciones espaciales de los rotíferos en un mismo cuerpo de agua bajo diferentes condiciones hidrométricas, se seleccionó la Laguna La Cuarentena, ubicada en el centro de la isla Carabajal, frente a la ciudad de Santa Fe $\left(31^{\circ} 42^{\prime} \mathrm{S}\right.$ $60^{\circ} 37^{\prime} \mathrm{W}$ ) (Fig.VI). Esta laguna es del tipo de "adosamiento" (Drago 1976). Tiene espejo de agua articulado en forma de brazos y de gran superficie, y se ha originado por la unión de varios segmentos de cauces abandonados (Drago 1972). Fue elegida para el análisis de la distribución espacial de rotíferos, por presentar considerable heterogeneidad ambiental debido a su forma dendrítica, con un cuerpo y un brazo principal, los que a su vez tienen brazos menores con áreas de distinta profundidad y cobertura vegetal. Para un 


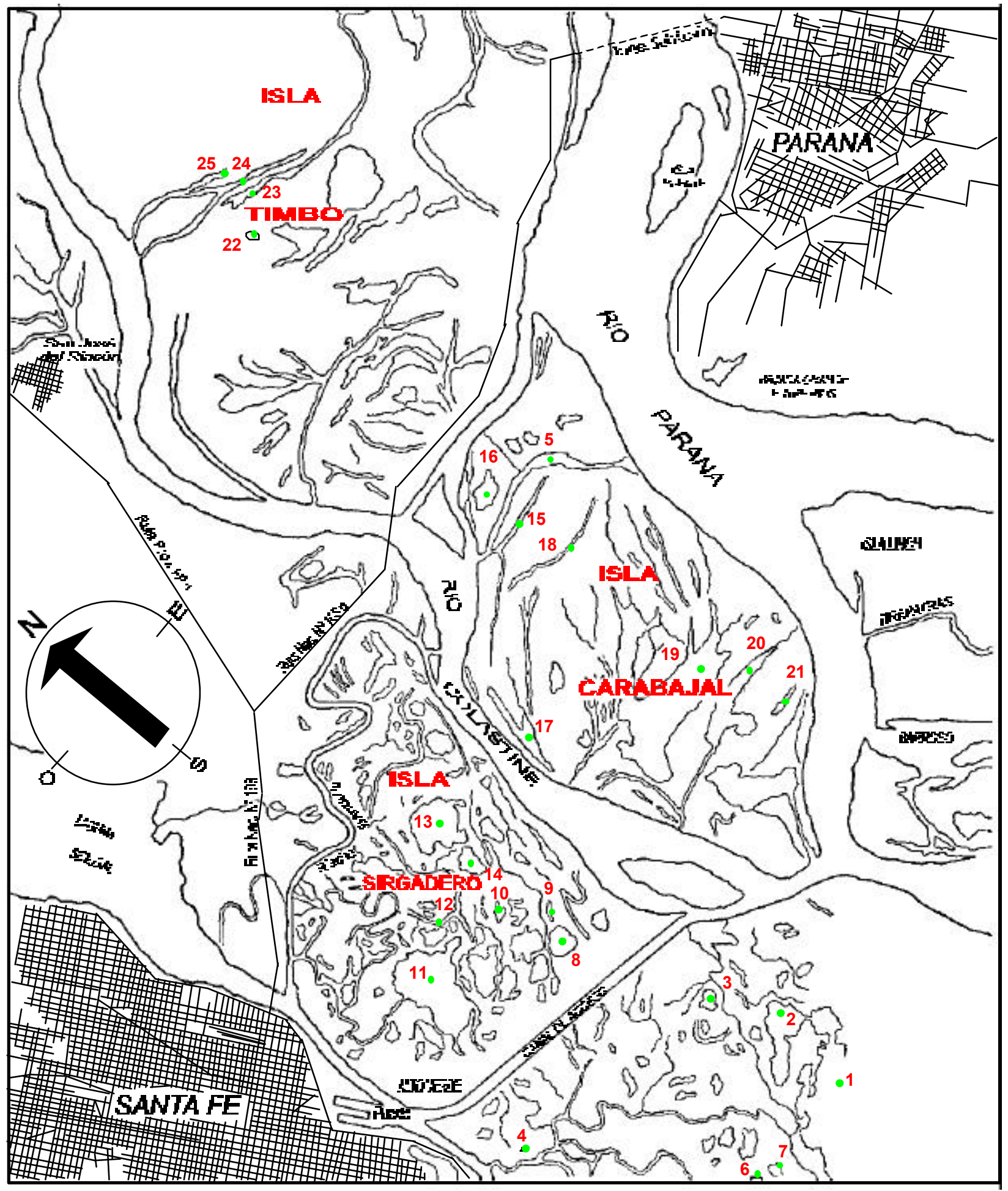

Fig. V. Localización de 25 lagunas isleñas. 


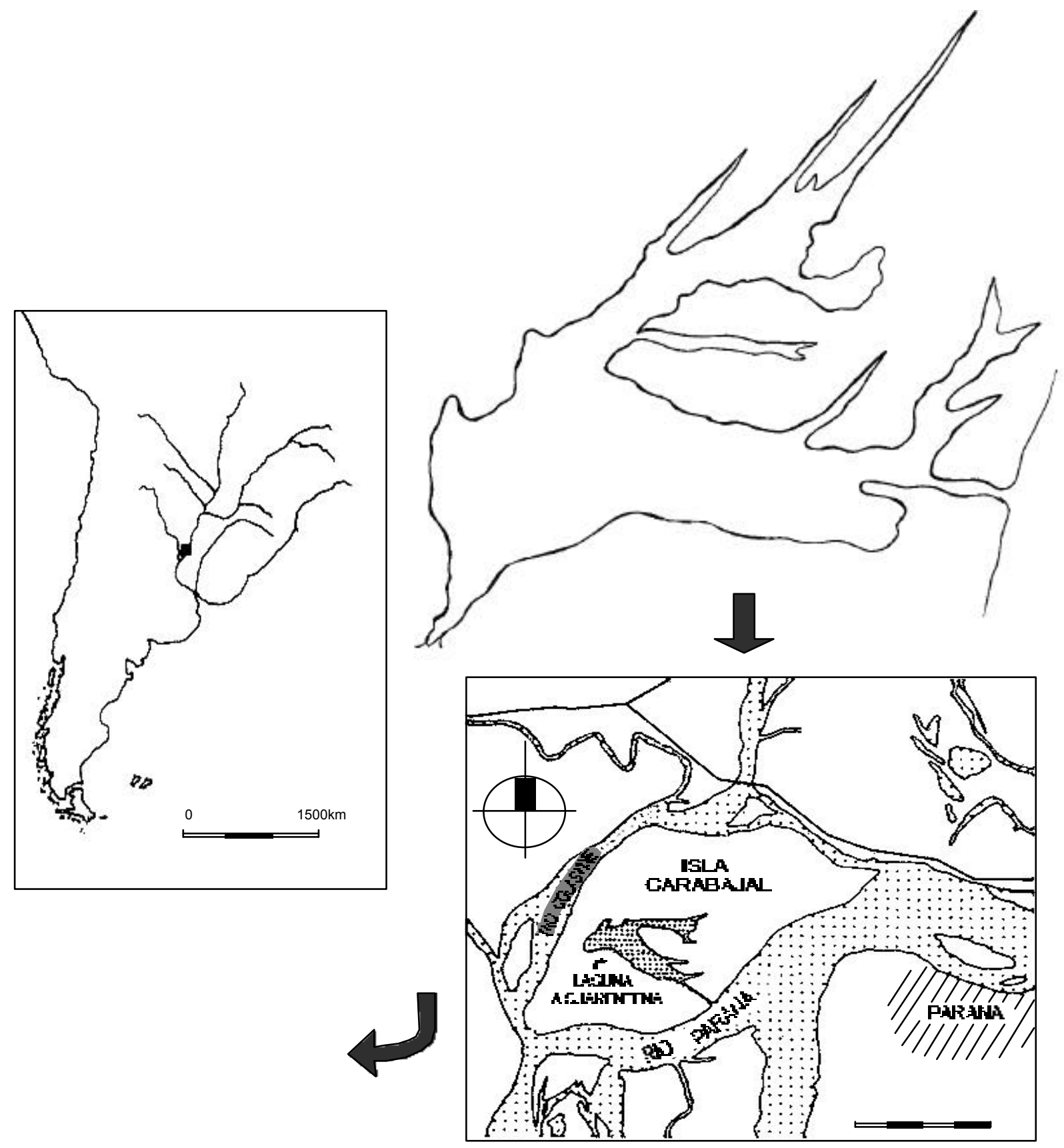

Fig. VI. Laguna La Cuarentena, su localización en Isla Carabajal.

nivel de 3,32 del Puerto de Paraná, la extensión del área sin vegetar fue de 274,5 ha (Oldani \& Tablado 1985). En su extremo sudeste se comunica directamente con el curso principal del Paraná, a través de un canal estrecho y poco profundo, por el extremo norte recibe agua de ambientes anegables durante la inundación. Se analizaron muestras tomadas en varias estaciones del año, ubicadas en las zonas pelágicas y litorales, en el período 1980-1981. 
5. El análisis de las variaciones temporales de la riqueza y composición en relación a las variaciones de nivel hidrométrico, se efectuó sobre material de la laguna Los Matadores, ubicada en la isla Clucellas, (31 $\left.41^{\prime} \mathrm{S}-60^{\circ} 42^{\prime} \mathrm{W}\right)$ (Fig.VII). Es de "expansión lateral" y ha

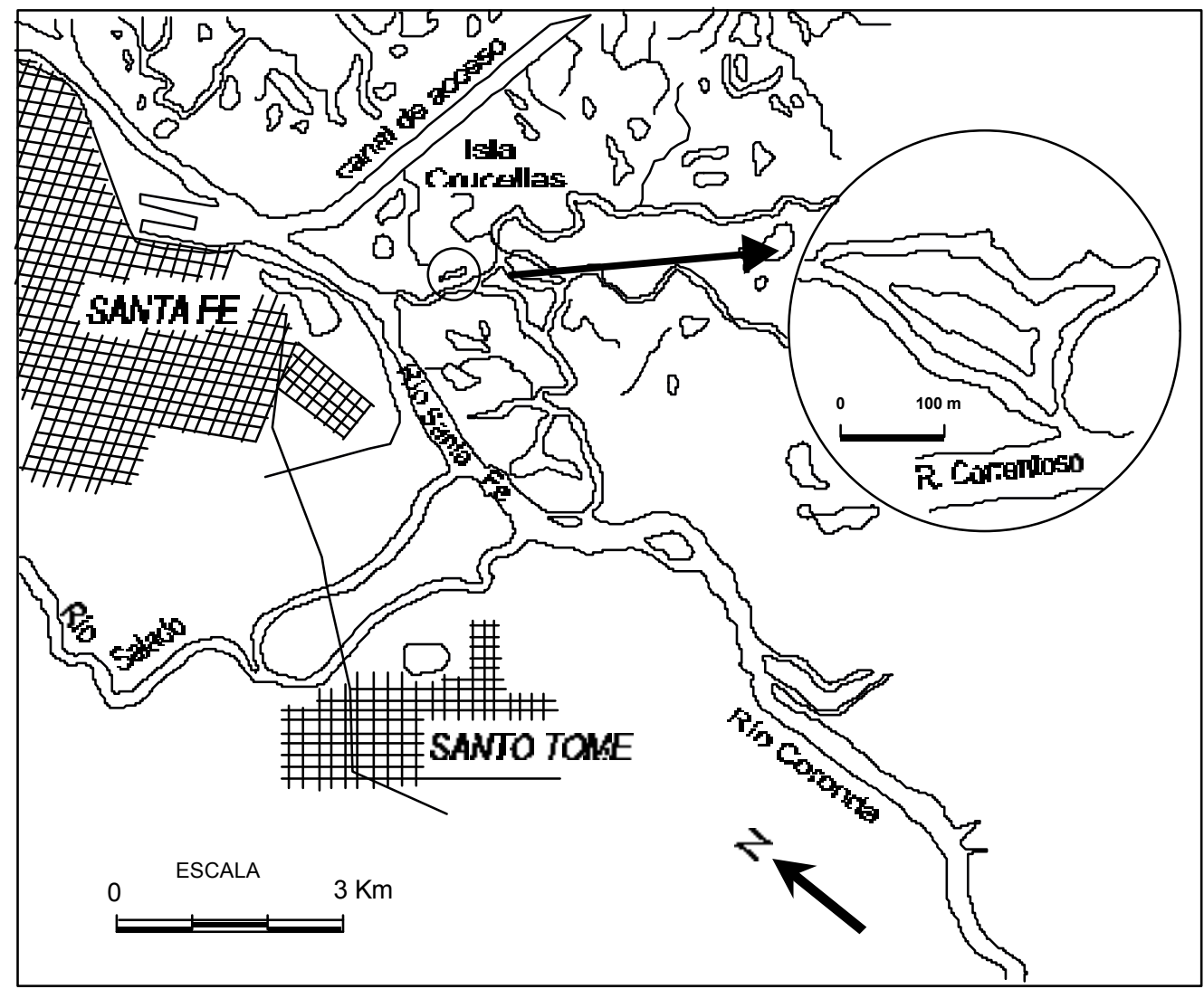

Fig.VI. Laguna los Matadores.

sido originada por cegamiento de un cauce secundario y posterior erosión de albardones (Drago 1980). Tiene un área aproximada de 3,29 ha. Tiene conexión directa con el río Correntoso, el que, a su vez, se comunica con el río Santa Fe. La comunicación se establece a través de un corto canal de unos $10 \mathrm{~m}$ de ancho en aguas medias. La diferenciación entre conexiones indirectas y directas en las lagunas de la planicie se refiere al tipo de ubicación de la misma, la cual determina la presencia o ausencia de algún otro cuerpo de agua intermedio (bañados, otras lagunas, etc.) entre los regímenes lótico y el lenítico. En las lagunas de conexión directa es donde la acción modificadora del cuerpo de agua lótico sobre el lenítico se observa con mayor claridad, a través de una sucesión de variaciones en el tiempo de residencia del agua, dado que no existe otro cuerpo de agua intermedio que se interponga en el flujo de agua que ingresa como consecuencia del desborde del canal y que pudiera constituir un factor de interferencia. 
Se dispuso de muestreos semanales en el área pelágica para una fase de conexión y posterior aislamiento con el río durante el año 1977 , cuando el Paraná presentara un comportamiento hidrológico similar al patrón medio anual descripto por Soldano (1947) para un período de más de 50 años.

6.-Para analizar el efecto inmediato de la inundación en la composición de rotíferos, se analizaron muestras correspondientes a períodos pre-inundación (enero de 1972) y pos-inundación (abril de 1972) en 11 lagunas de diferentes tamaños y características (ausencia-presencia de vegetación), ubicadas en las islas Los Mellados, Carabajal, Timbó y Sirgadero, próximas a la ciudad de Santa Fe. Estas lagunas corresponden a la serie de 25 lagunas muestreadas con el auxilio de un helicóptero.

La relación entre dos variables se expresó gráficamente a través de un diagrama de dispersión o diagrama cartesiano. Se calculó el coeficiente de correlación productomomento (Pearson), el valor de $\mathrm{p}$, indicando con la sigla NS cuando este no es significativo.

En algunos casos, se calculó la ecuación de la recta de regresión, estimándose las constantes de ordenada al origen y la pendiente de la recta.

Las diferencias entre medias fueron analizadas mediante el test $t \quad o$ el análisis de la varianza. Cuando los datos no cumplieron el requisito de la distribución normal, se utilizó el test no paramétrico de Kruskal-Wallis (Zar 1996).

Para estimar la afinidad faunística entre dos inventarios se utilizó el coeficiente de Jaccard ( fide Odum 1982)

$J=a /(a+b+c)$

$a=n^{\circ}$ de taxa comunes a ambos inventarios

$\mathrm{b}=$ taxa presentes solo en el inventario 1

$\mathrm{c}=$ taxa presentes solo en el inventario 2

Para analizar la afinidad faunística entre varias lagunas de una región o área se utilizó el índice de dispersión biótica o índice de Koch (1957)

$\mathrm{IBD}=\underline{\mathrm{T}-\mathrm{S} / \mathrm{n}-1} \times 100$

$S$

$\mathrm{n}=$ número de lagunas en una región o área determinada

$\mathrm{S}=$ número de especies presentes en la región o área 
$\mathrm{T}=$ suma aritmética de $\mathrm{S}_{1}, \mathrm{~S}_{2}, \mathrm{~S}_{3} \ldots \mathrm{S}_{\mathrm{n}}$

$\mathrm{S}_{1}, \mathrm{~S}_{2}, \mathrm{~S}_{3} \ldots \mathrm{S}_{\mathrm{n}}=$ número de especies en lagunas $1,2,3 \ldots \mathrm{n}$

Las afinidades faunísticas determinadas mediante el coeficiente de Jaccard fueron expresadas gráficamente mediante dendrogramas. Los enlaces de estos fueron establecidos mediante la técnica aglomerativa de pares no ponderados usando medias aritméticas "UPGMA" (Sokal \& Michener 1958).

Para analizar el recambio aparente de rotíferos en el curso principal del río entre dos años se utilizó la siguiente fórmula (Arnott et al. 1999)

$\mathrm{T}=100(\mathrm{I}+\mathrm{E}) /((\mathrm{S} 1+\mathrm{S} 2) \mathrm{t})$

$\mathrm{I}=\mathrm{n}^{\circ}$ de taxa presentes en el segundo año

$E=n^{\circ}$ de taxa perdidos entre los censos

$\mathrm{S} 1=\mathrm{n}^{\circ}$ de taxa en el año $1 ; \mathrm{S} 2=$ idem año 2

$\mathrm{T}=\mathrm{n}^{0}$ de años entre los censos

El término diversidad se utiliza en el sentido dado por Whitaker $(1960,1972)$ ("riqueza de especies"). En este estudio se calculó la diversidad alfa, la gamma y la beta. La primera es la diversidad local y se refiere al número de especies en un cuerpo de agua (Harrison et al, 1992, Amoros \& Bornette 2002), la gamma o diversidad regional es el número total de especies en un área o región. La beta es la diversidad entre comunidades y se relaciona a la tasa de recambio espacial, se calculó de acuerdo a la siguiente ecuación (Harrison et al. (1992)

$ß=((y / \bar{x})-1) /(N-1) \cdot 100$

y= número total de especies en un área o región, o diversidad regional.

$\bar{x}=$ promedio de las diversidades locales

$\mathrm{N}=$ número de ambientes muestreados

Esta medida resulta conveniente para comparar diversidades entre transectas de desigual tamaño. La diversidad beta variará entre 0 , cuando todas las especies de la región ocurren en todas las lagunas, es decir similitud total y 100 cuando cada especie ocurre en un solo hábitat o laguna, es decir la mas completa disimilitud.

Harrison et al. (1992) proponen también otra medida de la diversidad beta, la ß2 donde en lugar de considerar la diversidad alfa media se considera el máximo valor de la 
diversidad alfa en la colección de $\mathrm{N}$ sitios o hábitats. Varia también entre 0 y 100 y converge con la primer medida de $ß$ cuando la variabilidad en la diversidad alfa es pequeña.

ß2: $\left(\mathrm{S} / \mathrm{a}_{\max }\right)-1 /(\mathrm{N}-1) \times 100$

$\mathrm{a}_{\max }=$ es el valor máximo de diversidad alfa en la colección de $\mathrm{N}$ sitios.

Como estimador de la riqueza basada en la presencia de especies raras se utilizó la metodología del "jackknife " ( Baltanas 1992 , Kreb 1999)

$S=s+(n-1 / n) k$

$\mathrm{s}=$ número total de especies presentes en $\mathrm{n}$ unidades $\mathrm{o}$ cuadrados

$\mathrm{n}=$ número total de unidades muestreadas

k= número total de especies halladas una sola vez

También para datos de riqueza se empleó el estimador de Chao \& Lee 1992 (Fide Dumont \& Segers 1996)

$S=S . o b s+\left(L^{2} / 2 M+1\right)$

S. obs= número total de especies registradas

$\mathrm{L}=$ número de especies presentes en una sola muestra

$\mathrm{M}=$ número de especies presentes en dos muestras

La riqueza asintótica de especies se obtuvo a partir del método gráfico de Walford, basado en la construcción de un diagrama de dispersión de riqueza acumulativa (Ricker 1958). Un valor de riqueza asintótica mayor que la acumulativa indica que es necesario un mayor número de muestras para detectar todas las que ocurrirían.

\section{Algunas consideraciones sobre la riqueza de especies y su estimación}

Todas las mediciones de riqueza de especies son altamente dependientes de la escala espacial de muestreo, intensidad del análisis y competencia taxonómica del investigador (Brown 1990, Kalff 2002). Por otro lado, la representatividad de las muestras es la piedra angular en la evaluación de la riqueza, dado que la confiabilidad se relaciona directamente a la proporción de la comunidad muestreada (Baltanas 1992). Así es que el 
registro de especies raras es fuertemente dependiente del tamaño de la muestra (Lampert \& Sommer 1997). Considerando el tamaño de la escala espacial y temporal de un sistema como el del río Paraná, es más que importante considerar estas variables en las mediciones de la riqueza.

Interesa particularmente saber si en los ambientes estudiados un período determinado de tiempo que cubra diferentes niveles hidrométricos es adecuado para estimar la riqueza de rotíferos. Para este análisis, entre los ambientes descriptos precedentemente, se consideraron los siguientes: Laguna los Matadores, de conexión directa con el río, con una sola estación pelágica, en la que se realizaron muestreos semanales en el período de aguas altas-bajante; Laguna La Cuarentena, de conexión directa con el río y forma compleja por la articulación de varios brazos, donde se muestrearon entre 4 y 12 estaciones durante 6 fechas, representativas de distintos niveles hidrométricos; Canal Principal del río Paraná durante el evento de El Niño , periodo noviembre de 1982 -marzo 1983 en el cual se tomaron muestras durante 18 ocasiones.

Para conocer el grado de representatividad de la riqueza observada respecto de la esperada en los casos señalados, se tuvieron en cuenta dos tipos de estimadores: el del "jackknife" (Kreb 1999), donde se incluyen la especies encontradas solo una vez y el estimador de Chao \& Lee (1992) (fide Dumont \& Segers 1996), donde se consideran especies encontradas una y dos veces.

Según los datos de la Tabla I en la laguna Los Matadores, un periodo de estudio de 7 meses con muestreos semanales permite obtener entre el 82 y $87 \%$ de la riqueza esperada en su área limnética. En la Laguna La Cuarentena los seis muestreos realizados permiten obtener entre un 75 y $79 \%$ del valor esperado de riqueza, es decir menor que en la laguna anterior, pero aquí se trata de toda la laguna (área limnética + área litoral). La estimación más cercana a la esperada se obtuvo en los Matadores, con mayor frecuencia de muestreo. En cambio, durante el período que coincidiera con el fenómeno de El Niño, el muestreo realizado en el canal principal, pese a tener una frecuencia entre tres y siete días, resulta poco eficiente para ser representativo, seguramente por la magnitud del evento hidrológico.

Probablemente, la información más completa sobre diversidad de rotíferos es la existente sobre el canal principal ( $\mathrm{km} \mathrm{603)}$ donde los muestreos cubren un período continuo de varios años (1977-1983), período cuya extensión posibilitaría una mejor aproximación 
al conocimiento de la riqueza de un biotopo a través de muestreos a lo largo de ciclos anuales.

\begin{tabular}{|c|c|c|c|}
\hline & L. Los Matadores & .L. La Cuarentena & $\begin{array}{l}\text { Curso Principal (km 603) } \\
\text { Evento El Niño 1982-1983 }\end{array}$ \\
\hline $\mathrm{N}^{\circ}$ observado & 94 & 84 & 44 \\
\hline \multicolumn{4}{|l|}{$N^{\circ}$ esperado } \\
\hline Jacknife & 114 & 112 & 69 \\
\hline Chao \& Lee & 108 & 107 & 78 \\
\hline & & & \\
\hline
\end{tabular}

Tabla I. Riqueza específica de rotíferos observada y esperada en tres ambientes. 


\section{RESULTADOS Y DISCUSION}

\section{1.- AMBIENTES LÓTICOS}

\section{Fauna de rotíferos en cursos fluviales de distinta jerarquía}

\section{Curso principal}

En el curso principal, tanto por muestreos realizados a lo largo de más de 6 años en el km 606, como por los correspondientes al tramo Confluencia-Río de la Plata, se identificó un total de 113 especies de rotíferos. Sin embargo, debe destacarse que en muchas oportunidades se registraron individuos que no pudieron ser identificados, por ser numéricamente escasos o por presentar artefactos de contracción por efecto de la fijación con formol.

Los géneros que presentaron la mayor diversidad de especies fueron Brachionus y Lecane. Las únicas especies presentes en el $100 \%$ de los muestreos fueron K.americana, $K$. cochlearis y K. tropica. B. calyciflorus, B. caudatus austrogenitus, B. quadridentatus y Lecane bulla y L. proiecta fueron registradas en más del $75 \%$ de los muestreos. Solo 13 de las 113 especies registradas estuvieron presentes en más del $60 \%$ de los muestreos, en tanto que 34 especies, es decir el $30 \%$, fueron registradas en un solo muestreo, lo cual muestra un considerable porcentaje de especies de presencia ocasional.

\section{Cursos secundarios}

Se registró un total de 84 especies. Brachionus y Lecane fueron también, en estos ambientes, los géneros que presentaron mayor diversidad. Mientras $B$. angularis, $B$. budapestinensis, B. calyciflorus, B. alhstromi, B. austrogenitus, B. falcatus, B. havanensis y $B$. quadridentatus, y $L$. leontina, estuvieron representadas en el $80 \%$ de las muestras. Keratella americana, $K$. cochlearis y $K$. lenzi estuvieron representadas en todos los muestreos.

\section{$\underline{\text { Cursos tributaríos }}$}

En los cursos tributarios, se registró un total 81 especies en margen izquierda y 42 en margen derecha. Las especies que exhibieron mayor frecuencia fueron: $B$. angularis, $B$. calyciflorus, B. plicatilis, B. ahlstromi, K. americana y L. proiecta. 


\section{Consideraciones generales sobre la diversidad de rotíferos en los ambientes lóticos}

En el conjunto de ambientes lóticos estudiados se identificó un total de 145 especies (Tabla 1.1.), correspondientes a 36 géneros, pertenecientes a 12 familias del orden Ploimida, 6 del orden Flosculariacea y 1 del orden Collothecacea. Otros géneros fueron colectados en número muy escaso no pudiéndose identificar sus especies, cuya presencia, aunque esporádica, elevaría los valores de riqueza específica de rotíferos en estos ecosistemas.

La mayor diversidad correspondió a los géneros Brachionus, Lecane y Trichocerca, con 25, 33, 11 especies respectivamente. Si bien en muchos casos un número importante de especies se registraron en solo pocas ocasiones, es destacable la riqueza global de estos tres géneros en los ambientes de aguas corrientes lóticos.

La importancia relativa de los géneros Brachionus y Lecane en el río puede relacionarse principalmente a los rasgos biogeográficos del área de estudio. La del género Lecane, en cambio, puede asociarse además al "input" permanente de especies de zonas litorales vegetadas, como se discutirá más adelante.

El género Brachionus estuvo representado por algunas especies planctónicas, tales como $B$. angularis, B. calyciflorus y las especies del grupo caudatus, y otras que han sido consideradas como especies litorales como es el caso de Brachionus quadridentatus.

El género Lecane es considerado litoral, si bien su registro frecuente en los sistemas fluviales está de acuerdo con lo expuesto por Pejler (1962) en el sentido de que no requiere, necesariamente, de un sustrato para su desarrollo. El género Trichocerca es también considerado litoral, habiéndose registrado su mayor riqueza en los cauces secundaríos y tributaríos.

Los géneros planctónicos Synchaeta, Hexarthra y Asplanchna presentaron una baja diversidad y frecuencia en los ambientes fluviales. Asplanchna fue registrado principalmente en cauces secundarios, no en el curso principal y las especies de Synchaeta fueron registrados en cursos tributaríos con mayor salinidad.

Algunas especies estuvieron presentes en muchos de los ambientes estudiados; tal fue el caso de B. calyciflorus, B. austrogenitus, Euchlanis dilatata, Filinia Iongiseta, K. americana, K. cochlearis, K. tropica, L. bulla, L. proiecta, Polyarthra vulgaris y T. rattus. Este grupo de especies estuvo presente entre el 75 y $100 \%$ de las oportunidades de muestreo. Varios de 
tabla1.1 p.1 
tabla1, p.2 
tabla 1, p3 
ellos son, sin embargo, rotíferos litorales, cual es el caso de E. dilatata, L. bulla, L proiecta y $T$. rattus. De ellas, dos especies son especialmente destacables: L. proiecta por ser un especie endémica de la región Neotropical, muy frecuente en ríos de la cuenca del Orinoco y Amazonas (Saunders \& Lewis, 1988 ; Vásquez \& Wilbert 1992) y L. bulla que es una de las especies más eurítopas y común del género en todo el mundo ( Segers 1995 b).

Una característica compartida por todas las especies de rotíferos registradas en los ambientes fluviales del Paraná, pero particularmente en el curso principal, es su pequeña talla, en general menor a $300 \mu \mathrm{m}$. En todos los muestreos realizados no fueron frecuentes por ejemplo los morfotipos grandes de Brachionus calyciflorus, como tampoco el género Asplanchna, cuyas especies son de las de mayor talla entre los Monogononta.

Comparando la riqueza de especies entre los cursos de distintas jerarquías, la mayor diversidad de rotíferos se observó en el curso principal y cauces secundarios. La riqueza en los tributarios es comparativamente menor esto podría atribuirse a cuestiones metodológicas, pues se dispuso de mayor número de muestras del curso principal. No obstante, en los tributarios los muestreos se realizaron durante diferentes períodos hidrológicos y, en algunos casos, como el del río Salado se tomaron muestras en un considerable número de estaciones.

La afinidad faunística total entre curso principal y cauces secundarios y tributarios, calculada según el índice de Koch (1957) es del 12 \% siendo, en consecuencia, pocas las especies comunes a las tres jerarquías de cursos.

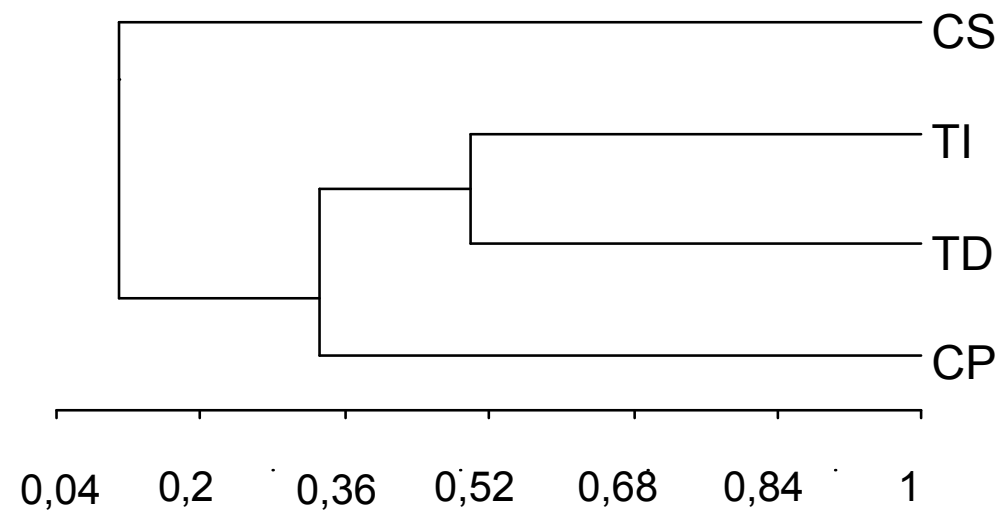

Coeficiente de Jaccard

Fig.1.1. Afinidades faunísticas entre ríos de distinta jerarquía: CP curso principal, CS cauces secundarios, TI tributarios margen izquierda, TD tributarios margen derecha. 
Si analizamos los distintos tipos de cauces ( Fig. 1.1) se observa que la mayor afinidad se registra entre los tributarios de margen derecha e izquierda; el curso principal se asemeja a ambos en un $36 \%$ y la mayor diferencia se observa entre este último y los cauces secundarios. Los cauces tributarios al desembocar en el curso principal realizan un aporte continuo de organismos, por lo que la rotiferofauna exhibe, entre ambos, mayor afinidad.

\section{Variaciones espaciales en la diversidad de rotíferos en el curso principal}

\section{Tramo Confluencia-Diamante}

A lo largo de $700 \mathrm{~km}$ del curso principal del Paraná, con un nivel hidrométrico de aguas bajas, se registraron 52 taxa. El género Brachionus fue el que exhibió mayor diversidad, registrándose 13 especies, Keratella americana, K.cochlearis, K.tropica, Trichocerca rattus, y Polyarthra vulgaris tuvieron presencia continua, siendo frecuente el registro de Ploesoma truncatum.

El número de especies por estación varío entre 5 y 22, ( $\times: 13,00 ;$ d.s.: 3,56) a lo largo de todo el tramo.

Considerando las estaciones del centro del cauce se observó un paulatino incremento en el número de especies aguas abajo . Los valores más bajos $(<10)$ se observaron en el área de la Confluencia con el Paraguay y los más altos $(>20)$ en las proximidades de ParanáDiamante (Fig. 1.2).

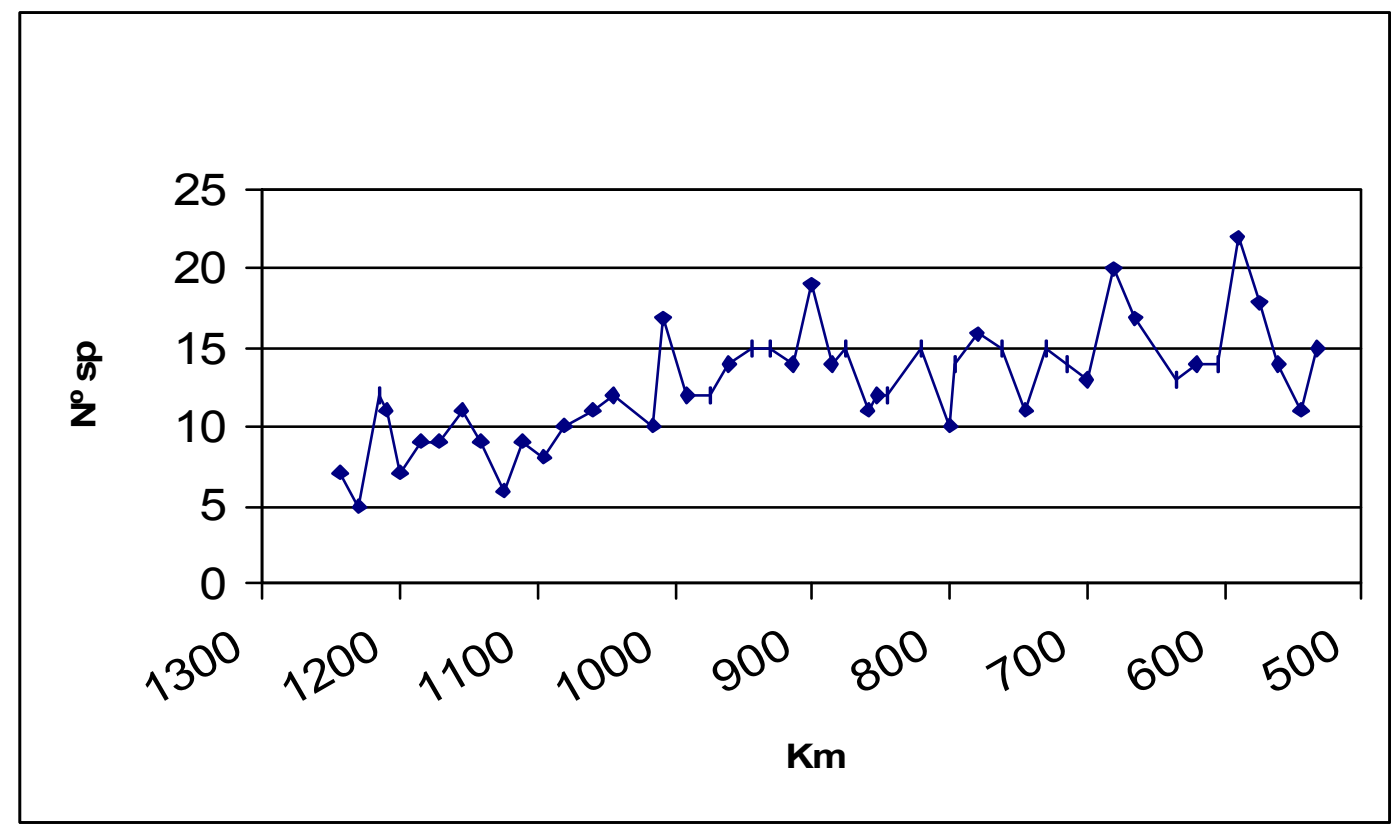

Fig. 1.2. Variaciones del número de especies de rotíferos en el curso principal del río Paraná, tramo Confluencia-Diamante (nivel hidrométrico en aguas medias) 
La Tabla 1.2. permite apreciar, en determinadas secciones del curso principal, las variaciones horizontales (entre ambas márgenes) que se observaron en la riqueza específica (Tabla 1.2 ). En el km. 1244, en la estación ubicada en la margen de la desembocadura del río Paraguay se registraron 16 especies en tanto que solo 7 se observaron en el centro del curso. En el km 1210, donde aún persiste la influencia del río Paraguay, visible a través de la coloración rojiza que le aportan los sedimentos del río Bermejo, se registraron 18 especies de rotíferos en la citada margen, mientras que en el centro del cauce se hallaron 11 y sólo 4 en su margen izquierda. El número de especies en común entre las estaciones de cada sección transversal fue variable. Fue muy bajo en los primeros tramos que reciben la influencia del río Paraguay, como así también en el km. 680. Esto coincide con las características del río, las aguas del río Paraná corren por la margen izquierda y las del Paraguay por el de la derecha, sin mezclarse, a lo largo de un tramo que varía entre 200 y 400 km (Bonetto \& Wais, 1995).

\begin{tabular}{|cccc|c|}
\hline KM & Ribera D. & Centro & Ribera Iz. & $\begin{array}{c}\text { No spp en } \\
\text { común }\end{array}$ \\
\hline 1244 & $16^{*}$ & 7 & & 5 \\
1210 & 18 & 11 & 4 & 2 \\
1170 & 12 & 9 & 5 & 2 \\
1008 & 15 & 17 & & 12 \\
876 & 15 & 15 & 20 & 8 \\
745 & 10 & 11 & 16 & 6 \\
680 & 18 & 20 & 7 & 4 \\
\hline
\end{tabular}

Tabla 1.2. Número de especies de rotíferos en transecciones horizontales del río Paraná, tramo Confluencia-Diamante, ubicadas a diferentes distancias del puerto de Buenos Aires. * Corrresponde a la margen que recibe las aguas del río Paraguay.

Considerando otros muestreos de parte de este tramo, el correspondiente a GoyaDiamante, se observaron diferencias según el nivel hidrométrico. Con nivel de aguas medias se registraron 10 especies y 18 con aguas altas. Las especies más frecuentes fueron $K$. americana, $K$. cochlearis, $T$. rattus, $P$. vulgaris y $L$. proyecta, mientras que K.americana, T. rattus y Brachionus calyciflorus lo fueron en aguas altas 
De este tramo de casi $600 \mathrm{~km}$ de largo, como se consignó en la metodología, se tomaron muestras en dos oportunidades (1972 y 1990), a diferentes niveles hidrométricos: aguas medias (1972) y aguas altas en bajante (1990). En el muestreo de 1972, se registró un total de 35 especies a lo largo de 58 estaciones. Los géneros más representativos fueron Brachionus (6 especies) y Lecane (5 especies). Las especies más frecuentes a lo largo del tramo fueron K. americana K.cochlearis, K.tropica, Trichocerca rattus, Polyarthra vulgaris y Brachionus quadridentatus. El número de especies por estación fue muy fluctuante, variando entre 2 y 11 especies ( $\bar{x}: 7$, d.s.: 2,25). No se observo una tendencia definida de cambios en la riqueza de especies en sentido longitudinal (Fig. 1.3). A la altura del puerto de Rosario la menor concentración de oxígeno, y mayor turbiedad registrados, no afectó negativamente a la riqueza de especies por estación.

En el muestreo de 1990 se registraron 62 taxa, a pesar de que solo se muestrearon 19 estaciones de las 58 consideradas en el primer muestreo. Se registró una gran proporción de especies de los géneros litorales Lecane, Colurella, Lepadella y Trichocerca. Lecane estuvo representado por 15 especies y Trichocerca por 4, contrastando con las 5 y 1 especies respectivamente registradas en el primer muestreo.

Las especies mas frecuentes a lo largo de todo el tramo fueron Keratella cochlearis, Polyarthra vulgaris y Brachionus caudatus que tuvieron una frecuencia de ocurrencia de 94, 89 y $61 \%$, respectivamente. K. tropica fue muy frecuente en Paraná de las Palmas y Paraná Guazú.

El número de especies por estación varió entre 3 y 25 ( $\bar{x}: 14$, d.s.: 7,05). Aguas abajo se observó un notorío incremento de la riqueza específica (Fig. 1.3), atribuible a la incorporación paulatina de especies, generalmente litorales. Esto hizo que las afinidades faunísticas entre las estaciones fueran muy bajas, inferiores a $0,5 \%$ (Fig. 1.4).

Por lo registrado en estos estudios, existe un grupo de especies adaptadas a las condiciones particulares del Canal Principal del río Paraná como son su alta velocidad de corriente y la carga de sedimentos suspendidos. En tal sentido, se pueden destacar las especies del género Keratella (principalmente $K$. americana y $K$. cochlearis), así como Polyarthra vulgaris y Trichocerca rattus. Otras especies parecen también estar bien adaptadas a estas condiciones, tales como Brachionus caudatus y $B$. quadridentatus, que estuvieron presentes en varios tramos del canal principal.

Habiéndose dispuesto de información para más de un período hidrométrico en un mismo tramo del curso principal, se puede observar que el menor número de especies de rotíferos se registra en períodos de aguas medias, cuando el número máximo de especies por 
estación de muestreo es menor a 12. En contraste, en aguas altas en proceso de bajante, se incrementa la riqueza de especies en el canal principal, siendo en este caso 26 el número máximo de especies registrado.
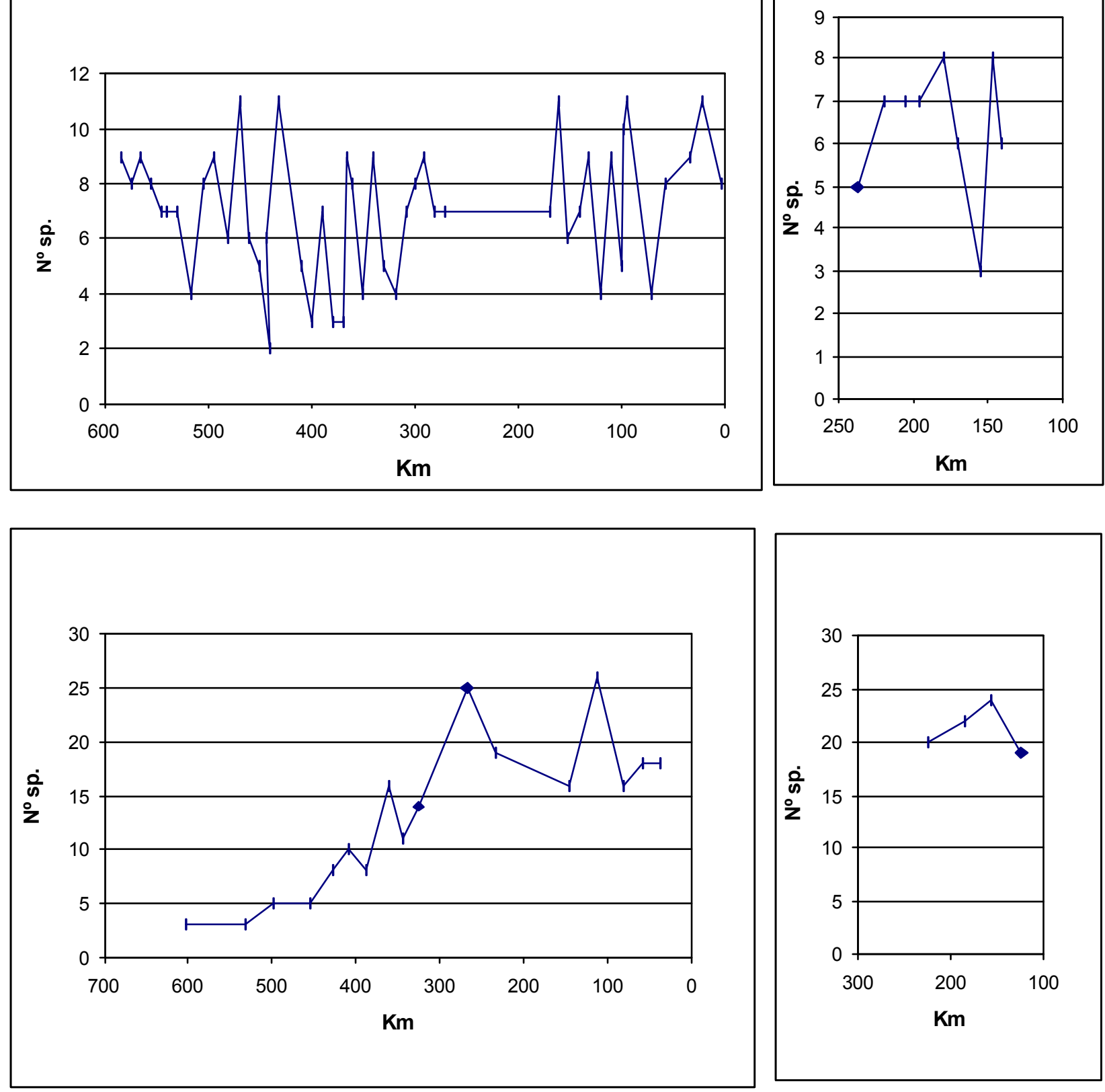

Fig. 1.3. Variaciones de la riqueza de Rotíferos en el curso principal, tramo Paraná- Río de la Plata, a un costado tramo Paraná Guazú e Ibicuy. Arriba datos del muestreo con un nivel hidrométrico de aguas medias, abajo con aguas altas en bajante 


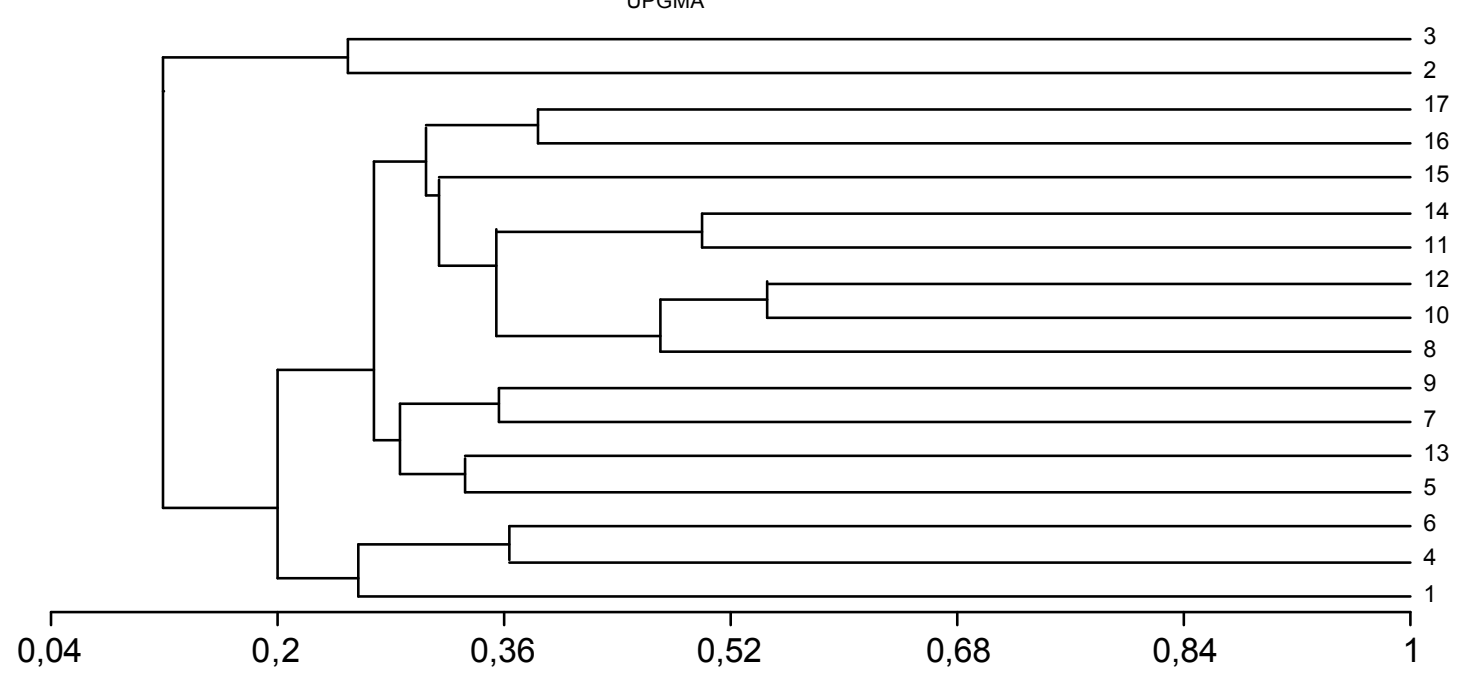

Coeficiente de Jaccard

Fig. 1.4 Afinidad faunística entre estaciones del curso principal tramo Santa Fe-Río de la Plata (aguas alta en bajante)

Los datos obtenidos no muestran un patrón definido de distribución espacial en el sentido longitudinal del eje fluvial. Las variaciones en riqueza de especies serían más evidentes en sentido temporal, en relación a determinados períodos hidrométricos. Así, tanto en el tramo Goya-Diamante como Santa Fe -Río de La Plata, la mayor riqueza se registra en aguas altas o altas en bajante.

\section{Variaciones temporales en la diversidad de rotíferos en el curso principal}

(Sección Paraná- Santa Fe, período octubre de 1976- marzo de 1983- diciembre de 1997abril de 2000)

El número total de especies presentes en el curso principal experimentó variaciones considerables a lo largo de los diferentes años de estudio (Fig 1.5 ).

La característica distintiva es la clara y sostenida tendencia a la disminución del número especies de rotíferos en el canal desde octubre de 1976 a marzo de 1983, que se continúa en el período 1997-2000. En el período 1976-1980, los picos de riqueza específica en el canal fueron mayores que 20 especies por muestreo. Desde enero de 1981 a marzo de 1983 los valores máximos no alcanzaron las 15 especies y en el período 1997-2000 no llegaron a las 10 especies. Esta relación entre número de especies y la variable tiempo puede verse en los diagramas de dispersión de la Fig.1.6, donde se observa una recta de tendencia negativa, particularmente en el período 1976-1983. La correlación entre ambos parámetros es significativa para el primer período de estudio y NS para el 
FIG. 1.5 


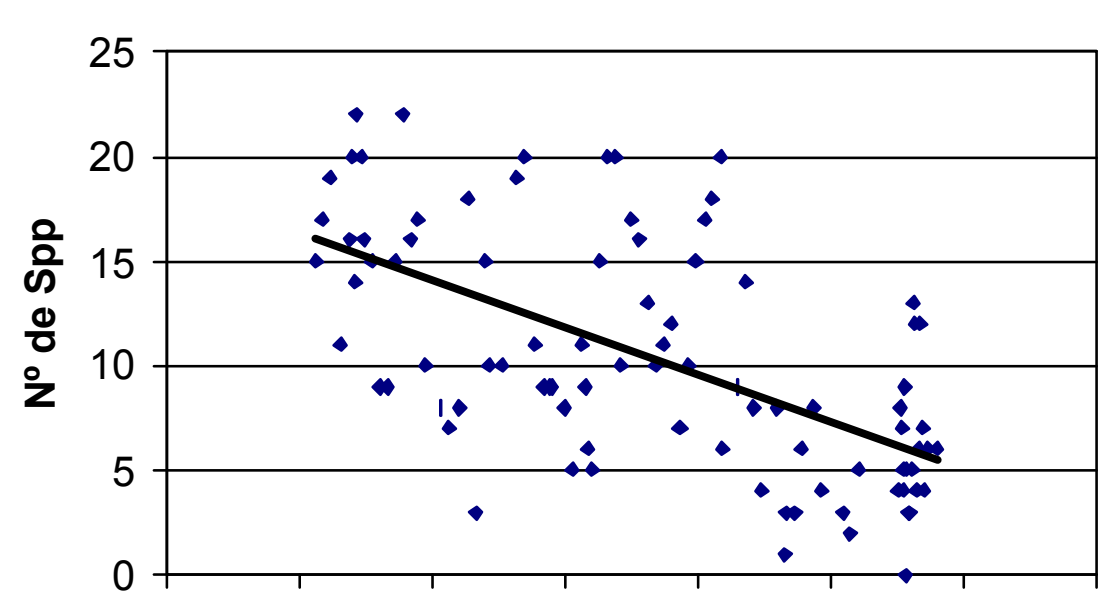

Tiempo (1976-1983)

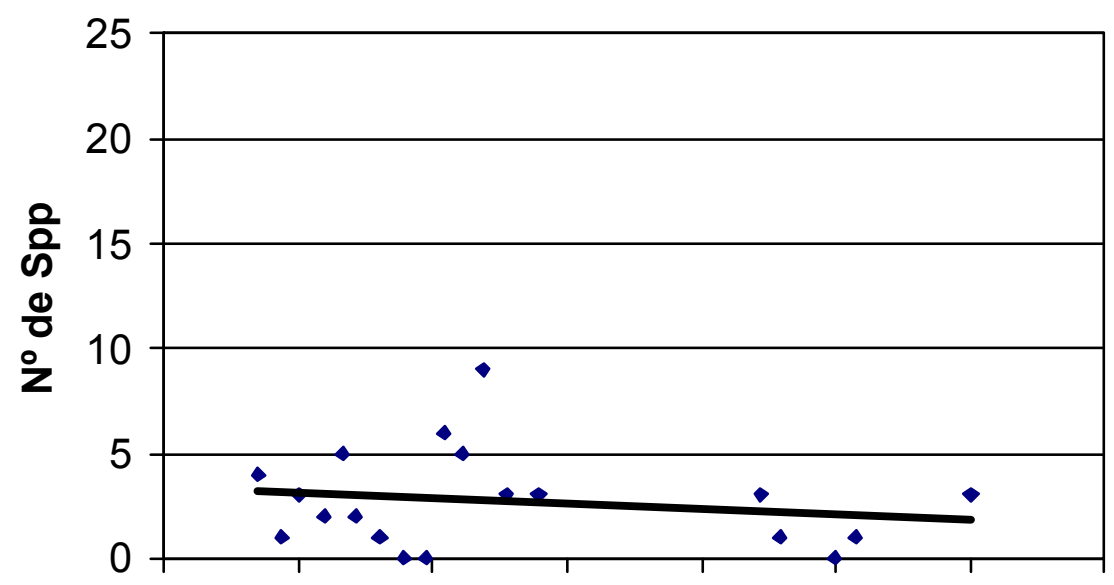

Tiempo (1997-2000)

Fig. 1.6. Diagramas de dispersión y líneas de tendencia entre número de especies de Rotíferos en el canal principal del río Paraná ( $k m$ 603) y la variable tiempo. Período 1976-1983: $r=-0,603, p<0,0001$; Período 1997$2000: r=-0,23, p=0,344$ NS. 
segundo período. Sin embargo analizando el conjunto de datos la correlación es muy significativa ( $r:-0,613, p<0,0001)$.

El grupo de especies conformado por K. americana, K. cochlearis, K. tropica, T. rattus y $L$. proiecta estuvo presente a lo largo de todos los meses del año en el período 1976-1983, Ploesoma truncatum fue la única especie que presentó una distribución claramente estacional, encontrándose solo en las muestras de octubre a diciembre, independientemente del nivel hidrométrico existente.

Las especies comunes a los inventaríos anuales de 1977-1982 y 1998 fueron $B$. calyciflorus, B. falcatus, K. cochlearis, L. bulla, P. vulgaris.

En el canal, la riqueza media anual varío entre 3,2 y 15,4 especies en el período 19771982 y en el año 1998, que se consideraron para este análisis por tener más de 10 muestreos al año. Estos valores presentaron una clara tendencia a disminuir en este período (Fig.1.7)

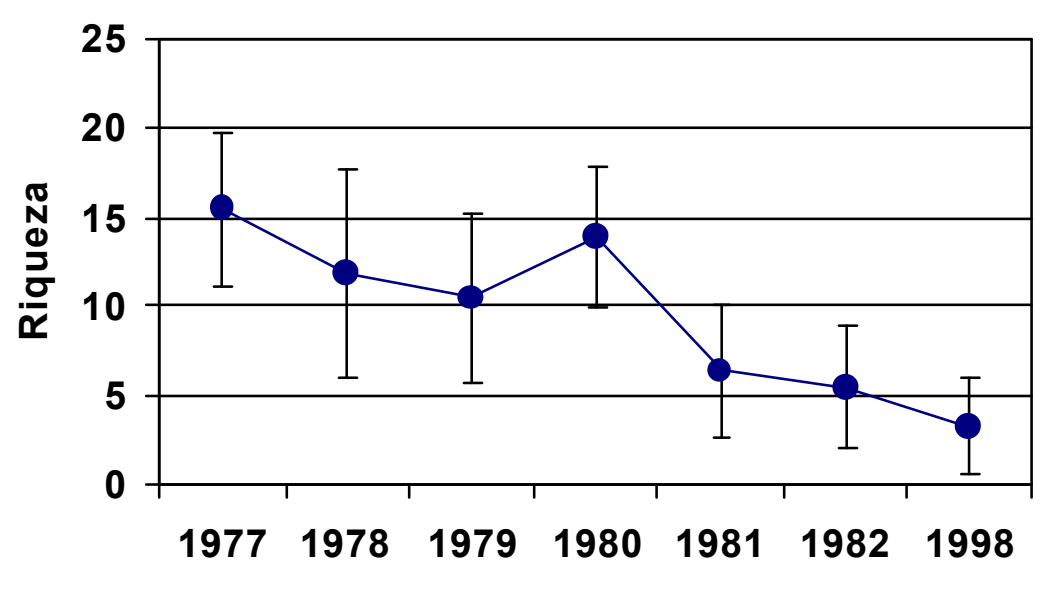

Fig. 1.7. Promedios anuales y d.s. del número de especies presentes en el curso Principal (km 603).

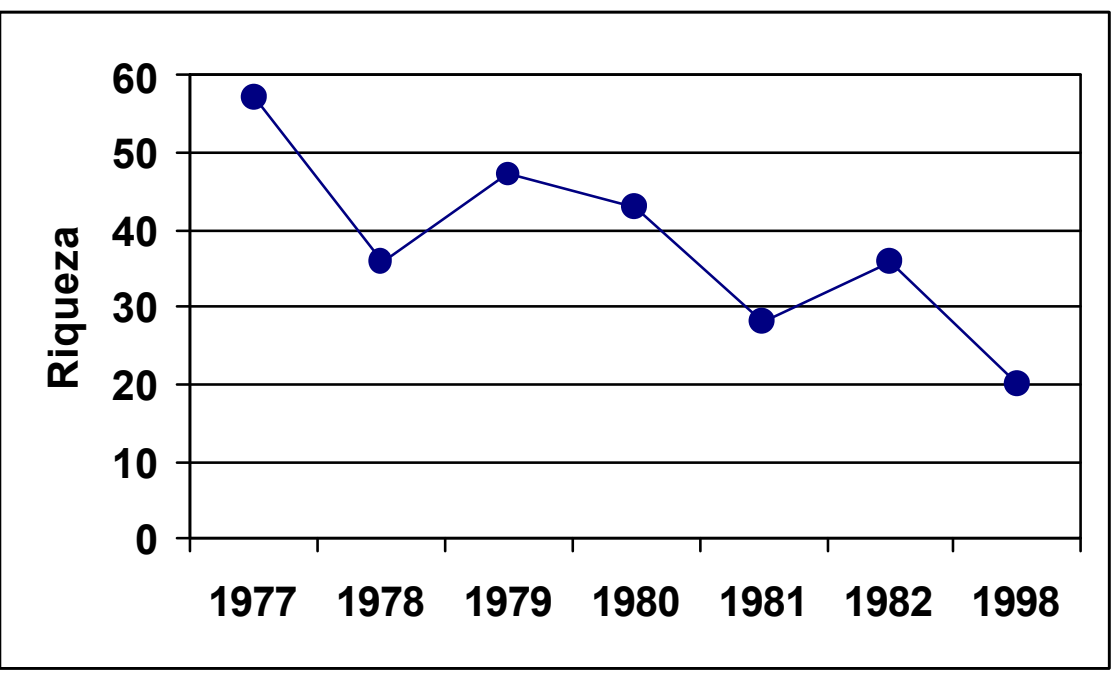

Fig. 1.8. Riqueza acumulativa anual de Rotíferos en el curso nrincinal $(\mathrm{km}$ 6ก.3) 
El número total de especies por año o riqueza acumulativa anual varío entre 20 y 57 especies. El mayor número correspondió a 1977 y el menor a 1998. Estos valores también mostraron una disminución a lo largo del tiempo (Fig. 1.8) La riqueza acumulativa de todo el período de estudio fue de 89 especies. La riqueza acumulativa asintótica ( calculada con el método gráfico de Walford) fue de 67 especies.

El porcentaje de especies detectadas en el río cada año respecto de la riqueza total del período de los 6 años consecutivos varío entre el 22 y $64 \%$. (Fig. 1.9)

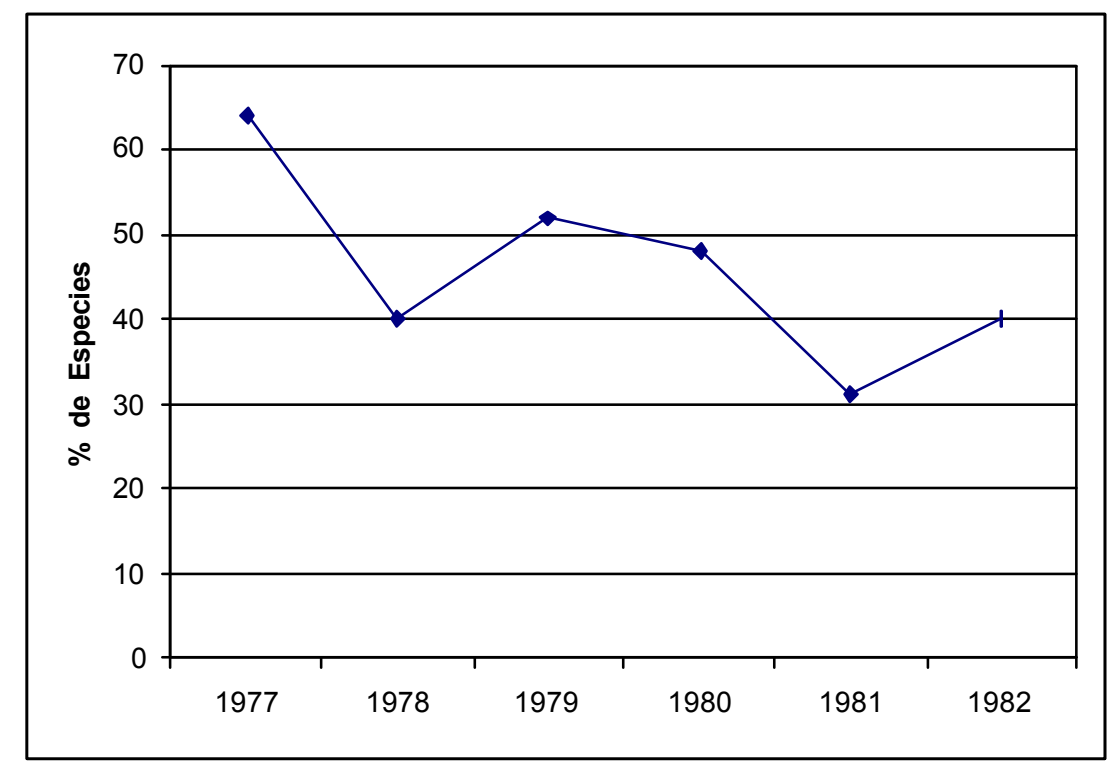

Fig. 1.9. Porcentaje de especies de Rotíferos detectadas anualmente del total registrado en 7 años de muestreos en el canal principal.

La tasa de recambio aparente de especies a lo largo de todo el período estudiado fue de $17,23 \%$. Entre años adyacentes fue de un promedio de $38,2 \& \%$ variando entre 33 y $45 \%$. La tasa más alta de recambio entre años adyacentes correspondió a las variaciones del 1982 respecto de 1981 (Fig. 1.10) la que podría estar asociada al fenómeno de El Niño, evento extremo de inundación registrado en ese año. Si bien el número total de especies no fue el más alto, se introdujeron en ese período especies que no habían sido registradas anteriormente (Fig. 1.11).

Un recambio alto de especies de rotíferos entre un año y otro muestra un cambio en las condiciones del sistema, gobernadas por el ciclo hidrológico, el cual no presentó un patrón regular de comportamiento. Analizando las especies incorporadas al canal respecto de un inventarío inicial, el correspondiente al año 1977, los mayores valores corresponden a los años 1979 y 1982. (Fig. 1.12) Los valores de las especies perdidas respecto de ese mismo 
inventarío fueron en aumento progresivo (Fig. 1.13). El año 1998 merece una consideración aparte, pues la riqueza de especies fue la más baja de todos los años de estudio, lo cual se

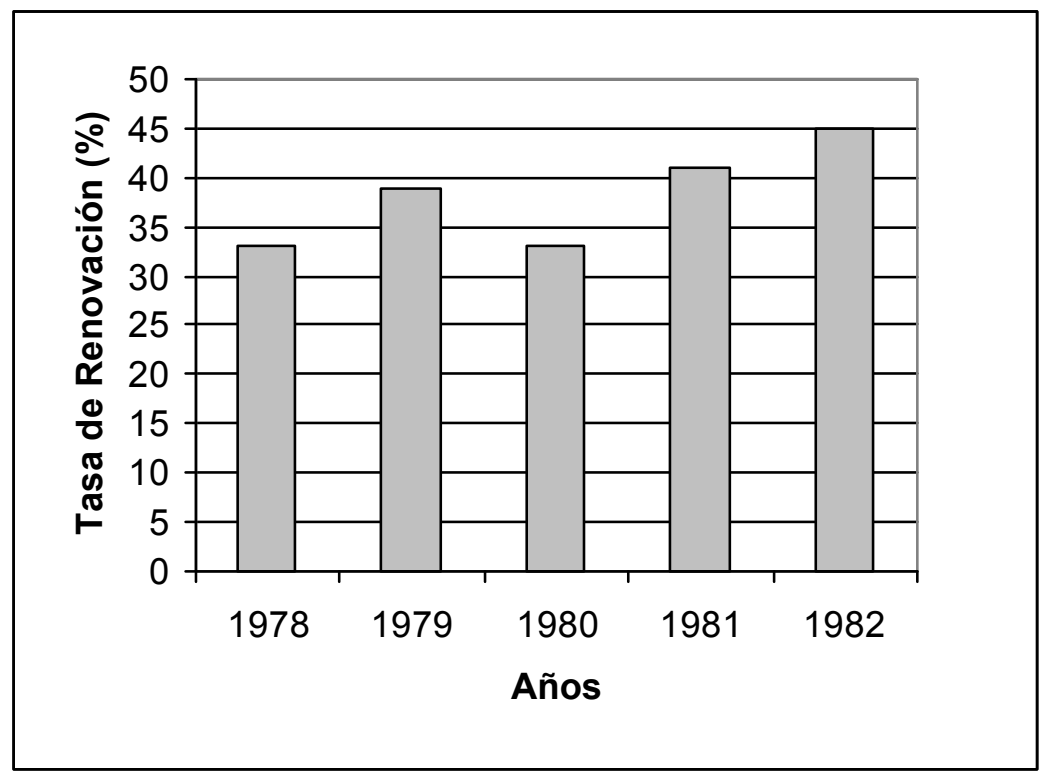

Fig. 1.10. Tasa de renovación de especies entre años adyacentes en el canal principal (km 603) a partir de 1977.

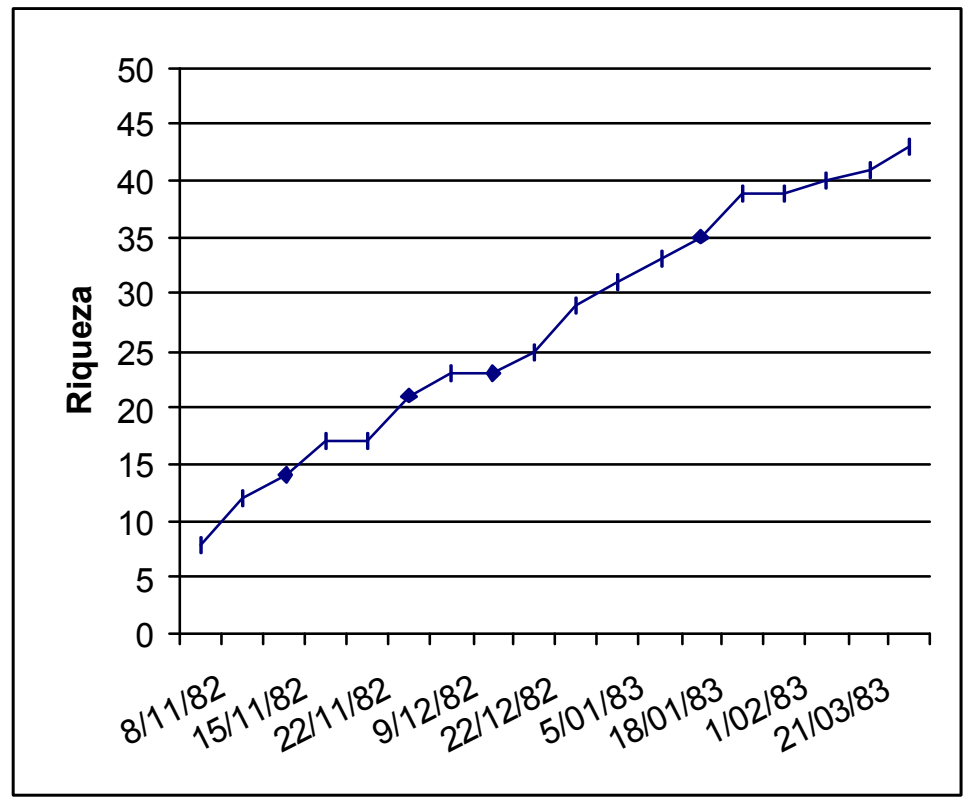

Fig. 1.11. Riqueza acumulativa de Rotíferos observada durante el evento de El Niño en el canal principal del río Paraná km 603), período del 4/11/82 al 21/03/83 (18 eventos de muestreo).

observó también en los pocos meses de muestreo de 1999 y 2000 . Este período se caracterizó por la presencia comparativamente muy escasa no solo de rotíferos sino también de crustáceos, la abundancia total también fue la más baja de todos los años de estudio, 
siendo Limnoperna fortunei en estado larval, el elemento dominante del plancton (José de Paggi, inédito).

Se calculó la afinidad faunística entre la riqueza acumulativa correspondiente a los años 1977-1982 y 1998. La mayor afinidad, pero siempre menor a 0,5, se observa entre pares de años consecutivos (Fig. 1.14). La composición de rotíferos observada en 1998 tiene una muy baja afinidad con los años anteriores, correspondientes a las décadas de los 70 y 80 .

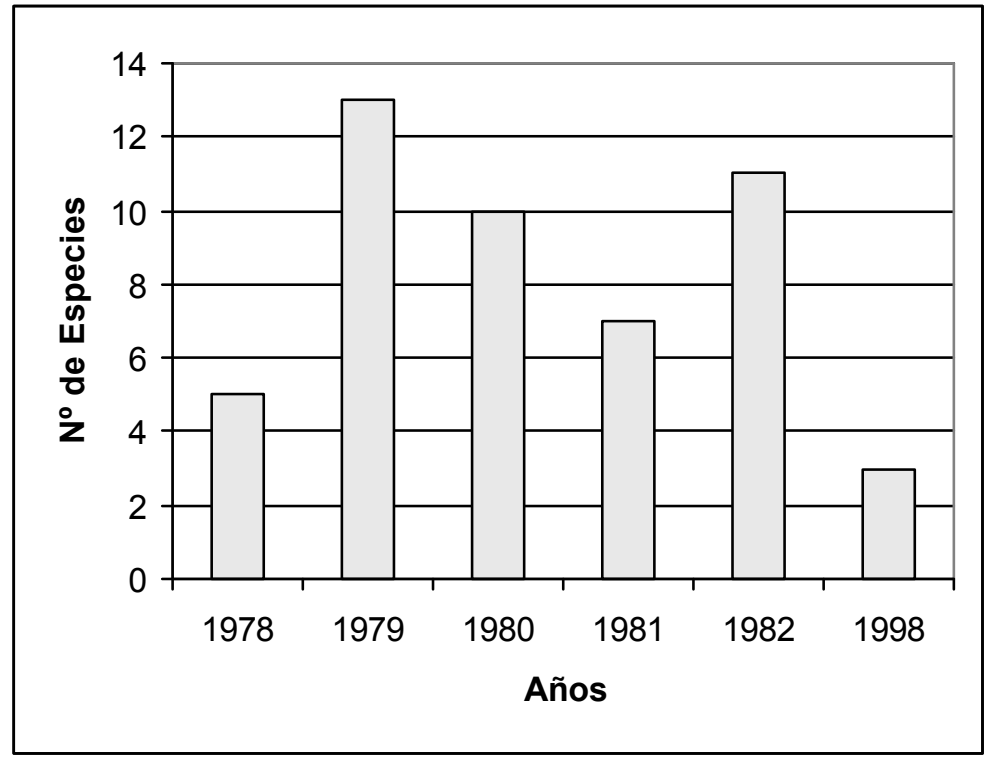

Fig. 1.12. Número de especies incorporadas en el canal principal del río Paraná (km 603) respecto del año 1977.

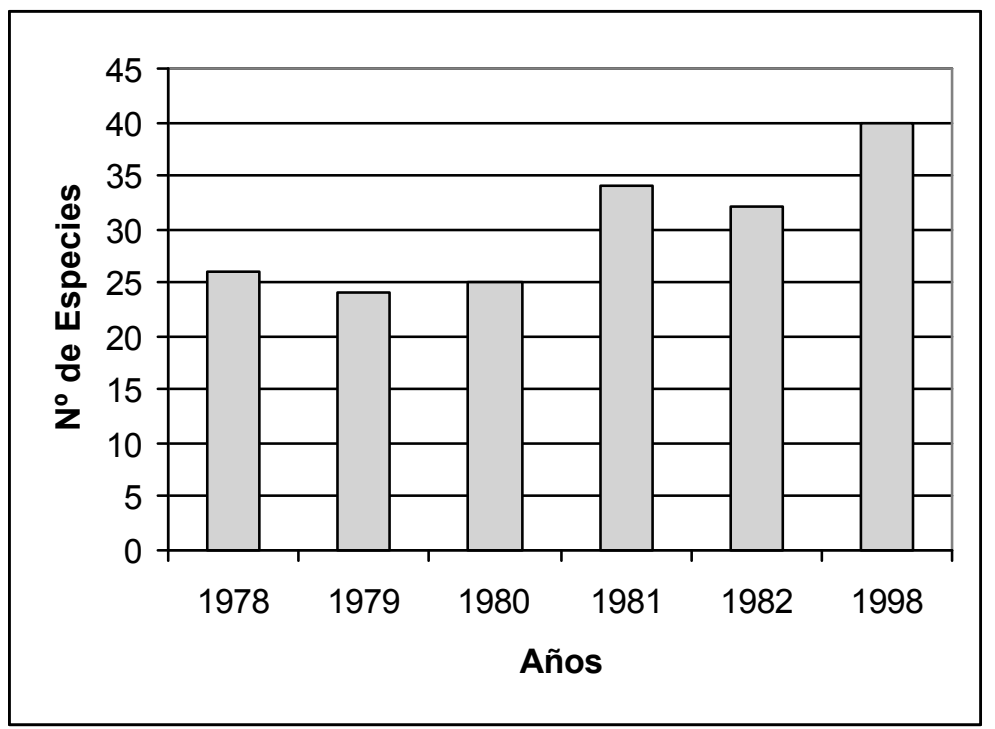

Fig. 1.13. Número de especies perdidas en el canal principal del río Paraná ( $\mathrm{km} \mathrm{603)} \mathrm{respecto} \mathrm{del} \mathrm{inventario}$ del año 1977.

Para observar si hubo divergencia entre la composición del primer año de estudio (1977) y los restantes, se calculó la correlación existente entre todos los valores de afinidad 
faunística y todos los intervalos posibles de años de muestreo. Se obtuvo un coeficiente de correlación de - 0,71 $(n=21)$ indicando una relación negativa entre afinidad faunística e intervalos de muestreo, dado que a medida que aumenta el intervalo disminuye la afinidad entre inventaríos. Esto indica que hubo un proceso de cambio progresivo en la composición de la comunidad a lo largo de los años.

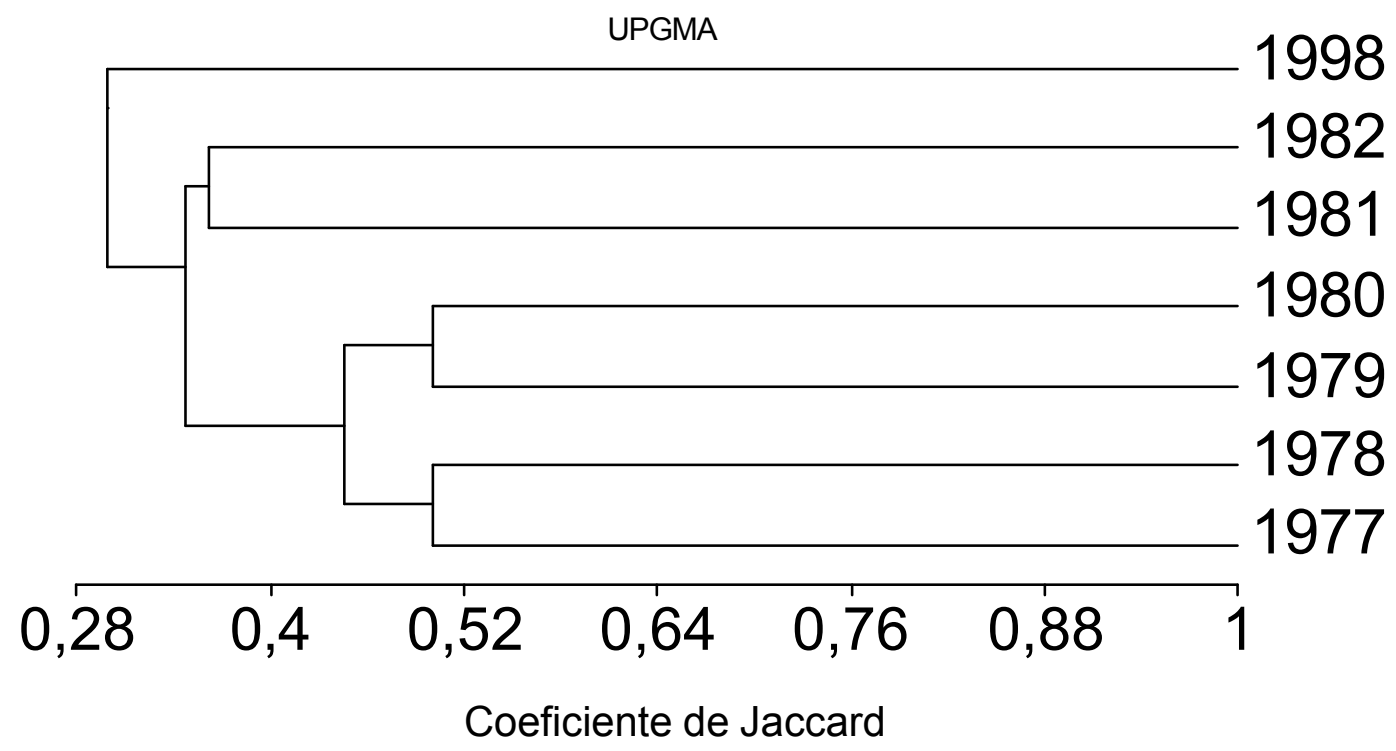

Fig. 1.14. Afinidades faunísticas entre riqueza acumulativa anual de Rotíferos del Curso principal (km 606).

\section{Diversidad temporal de los rotíferos y fluctuaciones de nivel}

Durante el período de estudio, que abarca un número importante de años, el río Paraná presentó notables variaciones hidrométricas ( Fig. 1.5 ), quizá exacerbadas por la manifestación de los dos últimos fenómenos de El Niño del siglo veinte. En el correspondiente a 1982-1983 se registró el mayor caudal del siglo, ocasión en que el valle del río Paraná fue completamente inundado por sobre $1 \mathrm{~m}$ de agua, incluyendo todos los ambientes en una planicie de $30 \mathrm{~km}$ de ancho (Depetris \& Kempe 1990). En concordancia con lo analizado por distintos autores y expresado en la Introducción, las variaciones hidrometricas anuales no presentaron un patrón regular.

Considerando la riqueza acumulativa anual y algunas características del ciclo hidrológico correspondiente (Tabla 1.3), se observa una relación negativa entre riqueza específica y nivel hidrométrico medio anual (Fig. 1.15). 
La diversidad de rotíferos puede analizarse también en relación a las fases de aguas altas y bajas del río, (Tabla 1.4 ). Las fases fueron definidas teniendo en cuenta un nivel de desborde del río de 3,42 en el Puerto de Paraná (Devercelli 2000) a partir del cual se produciría el ingreso de agua en las lagunas de ese sector de la planicie. Se consideraron

\begin{tabular}{|c|c|ccc|c|}
\hline AÑO & No MUESTREOS & N.H.M. & N.H.Max-N.H.Min. & M.P.I. & R.A. \\
\hline 1977 & 15 & 3,17 & $5,91-1,76$ & 4,15 & 57 \\
1978 & 10 & 2,46 & $3,91-1,32$ & 2,59 & 36 \\
1979 & 14 & 3,39 & $4,57-2,01$ & 2,56 & 47 \\
1980 & 12 & 3,71 & $5,14-3,05$ & 2,09 & 43 \\
1981 & 11 & 3,02 & $5,17-1,66$ & 3,51 & 28 \\
1982 & 17 & 4,25 & $6,43-2,65$ & 3,78 & 36 \\
1998 & 12 & 4,91 & $6,72-2,86$ & 3,86 & 20 \\
& & & & & \\
\hline
\end{tabular}

Tabla 1.3. Número de muestreos por año, niveles hidrométricos medios (N.H.M.) máximos (N.H.Max), mínimos (N.H.Min), magnitud del pulso de inundación (M.P.I.) y riqueza acumulativa (R.A.) calculada como el número total de especies registradas en el año de muestreo

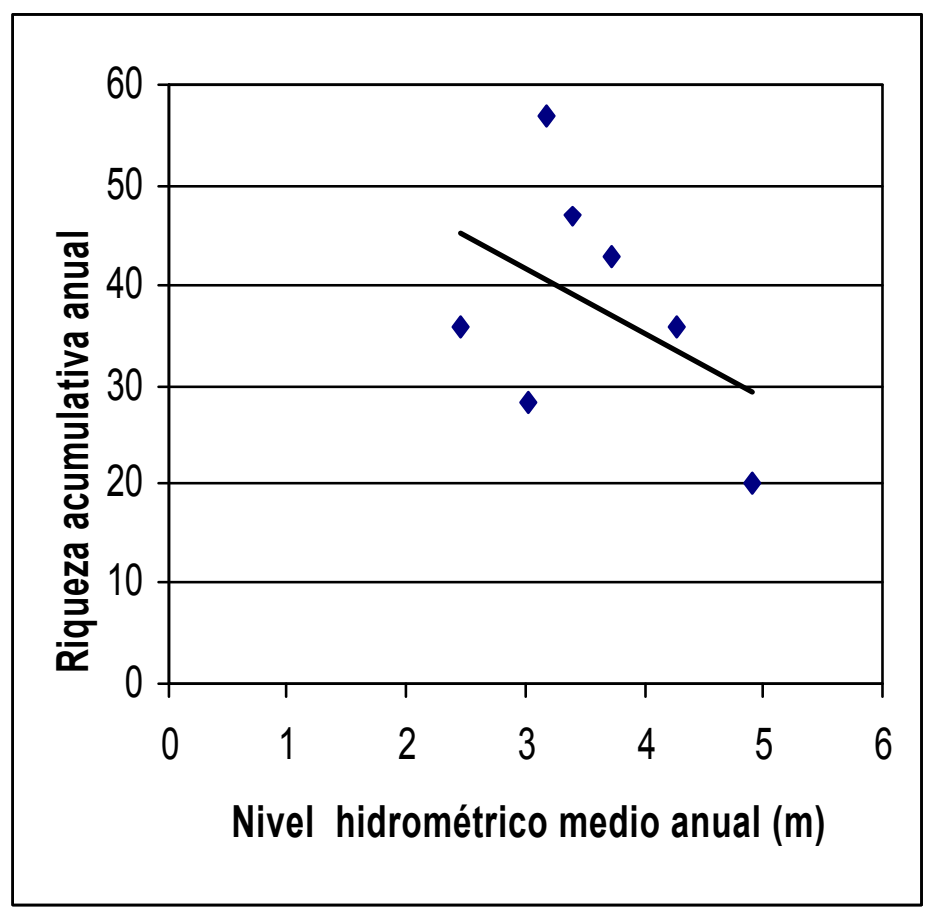

Fig. 1.15. Diagrama de dispersión y línea de tendencia entre la riqueza acumulativa anual de Rotíferos (período 1977-1982 y año 1998) en el canal principal del río Paraná ( $\mathrm{km} \mathrm{603)} \mathrm{y} \mathrm{valores} \mathrm{medios} \mathrm{anuales} \mathrm{del} \mathrm{nivel}$ hidrométrico correspondiente, $r=-0,437, p=0,325, N S$. 
las fases en las que se contó con una mayor frecuencia de muestreos (mensual como mínimo). No se incluyó en el análisis la fase de aguas altas (81-82). En cada una de las fases se tuvo en cuenta la duración (en meses) de las mismas y la intensidad o magnitud, expresada como diferencia entre los valores máximos y mínimos (Neiff 1990 ).

No se observó una correlación directa entre número de especies y duración y magnitud de las fases, pero sí surgen ciertas observaciones de interés. A nivel general se destaca una mayor riqueza de especies de rotíferos en las fases de aguas altas, principalmente en las fases 1977/78, 1979/80 y 1982/83. Estas fases tuvieron una duración de 4, 9 y 3 meses, respectivamente.

Períodos muy breves de sólo 3 o 4 meses de duración mostraron la presencia de más de 40 especies en el canal. En cambio en aguas bajas, en períodos largos de 7 y 11 meses de duración se registró un número menor.

\begin{tabular}{|c|c|c|c|c|c|c|}
\hline FASE & $\begin{array}{l}\text { DURACION } \\
\text { (en meses) }\end{array}$ & $\begin{array}{c}\text { MAGNITUD } \\
\text { (niv.máx-niv.mín) } \\
(\mathrm{m})\end{array}$ & No MUESTREOS & $\begin{array}{l}\text { No TOTAL } \\
\text { DE SPP. }\end{array}$ & $\begin{array}{c}\text { No DE SPP. } \\
\text { Lecane }\end{array}$ & $\begin{array}{l}\text { No DE SPP. } \\
\text { Trichocerca }\end{array}$ \\
\hline AB1 21/05/77 & & & & & & \\
\hline $\begin{array}{c}24 / 12 / 77 \\
\text { AB2 } 2 / 04 / 78\end{array}$ & 7 & 1,66 & 8 & 39 & 4 & 4 \\
\hline $\begin{array}{r}04 / 03 / 79 \\
\text { AB3 30/05/81 }\end{array}$ & 11 & 2,1 & 10 & 36 & 3 & 4 \\
\hline $22 / 12 / 81$ & 7 & 1,76 & 9 & 17 & 3 & 2 \\
\hline AA $1 / 01 / 77$ & & & & & & \\
\hline $20 / 05 / 77$ & 4 & 2,49 & 7 & 47 & 8 & 5 \\
\hline AA2 24/09/79 & & & & & & \\
\hline $26 / 06 / 80$ & 9 & 1,72 & 11 & 53 & 9 & 7 \\
\hline AA3 19/11/82 & & & & & & \\
\hline $21 / 03 / 83$ & 3 & 3,24 & 11 & 44 & 11 & 3 \\
\hline AA4 12/10/97 & & & & & & \\
\hline $07 / 12 / 98$ & 14 & 3,3 & 12 & 21 & 2 & 1 \\
\hline
\end{tabular}

Tabla 1.4. Datos de las fases de aguas bajas (AB) y altas (AA). Número de muestreos por fase, número total de especies y número de especies de los generos de mayor riqueza. Canal principal del río Paraná (km 603). 
Una mención aparte merece la fase de aguas altas del período 1997-1998, de 14 meses de duración, en ella, el número total de especies fue muy bajo y se encuentra en relación con lo referido anteriormente, acerca de la disminución de especies en el canal registrada en el último período de estudio.

Considerando el total de fases analizadas, en aguas bajas se registraron 55 especies y en aguas altas 89 (Tabla 1.5). Estos valores serían una expresión de la acción del pulso en la incorporación de especies de la llanura al canal principal y por lo tanto, de su acción sobre la diversidad temporal de éste último.

La mayor riqueza de especies de los géneros Lecane, Trichocerca y Testudinella se registró durante las fases de inundación; en cambio, la mayor riqueza de especies de Brachionus se observó durante las fases de bajante, particularmente en la primera de ellas (ver Tabla 1.5 ).

\begin{tabular}{|c|c|c|c|c|}
\hline & Total de especies & $\begin{array}{c}\text { Brachionus } \\
\text { número de especies }\end{array}$ & $\begin{array}{c}\text { Trichocerca } \\
\text { número de especies }\end{array}$ & $\begin{array}{c}\text { Lecane } \\
\text { número de especies }\end{array}$ \\
\hline AB & 55 & 14 & 3 & 5 \\
AA & 89 & 13 & 8 & 22 \\
\hline
\end{tabular}

Tabla 1.5. Riqueza acumulativa de rotíferos y de los géneros de mayor diversidad en el total de las fases de aguas bajas $(A B)$ y aguas altas $(A A)$ en el canal principal del río Paraná ( $k m$ 603). Período 1977-1983, 1997-1998.

El recambio aparente de especies calculado se asociaría también a los cambios hidrométricos del río. La mayor tasa de recambio, 45\%, es la del período 1982-1983, correspondiente al evento de EI Niño. Esto difiere de la tasa del 33 \% registrada entre 19771978, en la que no hubo un evento de inundación extraordinaria.

Debe señalarse que algunos géneros de distribución litoral se registraron en el curso principal únicamente en los períodos de aguas altas, tales como Dicranophorus, Collotheca, Scaridium, Macrochaetus y la mayoría de las especies de Testudinella.

Como se observa en la Figura 1.5 el número de especies en el canal es muy fluctuante en el tiempo, en coincidencia con los procesos de aumento y descenso del nivel de las aguas. Los pulsos de inundación determinan inicialmente una brusca caida en la riqueza de especies, probablemente por dilución y pérdida de organismos por el fuerte arrastre. Pero "a posteriori" el pulso determina un aumento de la conectividad de las lagunas del valle 
entre si y con el canal. Una vez pasado el momento inicial de elevación del nivel, a partir del comienzo del drenaje de las aguas de la planicie hacia al curso principal, se observa un marcado incremento en la riqueza de especies en el canal principal. Cuando el descenso del nivel es más rápido (años 1978 y parte de 1979) se observa un mayor aumento en el número de especies al principio del proceso, mientras que cuando el descenso es mas lento como fue en 1977, el incremento en el número de especies se registra casi al final del período de bajante.

El drenaje de las aguas hacia el canal principal tiene como efecto la incorporación de especies provenientes de las lagunas de la planicie. A mayor intensidad del pulso, lo que se determina por la diferencia entre los niveles máximos y mínimos puede esperarse una mayor superficie de la planicie inundada, mayor nivel de contacto de las aguas del río con los ambientes leníticos y un mayor número potencial de especies a ser incorporadas al canal. El número más alto de especies en la sección Paraná se registró en el año 1977, con la mayor magnitud del pulso, la que estuvo determinada en gran parte por los valores mínimos alcanzados por la bajante de ese año.

Sin embargo, en 1980 el número de especies también fue importante a pesar de registrarse la más baja magnitud del pulso de inundación. El río presentó un comportamiento particular ya que durante todo el año, mantuvo niveles superiores a los $3 \mathrm{~m}$, lo que habría determinado un flujo permanente de especies desde los ambientes inundandos, principalmente de los más próximos a sus riberas. Este aporte desde la planicie se documenta a través del registro de especies en ese año de géneros litorales en el canal, como se señalaba anteriormente, tales como Macrochaetus, Dicranophorus y otros.

En ríos templados el acople de hidrologia y temperatura es importante para la produccion de peces (Spark et al. 1990); también la capacidad de reclutamiento del plancton en el canal está condicionada por el estado hidrologico y la estación (Reynolds \& Decy 1996). En el caso de los rotíferos, las temperaturas más cálidas pueden favorecer no solo un aumento de la fecundidad y menor tiempo de desarrollo embrionario, sino también la eclosión de huevos de resistencia de muchas especies. Generalmente, durante los meses más cálidos se registra un mayor número de especies en el canal principal. Si bien no se observa una correlación estadísticamente significativa, la relación entre temperatura y riqueza es positiva. (Fig. 1.16).

\section{Riqueza específica, turbiedad y velocidad de la corriente}

La turbiedad del Paraná Medio luego del aporte del Bermejo es muy alta ( > $600 \mathrm{mg} / \mathrm{l}$ de sólidos suspendidos) e incluye un alto porcentaje de partículas finas, menores de 16 øm 
(Drago \& Amsler 1988). Se dispuso de datos de concentración de sedimentos suspendidos para el período octubre 1976- noviembre de 1980. Los valores variaron entre 62 y 609 mg/l. No se encontró una correlación significativa entre número de especies y sedimentos suspendidos $(r=-0,010, p=0,946)$

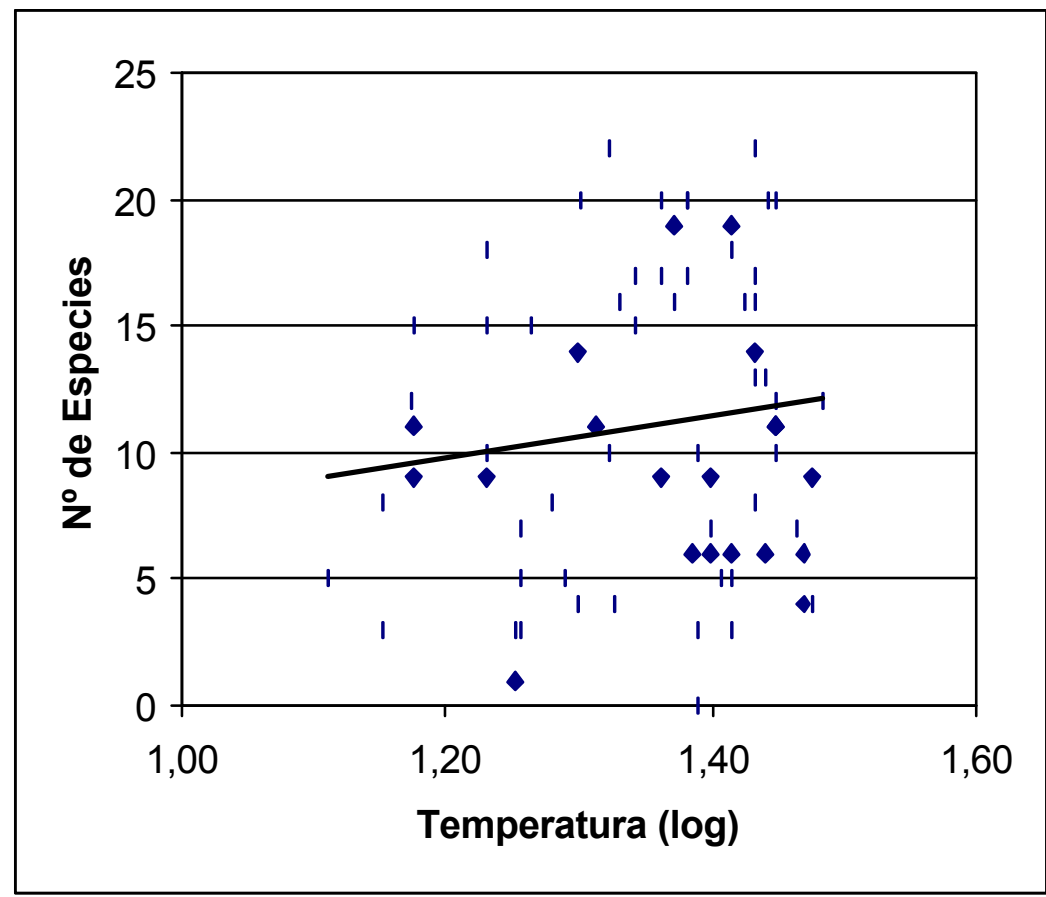

Fig. 1.16. Relación entre valores de temperatura del agua y número de especies de Rotíferos en el canal principal $(\mathrm{km}$ $603), r=0,125, p=0,297$ NS.

pero la mayor riqueza específica del período, observada en noviembre de 1978 se correspondió con valores bajos de sedimentos (<100 mg/l). (Fig. 1.17).

El efecto de los sedimentos suspendidos sobre el zooplancton en general, puede ser indirecto a través de la inhibición del desarrollo del fitoplancton o cambios en la estructura de esta comunidad o directo, a través de interferencia en los mecanismos de alimentación. A pesar de la importancia de la turbiedad en las aguas corrientes, el efecto sobre el zooplancton ha sido mejor analizado en ambientes lénticos, principalmente represas (Gliwicz 1969, Zurek 1980, Hart 1986 a b, 1988, Kirk \& Gilbert 1990). Shiel \& Walker (1985) han especulado que la alta turbiedad del río Darling, en Australia, puede limitar la fotosíntesis algal, afectando la tasa de crecimiento de los herbívoros del plancton.

Información complementaria ha sido aportada a través de estudios de ecología alimentaria de especies planctónicas (e.g. Gliwicz 1977, DeMott 1986, 1988).

Con respecto a los rotíferos, las experiencias de Kirk y Gilbert (1990) mostraron que son menos afectados que los cladóceros. Especies como B. calyciflorus, K.cochlearis y $P$. vulgaris, 
muy frecuentes en el río Paraná no son afectadas por las arcillas finas en suspensión. También en algunos lagos de represa de Ohio, Pollard et al. (1998) observaron que la turbiedad tiene una influencia mínima en la distribución y composición de los ensambles de rotíferos. Una de las causas de la dominancia de los rotíferos en el río, además de sus cortos tiempos generacionales lo cual compensa las pérdidas por arrastre, podría ser la mayor tolerancia del grupo a los sedimentos suspendidos.

Sin embargo, no deberían excluirse algunos efectos puntuales. Miquelis et al. (1998) mostraron experimentalmente que la turbiedad asociada a la turbulencia del agua incide desfavorablemente en la tasa de filtrado de Brachionus calyciflorus. La incidencia de la turbiedad es menor en aguas quietas, pues hay una acción sinérgica entre turbiedad y
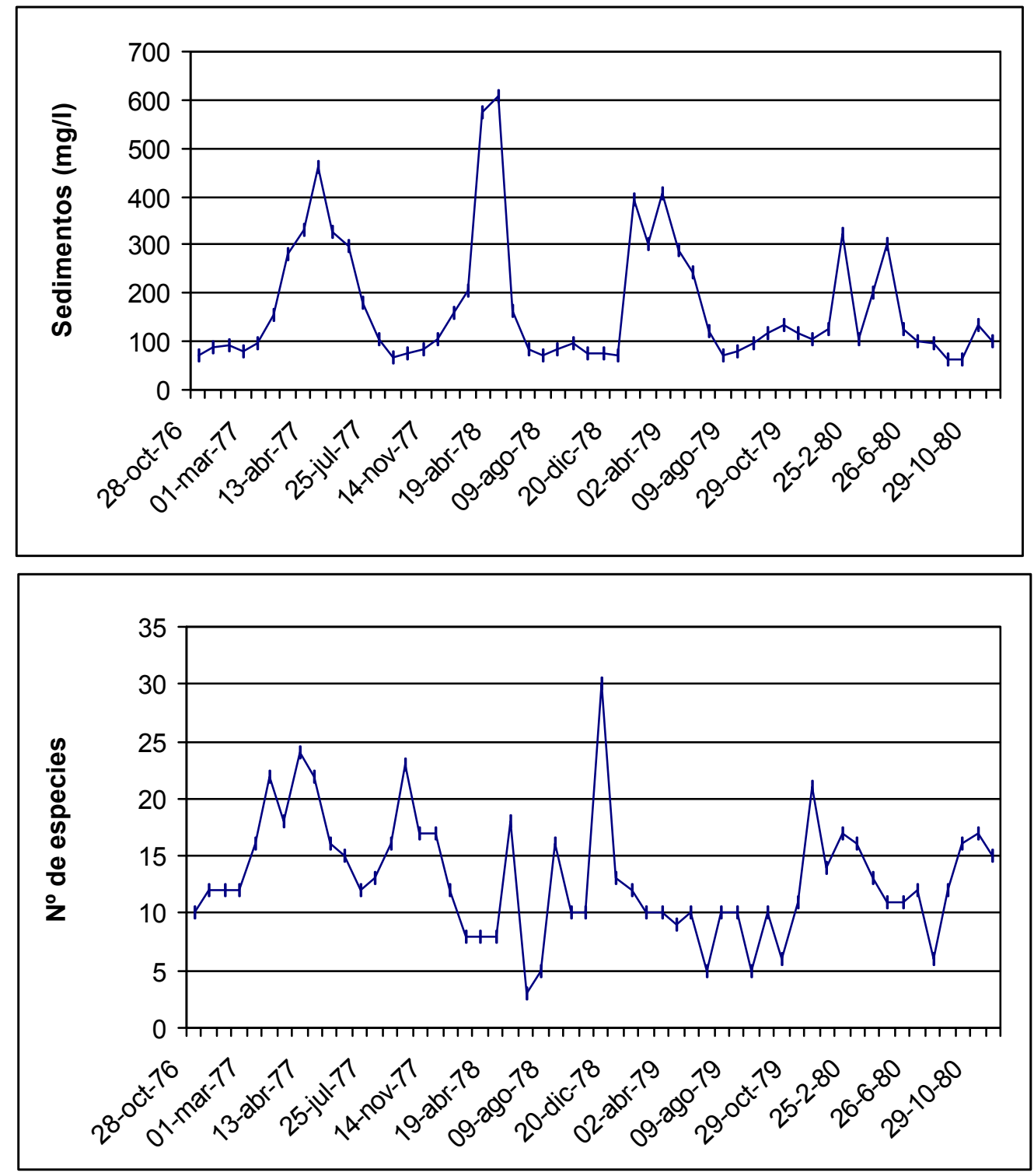

Fig. 1.17. Variaciones en la concentración de sedimentos y riqueza de Rotíferos en el canal principal del Río Paraná (km 603). 
turbulencia que es muy desfavorable para la alimentación. En el río Paraná, si bien se ha observado en varias oportunidades la presencia de esta especie, merece destacarse que nunca ha sido registrada en densidades importantes, alcanzando, en cambio, abundancias comparativamente mayores en las lagunas (José de Paggi, inédito) lo cual es concordante con las observaciones de Miquelis et al. (1998). Sin embargo, es discutible que esto pueda extenderse a otras especies del género como las del grupo $B$. caudatus ya que éstas son muy frecuentes en el canal principal y cauces de menor jerarquía.

Otra variable física importante para la permanencia de rotíferos en los cauces principales, es la velocidad de la corriente, que tiene efecto negativo sobre la abundancia del total de zooplancteres (José de Paggi, 1981). Comparando riqueza y velocidad de la corriente mediante un diagrama de dispersión, si bien no se registra una asociación estadísticamente significativa, se observa un línea de tendencia negativa (Fig.1.18).

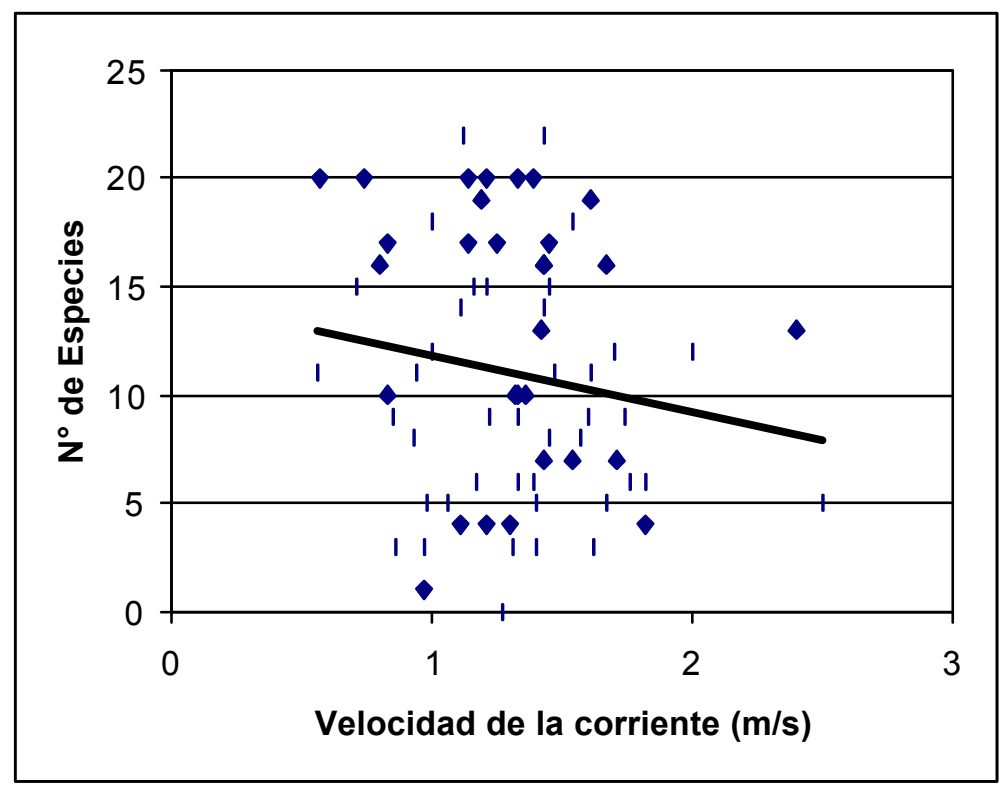

Fig. 1.18. Relación entre riqueza de Rotíferos y velocidad del flujo de agua en el canal principal $\mathrm{km} \mathrm{603)} \mathrm{período} \mathrm{1976-}$ $1983, r=-0,126, p=0,101 \mathrm{NS}$. 


\section{2.- AMBIENTES LENITICOS}

\section{Diversidad general de Rotíferos en ambientes de la planicie de inundación del río Paraná.}

Los muestreos realizados en 79 lagunas isleñas y de la planicie de inundación (áreas limnéticas y litorales), tanto en una o dos oportunidades o a lo largo de uno o más ciclos anuales en el período 1968-2000 permitieron registrar un total de 226 especies correspondientes a 44 géneros, distribuidos en 21 familias de la Subclase Monogononta (Tabla 2.1).

Del orden Ploima se registraron 14 familias de las 21 que comprende. Las mejor representadas fueron Brachionidae, con todos sus géneros, Lecanidae que es monogenérica y Trichocercidae. De los tres géneros de esta última, solo estuvo presente Trichocerca. Los géneros más ricos en especies fueron Lecane, Trichocerca y Brachionus, con 48, 25 y 23 especies cada uno. Lepadella de la familia Lepadellidae, estuvo presente con 15 especies destacándose además el género Testudinella, familia Testudinellidae, con 13 especies registradas.

La familia Notommatidae, muy diversa en géneros y especies, estuvo comparativamente muy poco representada, ya que se registraron solo 4 de sus 17 géneros: Cephalodella que a pesar de reunir 190 especies a nivel mundial, estuvo representada por solo tres; Notommata y Monommata, que de las 70 especies que ambas totalizan, estuvieron presentes solo 2 y finalmente Eosphora de la cual se registró solo una de sus 6 especies. De la familia Epiphanidae, con cinco géneros sólo se registró Epiphanes, frecuente en muestras planctónicas.

En los ambientes leníticos se registraron géneros no observados en los cursos lóticos, tales como Asplanchnopus, Eosphora, Gastropus, Horaella, Squatinella y Tripleuchlanis, los que presentan, en su mayoría, especies asociadas a las áreas litorales

Con respecto al orden Flosculariaceae se registraron sus 6 familias, con la mayoría de sus géneros, excepto Flosculariidae de la cual solo se registro un género, Sinantherina, de los 7 que reúne la familia.

En cuanto al tercer orden, Collothecaceae se registraron dos especies de una de las dos familias que reúne.

La mayor diversidad de Lecane y Trichocerca se relaciona a la estructura ambiental de muchas lagunas del valle de inundación. Todas las especies de Lecane necesitan de un substrato, solamente son capaces de desplazarse libremente por cortas distancias (Segers 1995b). Prácticamente lo mismo se aplica para Trichocerca, de las cuales sólo muy pocas pueden considerarse planctónicas (Ruttner-Kolisko 1974). La alta diversidad de ambos 
TABLA 2.1.1 
TABLA 2.1.2 
TABLA 2.1.3 
TABLA 2.1.4 
de géneros ocurren en lagunas someras y vegetadas, en las cuales la escasa profundidad determina la ausencia de límites claros entre la zona limnética y la zona litoral y todo el ambiente se comporta como "un litoral ". En cambio la alta diversidad de Brachionus se debe a que reúne especies que son tanto litorales como limnéticas

El escasísimo registro de géneros como Notommata, Monommata, Cephalodella se debería a que reúnen especies litorales y bentónicas, que requieren metodologías particulares de muestreo y especialmente de estudio, por sus cuerpos blandos (observación de organismos vivos). Lo mismo sucede con la familia Flosculariidae, cuyos géneros son, en su mayoría, sésiles,adheridos a un sustrato, por lo cual no debe considerarse en modo alguno que no estén bien representadas en los ambientes de la planicie.

\section{Riqueza y composición de rotíferos en lagunas ubicadas a lo largo del eje de escurrimiento N-S del río Paraná}

Para este análisis se consideran 39 lagunas ubicadas en el valle de inundación o en islas del curso principal desde el km. 1216 al 352 (entre las localidades de Corrientes y San Nicolás, aproximadamente). Las mismas fueron muestreadas en una sola oportunidad, en una o dos estaciones de su área limnética. La riqueza de especies varió entre 1 y 19 (Tabla 2.2). El género Brachionus estuvo representado en el $71 \%$ de las lagunas contribuyendo apreciablemente a enriquecer el elenco de especies planctónicas. Los géneros Trichocerca y Lecane estuvieron presentes en el 35,8 y $33 \%$ de las lagunas, respectivamente.

No se observó una tendencia definida en las variaciones de riqueza de rotíferos respecto de la ubicación de las lagunas, que puedan asociarse a la existencia de algún gradiente latitudinal, es decir no hubo mayor o menor riqueza hacia el norte o el sur. En contraste, se registró una relación entre riqueza de especies y de géneros y transparencia del agua, medida con el disco de Secchi. La mayor diversidad se halló en los cuerpos de agua con mayor transparencia (Fig. 2.1). No se encontró relación con otras variables como el pH; en general los ambientes con valores menores de 7 muestran una importante riqueza de especies (José de Paggi 1996, 2001) lo que en las lagunas con esta condición no se apreció, probablemente por tratarse de un análisis restringido al área limnética, es decir con un número menor de muestras por laguna.

Si se analizan, en cambio 12 lagunas distribuidas a lo largo del mismo sector pero en el que se incluyen también información sobre los rotíferos de las áreas litorales, se observa que el número de especies total por laguna es mayor, variando entre 6 y 46, siendo también mayor el número de géneros (Tabla 2.3). Aumenta el porcentaje de representación de los 
géneros litorales Lecane y Trichocerca, en cada laguna, disminuyendo comparativamente la del género Brachionus, que estuvo en el $50 \%$

\begin{tabular}{|c|c|c|c|c|c|c|c|c|}
\hline Kilómetro & Lagunas & $\mathrm{pH}$ & Sechi & Total Spp. & Total Gén. & $\%$ Brach & $\%$ Lecane & $\%$ Trich. \\
\hline 1216 & M. Pelón & 7,3 & 88 & 14 & 11 & 0 & 21 & 7 \\
\hline 1215 & Pelón & 7,3 & 20 & 9 & 7 & 11 & 0 & 0 \\
\hline 1197 & Nogueras & 6,7 & $s / d$ & 10 & 7 & 30 & 20 & 0 \\
\hline 1170 & La Bella & 7,3 & 93 & 13 & 11 & 7 & 0 & 7 \\
\hline 1170 & Sombrero & 6,9 & 47 & 5 & 4 & 0 & 0 & 0 \\
\hline 1023 & Ñatiú & 7,3 & 82 & 11 & 7 & 0 & 0 & 0 \\
\hline 960 & M. S.Jerónimo & 7,3 & 17 & 6 & 5 & 0 & 0 & 0 \\
\hline 913 & Malabrigo & 7,1 & 63 & 5 & 4 & 20 & 0 & 0 \\
\hline 825 & Gabriela & 7,3 & 26 & 11 & 10 & 9 & 0 & 9 \\
\hline 820 & Inga & 7,3 & 54 & 3 & 3 & 0 & 0 & 0 \\
\hline 781 & Curuzu Chalí & 7,4 & 20 & 6 & 5 & 0 & 0 & 0 \\
\hline \multirow[t]{8}{*}{600} & 22.L.en I. Timbó & 6,9 & 25 & 3 & 3 & 33 & 0 & 0 \\
\hline & 23.Idem & 6,9 & 50 & 7 & 6 & 28 & 0 & 14 \\
\hline & 24.Idem & 7 & 60 & 10 & 6 & 40 & 20 & 10 \\
\hline & 25.Idem & 7,2 & 60 & 11 & 7 & 18 & 0 & 18 \\
\hline & 5.L.en I. Carabajal & 6,9 & 65 & 12 & 7 & 33 & 0 & 0 \\
\hline & 15 Idem & 6,9 & 110 & 19 & 10 & 0 & 42 & 0 \\
\hline & 16.Idem & 7,3 & 30 & 17 & 7 & 35 & 5 & 11 \\
\hline & 17.Idem & 7,2 & 4 & 8 & 4 & 50 & 0 & 0 \\
\hline \multirow[t]{15}{*}{ a } & 18.Idem & 7,1 & 5 & 16 & 11 & 18 & 0 & 6 \\
\hline & 19.Idem & 7,4 & 8 & 4 & 4 & 25 & 0 & 0 \\
\hline & 20.Idem & 7,6 & 25 & 15 & 9 & 20 & 13 & 0 \\
\hline & 21. Idem & 6,4 & 10 & 5 & 2 & 80 & 0 & 0 \\
\hline & 8.L.en I. Sirgadero & 7,9 & 9 & 3 & 2 & 66 & 0 & 0 \\
\hline & 9.Idem & 6,6 & 100 & 13 & 8 & 15 & 7 & 15 \\
\hline & 10.Idem & 5,4 & 4 & 5 & 4 & 40 & 0 & 0 \\
\hline & 11.Idem & 7,2 & 2 & 1 & 1 & 100 & 0 & 0 \\
\hline & 12.Idem & 6,9 & 45 & 16 & 9 & 31 & 6 & 18 \\
\hline & 13.Idem & 6,9 & 50 & 10 & 8 & 30 & 10 & 0 \\
\hline & 14.Idem & 6 & 60 & 7 & 7 & 14 & 14 & 14 \\
\hline & 1.L. en I. Los Mellados & 7,5 & 10 & 3 & 3 & 0 & 0 & 0 \\
\hline & 2.Idem & 7,6 & 30 & 5 & 4 & 20 & 0 & 0 \\
\hline & 3.Idem & 7 & 35 & 5 & 3 & 60 & 0 & 0 \\
\hline & 4.Idem & 6,8 & 60 & 15 & 7 & 20 & 0 & 0 \\
\hline 590 & 6.Idem & 6,9 & 30 & 12 & 6 & 16 & 0 & 0 \\
\hline 420 & L.en I. frente Rosario & 7 & $s / d$ & 15 & 9 & 6 & 26 & 13 \\
\hline 420 & L.en I. frente Rosario & 7,4 & $s / d$ & 6 & 4 & 0 & 0 & 0 \\
\hline 352 & L.en I. Lechiguanas & 7 & $s / d$ & 6 & 6 & 0 & 16 & 16 \\
\hline 352 & L en I. Lechiguanas & 7,2 & $s / d$ & 17 & 5 & 0 & 5 & 17 \\
\hline
\end{tabular}

Tabla 2.2. Datos ambientales, número total de especies, géneros y porcentaje de representación de Brachionus, Lecane y Trichocerca en la composición de rotíferos de las lagunas (área limnética) ubicadas en el eje N-S. 
de los ambientes, mientras que Lecane y Trichocerca estuvieron presentes en el 100 y 91,6 $\%$. El cambio se relaciona a la incorporación del área litoral en el análisis. Estas áreas incrementan la diversidad total de rotíferos de cada laguna, al aumentar su heterogeneidad ambiental. El total de especies en cada laguna es precisamente una medida instantánea de la riqueza de nichos ecológicos.

No se observó tampoco aquí un gradiente latitudinal en el número de especies. Sin embargo, debe señalarse que en ese reducido grupo de 12 lagunas se registró un total de
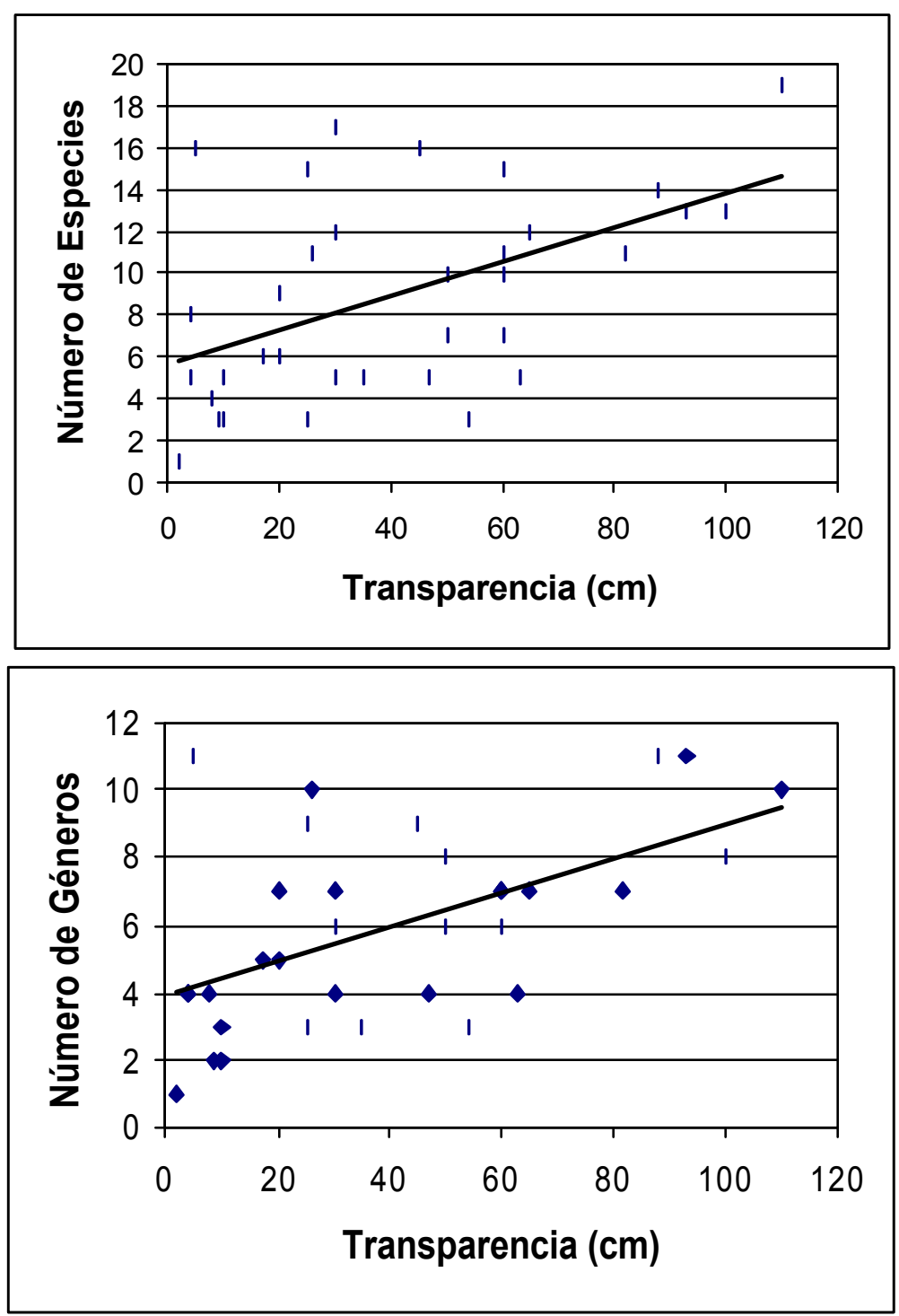

Fig. 2.1. Relación entre riqueza de especies y géneros en 34 lagunas de la planicie ubicadas en el eje N-S del río Paraná, tramo comprendido entre las localidades de Corrientes y San Nicolás, $\mathrm{km}$ 1216-352. Transparencia- Número de especies, $r=$ $0,507, p=0,002$. Transparencia- Número de géneros, $r=0$, $543, p=0,0009$. 
113 especies, y que las afinidades faunísticas entre ellas son bajas, inferiores al 50\% (Fig. 2.2). Se aplicó también el índice de dispersión biótica de Koch (1957) que permite obtener una medida de la afinidad de todo un grupo de ambientes, siendo muy baja la afinidad total entre todas las lagunas (11\%). No se halló ninguna especie común a todas, ni siquiera entre las planctónicas, solo dos especies: Keratella cochlearis y Polyarthra vulgaris estuvieron presentes en 9 y 8 del total de 12 lagunas. Entre las especies litorales Lecane bulla y Testudinella pattina fueron las más frecuentes, ambas presentes en 8 lagunas.

Las consideraciones precedentes sustentarían la idea de que el número de especies per se no sería suficiente como expresión de la variación de diversidad de rotíferos de las lagunas de la planicie a lo largo del curso del río Paraná, siendo preciso analizar la composición taxonómica.

\begin{tabular}{|c|l|c|c|c|c|c|}
\hline Kilómetro & Laguna & Total Spp. & Total Gén. & $\%$ Brach. & $\%$ Lecane & $\%$ Trich. \\
& & & & & & \\
\hline 1216 & Madrejón Pelón & 22 & 12 & 0 & 13 & 27 \\
1216 & Pelón & 14 & 11 & 14 & 7 & 7 \\
1197 & Nogueras & 10 & 7 & 30 & 20 & 0 \\
1170 & La Bella & 30 & 19 & 6 & 10 & 16 \\
1170 & Sombrero & 23 & 13 & 0 & 34 & 13 \\
1023 & Natiú & 27 & 15 & 0 & 11 & 18 \\
847 & Cartagena & 16 & 16 & 5 & 5 & 5 \\
820 & Ingá & 46 & 23 & 0 & 12 & 31 \\
590 & La Cuarentena & 6 & 5 & 0 & 23 & 10 \\
367 & L. 5 en I.Lechiguanas & 25 & 11 & 11 & 19 & 3 \\
352 & L. 3 en I.Cataneo & 12 & 9 & 0 & 25 & 8 \\
352 & L. 4 en I.Cataneo & & & & & 3 \\
\hline
\end{tabular}

Tabla 2.3. Diversidad de rotíferos en 12 lagunas (área limnética + área litoral) ubicadas en el eje Norte-Sur entre las localidades de Corrientes y San Nicolás

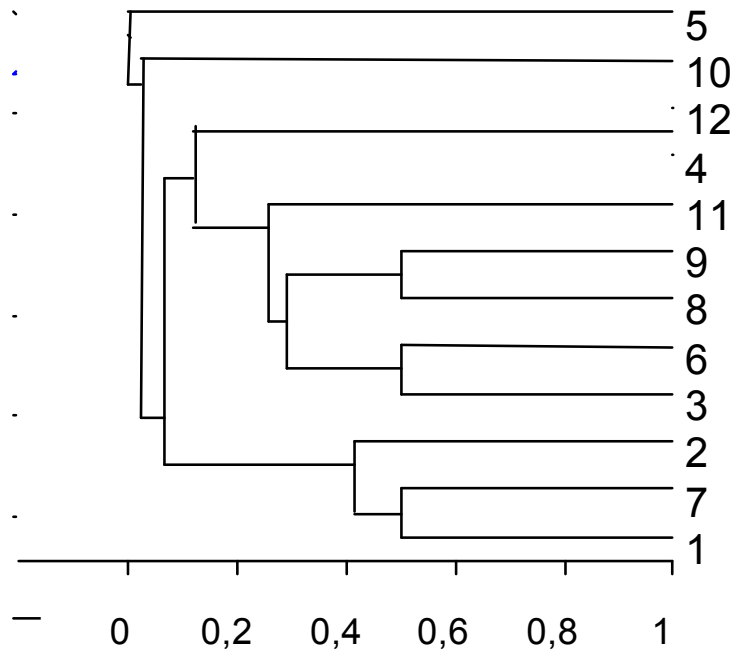

Fig.2.2. Afinidad faunística $(\mathrm{J})$ entre 12 lagunas ubicadas en el eje $\mathrm{N}-\mathrm{S}$ del tramo comprendido entre los kilómetros 1216 y 352. 


\section{Diversidad de rotíferos y complejidad ambiental}

1.- Riqueza y composición de rotíferos en áreas limnéticas y litorales vegetadas de una misma laguna

Para analizar la variación en riqueza y composición de especies entre zona limnética y zona litoral vegetada de una misma laguna para un determinado momento, se seleccionaron 6 lagunas ubicadas a lo largo del valle aluvial del río Paraná en el tramo comprendido entre los km 1216 y 820 , correspondiente a los primeros sectores por debajo de la confluencia con el río Paraguay (Tabla 2.4 ).

Las lagunas presentaron vegetación flotante arraigada y flotante libre. Entre las primeras se registraron Ludwigia sp., Nymphoides sp., Panicum elephantipes y Polygonum sp. Entre las segundas, Salvinia sp., Pistia sp. y Eichhornia crassipes. El porcentaje de la superficie cubierta por vegetación fue variable.

En algunas lagunas se observaron diferencias marcadas en la riqueza de especies entre las áreas limnética y litoral, como por ejemplo en la laguna Ingá, con solo 3 especies planctónicas: Keratella cochlearis, Conochilus unicornis, Polyarthra vulgaris, en el centro de la misma y 15 especies en el litoral vegetado. Allí se registró importante diversidad de especies de los géneros Lecane, Trichocerca, Testudinella, Scaridium, Cephalodella y Lepadella, así como la presencia de algunas especies planctónicas como Ascomorpha ovalis y K.cochlearis.

\begin{tabular}{|lcccccccccc|}
\hline Lagunas & $\mathrm{Km}$ & Prof. & $\mathrm{T}$ & Cond. & $\mathrm{pH}$ & $\mathrm{CV}$ & $\mathrm{T} . \mathrm{Spp}$ & $\mathrm{A} . \mathrm{A}$. & $\mathrm{A} . \mathrm{L}$. & $\mathrm{J}$ \\
\hline Pelón (1) & 1216 & 80 & 20 & 179 & 7,3 & 10 & 22 & $\mathbf{1 4}$ & $\mathbf{1 3}$ & 0,37 \\
Sombrero (2) & 1170 & 115 & 47 & 150 & 6,9 & 15 & 23 & $\mathbf{5}$ & $\mathbf{1 9}$ & 0,08 \\
La Bella (1,2) & 1170 & 157 & 93 & 150 & 7,3 & 70 & 30 & $\mathbf{1 3}$ & $\mathbf{2 0}$ & 0,18 \\
Yuruhatá (1) & 1085 & 25 & 21 & 70 & 7,3 & 5 & 14 & $\mathbf{9}$ & $\mathbf{9}$ & 0,44 \\
Natiu (2) & 1023 & 147 & 32 & 180 & 7,3 & 75 & 27 & $\mathbf{1 1}$ & $\mathbf{1 8}$ & 0,13 \\
Ingá (1,2) & 820 & 317 & 54 & 99 & 7,3 & 40 & 16 & $\mathbf{3}$ & $\mathbf{1 5}$ & 0,22 \\
\hline
\end{tabular}

Tabla 2.4. Total de especies de Rotíferos en el área limnética (AA), área litoral (AL) y afinidad faunística entre ambas (S), en lagunas de la llanura de inundación. Se señala ubicación de las mismas (distancia en kilómetros desde el Puerto de Buenos Aires), profundidad (Prof., m), transparencia $(T, \mathrm{~cm})$, conductividad (Cond., ìm/cm) y porcentaje de superficie cubierta por vegetación $(\mathrm{CV})$. 1: vegetación flotante arraigada, 2: flotante libre. 
En la laguna Yuruhatá y el madrejón Pelón, en cambio, el número total de especies en las aguas abiertas es igual o casi igual al del área litoral. Pero a números equivalentes o similares de especies entre áreas, la composición taxonómica es diferente, como lo muestra la relativamente baja afinidad faunística entre ambas $(0,44$ y 0,37 , respectivamente). Debe tenerse en cuenta que la laguna Yuruhatá fue la que presentó el menor porcentaje de cobertura vegetal.

El mayor número de especies por ambiente correspondió a los que poseían un mayor porcentaje de cobertura vegetal, La Bella y Ñatiú con 30 y 27 especies, la primera con vegetación mas diversa, Ludwigia sp., Eichhornia crassipes y Pistia sp., la segunda solo con E. crassipes. Sin embargo no se encontró ninguna asociación definida entre la riqueza y el tipo de vegetación, probablemente debido a que el número de lagunas analizadas en este grupo no fue alto y por consecuencia tampoco pudo efectuarse ningún análisis estadístico. En casi todos los casos se encontró una mayor diversidad de los géneros Trichocerca y Lecane en la zona litoral. Algunos géneros, tales como Collotheca, Dicranophorus, Monommata fueron exclusivos de la zona litoral. Las mismas especies de los géneros Keratella, Polyarthra y Filinia se encontraron generalmente en ambas zonas.

Lo expuesto muestra la relación entre la heterogeneidad ambiental definida principalmente por el porcentaje de la cobertura vegetal y la diversidad taxonómica, por lo cual una muestra de la zona limnética puede, en algunos casos, constituir una pobre aproximación a la riqueza real de una laguna.

2.-Variaciones en la diversidad de rotíferos entre lagunas de diferente tamaño con y sin litoral vegetado

Una de las características que imprimen un sello propio a los ambientes leníticos de los sistemas fluviales con planicie de inundación es, además de su escasa profundidad, la presencia de vegetación que suele formar una franja litoral de proporciones variables a lo largo del año con el cambio de la temperatura y extensión del fotoperíodo.

El posible efecto de la vegetación en la riqueza de especies se analizó considerando 25 lagunas someras ubicadas en las islas Timbó, Carabajal, Los Mellados y Sirgadero, las que a su vez corresponden a distintas unidades geomorfológicas. Se muestrearon en un período de verano de pre-inundación, y se agruparon por la presencia -ausencia de vegetación y por su tamaño relativo (menor y mayor de 5 ha de superficie) (Tabla 2.5). Los madrejones fueron considerados como grupo aparte dentro de los vegetados por sus características físicas (cuerpos grandes, alargados, originados por el cegamiento de cauces fluviales, con vegetación flotante y sumergida). 
Las lagunas presentaron vegetación flotante $(F)$, sumergida $(S)$ y algunas vegetación sumergida + flotante (SF) (Tabla 2.6). La vegetación flotante estuvo compuesta por Azolla sp., Salvinia sp., Eichhornia crasipes, Nymphoides sp, esta última flotante arraigada. La vegetación sumergida estuvo compuesta por Cabomba sp. Agrupando las lagunas por el tipo de vegetación la riqueza promedio para F, S y SF fue de 10, 12 y 12,8 respectivamente, en cuanto al número promedio de géneros fue de 7,2, 7,1 y 8,8 también respectivamente. El bajo número de lagunas con plantas flotantes no permitió realizar un análisis estadístico de comparación, pero los valores de riqueza de especies y riqueza de géneros fueron muy semejantes entre grupos.
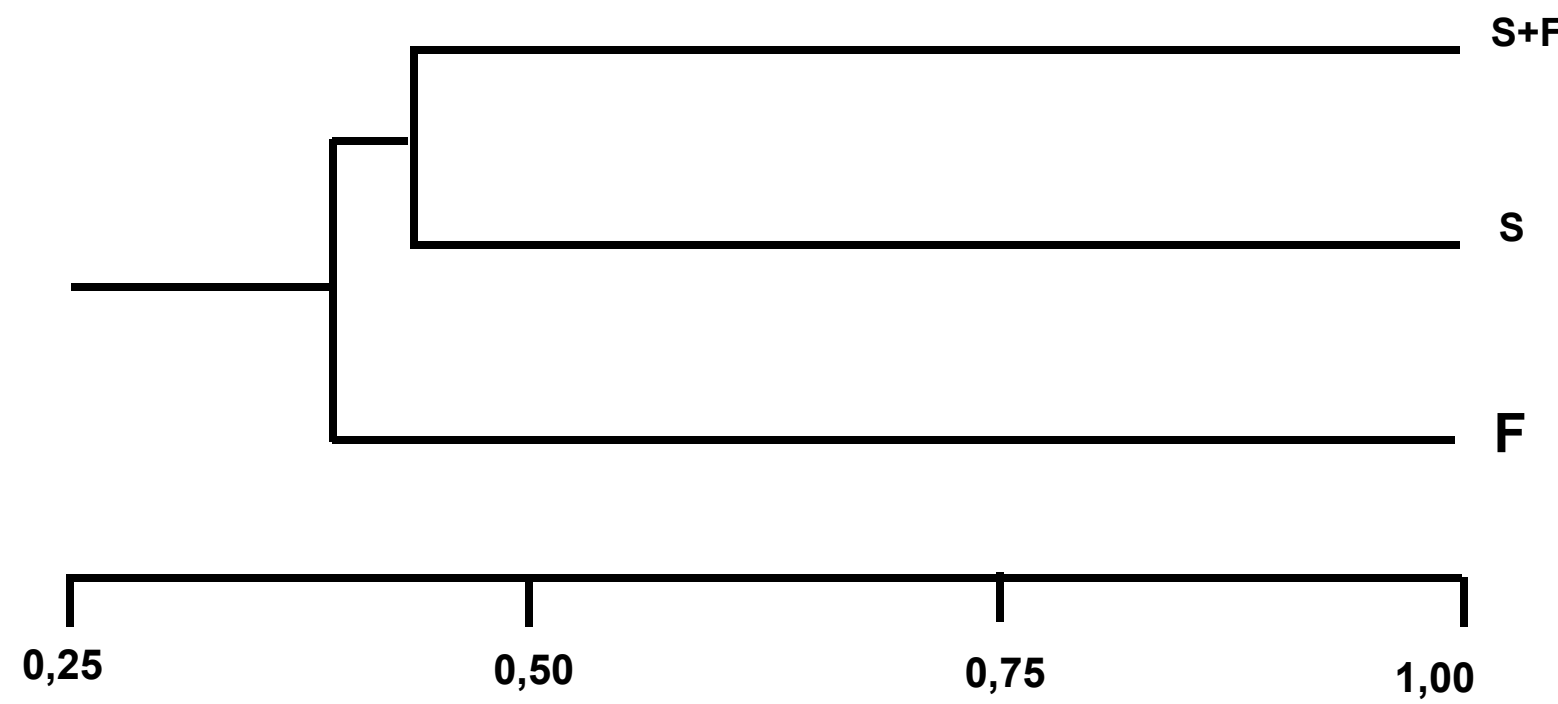

Fig. 2.3. Afinidad faunística entre 25 lagunas con vegetación flotante (F), sumergida (S) y sumergida + flotante (SF)

Se observaron diferencias en la composición de rotíferos entre lagunas de los tres grupos. Aunque, con valores menores a 0,50, la mayor afinidad faunística $(\mathrm{J})$ entre los grupos se da a nivel de ambientes con vegetación sumergida y sumergida + flotante (Fig. 2.3). Los elementos comunes a los tres grupos fueron especies planctónicas como Polyarthra vulgaris, Filinia longiseta, Keratella americana, K.cochlearis, K. lenzi y entre las noplanctónicas Lecane bulla y Collotheca cf. coronatta. Las lagunas con vegetación sumergida fueron las que presentaron mayor número de especies de Lecane, 8, las con vegetación flotante y sumergida + flotante presentaron 2 especies cada una. Algunos géneros como Cephalodella y Monommata se registraron solo en las lagunas con vegetación sumergida.

En los ambientes acuáticos someros en particular, la vegetación favorece el desarrollo de las comunidades de invertebrados, tanto en número de especies como biomasa; las áreas vegetadas sustentan mayor diversidad, aumentan la disponibilidad de recursos alimentarios 
y constituyen refugio para la depredación (Scheffer 1998). Una gran parte de los estudios de rotíferos del litoral de lagos y lagunas se ha centrado en el ánalisis de la distribución de abundancia en relación a los tipos de vegetación (Pontin \& Shiel 1985, Duggan et al. 1998, Duggan et al. 2001) menos en la relación entre esta última y la riqueza y composición específica. Kuczynska-Kippen \& Nagengast (2003) encuentran la mayor similitud entre la composición de rotiferos de las áreas con plantas flotantes y emergentes; la composición de las áreas con macrófitas sumergidas presenta una similitud más baja con los restantes grupos. Kuczynska-Kippen (2003) también encuentra diferencias en la composición de los rotíferos entre la región central y marginal de un mismo lecho de Myriophyllum. Los densos lechos de macrófitas sumergidas, con sus finas hojas favorecerían más la presencia de invertebrados pequeños como rotíferos y cladóceros que otras plantas más grandes con hojas anchas (Cyr \& Dowing 1988).

Se comparó la riqueza de especies de las lagunas vegetadas $(n=16)$ respecto de las no vegetadas $(n=9)$, la diferencia hallada entre ambos grupos fue significativa $(t=4,039, p=$ 0,0005). En cuanto al número de géneros, las diferencias entre ambos grupos de lagunas fueron también significativas $(t=4,33, p=0,0002)$. Las lagunas vegetadas tanto grandes como pequeñas presentaron la mayor diversidad de rotíferos (19 y 11 respectivamente). Proporcionalmente, los ambientes pequeños vegetados mostraron mayor número de especies que los grandes vegetados. A su vez los madrejones como grupo particular dentro de estos ambientes, fueron los que mostraron el mayor número promedio de especies (12,8 especies).

Las lagunas sin vegetación, independientemente de su tamaño, presentaron un número promedio menor de especies (4,33 y 5,0$)$.

Tanto los madrejones como las lagunas pequeñas con o sin vegetación se diferenciaron por poseer un $\mathrm{pH}$ levemente inferior a 7 . Esto se debió, posiblemente por los procesos de descomposición que tienen lugar en las lagunas con las altas temperaturas del verano y, particularmente, en ambientes pequeños y en aquellos con mucha vegetación, como los madrejones.

La riqueza de especies mostró una relación positiva con la transparencia, la cual a su vez es mayor en los ambientes vegetados. No se observó una relación significativa entre riqueza y área, riqueza y $\mathrm{pH}$, riqueza y conductividad (Figs 2.4, 2.5). 
Tabla 2.5 
Tabla 2.6 

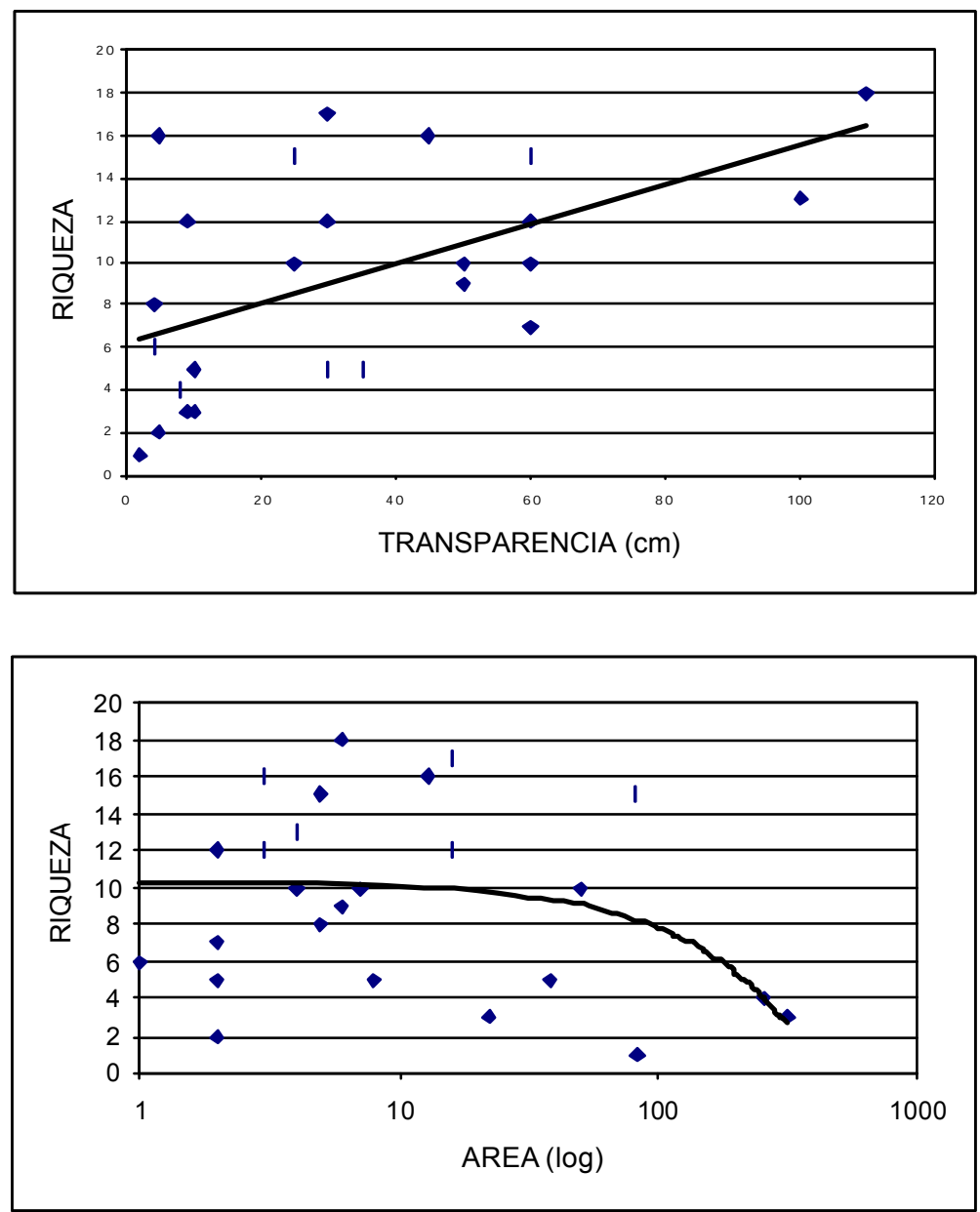

Fig. 2.4. Relaciones entre riqueza, transparencia y área en 25 lagunas. Riqueza-transparencia: $r=0,541, p=$ 0,0005; Riqueza-área: $r=-0,371, p=0,06$ NS.

Se analizó la riqueza agrupando las lagunas por la unidad geomorfológica a la que pertenecen. Las ubicadas en la unidad geomorfológica de avenamiento impedido (islas Los Mellados y Sirgadero) presentaron una riqueza promedio algo menor que las de la unidad de adosamiento de bancos (I. Carabajal) y de espiras de meandro (I.Timbó). (Tabla 2.7). Sin embargo la comparación de medias (test de Kruskal-Wallis) determinó que las diferencias tanto entre número de especies como número de géneros no son significativas ( $p=0,677$ y $p=0,690$ respectivamente). Como se señaló en capítulos anteriores la unidad de avenamiento impedido se caracteriza por lagunas redondeadas y someras, mientras que las de las otras unidades presentan formas alargadas, o con brazos articulados. 

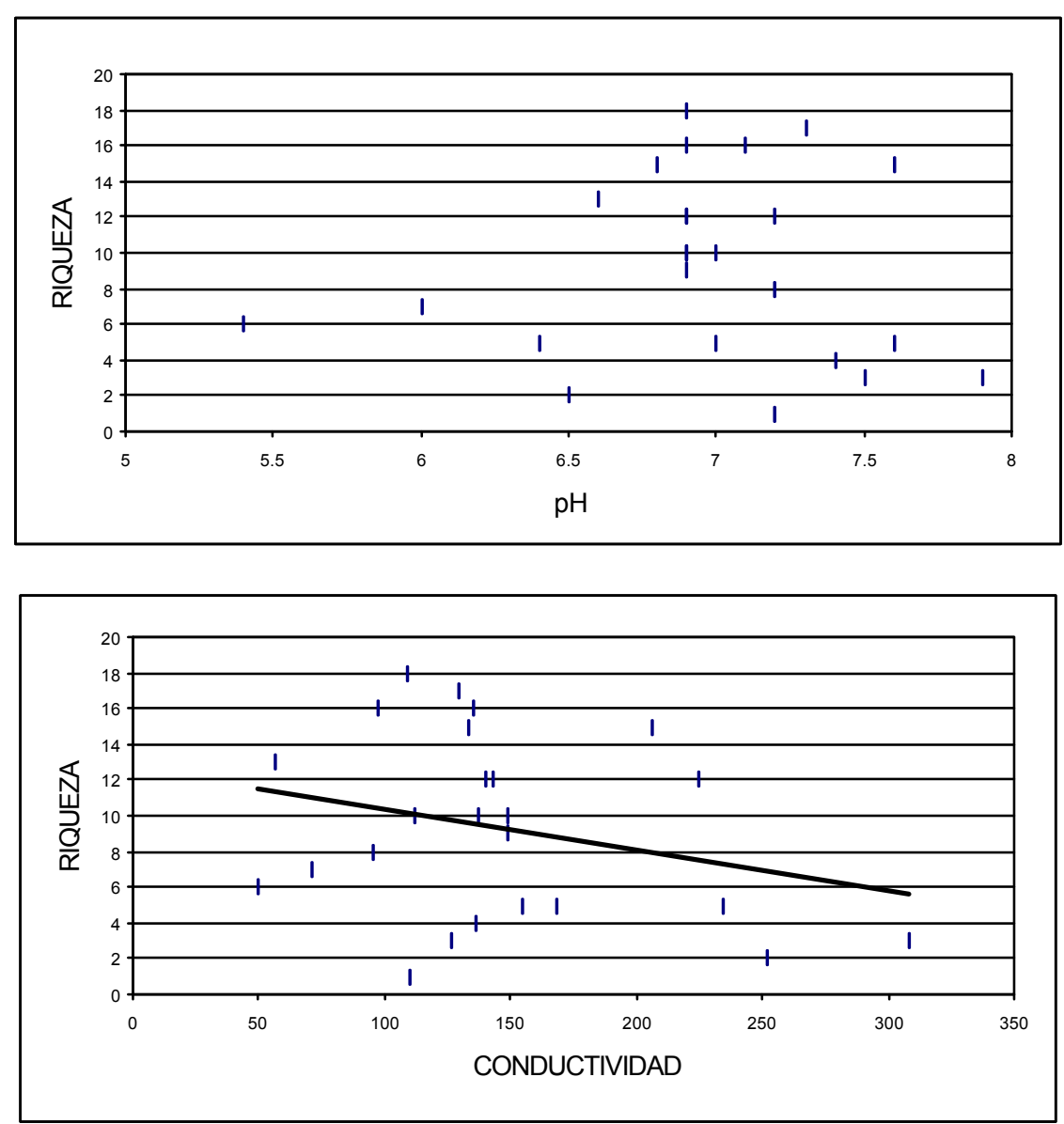

Fig. 2.5. Relaciones entre riqueza- $\mathrm{pH}, \mathrm{r}=0,008 \mathrm{p}=0,96$, riqueza- conductividad, $r=-0,271, p=0,188$ en 25 lagunas.

\begin{tabular}{|l|lc|c|c|}
\hline $\begin{array}{l}\text { Unidades } \\
\text { geomorfológcias }\end{array}$ & \multicolumn{2}{|l|}{ Avenamiento impedido } & $\begin{array}{c}\text { Adosamiento } \\
\text { de bancos }\end{array}$ & $\begin{array}{c}\text { Espiras de } \\
\text { meandro }\end{array}$ \\
\hline $\begin{array}{l}\text { MELLADOS } \\
\mathrm{n}=5\end{array}$ & $\begin{array}{c}\text { SIRGADERO } \\
\mathrm{n}=8\end{array}$ & $\begin{array}{c}\text { CARABAJAL } \\
\mathrm{n}=8\end{array}$ & $\begin{array}{c}\text { TIMBO } \\
\mathrm{n}=4\end{array}$ \\
\hline Riqueza de Géneros & $4,8(45)$ & $5,63(72)$ & $6,62(49)$ & $6,75(14)$ \\
Riqueza de Especies & $8(64)$ & $8,25(73)$ & $10,88(51)$ & $10,3(12)$ \\
\hline
\end{tabular}

Tabla 2.7. Valores medios y coeficiente de variación (entre paréntesis) de la riqueza de especies y géneros de rotíferos en lagunas ubicadas en distintas unidades geomorfológicas de la planicie del río Paraná, próximas a la ciudad de Santa Fe. 


\section{Variaciones espaciales y temporales en la diversidad de rotíferos en relación a la estacionalidad hidrológica}

1.-Variaciones espaciales y temporales en la diversidad de rotíferos en un mismo ambiente:

\section{Laguna La Cuarentena}

Esta laguna ubicada en la isla Carabajal, como se señaló en la Material y métodos, presenta una considerable heterogeneidad física por su forma dendrítica. Considerando su complejidad, se la seleccionó para analizar la diversidad de rotíferos dentro de una misma laguna en relación a sus cambios de nivel hidrométrico determinados por el ciclo del río. En tal sentido se tomaron datos de 4 muestreos representativos de las cuatro fases del comportamiento hidrológico del río señaladas en la Introducción. Se efectuó un análisis de afinidad entre estaciones utilizando el índice de Jaccard. El número y la localización de estaciones no fue constante, varió entre 4 y 12 en relación a los movimientos locales del agua según el nivel del río y a fin de obtener muestras representativas de cada área.

1.- Aguas en ascenso (10/12/80; $\mathrm{NH}: 3,29 \mathrm{~m})$. En este estado hidrométrico se produce el ingreso de un flujo de agua proveniente del río a través del canal donde se ubica la estación 2 y a través de un bañado que se conecta a la estación 4 . Se observan tres agrupaciones de estaciones por su afinidad. Las estaciones que más se asemejan por su composición de rotíferos (80 \%) son las 6 y 5 , ubicadas a lo largo de un sector de la laguna, que es el más aislado de la influencia del río. Le siguen, en orden de afinidad, las estaciones 8 y 3 y las 4 y 2 que corresponden a las áreas más cercana a la zona de desborde del río (Fig. 2.6).

2.- Aguas altas (4/03/81;NH: 5,06m) Esta fecha corresponde al nivel más alto del río en el período de aguas altas, registrándose un ingreso directo, masivo, de las aguas del Paraná por el canal y por la parte Norte de la laguna, a través de bañados existentes en la isla. Se registra una buena afinidad entre las estaciones 8 y 13 y 2 y 10 , se observa que las estaciones donde hay ingreso de agua desde el Norte de la isla, se agrupan entre sí a niveles progresivamente más bajos hasta la estación 7 (Fig. 2.7).

3.- Aguas en descenso (17/03/81;N.H.:4,44m). El río experimentó un leve descenso, pero las estaciones siguieron agrupándose en relación a los sectores de iguales características físicas de la laguna y franjas de ingreso del agua (Fig. 2.8). 
FIG.2.6 
FIG.2.7 
FIG. 2.8 
FIG.2.9 
4.- Aguas bajas (8/10/81;NH: 1,72): se consideró esta fecha para mostrar la distribución horizontal de las especies en una laguna totalmente aislada del río. Se forman muchos grupos y subgrupos de afinidad entre estaciones cercanas, 12 y 13, 5 y 6 . Las estaciones 3 y 4 presentan alguna afinidad entre si, probablemente por tener características similares de profundidad (35 y $40 \mathrm{~cm}$ respectivamente) y estar vegetadas (Scirpus sp y Azolla sp ) (Fig. 2.9).

En períodos de inundación la laguna acusó por un lado, el ingreso de agua del río Paraná en forma directa a través de un canal, y por otro lado, en sus brazos Norte, donde su ubican las estaciones 3, 4 y 5, recibió aguas de drenaje de la isla Carabajal. Alí el desborde comunicó entre sí varios cuerpos de agua ubicados en esa zona norte. Es decir hay un aporte directo de aguas provenientes del canal principal del río y un aporte proveniente del "barrido " de terrenos bajos inundados y otros ambientes leníticos.

La afinidad registrada entre estaciones dentro de la laguna estaría apreciablemente condicionada por la circulación del agua, lo que determina "franjas" de flujo que presentan una determinada composición de rotíferos. Por un lado, la franja que proviene del canal de conexión y por otro lado la franja que se genera por la entrada del agua proveniente de la isla, incrementándose particularmente en esta última el número de especies. En los momentos de aislamiento de la laguna, en los que además el número de rotíferos totales fue el menor, la mayor afinidad se observa, generalmente, entre dos estaciones físicamente próximas entre sí o cercanas por un elemento común como es la presencia de vegetación. Es decir, hay una mayor heterogeneidad ambiental dada por las morfología de la laguna y la distribución de la vegetación y esto se pone de manifiesto en la composición de los rotíferos que difiere bastante entre las estaciones.

La discusión antes desarrollada permite ver que en las lagunas de mayores dimensiones como el caso de La Cuarentena, de conexión directa al río, la heterogeneidad ambiental puede ser muy dinámica, en permanente cambio $\mathrm{y}$, en consecuencia, sustentar también una composición de especies muy variables en sentido témporo-espacial.

Incorporando a los datos del análisis previo dos fechas de niveles hidrométricos intermedios, se observa la significativa relación entre número de especies y ese parámetro (Fig. 2.10, Tabla 2.8) El mayor número de especies ocurre con el ingreso de las aguas que aportan material de arrastre, tanto del cauce principal como del lavado de parte de la isla y sus ambientes leníticos. A su vez, el menor número de especies se registró con los más bajos valores hidrométricos, los que determinaron una condición de aislamiento de la laguna respecto del río. 


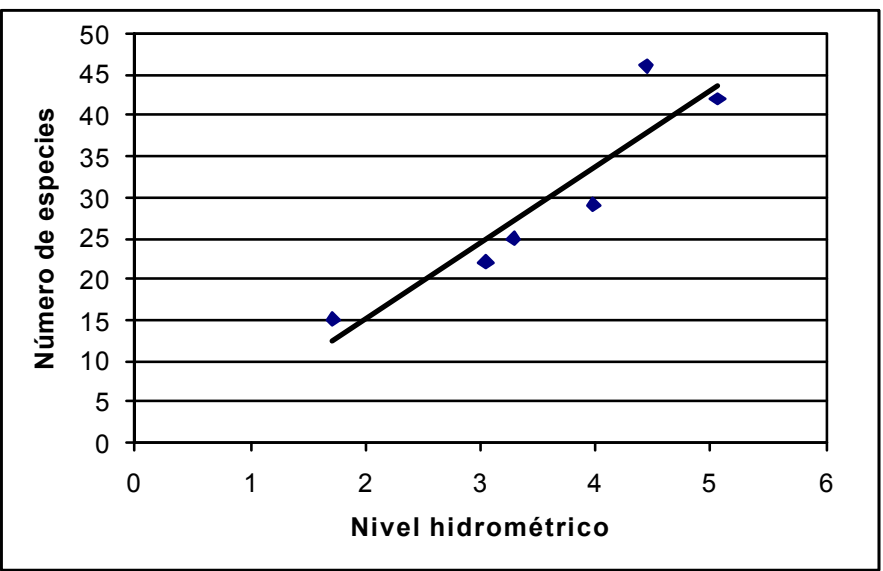

Fig. 2.10. Relación entre riqueza de Rotíferos de la Laguna La Cuarentena y nivel hidrométrico de río Paraná, $r=0,921, p=0,0009$.

\begin{tabular}{|r|c|c|c|c|c|c|c|c|c|c|c|c|c|c|}
\hline Fecha & N.HID. & T.SPP & E2 & E3 & E4 & E5 & E6 & E7 & E8 & E9 & E10 & E11 & E12 & E13 \\
\hline & & & & & & & & & & & & & & \\
\hline $10 / 12 / 80$ & 3,29 & 25 & 12 & 12 & 11 & 5 & 6 & & 21 & & & & & \\
\hline $4 / 03 / 81$ & 5,06 & 42 & 7 & 23 & & & 19 & 8 & 3 & 7 & 6 & 8 & 16 & 4 \\
\hline $17 / 03 / 81$ & 4,44 & 46 & 8 & 13 & 9 & 23 & & 19 & 5 & 13 & & & & \\
\hline $5 / 05 / 81$ & 3,04 & 22 & 7 & 8 & 4 & 5 & 14 & 5 & 3 & 4 & 6 & 5 & 6 & 7 \\
\hline $8 / 10 / 81$ & 1,72 & 15 & 5 & 5 & 10 & 4 & 5 & 5 & 8 & 7 & & & 6 & \\
\hline $12 / 01 / 82$ & 3,98 & 29 & & 9 & & 13 & & & 20 & & & & & 7 \\
\hline
\end{tabular}

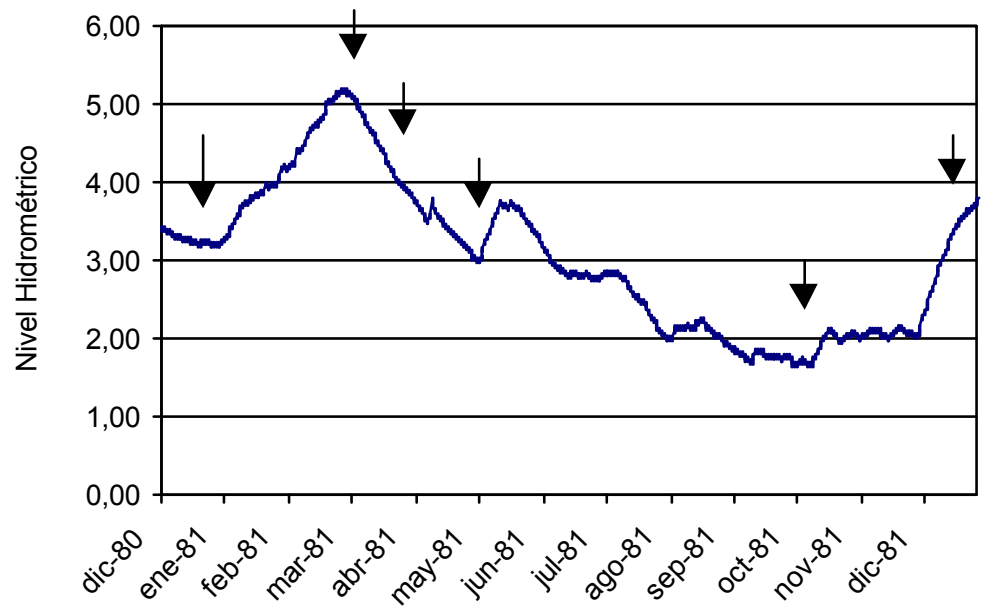

Tabla 2.8. Número total de especies y por estaciones en laguna La Cuarentena, con di ferentes niveles hidrométricos. Ubicación de las fechas de muestreo en el hidrograma correspondiente del río Paraná (Puerto de Paraná) 
Analizando el listado del total de especies por cada fecha y estado hidrométrico,

Fig. 2.11. La Cuarentena: Afinidad faunística entre la composición de especies de Rotíferos

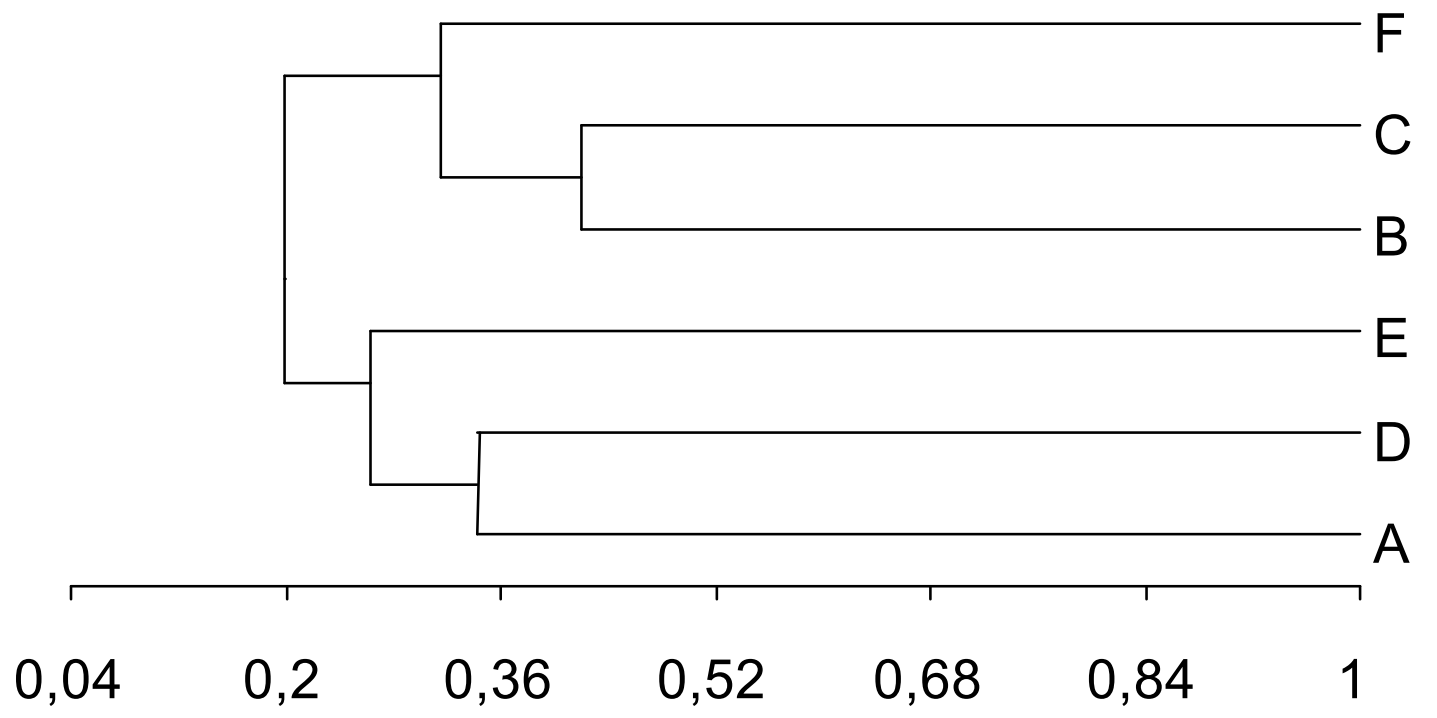

(acumulativa de varias estaciones) correspondientes a diferentes niveles hidrométricos del río Paraná (Pto de Paraná). Referencias A: 10/12/80 (3,29m), B: 4/03/81 (5,06 m), C: 17/03/81 (4,40m), D: 5/05/81 (3,04 m),E: 8/10/81 (1,72) F: 12/01/82 (3,98 m).

puede verse que la diferencia numérica a favor de los momentos de aguas altas se debe a un mayor número de especies de los géneros Lecane, Lepadella y Trichocerca. Estas especies de hábitat litoral son claras indicadoras de la existencia de un proceso de arrastre de organismos de áreas inundadas. No es de descartar, tampoco, el incremento en la riqueza de especies como consecuencia de la eclosión de huevos de resistencia por la remoción y arrastre de sedimentos de áreas emergentes que circundan a las lagunas. Las mayores afinidades que se registra en la composición total de especies por fecha se encuentra en general relacionada con las variaciones de nivel hidrométrico (Fig. 2.11). Los valores un poco más bajos de afinidad, entre niveles hidrométricos disímiles ( $E, D$ y $A$ ) estarían dados por un pequeño grupo de especies en común frecuentes durante todo el período de estudio.

\section{Variaciones temporales de la diversidad}

\section{Laguna Los Matadores}

Teniendo en cuenta el corto tiempo generacional en los rotíferos y por otro las relativamente rápidas variaciones de nivel hidrométrico en la planicie por los procesos 
de escurrimiento, se analizaron las variaciones semanales de la diversidad de Rotíferos durante la fase de descenso del nivel hidrométrico del río Paraná (marzoseptiembre de 1977), en una estación central de la laguna Los Matadores.

El periodo de estudio comprendió una fase de conexión de la laguna con el río y otra fase de aislamiento total. A partir de un nivel del río de 1,90-2,0 m (Puerto de Paraná), la laguna comenzó a conectarse con aquél, por la entrada de aguas provenientes de éste, a través de un corto canal de conexión directa.

En un período de 7 meses se registró un total de 94 especies sólo en su área limnética. Los géneros de mayor diversidad fueron Lecane y Brachionus seguidos por Trichocerca. Se registraron, además, otros géneros no planctónicos, como Dicranophorus, Lophocharis, Monommata, Mytilina, Scaridium, Trichotria. El número de especies varió en sentido temporal, observándose la mayor diversidad en los momentos de los más altos niveles hidrométricos del río, encontrándose un máximo de 36 especies el 23/03/77 con un altura del agua de 4,95m. Los valores más bajos se observaron con menores niveles hidrométricos, cuando la laguna ya se encontraba aislada de la influencia del río, siendo de 9 el menor número de especies (15/07/77) (Fig. 2.12). Si bien se observo una tendencia a un descenso continuo de la riqueza en forma paralela al descenso hidrométrico, a partir de mayo los valores de riqueza variaron en torno de un rango de solo 5 especies aproximadamente. El género Lecane mostró una relación entre la diversidad de sus especies y el nivel hidrométrico, no así Trichocerca, dado que presentó un rango de variación de la riqueza muy estrecho (Fig. 2.13).

Los cambios en la riqueza total de especies estuvieron asociados al nivel hidrométrico del río Paraná (Fig. 2.14). La diversidad temporal registrada es alta si se tiene en cuenta que corresponde a una sola estación ubicada en el área pelágica. Sin embargo, este dato es ilustrativo de las particularidades de las lagunas someras de la planicie de inundación de los ríos, donde el área considerada limnética recibe influencia de la zona litoral de la misma laguna o de otros ambientes conectados a ella temporalmente, a partir de los cambios en el nivel hidrométrico. La composición observada a lo largo de los siete meses de estudio es la expresión de este proceso, por cuanto la gran mayoría de las especies halladas no son planctónicas sino litorales o bentónicas. En el Paraná Superior, Bonecker et al. (1998b) registraron también una notoria variación temporal de la diversidad, donde una sola laguna exhibió en su área limnética un total de 99 taxa de rotíferos a lo largo de un período de 14 días en aguas altas y 78 taxa a lo largo de otro periodo de 14 días en aguas bajas, En este caso, en ambos se obtuvieron muestras diarias. En una laguna de la planicie de inundación del río Murray (Australia) Tan \& Shiel (1993) registraron 63 especies de rotíferos para un 
período de 25 días, 15 previos a la inundación y 10 posteriores a ella. Todo esto contrasta con lo que ocurre en área limnética de los grandes lagos de las regiones templadas donde lo frecuente es registrar solo unas pocas especies de rotíferos a lo largo del año, y en su gran mayoría planctónicas.
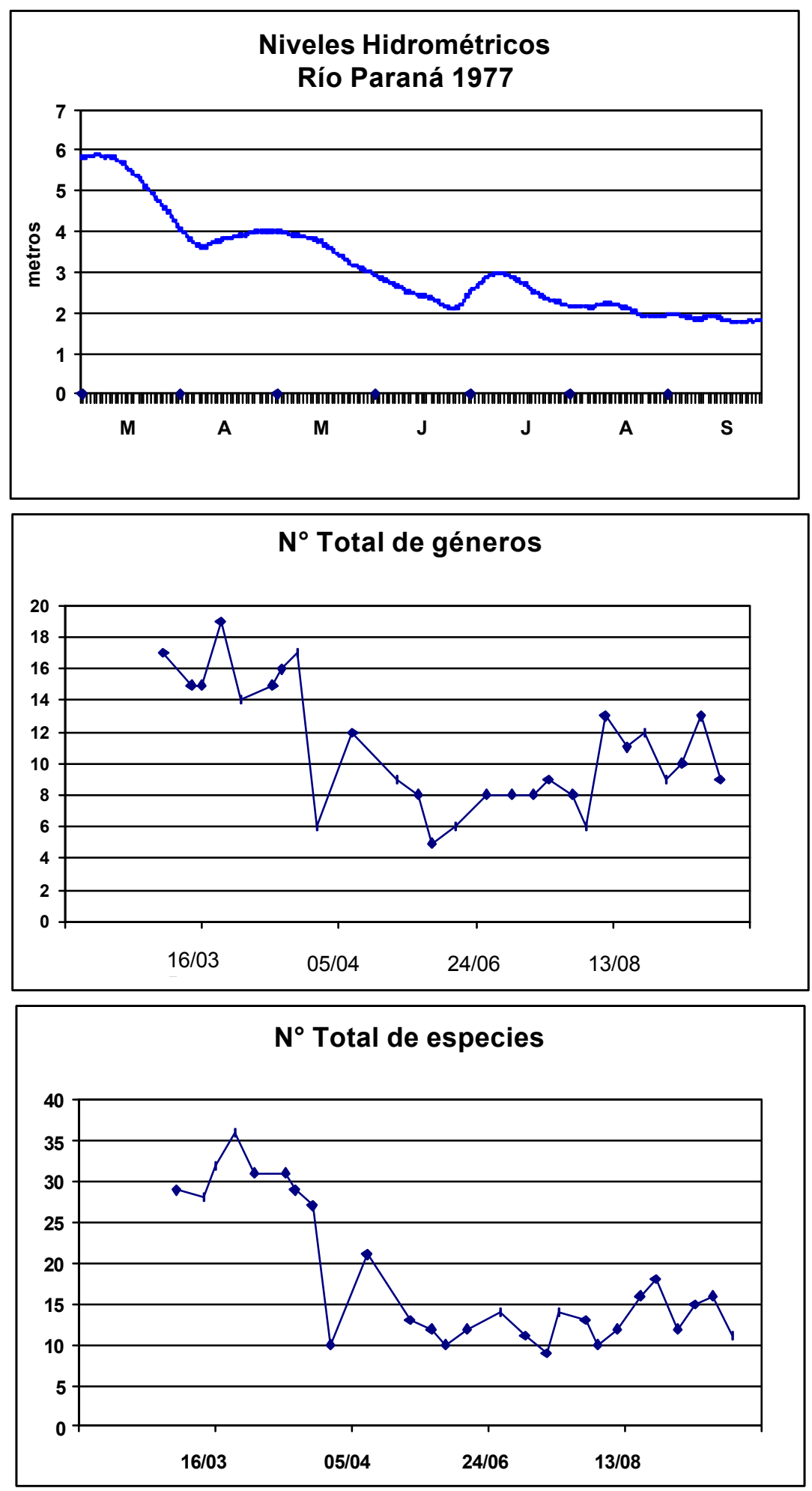

Fig. 2.12. Variaciones del nivel hidrométrico del río Paraná y del número total de especies y géneros en el área limnética de Los Matadores. 


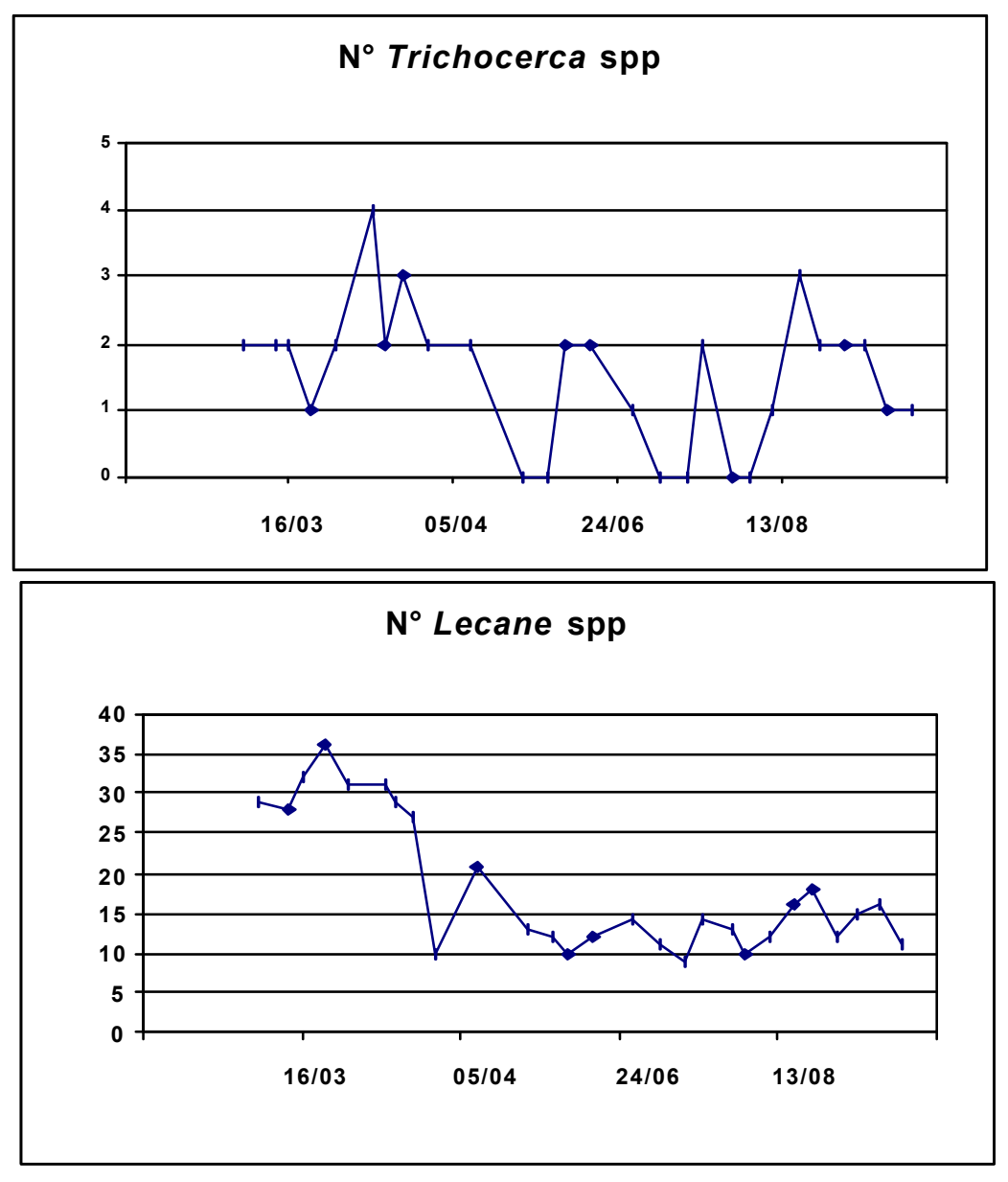

Fig. 2.13. Variaciones en el número de especies de Trichocerca y Lecane en laguna Los Matadores, área limnética.

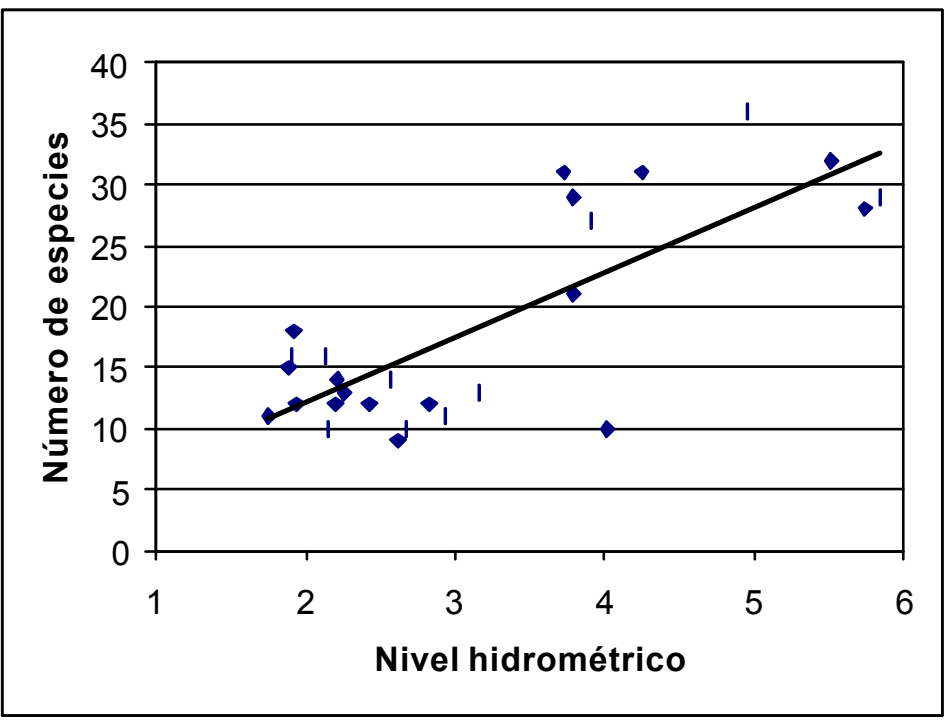

Fig. 2.14. Relación entre riqueza de Rotíferos de la Laguna Los Matadores (área limnética) y nivel hidrométrico del río Paraná, $r=0,781, p<0,0001$. 
Lo observado en esta laguna es también ilustrativo de la velocidad del cambio que experimentan estos cuerpos de agua de la planicie.

3.-Riqueza y composición de rotíferos en lagunas en estado de pre y pos-inundación.

A fin de analizar el efecto puntual del ingreso de agua de inundación en las lagunas de la planicie, se consideró un muestreo antes y después de este evento (febrero de 1972-abril de 1973). Se analizó la composición y riqueza de rotíferos en un grupo de 11 lagunas ubicadas en las islas Sirgadero, Timbó, Los Mellados y Carabajal. Los ambientes fueron mayoritariamente madrejones y lagunas grandes sin vegetación, disponiéndose solo de datos de dos lagunas con vegetación, una pequeña (menor que 5 ha) y otra grande.

\begin{tabular}{|c|c|c|c|c|c|c|c|c|c|c|c|c|}
\hline \multirow[b]{2}{*}{ Ambiente } & \multirow{2}{*}{\multicolumn{2}{|c|}{ Lag. Ubicación }} & \multicolumn{5}{|c|}{ Pre-Inundación } & \multicolumn{5}{|c|}{ Pos- Inundación } \\
\hline & & & $\begin{array}{l}\frac{0}{2} \\
\text { n } \\
\vdash\end{array}$ & 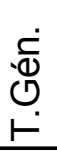 & $\begin{array}{l}\dot{0} \\
\frac{\pi}{0} \\
\text { வ0 } \\
\end{array}$ & $\begin{array}{l}\dot{0} \\
\stackrel{1}{J} \\
0\end{array}$ & $\begin{array}{l}\frac{1}{0} \\
\frac{0}{2} \\
0 \\
0\end{array}$ & $\begin{array}{l}\frac{0}{0} \\
\text { n } \\
\text { ト }\end{array}$ & $\begin{array}{l}\dot{\mathscr{\Phi}} \\
0 \\
0\end{array}$ & $\begin{array}{l}\dot{0} \\
\frac{\pi}{0} \\
\stackrel{0}{\circ} \\
0\end{array}$ & $\frac{\dot{d}}{\stackrel{d}{J}}$ & $\begin{array}{l}\frac{1}{0} \\
\frac{0}{2} \\
\text { do }\end{array}$ \\
\hline Peq.c/veg. & 9 & I. Sirgadero & 13 & 9 & 15 & 7 & 15 & 4 & 4 & 25 & 0 & 0 \\
\hline Gran.c/veg. & 20 & I. Carabajal & 15 & 10 & 20 & 13 & 0 & 11 & 6 & 18 & 0 & 0 \\
\hline \multirow[t]{4}{*}{ Gran.s/veg. } & 8 & I. Sirgadero & 3 & 2 & 66 & 0 & 0 & 12 & 8 & 8 & 0 & 0 \\
\hline & 11 & $"$ & 1 & 1 & 100 & 0 & 0 & 13 & 6 & 7 & 0 & 0 \\
\hline & 16 & I. Carabajal & 17 & 10 & 35 & 5 & 11 & 25 & 13 & 28 & 0 & 16 \\
\hline & 19 & $"$ & 4 & 4 & 25 & 0 & 0 & 18 & 10 & 16 & 10 & 5 \\
\hline \multirow[t]{5}{*}{ Madrejones } & 5 & I. Carabajal & 12 & 7 & 33 & 0 & 8 & 22 & 9 & 18 & 13 & 9 \\
\hline & 15 & $"$ & 18 & 10 & 0 & 44 & 0 & 14 & 10 & 28 & 25 & 25 \\
\hline & 18 & I. Timbó & 16 & 13 & 18 & 0 & 6 & 20 & 13 & 10 & 15 & 10 \\
\hline & 24 & $"$ & 10 & 6 & 40 & 20 & 1 & 9 & 8 & 10 & 22 & 11 \\
\hline & 25 & $"$ & 12 & 10 & 16 & 0 & 16 & 14 & 12 & 14 & 14 & 8 \\
\hline
\end{tabular}

Tabla 2.9. Número total de especies y géneros. Porcentaje de representación de los géneros más importantes en la composición de Rotíferos en lagunas isleñas próximas a Santa $\mathrm{Fe}$, antes y después de un evento de inundación. 
Considerando las lagunas en su conjunto las diferencias entre medias de los periodos de pre y post-inundacion no fueron significativas, tanto en el número de especies como de géneros ( $p=0,159$ y $p=0,300$, respectivamente).

Si el análisis se efectúa a nivel de grupos, es posible realizar algunas observaciones. En las lagunas grandes sin vegetación fue notorio el aumento de la riqueza de especies con la entrada del agua de inundación (Tabla 2.9), pudiendo citarse, a modo de ejemplo la laguna $n^{\circ} 8$ cuyo número de especies se incrementó de 3 a 12, y la laguna 19 de 4 a 18 especies. El número de géneros también aumentó.

El efecto fue más variable en los madrejones, $n^{\circ} 18$ de 16 a 20 especies, lag. $n^{\circ} 5$ de 12 a $22, n^{\circ} 25$ de 12 a 14 . En otros casos, el número de especies incluso disminuyó (lag. $\mathrm{n}^{\circ}$ 15, de 18 a 14). El número de géneros presentes en los madrejones se mantuvo igual o aumentó levemente con el ingreso de las aguas. En general el porcentaje de especies del género Brachionus fue mayor en el período pre-inundación; en cambio, Lecane y Trichocerca tuvieron mayor representación en la composición de los rotíferos luego de la inundación.

En las lagunas pequeñas o grandes con vegetación hubo una disminución del número de géneros y de especies en el período pos inundación. En una de ellas, la n 9, el número de especies fue de 13 y 4 antes y después de la inundación respectivamente.

\begin{tabular}{|lcl|cccc|}
\hline Tipo de Amb. & N $^{\circ}$ Lag. & Ubicación & Pre-In. & Pos-In. & Spp.com. & $\%$ \\
\hline Peq.c/veg. & 9 & I. Sirgadero & 13 & 4 & 3 & 35 \\
Gran.c/veg. & 20 & I. Carabajal & 15 & 11 & 5 & 38 \\
Gran.s/veg. & 8 & I. Sirgadero & 3 & 12 & 1 & 13 \\
& 11 & ". & 1 & 13 & 0 & 0 \\
& 16 & I. Carabajal & 17 & 25 & 13 & 62 \\
& 19 & 4 & 18 & 4 & 36 \\
Madrejones & 5 & I. Carabajal & 12 & 22 & 6 & 35 \\
& 15 & ". & 18 & 14 & 5 & 31 \\
& 18 & 16 & 20 & 5 & 28 \\
& 24 & I. Timbó & 10 & 9 & 5 & 53 \\
& 25 & " & 12 & 14 & 5 & 38 \\
\hline
\end{tabular}

Tabla 2.10. Número de especies en diferentes grupos de lagunas isleñas, antes y después de la inundación, especies en común entre ambos inventarios y porcentaje de las especies en común en el inventario total de las especies. 
El número de especies en común entre los dos períodos hidrométricos (Tabla 2.10) fue en general bajo, menor del $50 \%$, salvo en una laguna grande sin vegetación $\left(n^{\circ} 16\right)$ que fue del $62 \%$ y en un madrejón que fue del $53 \%\left(n^{\circ} 24\right)$. Esto significa que si bien en los ambientes vegetados no hubo un incremento importante de la riqueza de especies en total, sí hubo cierto recambio o movimiento de especies, ingresando unas y desapareciendo otras.

El ingreso del agua de desborde favorecería principalmente a las lagunas sin vegetación, de por sí menos diversas, aportando especies "barridas" de otros ambientes. Esto no se registra en las lagunas vegetadas y madrejones donde posiblemente la macrofitia ya existente en dichos ambientes actúa como un filtro de retención de organismos como lo señalaran oportunamente Hamilton et al. (1990) para lagunas del Orinoco.

\section{Diversidad de rotíferos y conectividad de los ambientes}

Se entiende por conectividad las interacciones entre diferentes ambientes acuáticos de un sistema que incluyen movimientos de agua, sedimentos, nutrientes, detritus y organismos vivos, de transporte pasivo y activo (Amoros \& Roux 1988, Ward \& Stanford 1995).

Una forma de analizar el grado de conectividad que tiene lugar entre los ambientes acuáticos del sistema y su carácter de fuerza homogenizadora de la composición faunística al permitir el intercambio de agua, nutrientes y organismos entre ellos, es a través del determinación de la diversidad beta (Amoros \& Bornette 2002).

Para analizar el efecto de la conectividad, se consideró el grupo de las 25 lagunas próximas a Santa Fe, de diversos tamaños y características, muestreadas en aguas bajas, considerándose posteriormente, además, 11 de ellas de las que se dispuso también datos correspondientes a períodos de aguas altas (ver Tablas 2.6 y 2.9). La diversidad beta antes de la inundación fue de 27 y 35 (según se consideren 25 y 11 lagunas respectivamente) y en el período posterior, de 17 (Tabla 2.11). Es decir hubo un decrecimiento de la diversidad beta, en el momento de aguas altas, cuando los ambientes tienden a parecerse más entre sí. La conectividad entre los ambientes, activada por la inundación, genera una mayor comunicación entre ellos y puede actuar como una fuerza de homogeneización, mientras que la diferenciación entre hábitats en cambio, que ocurriría en aguas bajas puede incrementarla (Ward et al. 1999, Amoros \& Bornette 2002), tal como se ve en el caso presentado. La diversidad regional no 
experimenta variaciones entre uno y otro estado en términos de número de especies, pero la presencia de cada especie se verifica en mayor número de hábitats. Una riqueza similar a nivel regional, de un sector dado de la planicie, antes y después de la inundación, puede indicar que el pulso actuó redistribuyendo organismos entre los ambientes pero no importando otros desde el canal o ambientes extra-región. Sin embargo, la mera comparación numérica puede ser simplista, ya que cotejando los inventarios de las lagunas en períodos pre y pos inundación, se observa que de un total de 63 especies, solo 27 son comunes a ambos períodos. Es decir entre uno y otro muestreo se produjo un cambio, con la desaparición de algunas especies y la incorporación de otras

\begin{tabular}{|c|c|c|c|c|}
\hline & D. Gamma & D. Alfa (X) & D. Beta & $N^{\circ}$ de hábitats \\
\hline \multicolumn{5}{|l|}{ Entre Lagunas } \\
\hline \multirow[t]{2}{*}{ Pre-Inundación } & 70 & 9 & 27 & 25 \\
\hline & 50 & 11 & 35,4 & 11 \\
\hline Pos-Inundación & 41 & 15 & 17 & 11 \\
\hline \multicolumn{5}{|l|}{ Entre planicie y canal } \\
\hline Gradiente longitudinal N-S, ab & 136 & 10,4 & $24(12)$ & 57 \\
\hline Gradiente transversal $E-O a b$ & 73 & 11 & $32(18)$ & 18 \\
\hline aa & 93 & 17,7 & $26(7)$ & 18 \\
\hline
\end{tabular}

Tabla 2.11. Valores de diversidad regional o gamma, diversidad beta y diversidad local o alfa. Entre paréntesis diversidad beta 2, ab: aguas bajas, aa: aguas altas, X: promedio.

Se analizó también la diversidad beta a lo largo de un gradiente geográfico como es el latitudinal, N-S , para un período de aguas bajas , considerando estaciones limnéticas únicamente. En tal sentido, se consideraron 39 lagunas (ver Tabla 2.2.) ubicadas en la planicie e islas, en el sector comprendido entre los km 1216 y 352, 15 estaciones en el curso principal del río, cada una de ellas distante de la otra aproximadamente $50 \mathrm{~km}$ y otras en tres ríos tributarios (Corrientes, Santa Lucía y Guayquiraró). El número total de especies fue de 136, con una diversidad alfa media de 10,4. La diversidad beta calculada para aguas bajas fue de 24. La diversidad ß2 de 12; es decir, la variabilidad en la diversidad alfa de los ambientes considerados no es pequeña, ya que ß2 es exactamente la mitad de ß.

Si bien para el cálculo de la diversidad beta las muestras no tienen necesariamente que ser simultáneas en el tiempo, se prestó especial atención a que pertenecieran a períodos hidrológicos similares. Se incluyeron lagunas entre Confluencia y Diamante y 
todas las estaciones fluviales, canal principal y tributarios muestreadas, con un nivel medio mensual de $1,98 \mathrm{~m}$ y máximos y mínimos de 2,72-1,50m respectivamente (septiembre de 1975), lagunas en el área Paraná-Santa Fe, nivel medio mensual 2,05m, máximos. y mínimos 2,76-1,26, respectivamente (febrero de 1972) y lagunas aguas abajo de Diamante, muestreadas con un nivel medio mensual de 1,99 m, máx. y mín. respectivamente de 2,64-1,51m (julio de 1972). Los niveles hidrométricos corresponden al puerto de Paraná. La gran mayoría de los ambientes fueron muestreados con temperaturas cálidas de primavera-verano.

Se analizó la diversidad beta también a lo largo de una sección transversal E-O, elegida por la existencia de un gradiente de complejidad ambiental en el sentido de curso principal- cauces de menor jerarquía - lagunas con mayor y menor desarrollo del litoral vegetado.

Se consideraron datos de riqueza en aguas bajas con valores medios mensuales de 1,98m (septiembre de 1975), 1,86m (octubre de 1981) y 2,12 m (octubre de 1987). Datos de aguas altas con valores medios mensuales de 3,12m (abril de 1972), 3,32m (marzo de 1975), 4,75m (febrero de 1981), 4,48m (marzo de 1981), 5,02 m (junio de 1987).

Se incluyó la composición de rotíferos del curso principal del río Paraná, cauces secundarios (ríos Santa Fe, Colastiné y Correntoso), lagunas (Cuarentena, El tigre, Los Matadores y 11 lagunas ubicadas en las islas Timbó, Carabajal, Sirgadero y Los Mellados). En total se consideraron 18 hábitats.

Para aguas altas se obtuvo un valor de diversidad $ß: 26$ y para aguas bajas de 32. La diversidad ß2 fue de 7 y 18, respectivamente. En este caso, se observa mayor diferencia entre las dos situaciones hidrométricas. La diferencia entre ambas medidas de diversidad, al igual que en los casos anteriores está señalando la variabilidad entre las diversidades locales.

Considerando el período de aguas bajas, cuando se dispuso de información para las transectas N-S y E-O, se observa que la diversidad beta es mayor en la transversal. Ello indicaría la existencia de un gradiente ambiental más definido en el sentido de este eje. Analizando la diversidad alfa promedio por ambiente puede verse como este gradiente se observa tanto en aguas bajas como altas. La heterogeneidad espacial, que ocurriría en estas transecciones o ejes queda reflejada en la diferencia entre valores de la diversidad regional o gamma y la diversidad alfa promedio. Cuando todas las especies aparecen en todos los ambientes, la diversidad gamma difiere muy poco de la diversidad local. 
Si bien la diversidad beta en períodos de aislamiento siempre se presenta mayor, indicando mayor disimilitud entre los ambientes, podría esperarse que el pulso de inundación por efectos de la conectividad homogeneizara fuertemente la composición de rotíferos dentro de una región o área, bajando fuertemente la diversidad beta. Sin embargo esto es relativo, pues, por ejemplo, en ningún caso en aguas altas se observaron valores menores de 10 . Esto estaría indicando que si bien la entrada del agua de río a la planicie provoca una redistribución de los organismos, esta no resulta uniforme. Probablemente, muchos organismos quedan retenidos por las macrófitas, y serán afectados por el arrastre, o estarán sujetos a una fuerte competencia. El número de especies de cladóceros en el plancton suele incrementarse en estos períodos (Paggi, com.pers.).

La diversidad local o alfa en un ambiente, en una escala temporal, puede estar muy influenciada por la conectividad hidrológica. En Figura 2.10 se observa la relación directa entre riqueza de especies en la laguna Cuarentena y nivel hidrométrico del río Paraná. Esta laguna está fuertemente influenciada por el río, a través de su conexión directa por un canal y en aguas muy altas también indirecta, a través de bañados lindantes en la parte norte de la cubeta. En este caso, el número de especies presenta un creciente aumento con la entrada del agua de río, a partir de los $3 \mathrm{~m}$ la que ingresa directamente por el canal o indirectamente drenando desde la parte norte de la isla.

Algo similar ocurre en la laguna Los Matadores, de conexión directa con un ambiente fluvial. Con valores de nivel del río superiores a los $3 \mathrm{~m}$ la diversidad es notoriamente mayor en el área limnética (Fig. 2.14). Solo se observa una fecha en la cual con un nivel de 4,02 m disminuyó el número de especies, probablemente en relación a las interacciones bióticas que tienen lugar, por el aumento en la abundancia de cladóceros (Paggi, com.pers.). No obstante, en ambos casos hay una clara tendencia de asociación entre la diversidad alfa y la conectividad hidrológica. La baja conectividad que impide o limita el intercambio de organismos, materia y energía entre los hábitats puede disminuir la biodiversidad en los ambientes de planicie de inundación (Ward et al. 1999). 


\section{LA ROTIFEROFAUNA DEL SISTEMA RÍO-LLANURA DEL PARANÁ Y CONSIDERACIONES SOBRE LOS FACTORES QUE DETERMINAN SU DIVERSIDAD}

El número total de especies de rotíferos registrados en el Paraná desde su confluencia con el Paraguay hasta su desembocadura es de alrededor de 240 . Corresponde a lo hallado en el canal principal y en los cauces de menor jerarquía, así como en ambientes leníticos de la planicie. Este número de especies representa poco más de un tercio (38\%) del total de las registradas en Sudamérica (Koste \& José de Paggi 1982, José de Paggi \& Koste 1995).

La mayor diversidad de especies se registró en los géneros Lecane, Brachionus y Trichocerca, en coincidencia con lo observado por distintos autores en ecosistemas acuáticos tropicales de Sudamérica, Asia y Africa (Koste 1972, Koste 1988, Segers et al. 1993).

Se han postulado varias hipótesis para explicar la diversidad de una región y sus patrones geográficos de variación; entre ellas se destacan aquellas que ponen énfasis en la heterogeneidad espacial (Pianka 1966), la estabilidad climática (Klopfer 1959), el disturbio intermedio (Connell 1978), la energía disponible (Connell \& Orias 1964), la productividad (Tilman 1982), y el tamaño del área (MacArthur \& Wilson 1967).

En los ecosistemas de agua dulce, la mayor diversidad se observa en los humedales muy heterogéneos y en la interfase de las áreas litorales con las pelágicas de lagos y ríos (Wetzel 1999, 2001). Los sistemas de ríos con planicie aluvial sostienen una muy elevada diversidad general, como consecuencia de su compleja estructura espacial de hábitat y de los cambios temporales predecibles en las condiciones ambientales Ward (1995).

En estos ríos, la diversidad biológica se relaciona fundamentalmente a las particularidades ambientales de un sistema donde canal principal y llanura constituyen una unidad funcional. Los primeros modelos conceptuales referidos a ambientes fluviales y las teorías de ellos derivadas han soslayado el rol de la planicie de inundación en el incremento y mantenimiento de la biodiversidad (Hynes 1970, Vannote et al. 1980). Especialmente a partir del estudio de ríos tropicales comienza a reconocerse la importancia de la unidad de paisaje que constituyen el canal y la llanura de inundación. Por otro lado, en estos sistemas es la planicie, precisamente, la que articula las aguas corrientes con las lénticas, y el sistema terrestre con el acuático ( Amoros \& Roux1988, Ward 1995, Junk et al. 1989). El gradiente longitudinal en las variables físicas de los ríos, particularmente de regiones templadas, ha tenido un rol protagónico en el estudio del funcionamiento de los sistemas fluviales. Sin embargo, en ríos con planicie de inundación desarrollada, la dimensión lateral (Amoros \& Roux1988, Ward 1989) agrega un elemento fundamental para una mejor comprensión del funcionamiento de estos macrosistemas y su biodiversidad. 
Ward et al. (1999) señalan que la diversidad biológica de los ríos con planicie de inundación sería una consecuencia de la dinámica fluvial que actúa sobre los procesos sucesionales, la conectividad ecológica y las propiedades de las zonas ecotonales, determinando su heterogeneidad témporo-espacial.

Hay dos elementos bien definidos que condicionarían la diversidad de los rotíferos del Paraná a nivel local y regional, la heterogeneidad espacial y la heterogeneidad temporal dada por el pulso de inundación.

La importancia de la heterogeneidad espacial en la diversidad de rotíferos se pone de manifiesto al considerar el incremento en la complejidad ambiental (número de hábitas) en sentido transversal, cuando se sitúa en un mismo eje al curso principal- los cursos de menor jerarquía y los ambientes leníticos de la planicie, tal como ocurre en una determinada laguna , que exhibe un gradiente de heterogeneidad estructural que, en sentido espacial está determinada por los rasgos que diferencian y distinguen a las áreas limnética y litoral.

La complejidad ambiental a nivel regional o local se traduce en una mayor oferta de nichos ecológicos, lo que a su vez reduce los niveles de competencia, permitiendo la mayor coexistencia de especies, y la existencia de gradientes en las variables físicas, como la velocidad de la corriente, tiempo de residencia del agua, y cantidad de material inorgánico en suspensión. Todo ello configuraría lo que Ward \& Tockner (2001) denominan diversidad estructural.

El curso principal del río representa el ambiente estructuralmente más simple, con menor número de hábitas, predominio de área pelágica, siendo la zona de transición acuático-terrestre comparativamente menor. Por otro lado, presenta condiciones físicas más rigurosas para los organismos del plancton, tales como alta velocidad de flujo y mayor concentración de sedimentos suspendidos. El gradiente transversal de complejidad ambiental se asocia a un incremento de la riqueza de rotíferos en el sentido: curso principal -- cauces secundarios tributarios - ambientes leníticos del valle. En la Fig 3.1 se observa ese gradiente en dos momentos hidrométricos, aguas bajas y altas; allí se incluyen tres lagunas, la primera, en la que solo se considera el área pelágica de un ambiente muy conectado al río (Los Matadores) y dos lagunas con áreas litorales bien desarrolladas (La Cuarentena y El Tigre).

La asociación entre este gradiente de complejidad y diversidad creciente desde el canal principal al límite externo de la llanura fue observado también en otras comunidades, 

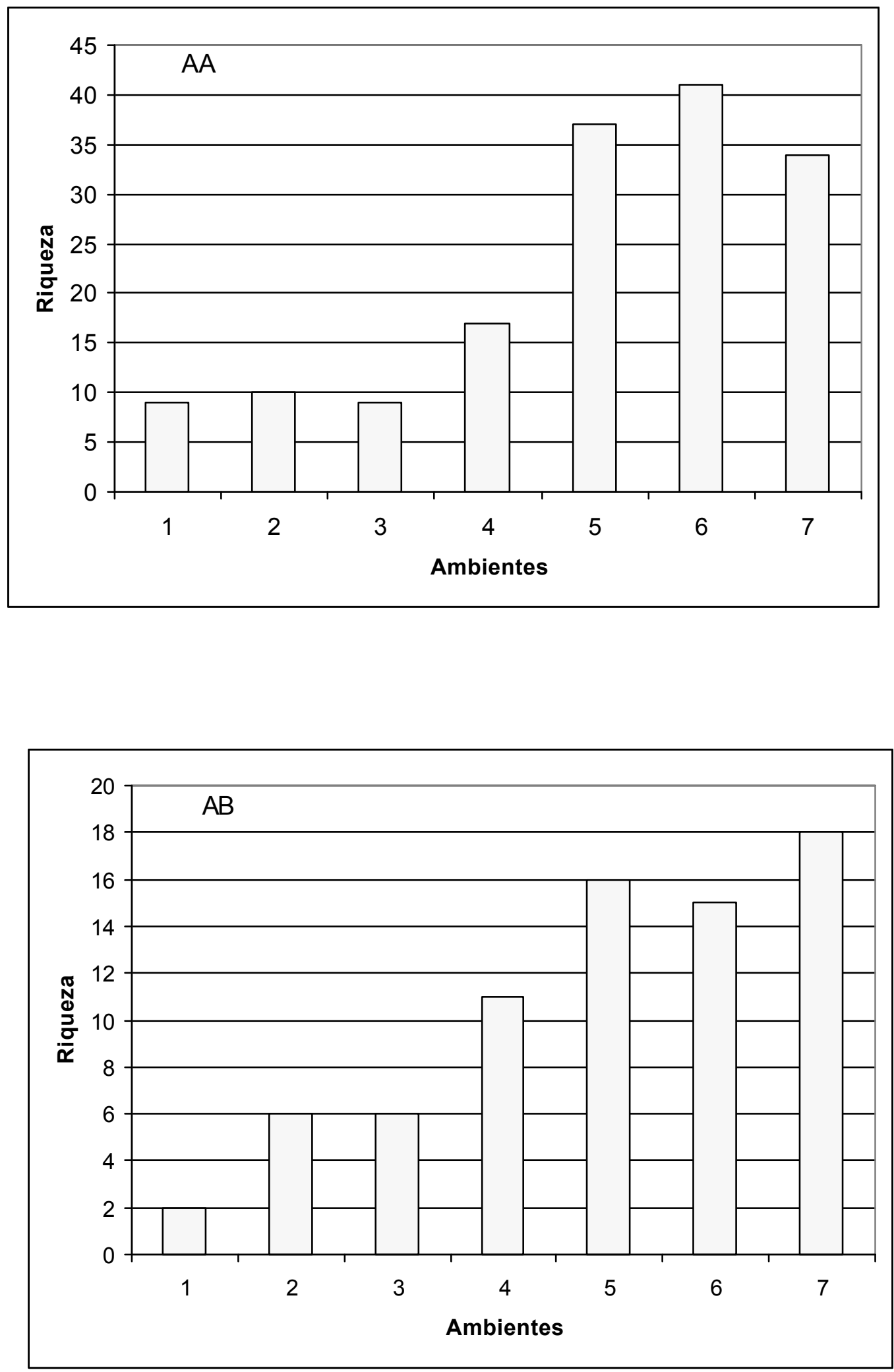

Fig. 3.1. Riqueza de Rotíferos en ambientes lóticos y leníticos en una sección transversal próxima a la ciudad de Santa Fe. 1. Curso principal del río Paraná. 2. Río Santa Fe. 3. 3. Río Colastiné; 4. Río Correntoso; 5. Laguna Los Matadores; 6.Laguna La Cuarentena; 7. Laguna El tigre. $A A$ aguas altas, $A B$ aguas bajas. 
(zooplancton, bentos y peces) (Quirós \& Cuch 1989, Paggi \& José de Paggi 1990, Marchese \& Ezcurra de Drago 1992, Neiff 1997).

Los dos extremos de un gradiente de la complejidad física lo constituyen entonces el canal principal y una laguna somera con litoral desarrollado y sus distintos tipos de vegetación. El canal principal del Paraná en el tramo Confluencia - Diamante, de unos 700 km de longitud, con 49 estaciones muestreadas consecutivamente presentó un total de 52 especies, mientras que en una sola laguna de la planicie de inundación, la laguna La Cuarentena, se registraron en una sola fecha de muestreo 46 especies (Tabla 2.7).

Una riqueza similar se ha hallado en otras lagunas como El Pacú y El Junco, ubicadas en el sur de Corrientes, 56 y 51 especies respectivamente en un único muestreo.

Considerando solam ente los ambientes fluviales, el canal principal y los ubicados en la plancie, tramo Goya-Diamante, se pueden considerar dos momentos hidrológicos diferentes en que se tomaron muestras en el canal principal y cursos de distinta jerarquía. Tanto en aguas medias como altas se registró un aumento del número de especies en el siguiente sentido: Curso Principal - Cauces Secundarios - Cauces Tributarios. (Fig 3.2). Ello se relacionaría con un gradiente en la velocidad de la corriente, caudal, material en suspensión y también mayor disponibilidad de recursos como el fitoplancton (García de Emiliani \& Manavella 1983) que opera también en este mismo sentido.

En las lagunas, un aumento local en la heterogeneidad espacial se relaciona con un mayor número de especies de rotíferos. Las áreas limnéticas en general presentan menor riqueza de rotíferos que la que puede hallarse en las áreas litorales vegetadas, como lo demuestran los estudios realizados en dos lagunas de planicie, la Sirena y El Tigre. Ambas fueron muestreadas durante una extensión temporal equivalente (14 meses). La primera, de 200 ha, estaba localizada en la estrecha planicie izquierda del Alto Paraná, provincia de Corrientes, en tanto que la segunda, de solo 3 ha, próxima a la ciudad de Santa Fe. En La Sirena se consideró una sola estación en la zona limnética, registrándose 55 especies (Corrales de Jacobo \& Frutos 1985), mientras que en El Tigre, 5 estaciones, incluyendo el área litoral vegetada (Eichhornia crassipes, Paspalum repens y Typha sp. ) se hallaron 111 especies (José de Paggi 1993). Más allá de que la planicie del alto Paraná presenta una menor diversidad que en los tramos inferiores, como se discutirá más adelante, las localidades estructuralmente más complejas, permiten la coexistencia de un mayor número de especies por segregación de hábitas (Menge \& Sutherland 1976). Por otro lado, en un estudio realizado en 3 lagunas de la planicie del Orinoco, durante 21 meses, considerando solo el área pelágica, se registraron 60 taxa de rotíferos (Vásquez \& Rey 1992). 


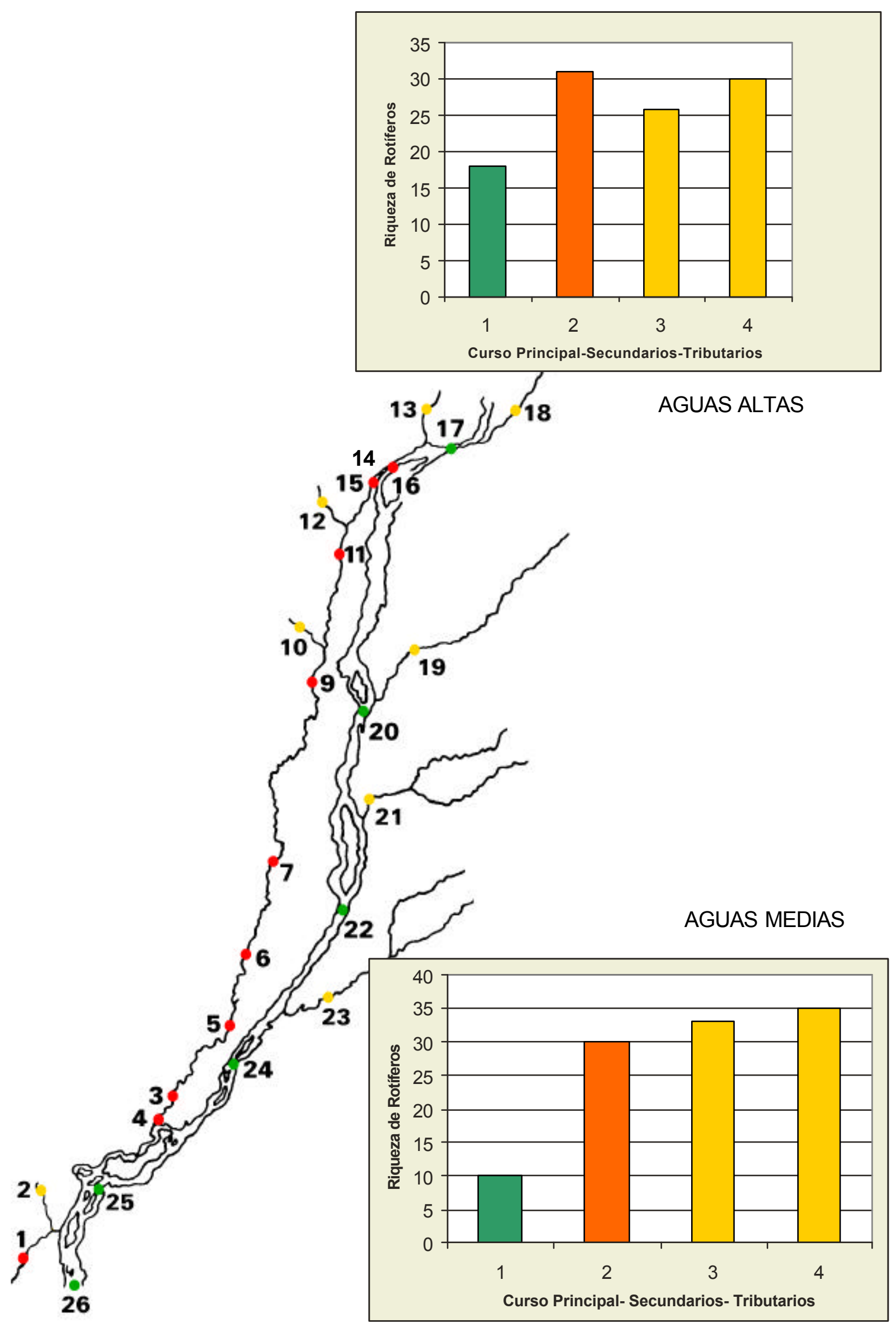


Fig.3.2. Riqueza de rotíferos en cauces de distinta jerarquía del tramo Goya-Diamante.

1.-R. Paraná, curso principal: 17, 20,22, 24, 25,26.

2.-Cauces secundarios:1.R.Coronda; 3,5,6,7,9,11,15.R.San Javier; 4.R.S.Rosa; 16. R. San Jerónimo.

3.-Tributarios margen derecha: 2.R. Salado; 10.A del Ombú;12. A Malabrigo; 13. R.Los Amores; 14. A $^{\circ}$ del Rey.

4.-Tributarios margen izquierda: 18. R. Santa Lucía; 19. R. Corrientes; 21. R.

Guayquiraró; 23. R. Feliciano.

La información evaluada en este trabajo muestra que en 6 lagunas, ubicadas a lo largo de un eje norte-sur en la planicie, el número total de las especies en cada una de ellas puede ser varias veces superior en la zona litoral que el número encontrado en el área pelágica (Tabla 2.4) y que las afinidades faunísticas entre ambas áreas es inferior al $50 \%$. Del mismo modo, cuando se comparan ambientes con y sin litoral vegetado se observa una riqueza promedio mayor en los que tienen vegetación (Tabla 2.6). Ello está en concordancia con la hipótesis de la heterogeneidad ambiental que propone que ambientes estructuralmente más complejos permiten la existencia de un mayor número de especies (Mac Arthur 1972).

La riqueza de rotíferos entre ambientes leniticos de la planicie varió también en relación al tamaño y forma de los mismos. En el estudio efectuado en 25 lagunas ubicadas en tres islas del valle, a la altura de la transección Santa Fe-Paraná, considerando únicamente el área limnética, se observó un incremento en el número de especies en el siguiente sentido:

-Lagunas pequeñas sin vegetación-Grandes sin vegetación-Grandes vegetadas-Pequeñas vegetadas- Grandes alargadas; estas últimas corresponden a los llamados madrejones, los que incrementan su heterogeneidad ambiental por el desarrollo que alcanza la cobertura de vegetación y probablemente por la presencia dominante de macrófitas sumergidas (Fig. 3.3).

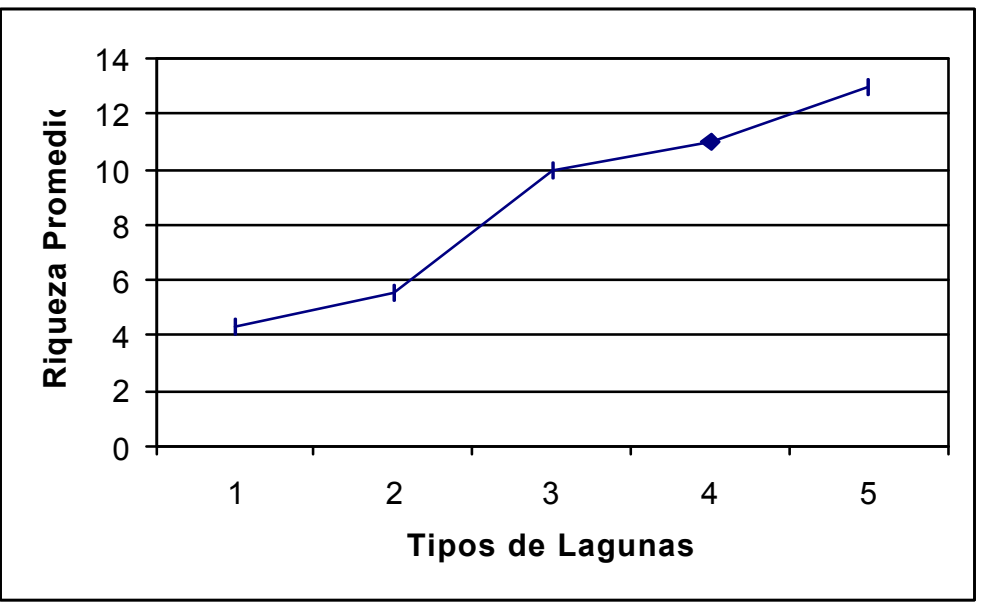

Fig.3.3. Riqueza promedio de Rotíferos según tipos de lagunas. 1. Pequeñas sin vegetación. 2. Grandes sin vegetación. 3. Grandes con vegetación. 4. Pequeñas con vegetación. 5. Madrejones. 
Considerando el canal principal, no habría una estructura o gradiente longitudinal definido por su complejidad física en el tramo estudiado, no existiendo grandes diferencias en cuanto a velocidad del flujo, transparencia del agua y distribución de oxígeno. En la riqueza de rotíferos las diferencias más notorias se observaron en sentido transversal, pero en relación principalmente a la zona de influencia de las aguas del Paraguay en el área de Confluencia (Tabla 1.2). Las diferencias en la distribución de la riqueza de especies no se manifestarían en sentido espacial longitudinal sino por el acople de la heterogeneidad temporal determinada por el pulso de inundación.

Los sistemas fluviales interactúan en tres dimensiones espaciales: longitudinal, lateral y vertical y en una dimensión temporal (Ward 1989). La dimensión longitudinal articula los procesos que ocurren aguas abajo con los de aguas arriba, la dimensión lateral se refiere al flujo activo y pasivo de organismos, nutrientes y agua entre canal y planicie, aludiendo la vertical a las interacciones entre canal y acuíferos.

La interacción del sistema en la dimensión longitudinal a lo largo del canal principal del Paraná, es difícil de evaluar por cuanto se trata de un canal con múltiples conexiones laterales y con una planicie bien desarrollada. Puede suponerse que la presencia de especies tropicales en el canal, observada luego de inundaciones extraordinarias, como la de 1982, puede atribuirse al aporte de aguas arriba. Sin embargo, es probable que dicho aporte se relacione en mayor grado con la contribución del Paraguay y su planicie al sistema, que con lo transportado desde los tramos superiores del Paraná. Las investigaciones realizadas sobre la dinámica del carbono muestran, precisamente, la importancia del aporte de este sistema (río Paraguay y Pantanal) y su contribución a la calidad química aguas abajo de confluencia (Depetris \& Kempe 1990). Por otro lado, algunos estudios de distintos autores muestran que la diversidad de rotíferos del río Paraná aguas arriba de la confluencia con el Paraguay es inferior (Rocha et al. 1994, Sendacz 1993).

Lansac-Toha et al. (1997) han señalado un total 154 taxa de rotíferos para la planicie de inundación del Paraná Superior. Registraron 133 taxa en ambientes leníticos y 106 y 105 en ambientes lóticos y semilóticos, respectivamente. Los géneros más diversos son los mismos que los registrados aguas abajo de Confluencia: Lecane (23 taxa), Trichocerca (19), Brachionus (12), pero la diversidad general parece ser menor.

Considerando los datos que se exponen en la Tabla 3.1 sobre estudios comparables realizados entre distintas secciones del Paraná, se observa que el número de especies en común es 20 , es decir, solo $22,4 \%$ de la especies halladas en la sección Paraná-Santa Fe (km 603). Ello estaría indicando que pocas especies perduran aguas abajo. Es probable que 
las especies encontradas a la altura de Corrientes y las de la sección Paraná-Santa Fe no provengan en su mayoría de aguas arriba sino de ingresos laterales por el intercambio con la llanura a través de cauces tributarios o secundarios. El número total de especies de rotíferos en el alto Paraná fue de 38 , mientras que en las secciones aguas abajo fue de 91 y 89. Esta mayor riqueza podría asociarse con el aporte del Paraguay y de una planicie lateral más extensa luego de la confluencia.

\begin{tabular}{|l|c|c|c|c|c|}
\hline \multicolumn{1}{|c|}{ Sección } & $\begin{array}{c}\text { Período de } \\
\text { Muestreo }\end{array}$ & Total Spp & Brachionus & Lecane & Referencia \\
\hline Alto Paraná & $1976-1978$ & 38 & 7 & 6 & Corrales 1979 \\
Km 1200 (Ctes.) & $1976-1979$ & 91 & 11 & 7 & Bonetto \& Corrales 1985 \\
km 603 (Paraná) & $1976-1982$ & 89 & 18 & 13 & Este estudio \\
\hline
\end{tabular}

Tabla 3.2. Riqueza de Rotíferos en el Alto Paraná y en dos secciones aguas abajo de la con fluencia con el Río Paraguay. Entre paréntesis localidades de referencia.

Por otro lado la afinidad faunística entre estaciones a lo largo del canal principal, en la sección Santa Fe-Río de la Plata (Fig.1.4) muestra claramente que la composición entre estaciones varía en forma considerable. Esta variación obedece particularmente a una mayor riqueza de especies en las estaciones de la última parte del tramo, debido a la incorporación paulatina de especies nuevas (Fig. 3.4). No se trata, en consecuencia, de un mismo pool de especies, transportada aguas abajo en sentido longitudinal. Muchas van desapareciendo y otras se incorporan.

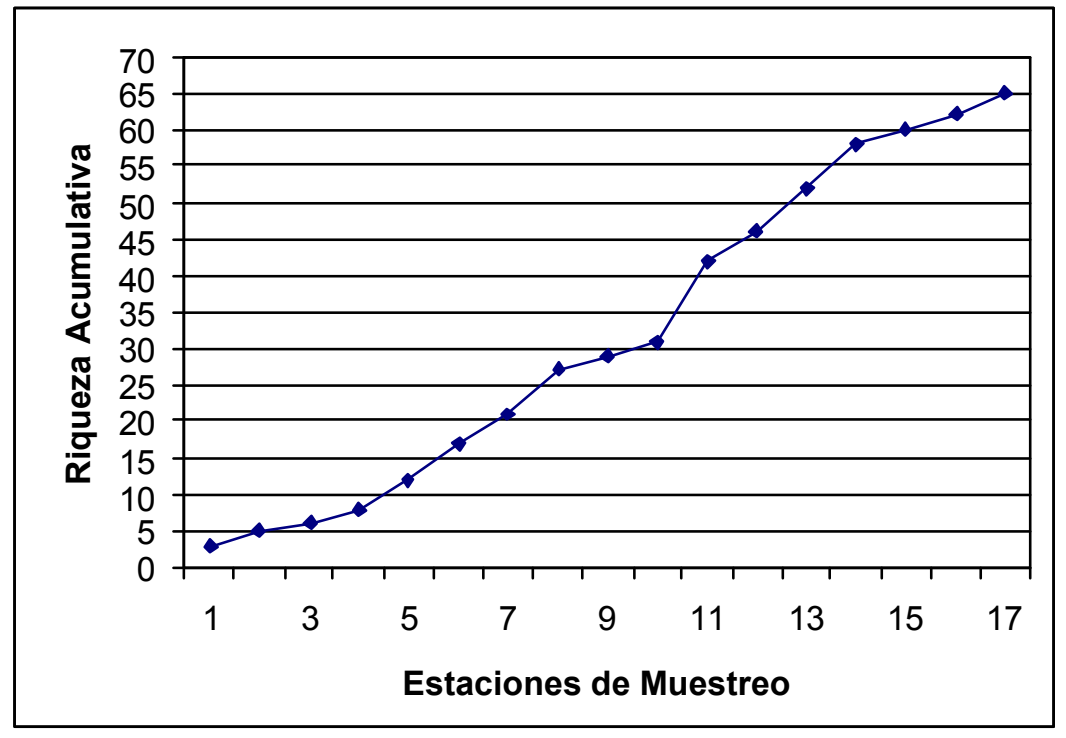

Fig. 3.4. Riqueza acumulativa de Rotíferos en el canal principal del Rín Paraná tramn Santa Fe-Rín de la Plata 
La dimensión lateral adquiere particular importancia cuando es activada por el pulso de inundación que conecta la planicie con el canal principal. Ward \& Stanford (1995) señalan que las interacciones laterales entre canal y planicie son extremadamente importantes en los tramos meandrosos y entrelazados de los ríos. El aporte lateral de la planicie se hace visible analizando la composición y riqueza de especies en un mismo tramo en períodos de aguas encauzadas y períodos de aguas altas o altas en descenso, cuando el agua escurre de la llanura al canal. En el tramo Paraná-Río de la Plata , de casi 600 km en aguas medias, en 60 estaciones se registraron 35 especies de rotíferos, mientras que en aguas en descenso, en solo 17 estaciones se registraron 65 especies (Fig.1.3). Este número estuvo conformado en más del $70 \%$ por especies litorales o litorales-bentónicas, las que ocurren generalmente en las lagunas. Lo mismo se observó en el tramo Goya-Diamante. En aguas medias se hallaron 9 especies y en aguas altas 18 especies. En ambos casos se tomaron muestras de igual número de estaciones. En el muestreo de aguas altas se halló Brachionus plicatilis que es poco frecuente en el canal principal del Paraná, pero sí en los tributarios o cauces secundarios con valores altos de conductividad. También se registró Brachionus calyciflorus, que es poco frecuente en el canal principal y lo es más en ríos de menor jerarquía y lagunas.

Considerando en general los distintos tramos estudiados en el curso principal, la mayor diferencia se observa no en sentido espacial, sino temporal, con un incremento del $50 \%$ o más del número de especies en aguas altas o altas en bajante.

A una escala temporal la riqueza acumulativa de especies de rotíferos en el canal principal, referida como inventario de especies (Tabla 1.1) puede considerarse como una expresión del aporte lateral o de la llanura, la que contribuye al mantenimiento y aumento de la riqueza de especies. Esta contribución es muy dinámica y depende no solo del pulso en si mismo, sino de su duración e intensidad, lo cual se relaciona a la extensión de la planicie anegada. El incremento en el número de especies del canal en períodos de aguas altas es el resultado de una mayor conectividad entre los ambientes. El aumento del porcentaje de especies litorales y bentónicas que se registra es un indicador de tal conectividad, ya que se trata de especies que son frecuentes en las lagunas vegetadas como las pertenecientes a los géneros Lecane, Trichocerca, y Cephalodella. Por todo este proceso de la dinámica fluvial, la diversidad temporal de rotíferos en el curso o canal principal podría considerarse como una expresión de la diversidad de la planicie. 
Si bien es posible considerar la composición de rotíferos del curso principal como una expresión de la potencial diversidad de la llanura, la magnitud del aporte de la llanura en la composición de los rotíferos del canal puede ser discutible.

Todas las especies encontradas en el curso principal se hallaron al menos una vez en las lagunas, pero en aquél, luego de muchos años de muestreo, sólo se registraron 113 especies de las 226 halladas en la planicie. Un análisis puntual en el tiempo es representativo de esto; por ejemplo, mientras en una sola laguna se encontró, en un período de 7 meses del año 1977, un total de 94 especies solamente en el área limnética (Los Matadores), a lo largo de todo ese mismo año, en 3 estaciones del curso principal de una transección ribera-ribera (km 606), la riqueza acumulativa de rotíferos fue de 57 especies. También resulta ilustrativo mencionar que en las 12 lagunas de la planicie ubicadas en sentido norte-sur, a lo largo del tramo Confluencia-Diamante, en un único muestreo se encontraron 113 especies, mientras que en el canal, en un tramo de la misma sección e igual período de muestreo, se registraron 52 especies.

Si bien no hay un análisis particular en cuanto a la riqueza total de rotíferos, los estudios realizados en el Orinoco señalan que una pequeña proporción del total de la biomasa del zooplancton transportado por el curso principal proviene de la planicie. En consecuencia, la composición del zooplancton del río se solapa solo parcialmente con las de los ambientes de la planicie (Vásquez \& Rey 1992, Lewis et al.1995). El transporte en cierto modo "ineficiente" desde la llanura es atribuido a la "rugosidad biológica" de ésta (vegetación terrestre), que atenúa la velocidad del flujo del agua, reteniendo organismos, y también, en algunos casos, a la depredación de los peces (Vásquez \& Rey 1989). Depetris \& Kempe (1990) encontraron en el curso principal del Paraná que el carbono orgánico particulado en el evento del Niño 19821983, no solo no experimentó aumento con respecto a años normales sino que fue aún más bajo sugiriendo que la planicie arbolada actúa como un filtro, reteniendo sedimentos y detritus.

Estos factores regularían el transporte de especies al canal, incidiendo también en la composición de los rotíferos, pero además la permanencia en el canal de las especies importadas podría ser muy breve, al ser controlada por las rigurosas condiciones físicas de éste. El número de especies de rotíferos frecuentes en el canal es reducido en tiempo y espacio; muchas no ingresan o sobreviven en el canal por no tolerar sus condiciones ambientales.

Acerca de la relación con la dimensión vertical, no tenemos evidencias de variaciones en la composición de especies, por cuanto no se han efectuado estudios sobre la microfauna de los acuíferos. Algunos autores señalan que para ríos europeos esta dimensión sería importante (Ward \& Tockner 2001). 
La heterogeneidad temporal está determinada por los cambios de nivel hidrométrico que activan y mantienen la conectividad ecológica que opera en una escala de tiempo y espacio, y que es entendida como el intercambio de agua, recursos y organismos dentro del canal, el acuífero y la planicie (Ward \& Stanford 1995). El pulso de inundación facilita el aumento del número de conexiones entre ambientes; hay una participación activa de las dimensiones espaciales que conforman estos sistemas, particularmente la lateral y la longitudinal.

El aumento de la conectividad favorece la diversidad de rotíferos en las lagunas, pues el pulso de inundación aumenta la riqueza de especies. Esto se observó en una laguna de conexión directa, como es el caso de la laguna Los Matadores, donde se registró un importante incremento de la diversidad. Solo en una estación del área limnética se registraron 94 especies en un período de 7 meses, que incluyeron el ingreso de las aguas lóticas.

En las 12 lagunas de las islas Sirgadero, Timbó y Carabajal, con muestreos antes y después de la inundación se observó en el área pelágica un incremento de hasta 300 veces en el número de especies.

El aumento en aguas altas de la riqueza de especies ha sido observada también en lagunas de la planicie del del Alto Paraná (Bonecker \& Lansac-Toha 1996) y del Amazonas (Hardy et al. 1984, Junk \& Robertson 1997).

Si bien en las lagunas la riqueza temporal de especies estaría relacionada al disturbio del pulso de inundación, es importante también tener presente factores como la competencia y depredación. En Laguna El Tigre, juntamente con el ingreso de las aguas lóticas, lo hacen también peces pequeños que se alimentan de plancton, disminuyendo notablemente los microcrustáceos, determinando una alteración de los patrones de competencia y favoreciendo el mantenimiento e incremento de la diversidad de rotíferos (Paggi com. pers., José de Paggi 1993). Junto con las aguas de inundación también en las lagunas puede producirse eclosión de huevos de resistencia en los sedimentos de la planicie, los que pueden ser arrastrados por los flujos de agua generados en los períodos de aguas altas.

La diversidad de rotíferos mantenida en niveles altos durante los momentos en que el pulso activa la conectividad de los ambientes del sistema puede ser entendida también como una consecuencia en parte del disturbio que se genera. 
Junk \& Weber (1996) han señalado que en estos sistemas el pulso de inundación actúa como un factor de disturbio intermedio que mantiene la diversidad biótica en muy altos niveles.

El disturbio intermedio genera una diversidad alta, al reducir los niveles de exclusión competitiva favoreciendo la coexistencia de un mayor número de especies. Un disturbio muy grande y uno muy pequeño, según la hipótesis del disturbio intermedio sustentarían una baja diversidad (Conell 1978). En el caso del río Paraná los eventos extremos como inundaciones y sequías extraordinarias se asocian a bajos niveles de diversidad de rotíferos. El pulso de inundación, en períodos normales o de menor recurrencia, al conectar los distintos ambientes produce un arrastre y redistribución de las especies que incrementa rápidamente la diversidad tanto en el canal como en las lagunas.

\section{La riqueza de Rotíferos del río Paraná respecto de la de otros ríos}

En cuanto a la riqueza y composición de rotíferos del río Paraná respecto de otros ríos, es interesante considerar principalmente los subtropicales o tropicales del hemisferio Sur que por su carácter de ríos con llanura de inundación (estructura) y por su régimen hidrológico pulsátil (funcionamiento) son más semejantes.

Con respecto al río Paraguay, hay pocos estudios publicados sobre la diversidad de rotíferos (Turner \& Da Silva 1992, Heckman 1998, Bonecker et al. 1998 a, Koste 1986, 1999). En la planicie de inundación del Paraguay próxima al área de confluencia con el Paraná, Koste (1996) registró un total de 138 especies en 9 muestras correspondientes a cinco pequeñas lagunas.

En el Pantanal se registraron 202 especies de Rotíferos Monogononta sólo en unas pocas lagunas, próximas a Corumbá y en una estacion del canal principal (Koste 1999).

La diversidad biológica general de este gran delta interno que es el Pantanal es muy elevada, dada su heterogeneidad física, a la vez que en el área confluyen linajes bióticos de varias Provincias biogeográficas (Cerrado, Amazónico, Mata Atlántica y Chaqueño (Adámoli \& Pott 1999), por lo cual es posible que su riqueza en rotíferos sea una de las más altas de las planicies de inundación de Sudamérica. Del total de las especies registradas en el Pantanal, el $50 \%$ estuvo presente en el Paraná.

El número de rotíferos de ambientes de la planicie de inundación del Amazonas, ha sido estimado en unas 300 especies (Junk \& Robertson 1997), aunque probablemente sea mayor. 
Hardy et al. (1984) en una sola laguna isleña con cobertura de macrófitas acuáticas (Lago Camaleao en la Amazonia Central), registraron durante un estudio de dos años un total de 175 especies.

Con respecto al Orinoco para el tramo bajo y el delta, se han identificado 116 taxa de rotíferos (Vásquez 1989). Esta información corresponde al curso principal, no habiendo estimaciones precisas que incluyan los ambientes acuáticos de la planicie.

En relación al Amazonas y al Paraguay, el bajo Paraná parecería tener una menor diversidad de rotíferos, pese a que tiene mayor diversidad que el alto Paraná. Debe señalarse que la diversidad química de las aguas del sistema del Amazonas es más alta que la del río Paraná (Sioli 1984). Muchos de los ambientes amazónicos estudiados presentan aguas ácidas o levemente ácidas que se caracterizan por su riqueza de rotíferos. En el río Nhamundá, cursos menores y lagunas próximas con aguas de $\mathrm{pH}$ entre 4,8 y 6 se encontraron 145 especies (Brandorf et al. 1982). En Roraima, región de Boa Vista, en ambientes con $\mathrm{pH}$ y conductividad menores de 6 y $11 \mu \mathrm{S} / \mathrm{cm}$ respectivamente, Segers \& Sarma (1993) registraron 66 especies y posteriormente Koste (2000) en una sola muestra cualitativa halló 149 taxa.

También debe tenerse en cuenta que, si bien los tres grandes ríos sudamericanos tienen un patrón de estructura y funcionamiento similar, sus particularidades hidrológicas pueden incidir en su biodiversidad. Por ejemplo, los tres presentan un régimen monomodal, pero la amplitud de las inundaciones, como así también la regularidad de los ciclos hidrológicos es mucho mayor en el Amazonas y Orinoco (Junk 1997, Lewis et al. 1995). La amplitud de la inundación está en relación directa con el área y fuerza de anegamiento de la planicie.

Shiel et al. (1998) reportan para 112 ambientes temporarios de tributarios del río Murray , Australia (ubicados entre $30-35^{\circ}$, por debajo del trópico de Capricornio, como el tramo estudiado del Paraná) 252 especies de rotíferos, un número comparativamente similar al del Paraná, si bien restringidos a un área más pequeña. Una diferencia importante de este río con respecto al Paraná es el mayor número de endemismos registrados en Australia, fenómeno que es común tanto a su fauna como a su flora.

Tanto en el Orinoco como en el Amazonas y en el Paraná los tres géneros de mayor diversidad son Brachionus, Lecane y Trichocerca. Coincidentemente, en el río Murray el mayor número de especies también corresponde a estos géneros (Lecane (30) Trichocerca (25) y Brachionus (23). La dominancia de especies de estos tres géneros para ríos tropicales ha sido especialmente detacada (Segers 1996). En general, la convergencia de estructuras de comunidades naturales es fuertemente dependiente de la presencia de ambientes físicos equivalentes (Morello 1984). En el Níger, Lecane comprende 28,5\% de las especies, Trichocerca $12,6 \%$ y Lepadella $11.6 \%$. Comparativamente, en el Paraná es 
más importante el género Brachionus. En el Niger sobre 207 especies solo 8 corresponden a este género. Probablemente, esto esté ligado al predominio de aguas ácidas o levemente ácidas de este sistema. Salvo B. sericus, presente en el Níger, y no registrado para América, todas las especies del género halladas en el Paraná son comunes a ambos.

El tramo estudiado del Paraná no puede considerarse en sentido estricto como tropical pero el río fluye desde el trópico húmedo a la región templada húmeda. Por ello, su fauna de rotíferos en general tiene muchos elementos tropicales. Según un análisis realizado por Green (1994) las asociaciones de rotíferos características de los trópicos estarian gobernadas por la temperatura y la salinidad. Las asociaciones de rotíferos planctónicos también pueden estar determinadas o afectadas por el tamaño del lago . En estudios de largo plazo, los lagos más grandes presentan mayor número de especies.

La alta salinidad se asocia a una reducción en el número de especies de rotíferos del orden de dos o tres especies, generalmente de los géneros Brachionus y Hexarthra. Su efecto se manifiesta con conductividad > 1000 uScm-1, pero es más marcado con conductividad > 3000 uScm-1 ( Green \& Mengestou 1991, Green 1994). En los ambientes salinos de la cuenca del Paraná, como son los cursos tributarios de la margen derecha, Los Amores y del Ombú, Saladillos y río Salado los géneros más importantes son Brachionus y Hexarthra, a los que debe agregarse también Synchaeta.

\section{Aspectos biogeográficos en la composición de rotíferos del Paraná}

La composición y riqueza específica de cualquier grupo de organismos acuáticos guarda relación con los factores físico-químicos, la disponibilidad de recursos, las relaciones de competencia y depredación y sus mecanismos de dispersión. En la composición de la microfauna de rotíferos del Paraná debe considerarse también la influencia de su ubicación biogeográfica. El sistema se incluye en la región Guayano-brasileña, caracterizada por su alta diversidad faunística. El curso principal del río con su trayectoria norte-sur constituye una excelente ruta de penetración de la fauna tropical hacia el sur (Ringuelet 1961) y, en particular, para los rotíferos por su desplazamiento pasivo.

La fauna de rotíferos que se halló en el Paraná presenta especies de distribución cosmopolita, pantropicales, tropicopolitas y endémicas de la Región Neotropical. Entendiendo por cosmopolitas las presentes tanto en el hemisferio Oriental como Occidental, con climas tropicales y templados, pantropicales a las especies restringuidas a la ancha franja comprendida entre los trópicos de Cáncer y Capricornio y tropicopolitas a las especies 
presentes en latitudes tropicales y subtropicales que ocasionalmente pueden alcanzar hábitats de regiones templadas.

La gran mayoría de las especies registradas son de distribución cosmopolita. Se encontraron también especies pantropicales como Brachionus falcatus, Filinia opoliensis, F.saltator, Keratella procurva, Lecane decipiens, L. elegans, Lepadella latusinus, L. benjamini, Platyias leloupi, y Scaridium bostjani, a pesar de que el tramo de estudio se halla por debajo del trópico de Capricornio,

Asimismo, se registraron especies de distribución disyunta, presentes en Sudamérica y en Europa como Lecane elsa y especies consideradas americanas como Horaella thomassoni, Keratella americana y Brachionus havanaensis, entre otras, aunque estas últimas se hayan registrado actualmente en Asia, donde habrían sido introducidas (Segers 2001).

Los estudios realizados han mostrado que la biota sudamericana en general posee un origen compuesto, distinguiéndose un componente austral, relacionado con otras áreas meridionales y un componente tropical relacionado con las biotas de Africa y América del Norte (Crisci et al. 1999). Entre los rotíferos del Paraná, el componente tropical es el predominante, siendo escasos los elementos australes. El género Notholca puede ser una excepción, pero solo representado por dos especies de amplia distribución. También se encontró en el Paraná Inferior Keratella moronensis, hasta ahora señalada para el Sur de Argentina (Modenutti et al. 1998).

En el Paraná se registraron especies endémicas de la Región Neotropical, presentes en las cuencas del Orinoco y Amazonas, como Brachionus dolabratus, B. mirus, B. insuetus, B. zahniseri, Hexarthra intermedia braziliensis. Lecane amazonica (=L.murrayi), L. braziliensis, L. proiecta ,Testudinella ohlei, y Lepadella donneri, entre otras. Un tercio de las especies endémicas de Lecane están presentes en el Paraná y casi los dos tercios del género Brachionus. El número total de especies endémicas neotropicales no incluye las descriptas en los últimos años y hasta ahora solo halladas en esta región como Mytilina lobata y Lepadella mataca Los hallazgos en el río Paraná representan el registro más austral de la gran mayoría de los endemismos mencionados.

Si bien hay especies endémicas restringidas a un área muy localizada del sur de Argentina que pertenecen a Brachionus y Keratella (José de Paggi 1990), en la cuenca del Paraná parecen ser escasísmos los endemismos de estos géneros. Sólo se ha registrado hasta el momento Brachionus laticaudatus, considerada en este trabajo como una especie del grupo $B$. mirus (ver Apéndice Taxonómico) no registrada anteriormente en otro lugar de la Región Neotropical. 
La gran mayoría de los considerados inicialmente endemismos Amazónicos fueron registrándose paulatinamente en el Paraná a medida que se realizaban más estudios. Es probable que la comunicación entre los tres sistemas fluviales más grandes de Sudamérica no permita la existencia de endemismos por cuencas, al menos para los rotíferos. Sus llanuras están conectadas hidrológicamente, ya que las divisorias de aguas no constituyen barreras permanentes y pueden comunicarse entre sí, aunque sea por horas (Morello 1984). Las conexiones entre cuencas y las conexiones intracuencas activadas por el pulso de inundación serían un excelente medio de dispersión de los rotíferos. Las aves migratorias podrían tener también un rol importante en la dispersión entre las cuencas. Con respecto al viento y la lluvia los estudios realizados por Jenkins \& Underwood (1998) ponen en duda el éxito de éstos como mecanismos de dispersión de rotíferos y crustáceos del plancton.

De todos modos los llamados "endemismos neotropicales" probablemente se hayan originados en la cuenca del Amazonas, cuya fauna y flora es considerada como un resultado de la evolución "in situ" sobre largos períodos. En cambio en áreas como la del Pantanal la existencia de períodos secos durante los períodos glaciares habría afectado la flora y fauna, incidiendo en el bajo número de endemismos. Los organismos actualmente presentes son, en gran medida, el resultado de la inmigración desde otras áreas, ya que allí confluyen varias provincias biogeográficas (Junk \& Da Silva 1995, Adámoli \& Pott 1999).

El Paraná por si solo constituye una vía real y actual de poblamiento hacia el sur de fauna acuática de tipo tropical o subtropical (Ringuelet 1961). Es posible que la similitud de la fauna del Paraná con la de ríos Africanos se establezca indirectamente a partir de la influencia de las otras dos cuencas sudamericanas, Amazonas y Orinoco. La relación entre estas últimas y las cuencas africanas es explicable, además de un origen gondwánico común, por patrones climáticos comunes, ya que se ubican en la amplia franja del trópico húmedo (Garnier 1961 fide Morello 1984), que incluye solo una pequeña parte superior de la cuenca del Plata. Morello (1984) señala que el trópico hiperhúmedo de llanura aluvial presenta fuertes homologías entre las cuencas del Amazonas y Congo.

Una síntesis de los rotíferos de Africa fue hecha por De Ridder (1987 ab) quien hiciera referencia a más de 450 taxa de rotíferos Monogononta. Estudios posteriores (De Ridder 1991, Segers et al.1993, Baribwegure \& Segers 2001) amplían este número que dista de ser el definitivo por cuanto hay regiones inexploradas, al igual que en Sudamérica. La riqueza específica, a nivel de esta región Oriental o Africana es similar a la registrada para la región Neotropical ( Koste \& José de Paggi 1982, José de Paggi \& Koste 1995). 
La cuenca del Congo, considerada muy antigua y climáticamente más estable que otras de Africa (Dumont 1983) presenta una considerable riqueza de rotíferos, referida en los escasos trabajos publicados. Algunos estudios sobre el río Lualuba (De Ridder 1981), tributario del Congo y de otros de la cuenca (Gillard 1959, De Smet 1988,1989) muestran una composición semejante en cuanto a la presencia de los mismos elementos pantropicales y tropicopolitas: Brachionus caudatus, B. falcatus, Keratella procurva, K. tropica, Platyias leloupi, Trichocerca chattoni y varios del género Lecane. Ploesoma africana, considerada como endémica de Africa (De Ridder 1981) también se registró en el Paraná. Asimismo, en la cuenca del Congo y de otros ríos Africanos está presente Notholca acuminata que es una especie de rara distribución en trópicos y subtrópicos (Guillard 1959, De Ridder 1987b), el género Notholca probablemente de origen laurásico está restringido casi en su totalidad a la region holártica (Dumont 1983). En algunos casos, el número de especies es similar al encontrado en el Paraná, por ejemplo De Ridder (1981) encuentra en el Lualuba unas 200 especies.

Hay semejanza entre la composición de Lecane y Trichocerca del río Paraná con otras áreas de Africa, : Mauritania (De Ridder 1987a) Sudan (De Ridder 1984a) Costa de Marfil (De Ridder 1984b), Argelia (De Ridder 1991) Nigeria (Segers et al. 1993), que se encuentran a una latitud mucho baja que el Paraná, por encima del Ecuador. Segers et al. (1993) registraron en el río Niger 59 especies de Lecane, de las cuales 31 se encontraron en el Paraná. Considerando el género Trichocerca, registraron 27 especies, de las cuales 15 estuvieron presentes también en el Paraná.

En cuanto al género Lecane, Segers (1996) señala alguna similitud entre la fauna del género de la región Neotropical con la Neártica, que podría resultar del intercambio entre continentes. En ese grupo se incluyen Lecane elsa y L. cornuta, bastante frecuentes en el Paraná.

De los tres géneros mejor representados en el Paraná, Brachionus es de origen gondwánico, con un genocentro probable en la región Neotropical (Dumont 1983). Lecane, con un genocentro tropical, presenta un gran porcentaje de especies tropicopolitas (casi el $50 \%$ de las descriptas) y, comparando con géneros limnéticos, exhibe una amplia variedad de modelos de distribución, con fuertes endemismos en la región Neotropical (Segers 1996). En cuanto al género Trichocerca, más del $50 \%$ de sus especies son de amplia distribución. Los endemismos están restringidos a la Región Holártica, no se los conoce para la Región Neotropical. Trichocerca braziliensis, considerada como tal por muchos años fue hallada también en Borneo (Koste 1988). Probablemente, el origen de este género sea Laurásico (Segers 2003). Además de estas consideraciones debe tenerse presente que tanto Lecane como Trichocerca, como se ha señalado en otras secciones, son géneros fuertemente litorales, 
estando su presencia en el río Paraná ligada a la existencia de áreas someras con vegetación en las lagunas de la planicie.

\section{CONCLUSIONES}

Conforme las hipótesis planteadas en el comienzo de este trabajo de tesis puede concluirse lo siguiente:

1.- La composición de rotíferos permite caracterizar solo parcialmente a los distintos ambientes acuáticos del sistema. Los ambientes lóticos, curso principal y secundarios, se caracterizaron por la presencia casi permanente de Keratella americana, K. cochlearis y $K$. tropica, que forman parte de las distintas asociaciones de rotíferos que se producen temporalmente. En la sección del canal principal frente a la ciudad de Paraná (km 603) una asociación típica registrada durante más de 6 años de muestreo fue la conformada por esas especies, más Trichocerca rattus y Lecane proiecta. En los cursos tributarios las asociaciones incluyen principalmente diversas especies de Brachionus. En las lagunas no se detectaron asociaciones de especies que presentaran una frecuencia similar a la observada en el curso principal. La composición específica de las asociaciones es muy variable tanto entre lagunas como dentro de un mismo ambiente a lo largo del año. Una diferencia en la composición que puede señalarse, respecto de los ambientes lóticos, es la participación en ellas de un mayor número de especies no planctónicas.

Considerando los dos grandes grupos de ambientes acuáticos del sistema, los lóticos y los leníticos, la caracterización más importante es la que se registra a nivel de la riqueza de especies (Tabla 3.2). Los ambientes lóticos se distinguen por una diversidad comparativamente más baja que la de los leníticos, para los primeros se registró un total de 145 especies y para los segundos 226 especies.

2.- Existe una relación entre la heterogeneidad ambiental y la riqueza de los rotíferos. La complejidad ambiental de los cuerpos de agua del sistema fluvial estudiado depende fundamentalmente de dos factores, la morfología y la presencia y abundancia de vegetación acuática. Mientras los ambientes lóticos tienen una forma básica similar de dos costas paralelas extendiéndose en un mismo sentido, los ambientes leníticos tienen una morfología muy diversa llegando a desarrollar altos grados de compartimentación espacial. A diferencia de los cuerpos de agua leníticos, la presencia de un flujo de agua unidireccional permanente y una turbiedad generalmente alta, asociada a la turbulencia generada por este flujo, hace que los cuerpos de agua lóticos sean ambientes poco propicios para el desarrollo de la vegetación acuática y palustre. 
La relación entre la heterogeneidad ambiental y la estructura de la taxocenosis de rotíferos se manifiesta especialmente en la diversidad alfa. Los menores valores se registran en los ambientes lóticos estructuralmente más homogéneos y los mayores en las lagunas. En éstas, el número de géneros se incrementa por la incorporación de aquellos litorales y/o bentónicos, tales como Dicranophorus, Dicranophoroides, Eosphora, Notommata, Scaridium entre otros y aumenta el número de especies de Lecane, Lepadella y Trichocerca. En algunas lagunas, el número de especies del área pelágica puede ser similar al del área litoral. Sin embargo, la afinidad faunística entre ambas es baja, menor del $45 \%$.

La heterogeneidad espacial de estos ambientes, junto con la transparencia del agua, resultan ser los principales factores asociados a la mayor riqueza de especies en las lagunas, no así otros factores como el área de las mismas.

3.- Si consideramos una transecta E-O, desde el curso principal del río Paraná a las lagunas del valle de inundación pasando por cauces secundarios y tributarios, se observa un gradiente de aumento progresivo en el número de especies de rotíferos. Este gradiente se relaciona con el incremento que se registra desde el canal principal a la llanura, del tiempo de residencia del agua, transparencia y heterogeneidad espacial y la disminución de la velocidad de la corriente. El gradiente de diversidad de especies asociado al de la complejidad ambiental es más definido en aguas bajas como lo muestran los mayores valores de diversidad â. En estas condiciones hidrométricas los distintos ambientes presentan características físicas más definidas al no encontrarse conectados entre sí por el pulso de inundación.

4.-Las familias Brachionidade, Lecanidae y Trichocercidae son las de mayor riqueza en el sistema del río Paraná. Ello se relaciona a su condición de "colector" de los tramos superiores y de ambientes leníticos de la planicie, su diversidad de hábitats, su diversidad temporal dada por el pulso de inundación y su ubicación biogeográfica. En el caso de los Brachionidae, en particular Brachionus, a la preponderancia de ambientes con $\mathrm{pH}$ neutro o levemente alcalino.

Si bien este trabajo puede constituir una base de información para otros faunísticos y ecológicos no debe perderse de vista que la diversidad potencial de especies de Rotíferos Monogonta del Paraná en su tramo argentino, debería ser aún más elevada, dada la enorme riqueza de ambientes acuáticos. 
No solo es necesario intensificar los muestreos a nivel de una localidad determinada, como se vio en los análisis de estimadores de riqueza (Material y Métodos) sino que debe disponerse de más datos del tramo que corresponde al delta o Parana inferior. Este último constituye una región de elevada heterogeneidad espacial y temporal con gran diversidad de ambientes (Bó \& Quintana 1999), por lo que el inventario de rotíferos podría enriquecerse.

Por otro lado, es imperioso profundizar el estudio de las áreas litorales de las lagunas, incluyendo metodologías de muestreo y de análisis que permitan conocer las especies fijas a sustratos. Durante mucho tiempo los estudios ecológicos y muchas veces faunísticos, fuertemente influenciadas por la metodología europea, generada a partir del estudio de grandes lagos, se basaron en muestras de plancton del centro de estos ambientes. Una muestra central puede ser poco representativa de la diversidad de ese momento en todo el cuerpo de agua, tal como se vio en los casos analizados en este trabajo. 


\section{ANÁLISIS TAXONOMICO}

BRACHIONIDAE Ehenberg, 1838

Esta familia reúne los siguientes Géneros y números de especies (Segers 2002):

Anuraeopsis Lauterborn 1900 (5 spp.)

Brachionus Pallas 1766 (55 spp.)

Kellicottia Ahlstrom 1938 (2 spp.)

Keratella Bory de St. Vincent 1822 (45 spp.)

Notholca Gosse 1886 (40 spp.)

Plationus Segers, Murugan \& Dumont 1993 (3 spp.)

Platyias Harring 1913 (3 spp.)

Como se señala, Brachionidae reúne 7 géneros con más de cien especies, en su mayoría planctónicas. Brachionus exhibe la mayor riqueza. En la cuenca del Paraná la familia está principalmente representada por este último género que predomina en los ambientes tropicales y subtropicales (Green 1994) siendo su número de especies comparativamente elevado. Es muy frecuente en todos los ecosistemas lénticos de la llanura de inundación y en los ríos. Le siguen en orden de importancia los géneros Keratella ,Plationus, Platyias y Anuraeopsis.

Notholca es muy escaso en los trópicos y subtrópicos (Green 1994), registrándose únicamente Notholca acuminata (Ehremberg) y N. squamula (O.F.Müller) en el río Paraná, generalmente en las muestras de otoño-invierno.

Una mención especial merece el género Kellicottia Ahlstrom que al igual que Notholca es frecuente en ambientes templado-fríos de la región holártica. Sin embargo, $K$. bostoniensis (Rousselet) ha sido registrada en Brasil (Lopes et al. 1997) y también en territorio argentino, en los ríos Iguazú y Uruguay (José de Paggi 2002b). En los últimos muestreos realizados en 1999-2000 en el bajo Paraná no ha sido encontrada, sin embargo, no es descartar su presencia en virtud de su área de distribución conocida. $K$. bostoniensis habría sido introducida en Brasil en la década del 90, por lo que constituiría un ejemplo de contaminación por especies (sensu Rapoport 1990). 
El género Brachionus será tratado con particular detalle, por considerarse unos de los más importantes en el río Paraná. A partir de su análisis se proponen algunos cambios en lo que concierne a su status taxonómico.

\section{GENERO BRACHIONUS}

Las especies reunidas en este género poseen un cuerpo oval o cuadrangular recubierto por una lóriga de espesor variable. En él se distinguen dos placas, una ventral y otra dorsal, en ocasiones presentan una tercera placa basal. Poseen un pie móvil, anillado, que puede retraerse totalmente. La lóriga tiene 6, 4 o 2 espinas en el borde anterior dorsal. En cambio el borde ventral es liso y más o menos recto o con ondulaciones. En algunas especies hay espinas posteriores laterales o sobre la abertura del pie. La corona está formada por cinco lóbulos. Generalmente, por debajo de la mitad del cuerpo se encuentran las antenas laterales. El trophi es maleado.

En cuanto a la taxonomía del género, este no es ajeno a los problemas generales considerados en la Introducción no existiendo hasta el presente ninguna revisión mundial actualizada. Las ultimas claves conocidas son las de Koste (1978) y Koste \& Shiel (1987).

Los caracteres diagnósticos considerados de mayor valor en la taxonomía de Brachionus son: número, forma y proporción relativa de las espinas anterodorsales u occipitales, posición y forma de la abertura del pie, presencia de espinas posteriores, propuestos por Ahlstrom (1940) y adoptados por la mayoría de los especialistas.

Sudzuki (1977) considera como carácter de menor valor la longitud y número de espinas occipitales, sin embargo estas son muy constantes en muchas especies, en los últimos estudios realizados en B. plicatilis (Ciros-Perez et al. 2001) se ha observado que la forma, longitud y disposición de estas espinas permiten diferenciar especies, ya efectivamente consideradas separadas entre sí por estudios moleculares y genéticos previos.

Hasta el momento el trophi no ha sido casi usado para la diagnosis ya que presentaría muy pocas diferencias entre las especies, pero es necesario profundizar los análisis para comprobar el alcance real de tal aseveración. Los caracteres morfológicos del trophi son sin embargo muy constantes para el género, permitiendo su separación efectiva de otros dentro de la familia (Segers 1993). 
Este género reúne especies con una gran plasticidad fenótipica, no obstante en la mayoría de los casos no ha sido posible aún determinar el límite preciso entre esas variaciones fenotípicas y los caracteres que definen otra especie diferente. La comprobación de la existencia de sibling especies dentro del género Brachionus por estudios genéticos y moleculares sin duda ha sido el estudio más relevante de los últimos años.

Según Dumont (1983) aproximadamente solo un 50\% de las especies de este género son cosmopolitas, una gran parte está restringida a las áreas subtropicales y tropicales, con endemismos principalmente en América del Sur y Australia. Según dicho autor el género podría ser de origen gondwánico con posterior invasión hacia Eurasia y América del Norte, la primera por dispersión desde Africa e India.

En el Paraná este es uno de los géneros de la familia mejor representados, ello se relacionaría con los requerimientos ecológicos de las especies y con la ubicación biogeográfica de la cuenca.

Los representantes de el género prefieren aguas en general alcalinas, lo que caracteriza bastante frecuentemente a los ambientes de la planicie de inundación. Si bien en veranos secos las lagunas al permanecer aisladas tienden a acidificar levemente sus aguas por los procesos de descomposición de materia orgánica o en algunos otoños de aguas bajas cuando la macrofitia se torna senescente. Algunos registros obtenidos en este estudio permiten ampliar la información sobre tolerancia a la salinidad. Así, por ejemplo $B$. variabilis Hempel se encontró en la cuenca del Paraná, en el río Salado con una conductividad superior a los $800 \mu \mathrm{S} / \mathrm{cm}$, en cambio en el Orinoco se la ha registrado con valores de $40 \mu \mathrm{S} / \mathrm{cm}$ (Vásquez \& Koste 1988). Por otro lado los ambientes lénticos cuando permanecen bastante tiempo sin conexión con el río sufren procesos de enriquecimiento natural y son muchas las especies de Brachionus que viven en condiciones de meso y eutrofia (Sladecek 1983).

Brachionus es muy diverso en la subregión Guayano Brasileña (Koste \& José de Paggi 1982) en la que se ubica la cuenca del río Paraná. Las especies registradas en este trabajo están presentes en otras áreas de la mencionada subregion biogeográfica, principalmente en las cuencas de los ríos Amazonas y Orinoco. A ellas debe sumarse también el registro de especies endémicas de esta región como Brachionus amazonica Koste \& Robertson, B. dolabratus Harring, B. mirus Daday, B. laticaudatus Paggi, y B. insuetus Ahlstrom. Pocas especies presentes en el Amazonas no han sido halladas hasta el momento en el Paraná, tales como B. adisi Koste \& Hardy. Otras especies 
como B. durgae Dhanapathi y B. poscurvatus Kuczynski halladas por Kuczynski (1991) en la Provincia de Buenos Aires, en la misma cuenca del Plata, no se encontraron hasta el presente en el Paraná.

Dentro del elenco de especies de distribución cosmopolita registradas en el río Paraná, algunas son más frecuentes en aguas tropicales y subtropicales, cual es el caso de Brachionus bidentata (Koste \& Shiel 1987).

\section{DESCRIPCION Y OBSERVACIONES SOBRE ALGUNAS ESPECIES}

Abreviaturas usadas:

LT: Longitud de la lóriga

AM: Ancho máximo de la lóriga

LEAL: Longitud espinas anteriores laterales

LEP: Longitud espinas posteriores laterales

LEPV: Longitud espinas posteriores ventrales

Dimensiones en micrómetros

Brachionus amazonica Koste \& Robertson 1983 (Lám. 1 fig.1)

Brachionus benningi (Leissling 1924), Koste \& Robertson 1983

Brachionus urceolaris amazonica, Koste \& Robertson 1983: 231, fig. 1a-i

Cuerpo pequeño con lóriga flexible, algunos ejemplares con una suave ornamentación.

Posee seis espinas dorsales, las laterales y medianas más desarrolladas que las intermedias, márgenes laterales de la lóriga más o menos angulosos. Abertura del pie más profunda en su lado ventral que en el dorsal. Antenas laterales ubicadas en el tercio inferior del cuerpo.

\section{Dimensiones}

LT 120-130, AM 90-114.

\section{Distribución}

Hasta el momento esta especie es considerada endémica de la Región Neotropical, habiendo sido registrada en Brazil, Venezuela, Ecuador y Paraguay (José de Paggi \& Koste 1995). 


\section{Comentarios}

Esta especie fue descripta originalmente como una subespecie de $B$. urceolaris, pero por sus caracteristicas morfológicas, además de su tamaño, constituye un taxon diferente, como también lo señalan Segers et al. (1998) .

Si bien no se han encontrado poblaciones abundantes en el Paraná, su presencia se ha registrado en varias ocasiones (lagunas en isla Noguera en Corrientes y en el sistema de los Saladillos, $\mathrm{pH} 6,4-7$, temperatura $28-30^{\circ} \mathrm{C}$ ). Los individuos hallados presentan una forma general bastante constante y muy similar al material original de Koste \& Robertson (1993) del lago Camaleao (Amazonas), con espinas anterolaterales no tan desarrolladas y divergentes como los ejemplares del lago Macaco (Amazonas) (Koste 1989) y los de Bolivia (Segers et al. 1998).

Brachionus angularis Gosse, 1851 (Lám. 1, fig. 2 a-e)

Brachionus testudo, Ehrenberg 1853: 190, 193

Brachionus minimus, Bartsch 1877: 49, Lám.1:7,8

Brachionus bidens, Lám. 1886:72 Lám. 31:30

Brachionus papuanus, Daday 1897: 142, fig. 9

Brachionus lyratus, Shephard 1911: 57, Lám. 21:5,6

Cuerpo pequeño, con una lóriga a veces muy delgada, apareciendo con deformaciones o contorno irregular por la fijación. Margen anterior dorsal con dos pequeñas espinas medianas. Abertura del pie ventral de forma semicircular u oval

\section{Dimensiones}

LT 80-125, AM 60-105.

\section{Distribución}

Cosmopolita.

\section{Comentarios}

Muy frecuente en el Paraná, particularmente en los ambientes eutróficos, tanto pequeños cauces (Los Amores, El Rey) con alta carga de materia orgánica de origen antrópico, como en lagunas en su período de aislamiento, durante los meses cálidos. Presente en el sistema del Salado, tributario del Paraná, mostrando tolerancia a altos valores de conductividad. Se han registrado poblaciones numerosas (254 ind/litro) en un cauce menor: Arroyo Cululú (marzo de 1996, conductividad $4000 \mu \mathrm{S} / \mathrm{cm}, \mathrm{O} 2:$ 2,01 mg/l, DBO5: 56,03 mg/l), en el río 
Salado (septiembre de 1996, $11.600 \mu \mathrm{S} / \mathrm{cm}$ ). También se observaron poblaciones abundantes con altos valores de DB05: 160 mg/l, en el arroyo Las Prusianas, (marzo de 1996). En el Paraná se registró una importante variedad de formas atribuibles a esta especie, registrándose la mayor variación a nivel del tamaño corporal (ver fig.uras).

\section{Brachionus calyciflorus Pallas 1766 (Lám.1 fig. 3 ab)}

Brachionus pala, Ehrenberg 1838: 511, Lám.43: 1

Brachionus amphiceros, Ehrenberg 1838: 511, Lám. 63:2

Brachionus dorcas , Gosse, 1851: 203

Brachionus decipiens, Plate 1886: Lám. 1886: 73

Lóriga lisa, fina y elástica. Margen anterior dorsal con cuatro espinas, las medianas generalmente de mayor longitud, en algunos morfotipos de igual longitud que las laterales, nunca menor. A veces con espinas laterales desarrolladas (procesos de quimiomorfosis).

\section{Dimensiones}

LT: $180-300$.

\section{Distribución}

Es una especie cosmopolita aunque en general prefiere las aguas cálidas de las regiones tropicales y subtropicales (Kutikova \& Fernando 1995).

\section{Comentarios}

Es una especie polimórfica, el desarrollo de espinas laterales se halla asociado a un proceso de quimiomorfosis por la presencia del depredador Asplanchna en el mismo biotopo. En el río Paraná es más frecuente en las lagunas ya que Asplanchna es poco frecuente en los ambientes fluviales.

Las poblaciones más abundantes de los distintos morfotipos se encontraron en los ambientes lénticos. La forma más frecuente fue B. c. f. typica. Puede señalarse como característica de los especímenes del Paraná la dominancia de formas de talla comparativamente pequeña, no mayor de $300 \mu \mathrm{m}$.

Es considerada como indicadora de condiciones de â-á Mesosaprobias en los ríos, sin embargo cuando a las mismas se le suma salinidad elevada es reemplazada por $B$. plicatilis. Ello podria deberse a que, según los estudios de Miracle \& Serra (1989), la fecundidad de $B$. calyciflorus es afectada por la salinidad. 
Brachionus tetracanthus, Collin 1897: 7 fig. 8

Brachionus forficula var. Apsteini, Fadeev 1925:289 fig. 11

Brachionus typica, Pourriot 1968: 476, fig. 3

Taxa infraespecíficos:

Brachionus caudatus f. vulgatus, Pourriot 1968: 476 fig.. 9:3b-.c

Brachionus caudatus f. vulgatus, Ahlstrom 1940: 156 Lám. 6: 8-10

no Brachionus caudatus f. vulgatus, Ahlstrom 1940: Lám. 6:6

Brachionus caudatus f. provectus, Ahlstrom 1940: 157, Lám. 6:1-2

Cuerpo más largo que ancho con una lóriga delgada y elástica, margen anterior dorsal con dos espinas centrales separadas por un sinus. Margen ventral ondulado. Espinas posteriores largas, levemente curvadas hacia dentro, nacen a partir de un estrechamiento posterior del cuerpo. .Ahlstrom (1940) distingue la forma provectus cuyas espinas posteriores son rectas ubicándose en el mismo eje del cuerpo, siendo tan largas como éste y la forma vulgatus cuyas espinas posteriores tienen una longitud reducida a menos de la mitad que la del cuerpo.

\section{Dimensiones}

LTI 150-180; AM 75-100.

\section{Distribución}

Es una especie frecuente en las regiones tropicales y subtropicales de América del Sur, Africa y Ceylan (Pourriot 1968, Chengalath et al. 1973).

\section{Comentarios}

Es considerada como la especie que presenta las mayores variaciones morfológicas dentro del género, atribuyéndosele una gran plasticidad fenotípica (Ahlstrom 1940). Sin embargo, en su mayoría no se conocen estados morfológicos intermedios que puedan asegurar que dichas formas extremas realmente constituyen una variación de la forma descripta originalmente por Barrois \& Daday (1894). Analizando básicamente el material del río Paraná y teniendo en cuenta las descripciones e ilustraciones de otros autores(Green 1960, Koste 1972, 1978), se considera que se trata de un grupo de especies, no de una especie muy variable morfológicamente. En tal sentido, en este trabajo se propone un status específico para algunas de las consideradas formas (B.caudatus f. personatus, B. c. f. austrogenitus y B. c. f. insuetus). 
Hay pocas ilustraciones originales de B.caudatus f. typica, (Green 1960, Pourriot 1968) incluso falta en el trabajo de Ahlstrom (1940).

$B$. caudatus f. typica es muy poco frecuente en los ambientes lénticos y lóticos del Paraná. Comparativamente, es más importante B. c. f. vulgatus, también señalada como la más frecuente en Estados Unidos (Ahlstrom 1940). Esta forma se ha registrado en ambientes con distinta calidad de agua, cauces secundarios pequeños como el Río Correntoso, en pocas oportunidades en el curso principal, $\mathrm{Km} \mathrm{603,} \mathrm{con} \mathrm{conductividad} \mathrm{de} \mathrm{40-60} \mu \mathrm{S} / \mathrm{cm}$ y en efluentes del Paraná como el río Salado, con valores de conductividad de 2.000 a 7.000 $\mu \mathrm{S} / \mathrm{cm}$, también en cauces de este mismo sistema en los que a la salinidad debe agregarse altas concentraciones de materia orgánica ( $A^{\circ}$ Cululú, DBO 56,03 mg O/l, 21/03/96). En estos últimos se ha registrado $B$. caudatus $f$. vulgatus coexistiendo con B.plicatilis. También se ha registrado $B$. c. f. vulgatus coexistiendo con $B$. austrogenitus (río Salado, 7/12/93). Las distintas poblaciones registradas en los ambientes mencionados no presentaron una variación de tamaño corporal importante, aunque sí una pequeña variación en la longitud de la espina posterior.

B. caudatus f. provectus fue observada con menor frecuencia, en los ríos Santa Fe y Coronda (con valores de conductividad entre 60 y $90 \mu \mathrm{S} / \mathrm{cm}$ ).

No es posible determinar cuan frecuente es realmente B. caudatus f. typica en los ríos sudamericanos. Ha sido citada para el Orinoco Saunder \& Lewis 1988, Vásquez \& Rey 1989), Paraná Superior Sendacz 1993, Bonecker et al., 1998 a,b, Perez Garcia et al., 1998) y lagunas isleñas del área de confluencia Paraná-Paraguay (Frutos 1993) pero los registros no han sido acompañados de ilustraciones. En el sistema del río Murray (Australia) es considerada como poco frecuente (Koste \& Shiel 1987) en cambio en el río Sokoto (Africa) es considerada el rotífero dominante por su abundancia y frecuencia (Green 1960). Los ejemplares encontrados en este último río corresponden a la forma típica y a la forma vulgatus, con variación de tamaño corporal y longitud de espinas posteriores.

Brachionus ahlstromi Lindeman 1939 (Lám.2, fig. 1 a-c)

Brachionus havanaensis var. ahlstromi, Lindeman 1939: 213, Lám.1: fig. 9

Brachionus caudatus var. personatus, Ahlstrom 1940: 158, Lám. 7: figs 1,2, 5-7

Brachionus ahlstromi, Gillard 1948: 164

Brachionus caudatus f. personatus, Koste 1978: 95, Lám. 14: 3 a-d, 13: 23 ae, 24

Cuerpo más largo que ancho, con una lóriga lisa o con suaves grabaduras. Margen anterior dorsal con 6 espinas, de las cuales las laterales son las más desarrolladas y generalmente 
divergentes, las espinas medianas e intermedias pueden presentarse muy reducidas en su longitud. El cuerpo se angosta posteriormente y presenta dos espinas bien desarrolladas, a veces curvadas hacia adentro, en otros ejemplares en forma recta.

Se ha observado una importante variación en cuanto al tamaño corporal.

\section{Dimensiones}

LT 115-320, AM 65-115.

\section{Distribución}

Registrada en América del Sur, América Central y América del Norte, probablemente pantropical, en Australia ha sido encontrada en aguas ácidas Koste \& Shiel 1987). Muy frecuente en la cuenca del Paraná, tanto en ríos como lagunas.

\section{Comentarios}

A partir del trabajo de Ahlstrom (1940) fue considerada como una forma de B. caudatus. Sólo Gillard (1948) la determina como una buena especie por la ausencia de formas intermedias. Sin embargo, este criterio no fue adoptado por la mayoría de los autores. Koste (1972) la registra como una especie pero luego en una clave general la trata nuevamente como forma (Koste 1978). En esta tesis se adhiere al criterio de Gillard.

$B$. ah/stromi se diferencia de B. caudatus por la presencia de 6 espinas anteroposteriores siendo siempre las laterales las más desarrolladas. La longitud relativa de las espinas anteriores puede ser un carácter importante, de hecho como lo señalara Ahlstrom (1940) para otras especies como B.calyciflorus y $B$. quadridentata.

B.ahlstromi es la especie de Brachionus más frecuente en el tramo medio del Bajo Paraná. Las diferencias de tamaño corporal en el género se han observado principalmente entre poblaciones de hábitats separados geográficamente (Ahlstrom 1940) aunque en nuestro caso tambien se observó variación dentro de un misma ambiente, donde tuvo carácter estacional. En la laguna El Tigre, la especie fue registrada en los muestreos semanales de enero de 1988 cuando se hallaron poblaciones con individuos comparativamente muy pequeños, lóriga delgada y deformable, con espinas anteroposteriores intermedias y medianas en algunos ejemplares casi atrofiadas y con espinas posteriores de longitud variable; las hembras portaban huevos de tamaño proporcionalmente muy grande. A partir de allí se registraron en los sucesivos muestreos ejemplares de mayor tamaño, con espinas posteriores, anteriores intermedias y medianas comparativamente más largas. Las formas de mayor talla se encontraron en una laguna cercana, madrejón El Alemán (24/02/69) constituyendo poblaciones pequeñas (< de 5 ind/litro). 
Hauer (1965) en su hallazgo de esta especie en el Amazonas observa variaciones en el tamaño corporal y longitud de las espinas posteriores muy similares a las referidas en el Paraná.

\section{Brachionus austrogenitus Ahlstrom 1940 (Lám 2, figs 2ab)}

Brachionus caudatus f austrogenitus, Ahlstrom 1940: 158, Lám. 7:3-4

Brachionus caudatus f. austrogenitus, Hauer 1953: fig. a, d, e

Brachionus caudatus f. austrogenitus, Hauer 1956: 290, figs 2 a,b, 3 ab,c

Cuerpo alargado que se angosta anterior y posteriormente, margen anterior con seis espinas, las laterales y las intermedias siempre de menor longitud que las medianas, las intermedias pueden estar casi obliteradas. Borde ventral con un sinus central. Espinas laterales de longitud variable, bien desarrolladas o muy cortas. En ejemplares con espinas laterales largas estas tienden a estar levemente curvadas hacia adentro, convergentes.

\section{Dimensiones}

\section{LT 115-210, AM 90-110.}

\section{Distribución}

Probablemente cosmotropical. En América del Sur ha sido registrada en ríos de la cuenca del Amazonas (Robertson \& Hardy 1984).

\section{Comentarios}

Ahlstrom (1940) la describió como una forma de B. caudatus, con espinas posteriores siempre desarrolladas. En este trabajo se la considera como una especie separada que integra, junto con B. ah/stromi, el grupo B. caudatus. Se caracteriza por las longitudes relativas de las espinas anteriores, allí las laterales e intermedias son siempre menores que las medianas. Un análisis biométrico muestra las relaciones diferentes en cada una de ellas en lo que hace a longitud corporal y ancho anterior y éste y ancho máximo (fig. I).

En el Paraná hay dos formas frecuentes una con las espinas posteriores bien desarrolladas (semejantes a los ejemplares de Ahlstrom) y tamaño general más grande y otra más pequeña con espinas posteriores de diferente longitud, en algunos casos muy cortas y levemente asimétricas (Lám.2, fig..2 a y 2 b ). En el Salado Inferior, poco antes de su desembocadura en el río Santa Fe (27/09/93), se encontró una población numerosa con individuos de esta última forma en que también las espinas anteriores estuvieron muy reducidas. Las poblaciones de los individuos con espinas posteriores largas se registraron principalmente en lagunas y en general constituyeron poblaciones más pequeñas $(<20$ ipl). 
Fig. 1. Relaciones biométricas entre B. austrogenitus ( ) yB. ahlstromi ( ). 1a- Relación ancho máximo (AM) - ancho anterior (AA) del cuerpo. 1b- Relación longitud del cuerpo (LC)(sin espinas caudales)-ancho anterior del cuerpo. 1c- Relación longitud del cuerpo (sin espinas caudales)-ancho máximo el cuerpo.

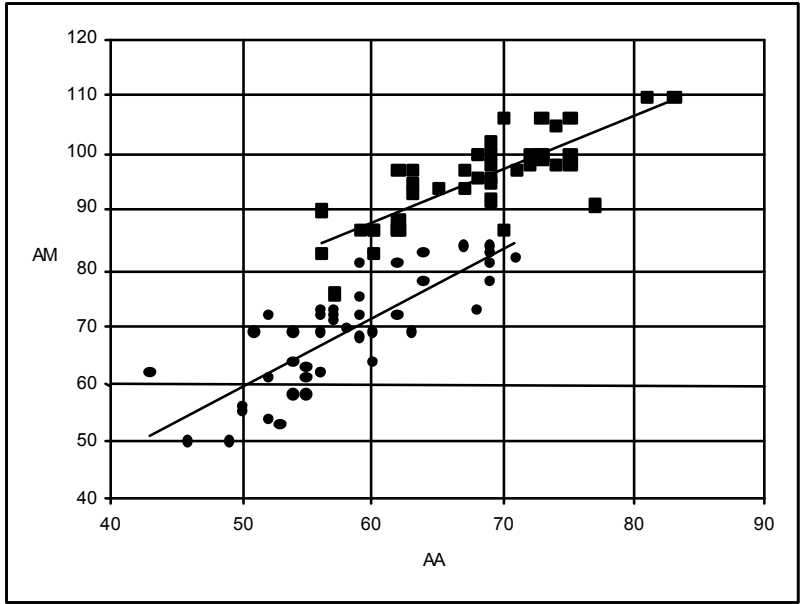

$1 \mathrm{a}$

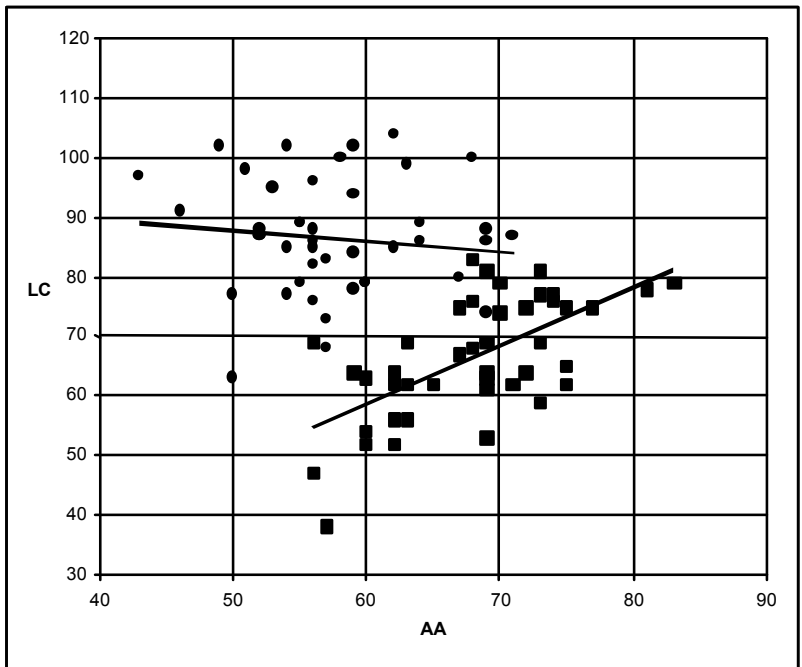

$1 b$

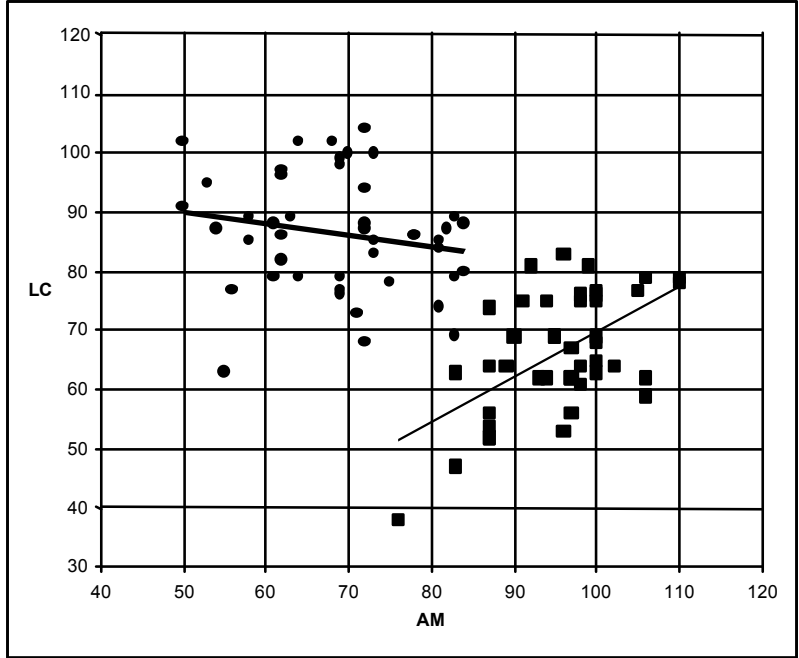




\begin{tabular}{|l|c|c|c|c|c|c|}
\hline Especie & Eje X & Eje Y & $\mathrm{r}$ & $\mathrm{p}$ & $\mathrm{a}$ & $\mathrm{b}$ \\
\hline $\begin{array}{l}\text { B. } \\
\text { austrogenitus }\end{array}$ & AA & AM & 0,7869 & $<0,0001$ & 33,5540 & 0,9135 \\
\hline B. alhstromi & AA & AM & 0,7983 & $<0,0001$ & $-0,4860$ & 1,1997 \\
\hline $\begin{array}{l}\text { B. } \\
\text { austrogenitus }\end{array}$ & AA & LC & 0,6294 & $<0,0001$ & $-0,5878$ & 0,9861 \\
\hline B. alhstromi & AA & LC & $-0,1140$ & 0,4557 & 96,3830 & $-0,1737$ \\
\hline $\begin{array}{l}\text { B. } \\
\text { austrogenitus }\end{array}$ & AM & LC & 0,5592 & $<0,0001$ & $-6,6732$ & 0,7644 \\
\hline B. alhstromi & AM & LC & $-0,1913$ & 0,2082 & 99,6930 & $-0,19,39$ \\
\hline
\end{tabular}

Tabla 1 : Valores de correlación de Pearson $(\mathrm{r}$ ), niveles de significación ( $\mathrm{p}$ ) y constantes de las ecuaciones de las rectas de regresión (a: ordenada al origen y b: pendiente) correspondientes a los diagramas de dispersión de la fig. 1 abc.

Hauer (1953) encontró en el nordeste de Brasil, la forma con espinas posteriores más desarrollada (fig.. a) y dos formas pequeñas (fig.. d y e) que son similares a las halladas dentro de una misma población del río Salado y que él las registra en localidades diferentes. Esas mismas formas fueron halladas también en muestras de Venezuela (Hauer 1956).

Brachionus insuetus Ahlstrom 1940 (Lám. 2, figs 3ab)

Brachionus caudatus f. insuetus, Ahlstrom 1940:158, PI 7:3-4

Brachionus insuetus (Ahlstrom), Gillard 1948: 164

Brachionus caudatus f. insuetus Ahlstrom, Koste 1978:95, Lám. 13:10

Lóriga con la superficie elevada y surcada por líneas más o menos marcadas que conforman un diseño variable. En el margen anterior dorsal presenta seis espinas cortas , de base ancha, a veces de extremos redondeados. El margen se eleva hacia el centro, donde se forma un sinus que separa a las dos espinas medianas que son las más desarrolladas. El margen ventral presenta un sinus mediano. Posee dos espinas posteriores robustas, divergentes y cortas, de una longitud que no supera la mitad del cuerpo. En vista lateral estas espinas se proyectan ventralmente, a diferencia de otras especies y formas del grupo $B$. caudatus. 


\section{Dimensiones}

LT 110-180, AM 90-120, LEP10-40.

\section{Distribución}

Fue registrado para la Amazonia peruana (Samanez 1988), brasilera (Koste 1972) y en El Pantanal (Turner \& Da Silva, 1992, Koste 1999). Sería endémica del Neotropis.

\section{Comentarios}

Esta especie difiere de $B$. caudatus por la presencia de las 6 espinas anteriores dorsales. Se distingue de B.ahlstromi con quien comparte el carácter de 6 espinas dorsales, por poseer siempre más desarrolladas las espinas medianas y siempre cortas las espinas laterales e intermedias. Por otro lado, las espinas anteriores a diferencia de B. ahlstromi y $B$. austrogenitus, se ubican en planos inclinados hacia el centro del cuerpo.

Gillard (1948) la considera como buena especie. Si bien no efectúa un análisis detallado, señala que es enteramente diferente en aspecto a $B$. caudatus y que fue encontrada por Ahlstrom (1940) en la provincia de Buenos Aires coexistiendo con $B$. caudatus f. provectus, no habiendo formas intermedias. Esta consideración no fue tenida luego en cuenta por sucesivos autores en la preparación de claves del género Koste 1978) quienes siguieron considerándola como formas. También fue registrada con este status taxonómico en varias listas (Koste \& José de Paggi, 1982, José de Paggi, 1990).

En esta tesis se adhiere al criterio de Gillard (1948) considerándola como una buena especie. Según se ha visto en el material examinado del río Paraná, la forma general del cuerpo y presencia de espinas anteriores son características constantes. La longitud de las espinas anteriores y posteriores puede ser variable, pueden presentarse más o menos reducidas, pero siempre están presentes.

En el río Paraná es, comparativamente, poco frecuente y de escasa abundancia relativa. En las lagunas se la ha registrado coexistiendo con B.ahlstromi de la que se diferencia claramente por el carácter de las espinas anteriores medianas más desarrolladas que es muy constante. Tampoco se observaron variaciones marcadas en la longitud de las espinas posteriores, que son similares a las observadas en ejemplares del Amazonas, registrados por Koste (1972) o de la provincia de Buenos Aires, estudiados por Ahlstrom (1940). La especie toleraría condiciones de elevada salinidad ya que ha sido encontrada en el río Salado coexistiendo con B.plicatilis y B. caudatus $f$. vulgatus, con valores de conductividad superiores a $800 \mu \mathrm{S} / \mathrm{cm}$. 
Brachionus mirabilis, Daday 1901: 24 fig. 7

Brachionus mirabilis, Daday 1905: Lám. :9,10

Brachionus mirabilis , Ahlstrom 1940: 167 Lám. 11:5-8

Brachionus mirabilis, Koste 1974: 51 Lám. 2: 1 a-e

Brachionus quadridentatus mirabilis, Koste \& Shiel 1987: 980 figs 12, 16:3

Cuerpo alargado, con una lóriga generalmente granulada. Margen anterior dorsal con 6 espinas, las medianas más desarrolladas y curvadas hacia fuera. Margen ventral con un sinus central. Espinas laterales posteriores. La placa ventral se angosta posteriormente y se continúa en dos espinas de igual longitud que, en vista lateral, se proyectan formando un ángulo de $45^{\circ}$ respecto del cuerpo. La abertura del pie se ubica en la base de estas dos espinas posteroventrales, cubierta por una vaina que presenta en su borde dos pequeñas espinas.

\section{Dimensiones}

LT 300-350, AM 155-165, LEP 130-150, LEPV 80-100.

\section{Distribución}

Probablemente trópica y subtropicopolita.

\section{Comentarios}

Esta especie fue considerada como tal por algunos autores (Ruttner-Kolisko 1974, Koste 1974) y como subespecie o forma de B.quadridentatus por otros, si bien sin efectuar discusión alguna sobre el cambio de status (Koste \& Shiel, 1987, Segers et al. 1993, Segers \& De Meester 1994). Los dibujos originales son pocos y eso impide conocer una posible variabilidad.

Considerando el material registrado en el Paraná se concuerda con Ahlstrom (1940) de que se trata de una especie válida. Los caracteres diagnósticos que la separan de $B$. quadridentatus son las largas espinas posteroventrales que nacen de la base de la abertura del pie. Estas espinas están acompañadas por espinas posteriores laterales también largas. Ambas son bastante simétricas. En B. quadridentatus a pesar de todas las variaciones que muestran las espinas posteroventrales no se encuentran en ningún caso desarrolladas como en $B$. quadridentatus. 
En B. quadridentatus en las formas con espinas posterolaterales largas la lóriga presenta una forma marcadamente cuadrangular con un notorio ensanchamiento lateral del cuerpo acompañada de espinas anteriores intermedias muy cortas y las centrales y laterales bien desarrolladas. En cambio B. mirabilis presenta una lóriga más alargada y las espinas anterodorsales intermedias son proprorcionalmente más largas. En su conjunto, la forma de la lóriga y la proporción relativa de las espinas anterodorsales config.uran un patrón particular en $B$. mirabilis

Una forma relativamente intermedia la presenta el ejemplar de Nueva Guinea dibujado por Koste \& Shiel (1987), con un cuerpo más ancho y espinas anterodorsales laterales e intermedias pequeñas, aunque no hay referencia a la variabilidad dentro de esa población.

La variabilidad de $B$. mirabilis que puede observarse hasta ahora considerando los registros de Ahlstrom (1940), de Koste (1974) para una población de Amazonas y la presentada en el Paraná, es limitada y no involucra cambios importantes en el patrón morfológico. Mientras no se registre una variabilidad intrapoblacional importante en la longitud de las espinas posterolaterales y posteroventrales que se inserten en un rango de continuidad de variación en $B$. quadridentatus, no es posible cambiar el estatus específico dado originalmente por Daday (1897) y refrendado en la redescripción de Ahlstrom (1940).

Brachionus mirus Daday 1905 (Lám.3, fig.2)

Brachionus mirus f. typica, Paggi 1973: fig. 16-17

Brachionus mirus, Koste 1978: 83

Cuerpo más largo que ancho, con 4 espinas anteriores, las laterales rectas o divergentes bien desarrolladas y las espinas medianas muy pequeñas. Borde anteroventral formando un sinus central. El cuerpo se angosta posteriormente continuándose con dos espinas largas divergentes o rectas. La abertura del pie, de posición ventral, se halla franqueada por dos proyecciones laterales, claviformes, de longitud variable.

\section{Dimensiones}

LT 180-210, AM 68-75, LEAL 35-48.

\section{Distribución}

Hasta el presente solo conocida de América del Sur. 


\section{Comentarios}

Esta especie fue descripta originalmente por Daday (1905) sobre material del Paraguay y casi simultáneamente fue posteriormente hallada en el Amazonas (Koste 1972) y en el río Paraná (Paggi 1973). Este último realizó un análisis de las variaciones de esta especie. En base a estos estudios, la revisión del material original y nuevo material proveniente de muestreos posteriores de las mismas localidades, se propone un status específico para las formas laticaudatus y voigti .

B. mirus var reductus (Koste 1972) hallada hasta ahora sólo en el Amazonas y en El Pantanal (Koste 1999), probablemente represente una especie diferente, con un cuerpo notablemente ensanchado posteriormente, con espinas de base muy ancha $y$ convergentes.

B. mirus fue registrada en lagunas próximas a Santa $\mathrm{Fe}$, en la isla Carabajal, laguna El alemán y madrejón Don Felipe, no habiéndose observado con frecuencia en otros ambientes del Bajo Paraná.

Brachionus laticaudatus Paggi 1973 (Lám.3, fig.3)

Brachionus mirus f. laticaudatus, Paggi 1973:329, fig. 22-24

Brachionus mirus f. laticaudatus, Koste 1978: 85, Lam. 33a, fig. 4 a-c

Brachionus mirus laticaudatus, Koste 1999: Lám. 3 fig. d

Cuerpo angosto con cuatro espinas anterodorsales cortas, de igual longitud. Las laterales presentan una pequeña espina dorsal. Posee dos espinas posteriores de igual longitud, convergentes. La abertura del pie ubicada ventralmente, posee a ambos lados dos proyecciones claviformes bien visibles y también convergentes.

\section{Dimensiones}

LT 180-215, AM 85-90.

\section{Distribución}

Hasta el momento sólo registrada en el río Paraná y en El Pantanal (Koste 1999).

\section{Comentarios}

Esta especie, si bien cercana a B. mirus, difiere de ésta por la presencia de cuatro espinas anteriores bien desarrolladas, por su vista lateral y por las espinas posteriores convergentes en distinto grado hasta ejemplares con las extremidades de las espinas enfrentadas. Estos caracteres son constantes en las poblaciones analizadas. No se observaron formas 
intermedias en el material estudiado ni tampoco en el observado anteriormente ( Paggi 1973: fig. 22-24).

$B$. laticaudatus no es frecuente ; solo se registró en lagunas próximas a la ciudad de Santa Fe, ubicadas en las islas Carabajal y Sirgadero.

\section{Brachionus voigti Hauer 1961(Lám. 3, figs 4ab)}

Brachionus voigti, Hauer 1965: 348-349 Lám. 8 a-b

Brachionus mirus var. voigti, Koste 1978: 85 Lám. 14 a-b, 33 a-3

Brachionus mirus f. angustus, Koste 1986:

Brachinus mirus mirus, Koste, 1999: 188 Lám. 3 a,c

Cuerpo alargado, más bien estrecho, cuatro espinas anterodorsales, las medianas muy pequeñas y las laterales bien desarrolladas, convergentes, a veces fuertemente curvadas. En vista lateral se puede ver el extremo distal curvo ventralmente y con una o dos espinitas dorsales. Espinas posteriores rectas o convergentes. Abertura del pie ventral flanqueada por dos proyecciones bien visibles, como en $B$. mirus y $B$. laticaudatus.

\section{Dimensiones}

LT 210-240, AM 88-90.

\section{Distribución}

Sería endémica de América del Sur.

\section{Comentarios}

Esta especie ha sido considerada en general como una forma de B. mirus. Sin embargo, presenta características constantes que permiten separarla como especie. A diferencia de $B$. mirus, las espinas laterales son convergentes, con su extremo siempre curvado ventralmente y con una o dos pequeñas espinas dorsales. Shaden (1977) analizando el polimorfismo de Brachionidae en una laguna de inundación del Amazonas solo encontró variación en la reducción relativa de la espina caudal derecha de esta especie. En el Paraná se la registró en lagunas próximas a Santa Fe, El Alemán y madrejón Don Felipe. 
Brachionus muelleri, Ehrenberg 1834

Brachionus hepatotomus, Gosse 1851

Brachionus plicatilis asplanchnoides, Charin 1947

Brachionus plicatilis longironis, Fadeev 1925

Cuerpo recubierto por una lóriga fina y elástica, lo que determina que algunos ejemplares sufran deformación por la fijación. Cuerpo alargado, angosto. Espinas anterolaterales de igual tamaño, con ángulo generalmente obtuso, de base muy ancha, las intermedias tienen un borde externo sigmoideo. Se han registrado dos formas que difieren en el tamaño corporal, una menor, con espinas anteriores más cortas y anchas en su base presente en la laguna Palo pelado $(1.100 \mu \mathrm{S} / \mathrm{cm}, 1 / 02 / 00)$ y otra de mayor tamaño, espinas anteriores más largas presente en el arroyo Calchaquí con muy elevada conductividad (10.700 $\mu \mathrm{S} / \mathrm{cm}$, DBO 122 mg.O/l, 19/13/96).

\section{Dimensiones}

LT 210-285, AM 145-190.

\section{Distribución}

Cosmopolita.

\section{Comentarios}

El grupo plicatilis es sin duda dentro del género y probablemente entre los rotíferos en su totalidad, el que más ha sido estudiado. En un principio, los estudios se encaminaron a conocer mejor la biología y ecología de una especie generalista de distribución cosmopolita que resulta de gran utilidad en acuicultura de peces marinos. Estudios posteriores aportaron información sobre la fase sexual del ciclo de vida de los rotíferos Monogononta (Aparici et al. 1996, Serra \& King 1999) y fue empleada en estudios de ecotoxicología ( Snell \& Janssen 1995). En los últimos años las investigaciones se enfocaron a demostrar su identidad de sibling specie. Estudios genéticos y moleculares demostraron fehacientemente que en realidad la inicialmente denominada $B$. plicatilis es un complejo de especies con al menos tres morfológicamente reconocibles ( Ciros-Perez et al. 2001).

Un morfotipo atribuible a B. plicatilis, también considerado como "L-type" (Oogami 1976 en Segers 1995c) se encuentra en la cuenca del Bajo Paraná en ambientes salinos, principalmente tributarios de la margen derecha. En esos casos ha conformado poblaciones de gran tamaño. Este morfotipo también está presente, esporádicamente y representado por pocos individuos en lagunas de la planicie de inundación del río Paraná. 
En este trabajo se determina esta especie o morfoespecie utilizando los caracteres morfológicos propuestos por Fu et al. (1991) y Cirós Perez et al. (2001) que corresponden al aspecto general del cuerpo y forma y proporción de las espinas anterodorsales. Se desconoce si las dos formas indicadas en la descripción pertenecen a una misma especie, ello requeriría sin duda la realización de estudios a nivel molecular.

Brachionus rotundiformis Tschugunoff 1921 (Lám. 3, fig. 6 )

Brachionus muelleri rotundiformis, Tschugunoff 1921

Cuerpo más bien pequeño, redondeado recubierto por una lóriga delgada. Espinas anterolaterales triangulares terminadas en ángulo agudo, espina mediana en la mayoría de los ejemplares más corta que las otras.

\section{Dimensiones}

LT 120-140, AM 90-110.

\section{Distribución}

Se trataría de una especie cosmopolita.

\section{Comentarios}

Este morfotipo fue considerado como una forma de $B$. plicatilis. Los estudios realizados a nivel morfométrico y molecular determinaron su identidad específica (Fu et al. 1991, CirosPerez et al. 2001) En la cuenca del Paraná se lo registró en el arroyo Las Garzas.

Brachionus sessilis Varga 1951 (Lám. 4, fig.s 1abc)

Brachionus urceolaris sessilis, Koste 1978: 79, Lám. 9: fig.s 6 a-c

Brachionus sessilis, Koste \& Shiel 1987: 987, fig. 19:5

Brachionus sessilis, Chengalath, Fernando \& Koste 1973: 40, fig.s 36-39

Brachionus sessilis, Ruttner-Kolisko 1974: 65 


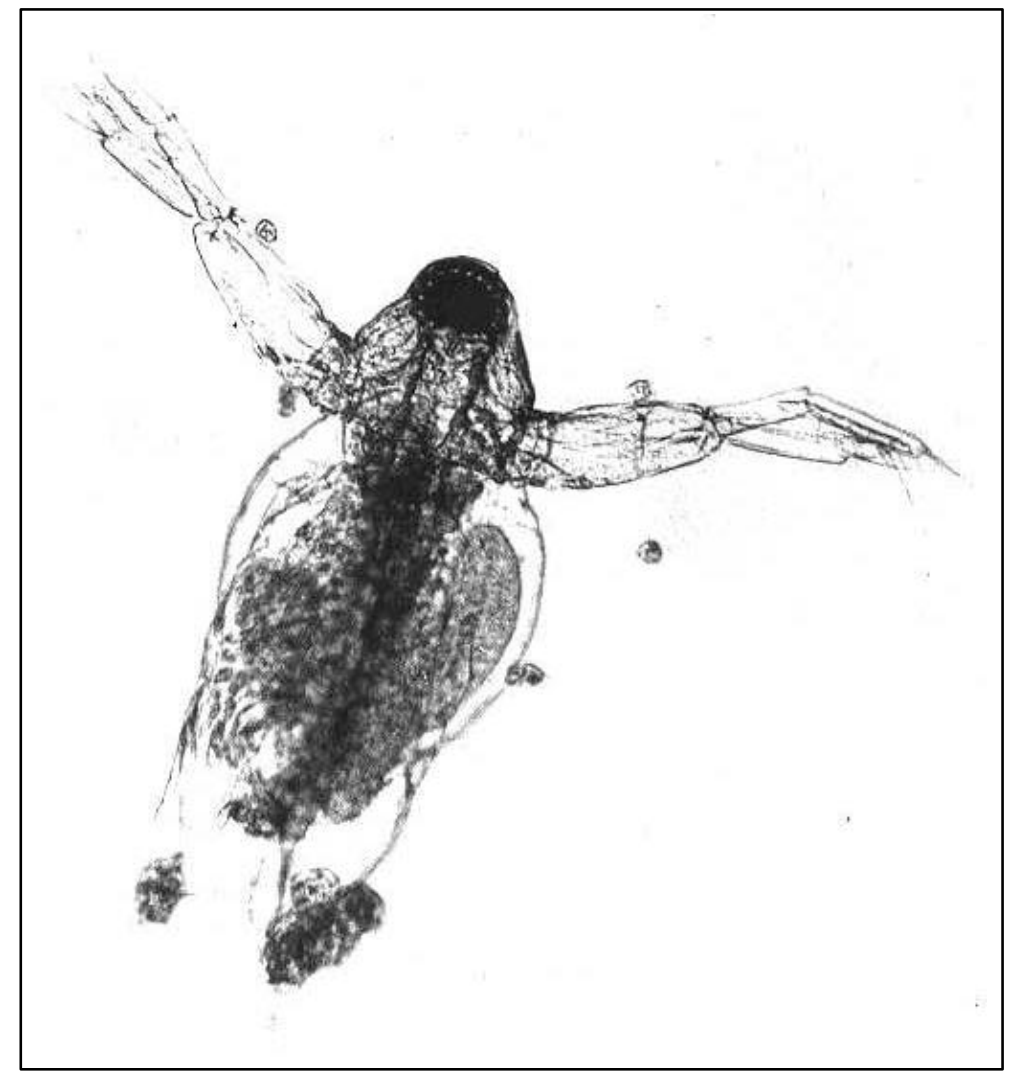

Fig.. 1. Brachionus sessilis epizooico sobre Diaphanosoma brevireme, lag. El Tigre

Cuerpo ancho, redondeado con una lóriga lisa y delgada, con cuatro espinas pequeñas en el margen antero-dorsal

Abertura del pie poco profunda en la placa dorsal, pero bien visible, en forma de $U$, en la placa ventral.

\section{Dimensiones}

LT 90-100 $\mu \mathrm{m}$. Huevos subitaneos 75x 50 .

\section{Distribución}

Aparentemente cosmopolita, pero poco frecuente.

\section{Comentarios}


$B$. sessilis pertenecería al grupo B. urceolaris, siendo de dimensiones mucho más pequeñas que las otras especies. Es epizooica sobre Cladóceros, hallada originalmente sobre Diaphanosoma brachyurum en el Lago Balaton (Hungría) y en el lago Maggiore (Italia) (fide Green 1974) y sobre D. excisum (Sars) en Sri Lanka (Chengalath et al. 1973). Se registró por primera vez para la región Neotropical en la cuenca del Paraná, en el río Paraná (km 603, ribera derecha), epizooica sobre D. brevirreme (Fig.. 2 ) y en la laguna El Tigre, en las estaciones litorales y en su forma libre en el área pelágica.

\section{OTRAS OBSERVACIONES (Lám.4, fig.s.2-6)}

En la cuenca del Paraná es frecuente B.dolabratus Harring 1915 que como se mencionó al comienzo, hasta el presente es considerada como endémica de la región Neotropical. Esta especie puede presentar altas densidades en las lagunas particularmente. Se han registrado dos morfotipos(Lám.4 fig.s 6 a y 6b). Uno de gran tamaño (Long: 145, ancho: 140 en Lag. №5, Isla Carabajal, abril de 1972) y otro pequeño con espinas muy poco desarrolladas (Long. 90 , ancho 80 en El Tigre, abril de 1988). La forma grande es similar a los ejemplares de Panamá de la descripción original (Harring 1914) y la forma pequeña es similar a los ejemplares de Brasil descriptos por Ahlstrom (1940).

Es muy frecuente la presencia de $B$. falcatus, especie de amplia distribución en los trópicos. Al igual que en otros sistemas fluviales estudiados (Green 1960) su presencia es más frecuente en las lagunas que en los ambientes lóticos

B.chelonis, especie frecuente en las lagunas, tendría una distribución restringida a América del Sur y Central, siendo probablemente estenoterma cálida, ya que su registro en el sur de Argentina es muy escaso.

También están presentes en el Paraná, aunque con menor frecuencia, $B$. nilsoni Ahlstrom 1940, y B. rubens, esta última epizooica sobre cladóceros (Koste y Shiel 1987), pero en nuestro caso se la registró siempre en estado de vida libre.

GENERO ANURAEOPSIS (Lám. 5, fig.1 a-c y 2 a-b )

Reúne especies pequeñas, de cuerpo alargado, ovoide, Poseen una lóriga flexible que forma dos placas una dorsal convexa y otra ventral plana, unidas por una cutícula delgada . Carecen de pie.

Este género es considerado como estenotermo cálido. Se han descripto aproximadamente una docena de especies (en Ruttner Kolisko 1974 y Koste 1978); sin embargo, es un género 
que necesita una profunda revisión a partir del polimorfismo real o supuesto de los especies que incluye.

En el Paraná se registran dos morfoespecies A.fissa (Gosse 1851) y A. navicula Rousselet 1910, la segunda considerada como una forma de la primera, pero podrían ser diferentes por la forma general del cuerpo, superficie de la lóriga y márgenes aserrados RuttnerKolisko 1974). Dentro de cada una de ellas es posible hallar variaciones intrapoblacionales. A. fissa es particularmente variable en forma y tamaño, pero siempre carece de granulación sobre la superficie del cuerpo y posee el borde ventral liso. A. navicula con una una placa dorsal elongada presenta una fina granulación cubriendo todo el cuerpo y los márgenes anteriores, particularmente el ventral, de aspecto aserrado.

A.fissa se encontró en El Alemán (próximo a Santa Fe, 22/12/69) y laguna Timbó (Corrientes, 4/12/92) y A. navicula en la Laguna La Cantera, en Corrientes (9/12/92). El carácter de la forma alargada y la presencia de granulación en esta última especie es señalado como constante. Sin embargo Paggi (1973) encontró en ambientes del Paraná (lagunas de las islas Sirgadero, Carabajal y el Vado ) las dos morfoespecies, pero en la atribuible a $A$. navícula tanto la superficie de la lóriga como los bordes son lisos.

Hasta el momento no se han hallado en el Paraná otras especies del género presentes en el Amazonas (Koste 1972, 1974) como A. sioli Koste 1972, A. coelata A. quadriantennata (Koste 1974) (_= Paranuraeopsis Koste 1974, según Segers 2002).

GENERO KERATELLA(Lám. 5, figs.4-5, Lám.6, fig.s. 1-5)

Reúne especies que carecen de pie, cuerpo cubierto por una gruesa lóriga en la que se distinguen dos placas, una dorsal convexa y una ventral generalmente plana. La superficie de la placa dorsal presenta una estructura de facetas poligonales diferentes en ubicación según las especies. Anteriormente presentan seis espinas y posteriormente una o dos espinas de igual o variable longitud.

Keratella es un género planctónico, que puede ser considerado como el más común en las aguas continentales desde el Artico a la Antártida, siendo difícil hallar un ambiente acuático que no albergue a una de sus especies (Ahlstrom 1943). Presenta más de 40 de ellas en todo el planeta, pero probablemente la única realmente cosmopolita es $K$. cochlearis, presentando el resto una distribución bastante determinada, en tanto que otras constituyen claros endemismos. En la región Neotropical, estos últimos se localizan principalmente en el sur de Argentina y Chile (K. yamana Boltovskoy \& Urrejola 
1977, K.ona Boltovskoy \& Urrejola 1977, K.kostei Paggi 1981, K. thomassoni Hauer 1958).

En la cuenca del Paraná y en el sector que nos ocupa se han registrado 7 especies, algunas de distribución cosmopolitas como K. cochlearis (Gosse 1851), cosmopolita de aguas ácidas como K. serrulata (Ehrenberg 1838) o pantropicales como K.tropica (Apstein 1907), K. lenzi Hauer 1953 y K. procurva (Thorpe 1891) y especies restringidas a América como K. americana Carlin 1943.

La diversidad del género es comparativamente baja en la región Neotropical, donde las especies conocidas son aproximadamente 15 y de éstas sólo la mitad están presentes en el tramo del bajo Paraná.

K.americana, K.cochlearis y $K$. tropica son los rotíferos más frecuentes en el cauce principal del río Paraná en el sector estudiado. En las lagunas su presencia es también frecuente, pero está determinada por la existencia de un área limnética bien definida.

K. americana es, de las tres especies mencionadas, la que se presenta poblaciones menos numerosas (generalmente $<20$ ind/litro). No se registraron variaciones importantes intrapoblacionales o entre localidades. Sin embargo la longitud de la espina caudal puede presentar variaciones temporales, como lo observaron Shaden (1977) en una laguna de inundación del Amazonas y Vásquez (1991) en una laguna del Bajo Orinoco, donde las variaciones fueron asociadas a los cambios de nivel hidrométrico y a la abundancia de recursos indirectamente condicionada por tales variaciones.

K.cochlearis es considerada como una especie muy polimórfica, con variaciones en la talla corporal y longitud de la espina posterior a lo largo del año o entre localidades. Algunas variaciones estarían asociadas a los factores físicos como la temperatura y turbulencia del agua y otras a la productividad del ambiente. En algunos casos, las formas se aíslan genéticamente, en tal sentido, $K$. c. f. tecta podría tener un status taxonómico específico (Nogrady et al. 1993).

En ambientes del río Paraná esta especie manifestó variaciones temporales en una misma laguna o entre localidades. En la laguna Los Matadores (11/04/77) se observaron aún en una misma población, morfos con distinto grado de desarrollo de la espina caudal. $K$. cochlearis f robusta, fue registrada con dos morfos ,uno de gran tamaño en Laguna Ingá (16/09/79) (longitud total: 170-190, espina posterior: 50-65 $\mu \mathrm{m}$, y otro pequeño en madrejón Malabrigo (7/09/79) (longitud total: 110-115, espina posterior: 30-40 $\mu \mathrm{m}$ ) . La 
presencia de estos morfos podría estar relacionada con las interacciones bióticas que tienen lugar en los ecosistemas. La presencia de competidores y depredadores que excretan sustancias químicas inducen cambios en la longitud de las espinas o el tamaño corporal en Keratella ( Stemberger \& Gilbert 1987, Marinone \& Zagarese 1991). Los ejemplares de mayor tamaño se encontraron en una laguna con una fuerte dominancia de cladóceros, principalmente Daphnia gessneri, donde los rotiferos estaban representados además de Keratella cochlearis, únicamente por Conochilus unicornis y Polyarthra vulgaris. Los ejemplares pequeños de K. c. f. robusta fueron en cambio registrados en un ambiente con menor abundancia de cladóceros y entre éstos con dominancia de especies de talla comparativamente menor, como Diaphanosoma sp.

En el curso principal del Paraná $K$. cochlearis se caracteriza por presentar morfotipos de pequeño tamaño y generalmente con espina caudal comparativamente corta. De un

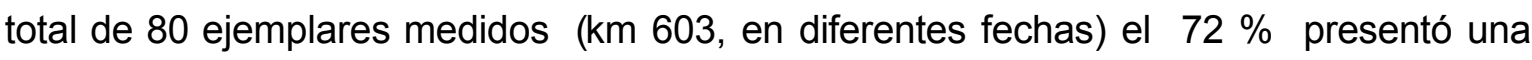
longitud total menor de $150 \mu \mathrm{m}$. Posiblemente esto se relacione con el hecho de que en el ambiente fluvial no se hallan presentes en abundancia posibles depredadores, como Asplanchna, copépodos cyclopoideos o peces planctívoros. La densidad de los depredadores sería un factor importante en el grado de inducción de cambios fenotípicos en otras especies del género como K. tropica (Zagarese \& Marinone 1992).

K. tropica es muy frecuente a lo largo de todo el año en los ambientes lóticos y lénticos. También presenta importantes diferencias de tamaño y grado de desarrollo de las espinas caudales. Como en K. cochlearis, se ha observado que la forma predominante en el curso principal es pequeña y con un desarrollo menos exhuberante de las espinas caudales (Long. total 150-210 $\mu \mathrm{m}$ ). Esta especie evidentemente puede tolerar muy bien la salinidad. En un estudio realizado por Dieguez \& Modenutti (1996), K. tropica fue la única especie del género encontrada en un lago de la Patagonia con la mayor conductividad $(1.600 \mu \mathrm{S} / \mathrm{cm})$. En el presente estudio fue también la única especie del género en un tributario con una conductividad casi seis veces mayor (río Salado, aguas abajo Las Flores, 20-9-93, $6.100 \mu \mathrm{S} / \mathrm{cm}, 1.495 \mathrm{mg} / \mathrm{l} \mathrm{Cl-)}$ formando poblaciones abundantes por tratarse de un ambiente lótico (120 ipl).

K. lenzi Hauer 1953 es relativamente frecuente en las lagunas, principalmente en las muestras litorales, aunque en general en bajo número. Para $K$. lenzi a diferencia de $K$.cochlearis y $K$. tropica, no se conocen variaciones fenotípicas, con excepción de la forma descripta por Marinone (1994) K. lenzi f. ayui, con una o dos espinas posterolaterales. Esta forma, presente en el sistema del Uruguay de la Cuenca del Plata, 
no ha sido registrada hasta el momento en el Paraná, si bien como lo comenta dicha autora pudo haber pasado desapercibida por su semejanza con formas de espinas caudales cortas de K. tropica o K. procurva.

K. procurva y K. serrulata son especies de distribución rara en el Paraná, particularmente la segunda. Han sido halladas en muy pocas ocasiones. Paggi (1973) la registró a la primera en una laguna de la Isla Los Sapos, próxima a Santa Fe y Paggi \& José de Paggi (1973) registraron la segunda en el río Colastiné y curso principal del río Paraná ( $\mathrm{km} \mathrm{440).}$

En este estudio se registró $K$ morenoi Modenutti, Dieguez \& Segers, hasta ahora solo hallada en Argentina:. La especie fue observada en una única estación del tramo inferior del curso principal del río Paraná. Su distribución podría ser muy particular pues hasta el presente había sido hallada solamente en una laguna temporaria en la meseta patagónica (Modenutti et al. 1998). Probablemente esté presente también en la provincia de Buenos Aires y desde allí haya llegado al curso principal del Paraná, ya que en ese mismo estudio no se la registró aguas arriba. Tampoco fue hallada en el muestreo anterior del Paraná inferior.

\section{GENERO PLATYIAS (Lám. 7, figs. 1 )}

Es un género específicamente litoral, posee un cuerpo recubierto de una lóriga gruesa, comprimido dorso-ventralmente. Posee un pie que se inserta ventralmente y se encuentra pseudosegmentado. El trophi es maleado, diferenciándose bien del de los restantes géneros de la familia. Por su estructura sería muy primitivo (Segers 1993).

El género reúne tres especies $P$. quadricornis (Ehremberg), $P$. leloupi Gillard y $P$. latiscapularis Koste.

En el Paraná se encuentran presentes los dos primeros. De ambas, $P$. quadricornis es la más frecuente en el litoral de las lagunas, hallándose ocasionalmente algunos individuos en el área limnética. También se ha observado, aunque siempre en bajo número, en el curso principal del río, particularmente luego de los procesos de inundación del valle.

$P$. leloupi, en cambio, es de frecuencia rara, habiéndosela encontrado siempre en el litoral vegetado de las lagunas, en muy bajo número y coexistiendo con $P$. quadricornis . 
Ambas especies se diferencian claramente por la presencia en la primera de una larga quilla central sobre la placa dorsal de la lorica. En el material estudiado no se ha registrado P. latiscapularis, considerada endémica del Amazonas (Segers et al. 1993).

\section{GÉNERO PLATIONUS (Lám. 7, figs. 2 )}

Es, como Platyias, un género litoral. Cuerpo con una lóriga más o menos gruesa, con espinas anteriores y posteriores bien desarrolladas. El cuerpo puede o no presentar diseños. Pie de inserción terminal, con pseudosegmentos y terminando en dos dedos iguales en longitud. Trophi maleado.

Segers et al. (1993) considera que reuniría tres especies: $P$. patulus (O.F. Müller 1786), $P$. polyacanthus (Eheremberg 1834) y P. macracanthus (Daday 1905). Sin embargo hasta el momento no se han señalado evidencias que justifiquen el status específico de esta última.

En el bajo Paraná se encuentra $P$. patulus que es posiblemente el rotifero litoral más frecuente en todas las lagunas, muchas veces presente además en sus áreas limnéticas. Se la registrado también en los ríos de distinta jerarquía, probablemente arrastrada desde las áreas inundadas.

En algunas ocasiones se ha registrado $P$. patulus $f$. macracanthus (El Alemán, 22/12/69), que se caracteriza por su gran talla y espinas caudales muy desarrolladas. 
LECANIDAE Remane 1933

Esta familia incluye solo el género Lecane Nitzsch 1827 el que se encuentra ampliamente distribuido en los ambientes acuáticos continentales. Reúne especies comparativamente eurioicas y puede considerarse como representativo de los rotíferos Monogononta no planctónicos y no sésiles (Pejler \& Berzins 1994). A pesar de poseer dedos desarrollados, las especies no muestran una dependencia total del sustrato (Pejler 1962); esto explicaría su alta frecuencia en el plancton de los ambientes fluviales y leníticos y en la zona litoral.

Algunas de sus especies como L. lunaris y L. closterocerca pertenecerían según Pejler y Berzins (1994) a los más ubicuos de todos los rotíferos. Si bien el grupo tiene distribución mundial, incluyendo el Artico y la Antártida, su mayor diversidad se registra en los trópicos (Segers 1995 a,b, 1996).

\section{GENERO LECANE}

Cuerpo cubierto por una lóriga, constituida por una placa ventral y una dorsal, unidas lateral y caudalmente por una membrana denominada pleural. La superficie de la placa dorsal puede ser lisa o tener una ornamentación definida con pliegues, surcos, etc. La ventral es generalmente lisa y puede tener pliegues longitudinales o uno transversal, más o menos definido, completo - de lado a lado - o incompleto. Generalmente su superficie es menos ornamentada que la dorsal. Los bordes anteriores de la lóriga, dorsal y ventral pueden ser coincidentes o no, rectos, curvos, tener pequeñas espinas laterales 0 centrales, etc.

La placa dorsal puede terminar posteriormente en forma redondeada o truncada. La ventral se continúa posteriormente con la placa del pie, disponiéndose lateralmente un par de placas coxales separadas entre sí por el pliegue prepedal (para otros autores este constituye el primer segmento del pie) que puede ser alargado o bien corto y ancho. Este se continua con el pseudosegmento del pie (también considerado como segundo segmento del pie). Del pseudosegmento salen dos dedos completamente separados 0 fusionados, total o parcialmente. Los dedos pueden ser rectos o suavemente curvados, terminar en punta más o menos aguzada o poseer uñas bien definidas, largas o cortas. 
El género ha sido sometido a una revisión mundial (Segers 1995ab) y en los últimos años se han descripto nuevas especies, en particular para áreas tropicales. Hasta el presente se conoce un total de 170 (Segers 2002). En el Paraná se han registrado 50 de ellas, pero su diversidad probablemente sea más elevada.

En cuanto a la taxonomía si bien la revision de Segers (1995ab) significó un gran avance, hay problemas aún no resueltos, particularmente en relación al grado de variabilidad de los caracteres. Esta revisión solo se basa en la morfología del cuerpo ya que el trophi no parece presentar características específicas.

Se considera que el género exhibe un amplio rango de variabilidad intraespecífica, los caracteres morfológicos variarían según las condiciones ambientales (Segers 1995 a). Sin embargo, raramente se analizan las variaciones intrapoblacionales, debido, posiblemente no solo a la falta de estudios más minuciosos sino también al hecho de que muchas especies son observadas formando poblaciones de pocos individuos, hecho bastante común entre los taxa litorales (Nogrady et al. 1993). Los estudios biométricos son escasos y es frecuente la falta de precisión en las descripciones y particularmente en las diagnosis diferenciales.

\section{DESCRIPCION Y OBSERVACIONES SOBRE ALGUNAS ESPECIES}

En el registro mundial del género (Segers 1995a), sólo se citan para toda Argentina 24 especies del total de las 50 registradas para el Paraná y de las 2 halladas únicamente en provincias del noroeste (José de Paggi 1989). Ello obedece principalmente a que los hallazgos de muchas especies no han sido acompañados de registros gráficos en las publicaciones, correspondiendo varios de ellos a citas en inventarios de trabajos ecológicos. En unos pocos casos se debe también al desconocimiento de trabajos publicados en revistas argentinas.

En tal sentido se incluyen comentarios sobre algunas de esas especies u otras cuya presencia merece destacarse por ser muy frecuentes, incluso en ambientes lóticos, 0 por poseer un interés particular.

\section{Abreviaturas usadas:}

LPD: Longitud de la placa dorsal LPV: Longitud de la placa ventral APD: Ancho de la placa dorsal APV: Ancho de la placa ventral 
LD: Longitud total (incluida la uña) del/los dedos

LU: Longitud de la uña o pseudouña

Dimensiones en micrométros

Lecane aegana Harring 1914 (Lám. 8, fig. 1)

Lecane tenuiseta aegana, Kutikova 1970: 450-451, fig.609

Lecane tenuiseta, Martínez \& José de Paggi 1988:291, fig 16ab

Bordes anteriores casi coincidentes, dado que el dorsal es levemente convexo y el ventral recto. La placa dorsal es más angosta que la ventral. Ambas presentan una ornamentación debida a la presencia de pliegues cortos y suavemente curvos. El pseudosegmento del pie es cuadrangular, con expansiones laterales y no se proyecta por debajo de la lóriga. Los dedos de bordes rectos y paralelos terminan en una uña bien separada.

Dimensiones

LPD: 66-70, LPV: 69-71, APD: 50-52, APV: 49-51, LD: 30-32, LU: 10-11.

Distribución

Se trataría de una especie de presencia poco frecuente (Segers 1995b).

\section{Comentarios}

Fue descripta para Argentina (Martínez \& José de Paggi 1988) como L. tenuiseta Harring 1914. Como lo señala Segers (1995b), ambas especies son similares, la diferencias reside en que $L$. aegana posee las uñas de los dedos de menor longitud y su cuerpo es menos elongado. En ocasiones, este último carácter es menos visible cuando el material sufre contracciones severas por la fijación.

En este trabajo se analizaron estos caracteres tomando las medidas de los individuos del río Paraná y los aportados por la literatura específica (Koste \& Shiel 1990, Segers 1995b). Se observó que la relación largo/ancho es en $L$. aegana: 1,20-1,21 y en $L$. tenuiseta 1,54-2,0. En cuanto a la relación longitud total del dedo/ longitud de la uña se observó la siguiente: $L$. aegana: 4,0-4,3, L. tenuiseta: 2,14-2,70.

Lecane arcula Harring 1914 (Lám. 8, fig.2 )

Lecane strandi, Berzins 1943 
Bordes anteriores rectos y coincidentes con dos espinas laterales bien desarrolladas. Placa dorsal con ornamentaciones, más ancha que la ventral, terminada en forma suavemente redondeada. La placa ventral presenta un pliegue transversal corto limitado por dos pliegues verticales. Pliegue prepedal (o primer segmento del pie) alargado. El pseudosegmento del pie es cuadrangular con pequeñas expansiones laterales y se proyecta por debajo de la lóriga. Los dedos, de bordes paralelos, terminan en uñas bien delimitadas. En el material examinado las espinas accesorias de las uñas mencionadas en otras descripciones (Segers 1995b) son poco desarrolladas, pasando desapercibidas.

\section{Dimensiones}

LPD: 58-63, LPV: 65-68, APD: 50-52, APV: 41-43, LD: 21-22, LU: 5-6.

\section{Distribución}

Cosmopolita pero poco común.

\section{Comentarios}

Fue citada para Argentina (sin precisión de localidad) por Murray (1913) en su estudio sobre Rotíferos de América del Sur. Si bien se la encuentra citada en los inventarios de trabajos ecológicos, no se han publicado descripciones ni ilustraciones. Es poco frecuente y ha sido observada en bañados asociados al río Mocoretá (10/12/92) y al arroyo La Pepita (pH 7,8, conductividad $405 \mu \mathrm{S} / \mathrm{cm}, 8 / 12 / 92$ ).

\section{L. aspasia, Myers 1917 (Lám. 8, fig. 3)}

L. stichaeoides, Martínez \& José de Paggi 1988: 291, fig. 14

Bordes anteriores ventral y dorsal rectos, casi coincidentes con pequeñas espinas laterales. Placa dorsal más angosta que la ventral, con ornamentación. Placa ventral con un surco transversal incompleto. El pie se proyecta escasamente por debajo del cuerpo con dedos de bordes paralelos, terminados en una uña bien diferenciada.

\section{Dimensiones}

LPD: 82-87, LPV: 85-90, APD: 69-73, APV: 70-73, LD: 33, LU: 7.

\section{Distribución}

Es una especie cosmopolita. Frecuente en el Paraná, aunque siempre en escaso número.

\section{Comentarios}


Es similar a L. haliclysta Harring \& Myer 1926, diferenciándose de aquella porque el pie se proyecta muy escasamente por debajo del cuerpo y por la forma del pseudosegmento , comparativamente más ancho y corto. Esta especie fue descripta para Argentina (Martinez \& José de Paggi 1988) como L. stichaeoides Hauer 1938 que posteriormente fue considerada sinónima de L. halyclista por Segers (1995b) .

Lecane doryssa Harring 1914 (Lám. 8, fig. 4)

Non Lecane doryssa, Kutikova 1970

Márgenes anteriores dorsal y ventral coincidentes, rectos, levemente curvados. Placa dorsal muy ornamentada más angosta anteriormente y más ancha que la ventral en su parte media. Placa ventral con un pliegue transversal incompleto. Pliegue prepedal alargado terminando en una proyección mediana. El pseudosegmento del pie es ancho proyectándose por debajo de la lóriga. Los dedos son cortos, siendo la relación longitud del cuerpo /longitud dedos: 2,8-2,9. Uñas completamente separadas.

\section{Dimensiones}

LPD: 50-55, LPV: 60-64, APD: 51-55, APV: 50-52, LD: 18-21, LU: 9-10.

\section{Distribución}

Cosmotropical-cosmosubtropical.

\section{Comentarios}

Es considerada como una especie poco frecuente. Presente en escaso número en ambientes lénticos, próximos a Santa Fe (laguna El Tigre) y Corrientes (laguna La Cruz). No había sido descripta ni ilustrada anteriormente para Argentina.

Lecane eutarsa Harring \& Myers 1926 (Lám. 8, fig.5 )

L.amazoniana, Koste \& Robertson 1983:232, fig.5 a-c

L. stichaea var. amazonica, Koste 1978: 230, fig. 75:13

L. amazonica, Koste \& Bottger 1992: 288-289, fig. 8

L. amazonica, José de Paggi \& Koste 1988:17, fig. 11

Bordes anteriores coincidentes y levemente cóncavos, con espinas laterales de base ancha y levemente curvadas hacia adentro. La placa ventral es más angosta que la dorsal, principalmente en su parte media por poseer bordes laterales rectos. El pseudosegmento del pie se proyecta fuera de la lóriga, casi tan largo como ancho. Los 
dedos delgados y de bordes rectos poseen una uña que se inserta sobre el lado interno de los dedos, es decir no se dispone centralmente en el extremo del dedo.

\section{Dimensiones}

LPD: 98-110, LPV 115- 120, APD: 65-70, APV: 58-60, LD: 40-42, LU: 10-12

\section{Distribución}

Endémica de la región Neotropical.

\section{Comentarios}

Hallada en río Saladillo (José de Paggi \& Koste 1987) y determinada como $L$. amazoniana Koste \& Robertson 1983, posteriormente considerada como sinónima de $L$. eutarsa (Segers 1995a). Es considerada endémica de la región Neotropical. Puede confundirse con $L$. robertsonae Segers, pero en esta última la uña se inserta en el centro del dedo y los bordes anteriores ventral y dorsal son rectos.

\section{Lecane papuana (Murray, 1913) (Lám. 8, fig. 6 )}

Lecane yamunensis, Novotná-Dvorakova 1962: 175. Fig. a-c Lecane presumpta, Ahlstrom 1938:97-98, Lám. 7:1

Se caracteriza por tener una placa dorsal anteriormente más angosta con un margen anterior recto. La placa ventral presenta el borde anterior que se extiende sobre el dorsal lateralmente con proyecciones semicirculares separadas por un sinus mediano. A su vez esta placa está dividida por un pliegue transversal completo. Pliegue prepedal ancho y pseudosegmento del pie de forma trapezoidal, no se proyecta por debajo del cuerpo. Dedos cortos, relación longitud del cuerpo/ longitud dedos: 2,38-2,80. Pseudouñas con pequeñas uñas accesorias.

\section{Dimensiones}

LPD: 93-100, LPV: 105-109, APD: 82-84, APV: 80-85, LD: 26-30, LU: 8-10.

\section{Distribución}

Estenoterma cálida con distribución pantropical y pansubtropical.

\section{Comentarios}

No había registros gráficos de los hallazgos de esta especie en Argentina por lo cual su presencia no fue incluida en el registro mundial (Segers 1995a). Es bastante frecuente en el curso principal y cauces secundarios del Paraná. 
Placa dorsal con pequeñas granulaciones y borde anterior suavemente convexo. Es muy característica por poseer una placa ventral que se proyecta sobre la dorsal exhibiendo un borde anterior con dos lóbulos separados por un sinus mediano. La placa ventral presenta un pliegue transversal completo. En vista lateral puede apreciarse que ambas placas son fuertemente convexas. Dedos con pseudouñas y pequeñas espinas accesorias. Los dedos son cortos, la relación largo del cuerpo/ longitud de los dedos es $3,70-3,72$.

\section{Dimensiones}

LPD: 110-115, LPV: 120-125, APD: 85-90, APV: 100-105, LD: 21-24, LU: 3-4.

\section{Distribución}

Segers (1995) la considera endémica de la cuenca del Amazonas, aunque sin embargo es una especie muy frecuente en el curso principal y cauces secundarios del Paraná (José de Paggi 1978 e inédito ) y en el río Orinoco (Saunders \& Lewis 1988, Vásquez \& Wilbert 1992).

\section{Comentarios}

En el curso principal del río Paraná, $\mathrm{km} \mathrm{603,} \mathrm{fue} \mathrm{registrada} \mathrm{a} \mathrm{lo} \mathrm{largo} \mathrm{de} \mathrm{todo} \mathrm{el} \mathrm{año,}$ durante el período 1977-1980. Evidentemente se trata de una especie adaptada al ambiente lótico, como también lo estaría indicando su presencia frecuente en los ambientes fluviales del sistema del Orinoco. Probablemente su cuerpo globoso, favorece su permanencia en las aguas corrientes.

Lecane rhenana Hauer 1929 (Lám. 8, fig. 8)

Bordes anteriores casi rectos, más o menos coincidentes. Placa dorsal más ancha que la ventral. Esta última con un pliegue transversal completo, placas coxales redondeadas. El pseudosegmento del pie no se proyecta fuera de la lóriga, dedos rectos, relativamente cortos, aproximadamente $1 / 4$ de la longitud de la lóriga, terminados en uñas bien visibles con pequeñas espinas laterales accesorias.

\section{Dimensiones}

LPD : 100-110, APD 110-115, LPV 115-120, APV 105-110, LD: 50-55.

\section{Distribución}


Podría ser cosmopolita . Según Segers (1995b) puede pasar desapercibida pues por su aspecto general puede confundirse con L. luna o L. curvicornis, difiriendo sin embargo de éstas, por su borde anterior casi recto, dedos cortos y tamaño corporal comparativamente pequeño.

\section{Comentarios}

No es una especie frecuente en el Paraná, habiéndosela encontrado en raras ocasiones en el curso principal ( $\mathrm{pH} 7$, conductividad 60-70 $\mu \mathrm{S} / \mathrm{cm}$ ), y sólo en una laguna (EI Tigre, $\mathrm{pH}$ 6,9, conductividad $120 \mu \mathrm{S} / \mathrm{cm}$ ). Hasta el momento no ha sido registrada en otras cuencas cercanas, como El Pantanal del río Paraguay (Turner \& Da Silva, 1992, Heckman 1998, Koste 1999).

Lecane robertsonae Segers 1993 (Lám. 8, fig. 9 )

Lecane aspasia amazonica, Koste \& Robertson 1983: 233 figs. 6 a-c

Cuerpo alargado cubierto por una lóriga delgada ornamentada, borde anterior con espinas laterales bien desarrolladas. Placa dorsal más ancha que la ventral solo en la parte media. El pseudosegmento del pie se proyecta por debajo de la lóriga presentando pequeños lóbulos laterales. Dedos delgados de bordes paralelos terminando en uñas largas bien separadas.

Se diferencia de $L$. eutarsa por cuanto el borde anterior es recto y por la uña que es una continuación del dedo (en $L$. eutarsa este tiene inserción excéntrica).

\section{Dimensiones}

LPD:100-102, LPV: 110-114, APD: 72-73, APV: 55-59, LD: 30-32, LU: 10-11.

\section{Distribución}

Probablemente de distribución tropical y subtropical.

\section{Comentarios}

Esta especie fue inicialmente considerada endémica de la cuenca del río Amazonas. Sin embargo fue hallada en el Parque Nacional Río Picomayo (José de Paggi 2001) y en este estudio fue registrada en una laguna en Isla Noguera $(\mathrm{pH} \mathrm{6,0),} \mathrm{frente} \mathrm{a} \mathrm{la} \mathrm{ciudad} \mathrm{de}$ Corrientes. Su distribución conocida hasta muy recientemente sugería un endemismo Neotropical ; sin embargo, recientemente fue hallada en Tailandia (Segers et al. en prensa).

Lecane stenroosi (Meissner 1908) (Lám. 8, fig. 10) 
Cuerpo oval. Borde anterior dorsal recto, el ventral tiene un sinus central y se continúa lateralmente formando dos espinas curvadas hacia adentro. Placa dorsal más angosta que la ventral, ; en ésta está presente un pliegue transversal completo. Pseudosegmento del pie rectangular, láminas coxales más o menos redondeadas. Un solo dedo, generalmente ensanchado en la base y adelgazado en su parte media. El dedo termina en dos uñas que pueden o no estar fusionadas, con pequeñas espinas accesorias.

\section{Dimensiones}

LPD: 110-115, LPV: 110-120, APD: 90-100, APV: 95-105, LD: 45-50, LU: 10-11.

\section{Distribución}

Es cosmopolita, aunque poco frecuente

\section{Comentarios}

Esta especie, pese a poseer poblaciones de pocos individuos, es bastante frecuente en la cuenca del río Paraná, aguas abajo de Confluencia. Puede ser confundida con $L$. cornuta pero se diferencia de ésta por su borde ventral con un sinus y proyecciones laterales y borde dorsal recto. Fue registrada en los primeros estudios sobre rotíferos del Paraná (José de Paggi 1978), pero este hallazgo no fue incluido en Segers (1995 a,b) por lo que su presencia para Argentina se confirma nuevamente en este estudio.

Lecane tenuiseta Harring 1914 (Lám. 8, fig. 11 )

Lecane punctata, Carlin-Nilsson 1934:9. Fig.4

Lecane aegana, Tarnogradski 1961:48 Lám. 22: 1-3

Lóriga delgada, márgenes anteriores dorsal y ventral casi rectos, coincidentes, con los extremos laterales formando ángulos. Placa dorsal y ventral de aproximadamente igual ancho. Esta última presenta un tenue pliegue transversal incompleto. Lámina del pie y láminas coxales redondeadas. El pie no se proyecta por debajo de la lóriga, presenta dedos provistos de largas espinas.

\section{Dimensiones}

LPD: 62, LPVI:75, APDI: 42, APLV: 40, LD: 18, LU: 12.

\section{Distribución}

Cosmopolita.

\section{Comentarios}


No fue registrada anteriormente en el Paraná. Si bien está considerada como una de las especies euritópicas más comunes del género (Segers 1995b), no es frecuente en los ambientes del Paraná y sólo se hallaron dos ejemplares en el litoral pantanoso del río Mocoretá (Entre Ríos).

\section{OTRAS OBSERVACIONES}

Del total de 87 especies de Lecane registradas para la región Neotropical (Segers 1996), en el Paraná se encuentra un poco más de la mitad (46). La especie más frecuente en todo el sector estudiado de la cuenca fue L.bulla una de las más cosmopolitas del género. Además de ella, las más frecuentes en los ambientes fluviales fueron $L$. leontina, $L$. papuana y $L$. proiecta. En los ambientes lénticos, a las ya citadas con excepción de la última, deben agregarse L. Iuna, L. Iudwigii y L. lunaris.

Si bien se analizó un número considerable de muestras de áreas vegetadas donde las especies del género desarrollarían poblaciones más abundantes, muy pocas ( $L$. curvicornis, L. leontina y L. bulla) exhibieron densidades relativamente elevadas (> 20 ipl.).

L. curvicornis si bien es cosmopolita es más frecuente en ambientes con temperaturas cálidas. En las lagunas, desde Confluencia a Diamante, se han registrado varios morfotipos, según la forma de los márgenes anteriores, levemente cóncavos o en forma de $\mathrm{V}$, presencia de pequeñas espinas laterales desarrolladas, ornamentación de la lóriga: L.curvicornis f. acronycha, L. curvicornis f. lofuana, L. curvicornis f. nitida, Las variaciones en esta especie fueron analizadas anteriormente (Martínez \& José de Paggi 1988).

L. leontina , común en trópicos y subtrópicos es más frecuente en lagunas del sector medio del Paraná. Se hallaron principalmente dos morfotipos uno con la parte posterior del cuerpo truncada y el otro con la parte posterior elongada.

L. rhytida Harring \& Myers 1926 es una especie conocida para Africa y Nueva Guinea. Si bien en muy escaso número, es frecuente en las lagunas de los primeros sectores del Paraná luego de la confluencia con el río Paraguay. En ella es característico el pie que se proyecta poco de la lóriga y que posee marcadas expansiones laterales, lo cual la 
distingue de L. lauterboni Hauer 1924 y L. donneri Chengalath \& Mulamoottil 1974, especies cercanas no presentes en Argentina.

L. quadridentata (Ehremberg 1832) es frecuente en el litoral de las lagunas del río Paraná, donde también se encontró L. quadridentataf. gigantea Koste 1988 (Lám.8, figs. 12 y 13$)$

De las especies registradas en el Paraná un importante número de ellas si bien tienen distribución cosmopolita son más frecuentes en las áreas tropicales y subtropicales o son marcadamente estenotermas cálidas, por ejemplo: L. aculeata, L. doryssa, L. elegans, $L$. halyclista, L. hornemanni, L. leontina, L. monostyla, L. obtusa y L. punctata.

En la cuenca del bajo Paraná, como se señaló anteriormente, también se hallaron especies consideradas hasta el presente como endémicas de la región Neotropical: $L$. amazonica, L. eutarsa, L. marchantaria y L. proiecta. 
TRICHOCERCIDAE Harring 1913

La familia reúne tres géneros, Ascomorphella Wiszniewski 1953, Elosa Lord 1891 y Trichocerca Lamarck 1801 (subgénero Diurella Bory de St. Vincent 1824). Los dos primeros tienen, respectivamente, 1 y 2 especies, en tanto que Trichocerca, el único de estos géneros registrado en este trabajo, incluye aproximadamente 75 especies (Segers 2002).

\section{GENERO TRICHOCERCA}

Cuerpo alargado, en forma de vaso, cubierto por una lóriga, generalmente delgada y elástica. El extremo apical puede extenderse en prolongaciones aguzadas a modo de dientes o presentar pliegues más o menos profundos. La cabeza exhibe una corona de cilios de estructura sencilla a modo de anillo y el campo apical presenta uno o dos palpos raramente visibles en material contraído. A lo largo del dorso pueden observase una o dos bandas estriadas, largas o cortas, denominadas quillas, que pueden tener diferente altura en vista transversal del cuerpo. Pie corto, pudiendo los dedos estar bien desarrollados o el derecho muy reducido en su longitud o atrofiado. En la base de los dedos pueden observarse pequeñas cerdas. El trophi es de tipo virgado, asimétrico, con fulcrum y manubrios largos; los dos manubrios pueden ser desiguales, siendo el izquierdo generalmente el más robusto pudiendo terminar con una fuerte curvatura distal.

Trichocerca es un género litoral, pero en las lagunas de la planicie de inundación del río Paraná, por su característica de ambientes acuáticos someros, vegetados, generalmente sin un área pelágica definida, las especies de este género son frecuentes también en el plancton. Trichocerca, juntamente con el género Lecane, son los de mayor diversidad en los ecosistemas de ríos con planicie aluvial (Segers et al. 1993).

Los caracteres morfológicos usados en la taxonomía del género son, principalmente, forma del margen anterior de la lóriga, presencia de quillas, longitud de los dedos y morfología del trophi. Un análisis de este último resulta imprescindible, aunque algunas claves no siempre lo incluyan. Los individuos fijados sufren una fuerte contracción del cuerpo y en este estado varias especies se parecen entre sí, siendo esencial el análisis del trophi para detectar las diferencias específicas. 
Se distinguen dos subgéneros que se diferencian entre sí por el desarrollo de los dedos, $T$. s.str. y $T$. diurella ; en la primera, los dedos son de diferente longitud, representando el derecho menos de $1 / 3$ del izquierdo, mientras que en el segundo ambos dedos son iguales o casi iguales.

En cuanto a la taxonomía del género debe señalarse que, excepto el reciente aporte de Segers (2003), no se dispone de revisiones previas detalladas. En general se desconoce la variabilidad intrapoblacional de los caracteres morfológicos utilizados corrientemente en la diagnosis de las especies. Este problema es difícil de resolver ya que la mayoría de ellas no exhiben elevada densidad, ni siquiera en las áreas litorales. Hay pocos registros gráficos originales, pese a ser un género muy referenciado en estudios ecológicos, siendo utilizados, en algunos casos, como indicadores de calidad del agua. Ello impide conocer si se trata exactamente de la especie señalada, incidiendo, a su vez, en un contexto general, en el conocimiento de la distribución real de las especies. Algunos registros gráficos incluidos en claves de difusión internacional son incompletos. Siendo el trophi una estructura de análisis importante, no siempre es descripto e ilustrado; en algunas especies, ambos o uno de los manubrios del trophi presentan curvaturas distales, lo cual se utiliza como elemento diagnóstico. Sin embargo, muchas veces esta pieza es dibujada por los autores en vista frontal por lo cual se presentan como rectos. Una consulta rápida a los atlas de dibujos de las claves, por parte de los no especialistas, puede llevar a determinaciones erróneas.

En la cuenca del Paraná se han identificado 27 especies. En la Argentina el total registrado, incluyendo las que figuran en trabajos extra-taxonómicos, es apenas superior, unas 30 especies. No obstante, este género ha recibido también aquí, muy poca atención, siendo escasos los registros gráficos del cuerpo y trophi, no habiendo, en consecuencia certeza acerca de las determinaciones realizadas. Del total de las especies citadas en este estudio para el río Paraná, sólo tres fueron consideradas en trabajos taxonómicos previos con observaciones sobre su morfología, dimensiones y con registros gráficos: T. abilioi, $T$. insulana (= T. montana), T. vernalis (José de Paggi, 1996, 2001).

Del total de las 27 especies registradas en el río Paraná, 17 son de distribución cosmopolita, 8 cosmo (sub) tropicales y dos (T. rattus y T. cf. gracilis) tienen una distribución menos conocida, en parte a causa de su estatus taxonómico poco claro. (Koste 1978, Shiel \& Koste 1993, Segers 2003). 
Del total de las especies halladas, $T$. capucina, $T$. dixonnutalli, $T$. tenuior y $T$. voluta son registros nuevos para la Argentina.

\section{DESCRIPCION Y OBSERVACIONES SOBRE ALGUNAS ESPECIES}

Abreviaturas usadas:

LC: longitud del cuerpo

LDI: longitud dedo izquierdo

LDD: longitud dedo derecho

LTR: longitud del trophi

Dimensiones en micrómetros

Considerando la ausencia de revisiones completas actualizadas se adoptan, en general, las sinonimias propuestas por Koste (1978).

Trichocerca bicristata (Gosse 1887) (Lám. 9, fig. 1)

Cuerpo cilíndrico, con dos quillas anchas que corren a lo largo de su lado dorsal. El dedo izquierdo es casi tan largo como el cuerpo. Koste (1972, lam.49: 1b) señala que en ejemplares provenientes del río Amazonas, dicho dedo termina en una especie de uña o triapicalmente, lo cual no fue observado en los individuos del río Paraná. Trophi asimétrico, con rami y manubrio izquierdo más desarrollado que el derecho. El manubrio izquierdo está fuertemente curvado distalmente, formando un "talón" posterior, en tanto que el derecho es más delgado y posee una curvatura distal muy suave.

\section{Dimensiones}

LC: $210-230$, LDI: 200-210, LTR: 75-80, morfotipo pequeño: LC 170-180, LDI: 160-165, LTR: 70-75.

\section{Distribución}

Cosmopolita. 


\section{Comentarios}

En el río Paraná se encontraron dos morfotipos, uno de tamaño grande y otro pequeño. Sin embargo, la estructura del trophi es la misma, solo que en el primero de los morfotipos el manubrio derecho presenta una menor curvatura distal. Este último morfotipo, hallado frecuentemente en ambientes tropicales y subtropicales, fue confundido con Trichocerca mucosa (Stokes 1896) por su tamaño y aspecto general del cuerpo con doble quilla (Hauer 1956, Koste 1972). Sin embargo, detallados estudios posteriores acerca de esta última especie, muestran que la misma tiene otras características morfológicas distintivas (Segers 1997).

En la cuenca del río Paraná es una especie bastante frecuente en lagunas ubicadas en las provincias de Chaco, Corrientes y Santa Fe, así como en lagunas de las Islas Lechiguanas, generalmente presente en aguas de $\mathrm{pH}$ neutro o levemente alcalino de conductividad $<200 \mu \mathrm{S} / \mathrm{cm}$.

Trichocerca braziliensis (Murray 1913) (Lám. 9, fig. 2 )

Trichocerca elongata braziliensis, Koste 1978: 397. Lam.137:1 a-g

Cuerpo corto, con una quilla dorsal ancha bien visible que ocupa no más de 1/3-1/4 de la longitud de aquel. Dedo izquierdo muy desarrollado, algo más largo que el cuerpo. El trophi es característico por poseer ambos manubrios fuertemente curvados formando un "talón" posterior. El álula del ramus izquierdo termina en una única proyección, en cambio la del ramus derecho es comparativamente más desarrollada y termina en dos puntas.

\section{Dimensiones}

LC: 160-180, LDI: 170-180, LDD: 30, LTR: 90-95.

\section{Distribución}

Cosmopolita-cosmotropical.

\section{Comentarios}

Esta especie fue hallada por mucho tiempo solamente en la región Neotropical, por lo cual era considerada endémica, aunque posteriormente fue registrada en Borneo, Tasmania, Nigeria y Papua (Koste 1988, Koste \& Shiel 1987, Segers 1993, Segers \& De Meester 1994). Fue considerada como una subespecie de $T$. elongata pero es mucho más pequeña y difiere de aquella por las terminaciones de las álulas del trophi. Por otro lado, ambas especies fueron encontradas conviviendo en La laguna Ingá y Madrejón Ñatiú en la Provincia de Santa Fe, en ambientes someros con 40 y $75 \%$ 
respectivamente de área cubierta por vegetación, pH 7 a 7,3 y conductividad de 99 a 180 $\mu \mathrm{S} / \mathrm{cm}$.

Esta especie ha sido muy citada para la Región Neotropical; sin embargo, sus registros gráficos son muy escasos.

Trichocerca capucina (Wierzejski \& Zacharias 1893) (Lám. 9, fig. 3 )

Cuerpo cilíndrico en el que pueden observarse, aún en individuos contraídos, una especie de capucha que cubre la cabeza. Ventralmente posee una serie de pliegues en la región apical delimitada del tronco por líneas transversales. De ambos dedos, el izquierdo es el más desarrollado. Trophi con manubrio derecho más robusto que el izquierdo, álulas del rami terminadas en punta.

\section{Dimensiones}

LC: 180-200, LDI: 75-78, LTR: 45-50.

\section{Distribución}

Cosmopolita, pero poco frecuente.

\section{Comentarios}

Los ejemplares hallados en el río Paraná no presentaron variaciones en el desarrollo de la capucha y pliegues apicales, como los señalados por Koste (1978). Esta especie fue registrada en muy pocas oportunidades (laguna Los Matadores, ver tabla 2.1). Si bien es nueva para Argentina, la especie era conocida para la Región Neotropical (Koste \& José de Paggi 1982).

Trichocerca dixonnutalli (Jennings 1903) (Lám. 9, fig. 4 )

Coelopus inermis, Linder 1904: 240, Lam.4:9

Cuerpo de tamaño muy pequeño, corto y robusto. En individuos contraídos por la fijación el ancho es casi 2/4 su longitud. En la parte apical presenta algunos pliegues longitudinales, y una suave constricción separa la cabeza del tronco. No posee quilla estriada, pero en el lugar que ésta suele ocupar, corre un surco en el que se aloja la antena dorsal. Dedo izquierdo más desarrollado en longitud, la cual es aproximadamente la mitad de la del cuerpo, en tanto que la del dedo derecho es $2 / 3$ del aquel. Trophi asimétrico, manubrio 
derecho muy delgado y recto a modo de una fina varilla, más corto que el izquierdo. Este último en cambio, es robusto y curvado distalmente. El uncus izquierdo presenta 4 dientes.

\section{Dimensiones}

LC: 100-120, LDI: 40-45, LDD: 25-27, LTR: 33-35.

\section{Distribución}

Cosmopolita.

\section{Comentarios}

Shiel \& Koste (1993) registran esta especie en las planicies de inundación de ríos de Australia formando parte del ticoplancton y perifiton. En la cuenca del Paraná se la encontró en la zona litoral del Madrejón Ñatiú, en un área con dominancia de Eichhornia sp. y de la laguna Ingá, vegetada con Salvinia sp., Eichhornia sp. y Ninfoides sp.

Trichocerca elongata (Hudson \& Gosse 1886) (Lám. 9, fig. 5 )

Mastigocerca grandis, Stenroos 1898: 144, Lam.2:8

Cuerpo alargado, sin dientes en el borde anterior. Dorsalmente presenta una quilla doble, corta, que no sobrepasa el tercio de la longitud del cuerpo. Dedo izquierdo bien desarrollado, más de 2/3 la longitud de la lóriga, dedo derecho rudimentario. El trophi es asimétrico, con su sector izquierdo más desarrollado que el derecho. El manubrio izquierdo es robusto y se curva formando un codo. El manubrio derecho es muy delgado y recto.

Dimensiones: LC: 300-350 LDI: 225-230, LTR: 75-80.

Distribución: cosmopolita.

Comentarios: esta especie fue citada para Argentina por diversos autores (fide José de Paggi 1990) pero no había registros gráficos de su cuerpo y trophi. Se la encontró en lagunas de Santa Fe y Chaco con pH 7-7,3 y conductividad $<200 \mu \mathrm{S} / \mathrm{cm}$.

Trichocerca cf gracilis (Tessin 1890) (Lám. 9, fig. 6 )

Cuerpo delgado, el ancho es algo menos de $2 / 7$ de su longitud. En la parte anterior de la lóriga presenta pliegues longitudinales, separados del tronco por un surco transversal. 
Dedo izquierdo desarrollado con una longitud algo mayor que la mitad del cuerpo. Dedo derecho casi atrofiado.

Manubrio izquierdo del trophi robusto y curvado distalmente, recorrido por estrías longitudinales, manubrio derecho más delgado y comparativamente menos curvado distalmente. Alula del ramus izquierdo bien desarrollada.

\section{Dimensiones}

LC: 150-160, LDI: 80-85, LTR: 35.

\section{Distribución}

Estaría presente en América, Europa y Australia, la falta de descripción del trophi no permite conocer con certeza su distribucion.

\section{Comentarios}

Esta especie fue descripta originalmente sin considerar el trophi ; tampoco lo hicieron los pocos autores que posteriormente la registraron, entre ellos Koste (1972) quien la halló en el río Amazonas. La morfología externa de los ejemplares del Paraná coincide con la descripta para la especie, pero al no contar con análisis previos del trophi, el estatus definitivo de estos ejemplares del Paraná queda en revisión. Se la registró en la laguna Los Matadores, Santa Fe.

Trichocerca porcellus (Gosse 1851) (Lám. 9, fig. 7 )

Acanthodactylus tigris, Tessin 1890: 153, Lam.1:13

Cuerpo cilíndrico, corto y grueso, borde anterior terminado en dos dientes bien visibles uno de ellos generalmente de mayor tamaño. La cabeza se separa del tronco por un suave adelgazamiento del cuerpo. Posee una quilla que corre desde la base de los dientes anteriores a lo largo de los 2/3 del cuerpo. El pie presenta dos dedos curvados hacia arriba, cortos, con cerdas en la base. El izquierdo es un poco más largo que el derecho, siendo aproximadamente $1 / 3$ de la longitud del cuerpo contraído. El trophi presenta el ramus izquierdo más desarrollado que el derecho. El manubrio izquierdo es muy conspicuo, grueso y recto terminando en forma de ancla; el manubrio derecho es aproximadamente $1 / 3$ la longitud del izquierdo, recto y delgado a modo de una varilla.

\section{Dimensiones}

LC: 170-200, LDI: 45-50, LTR: 53-60. 


\section{Distribución}

Cosmopolita.

\section{Comentarios}

Bastante frecuente, presente en lagunas próximas a la ciudad de Santa Fe y en la provincia de Chaco (lagunas Sombrero, La Bella e Ingá) en aguas con conductividad < 200 $\mu \mathrm{mS} / \mathrm{cm}$.

\section{Trichocerca rattus (O. F. Müller 1776) (Lám. 10, fig. 1 )}

Rattulus carinatus, Lamarck 1801:394

Trichocerca cristata, Harring 1913:102

Cuerpo alargado, curvado dorsalmente, con una quilla que ocupa su mitad superior, con un ancho campo estriado. Borde anterior liso, sin dientes. Pie corto y cilíndrico. Dedo izquierdo tan largo como el cuerpo. Dedo derecho corto, de igual o menor en longitud que las cerdas acompañantes de su base. Fulcrum ancho distalmente a modo de $T$ invertida. Manubrio izquierdo más robusto que el derecho con el extremo distal curvado. En los ejemplares del río Paraná el manubrio derecho es casi recto, si bien este puede observarse también con una suave curvatura distal (Shiel \& Koste 1993). Ramus izquierdo más desarrollado, con el álula bifurcada. Alula derecha corta y de extremo redondeado.

\section{Dimensiones}

LC: 150-160, LDI: 140-145, LTR: 45-50.

\section{Distribución}

Cosmopolita.

\section{Comentarios}

Presente, aunque siempre en escaso número, desde Confluencia hasta el Río de la Plata, en ambientes con pH de 6,9-7,9, conductividad < $100 \mu \mathrm{S} / \mathrm{cm}$. Koste (1978) considera que puede vivir en un amplio rango de calidad de agua. Segers (2003) señala que su distribución estaría limitada a aguas frías y que probablemente en las regiones tropicales y subtropicales de América del Sur esté presente solamente $T$. braziliensis a quien se parece considerablemente. Sin embargo, el trophi de los ejemplares de T. braziliensis hallados en el río Paraná es casi el doble de tamaño que el de T. rattus y mientras que en la primera los dos manubrios son curvados en su extremo distal en la segunda uno de ellos es muy delgado y casi recto. Dado que $T$. rattus posee diferentes morfotipos, evidentemente es necesario un estudio más detallado de la especie que implique análisis 
del trophi. Sobre esta especie son muy escasos los dibujos y observaciones originales, sobre todo a nivel de los manubrios, los que si no son analizados en la posición correcta puede llevar a confusiones. La especie aquí considerada como $T$. rattus debería ser analizada también comparando ejemplares de la región holártica, lo que hasta el momento no ha sido posible.

Trichocerca ruttneri Donner 1953 (Lám. 10, fig. 2 )

\section{? Diurella dixon-nutalli, Hauer 1937/38: 377 fig.24}

Cuerpo robusto, curvado dorsalmente. En la parte anterior de la cabeza puede observarse un campo estriado corto que parte desde el borde anterior y llega hasta donde comienza el tronco. El pie es corto y cónico y de él salen dos dedos de los cuales el izquierdo está más desarrollado. En el nacimiento de estos últimos se observan también cerdas accesorias cortas. El fulcrum posee una base ancha, a modo de $\mathrm{T}$ invertida, el ramus izquierdo está mas desarrollado que el derecho, prolongándose en un álula de extremo afilado. Ambos manubrios son casi iguales en longitud y presentan el extremo distal curvado. Uncus izquierdo con cuatro dientes.

\section{Dimensiones}

LC: 170-175, LDI: 55-60, LDD: 40, LTR: 45.

\section{Distribución}

Cosmotropical.

\section{Comentarios}

Si bien es una especie conocida para la región neotropical (Koste \& José de Paggi 1982), su presencia en Argentina no había sido confirmada.

Trichocerca tigris (O.F. Müller 1786) (Lám. 10, fig. 3 )

Heterognathus macrodactylus, Schmarda 1859:52 Lam.12: 105

Cuerpo alargado, arqueado en ejemplares contraídos, borde anterior de la lóriga terminado en un diente robusto de punta aguzada y base ancha, formándose a ambos lados de éste pliegues longitudinales. Un suave pliegue transversal separa del tronco a la parte anterior. Quilla doble que corre desde la base del diente a lo largo de las dos terceras partes del 
cuerpo. Ambos dedos del pie están bien desarrollados, con cerdas cortas acompañantes.

El trophi presenta el manubrio izquierdo muy robusto en forma de ancla.

\section{Dimensiones}

LC: 180-190, LDI 70-80, LDD:50-55.

\section{Distribución}

Cosmopolita.

\section{Comentarios}

Esta especie es bastante frecuente en las áreas litorales vegetadas de las lagunas, aunque se la ha observado en muy baja densidad relativa.

Trichocerca voluta (Murray 1913) (Lám. 10, fig. 4 )

Trichocerca tropis , Hauer 1937: 286, Lám. 2 a-g

Cuerpo robusto, cilíndrico, corto. Posee una ancha quilla dorsal doble que se extiende desde la región apical hasta la base del pie. En corte transversal puede verse que ésta no sólo es ancha sino también elevada, proyectándose hacia afuera. Borde anterior liso sin espinas. Dedos cortos de casi igual longitud, aproximadamente 1/8 que la del cuerpo. El trophi presenta el manubrio y el ramus izquierdo más desarrollados, formando este último un álula de extremo muy aguzado. El manubrio izquierdo presenta el extremo distal curvado generando un talón posterior. El derecho es delgado y recto a modo de una fina varilla, siendo muy corto, representando aproximadamente la mitad de la longitud del izquierdo. Uncus izquierdo con una hilera de finos dientes. Fulcrum con una ancha base a modo de T invertida.

\section{Dimensiones}

LC: 150-160, LD: 35-40, LTR: 60-65.

\section{Distribución}

Cosmotropical.

\section{Comentarios}

Se la halló únicamente en el madrejón Pelón, ubicado en la isla del mismo nombre, situada frente a la provincia de Chaco, $\mathrm{pH} 7,3$, conductividad $179 \mu \mathrm{S} / \mathrm{cm}$.

\section{OTRAS OBSERVACIONES}


Entre las especies registradas en el río Paraná es muy frecuente, aunque siempre con escaso número de individuos, T. similis (Wierzejski) f. grandis. Si bien está presente T. similis típica, el morfotipo de mayor tamaño es el más frecuente. Este tendría una distribución marcadamente tropical, muy común en la cuenca del Amazonas (Koste 1972, 1989, Segers 2003).

Otras especies de distribución cosmopolitas, pero no confirmadas su presencia en Argentina fueron encontradas en este estudio; ellas son: T. insignis (Herrick) y T. scipio (Gosse) (Lám.10, fig. 5). 


\section{NUEVOS REGISTROS PARA LA FAUNA ARGENTINA}

Además de las 6 especies de Trichocerca que constituyen nuevas citas para Argentina, en este estudio se registraron 6 especies no conocidas previamente para el país, pertenecientes a los géneros Eosphora (Notommatidae), Euchlanis (Euchlanidae), Gastropus (Gastropodidae), Dicranophorus y Dicranophoroides (Dicranophoridae).

\section{Eosphora ehrenbergi (Ehrenberg 1832) (Lám. 11, fig. 1 )}

Notommata najas, Ehrenberg 1832: 132

E. ehrenbergi, Weber \& Montet 1918: 123

Los ejemplares se presentaron muy contraidos, en forma de saco, pero con el pie segmentado y los dedos visibles. El trophi es más pequeño que el descripto para la especie ( Nogrady \& Pourriot 1995 ), sin embargo presenta las características señaladas para el mismo. Unci con un solo diente, rami triangular, fulcrum robusto y muy ancho en vista lateral. Fulcrum con láminas laterales desarrolladas en su parte proximal. Hypofaringe par visible.

\section{Dimensiones:}

Longitud del trophi 45-50 $\mu \mathrm{m}$.

\section{Distribución}

Es una especie considerada cosmopolita

\section{Comentarios}

El género es litoral, reúne seis especies, cinco de ellas fueron citadas para Sudamérica, en Ecuador y Brasil. E. ehenbergi fue hallada solamente en Ecuador (Koste \& Bottger 1992). En el Pantanal se registraron unicamente E. anthadis Harring \& Myers y $E$. thoides Wulfert (Koste 1999), que presenta un trophi marcadamente diferente del de $E$. ehrenbergi.

La especie fue encontrada en una sola localidad, una laguna ubicada en Isla Nogueras, frente a Corrientes, $50 \mathrm{~cm}$ de profundidad, $\mathrm{pH} 6,4, \mathrm{~T} 25^{\circ} \mathrm{C}$, vegetación abundante con predominio de Scirpus sp. 
Gastropus minor (Rousselet 1892) (Lám. 11, fig. 2 )

Notopus minor, Rousselet 1892: 359 Fig 24:9-10

Hypopus ritenbeki, Bergendal 1892: 45 pl. 1: 6

Notopus fennicus, Stenroos 1898: 120 pl. 1:23-24

Gastropus minor, Weber 1898 p.752

Postclausa minuta, Hilgendorf 1899: 125 pl. 10:11

Postclausa circularis, Hilgendorf 1899: 126 pl.10:12

Cuerpo pequeño, redondeado, cubierto por una loriga delgada, elástica en apariencia. El pie se inserta ventralmente y termina en dos dedos iguales que se afinan en el extremo distal. Trophi con ramus triangulares terminados en álulas aguzadas, fulcrum de longitud aproximada a la del rami, unci con un diente bien afinado. Los manubrios son curvados en sus extremos y poseen una lamela doble, ancha y transparente muy visible en vista lateral.

\section{Dimensiones}

Longitud cuerpo: 80-95, trophi: 25-30 $\mu \mathrm{m}$.

\section{Distribución}

Cosmopolita

\section{Comentarios}

El género Gastropus solo tiene tres especies, planctónicas. El género no es muy frecuente en Argentina, donde se habia registrado solo G. stylifer Imhof. Se registró G. minor en una sola oportunidad, en una laguna ubicada en isla Lechiguana, frente a San Nicolás (provincia de Buenos Aires), pH 7,0.

\section{Dicranophoroides claviger (Hauer 1965) (Lám. 11, fig. 3 )}

Itura claviger, Hauer 1965: 355-356, figs 14 a-d

Itura claviger, Koste 1972: 381, pl 18, fig 2

Dicranophorus claviger, Koste 1978: 462, pl 168, figs 2 a-f 
Los ejemplares hallados presentaron cuerpo contraido, alargado, en forma de vaso, muy plegado en su parte anterior cefálica, mostrando una loriga delgada y fácilmente deformable por la fijación con formol. Posee dedos cortos y afinados en sus extremos.

El trophi forcipado, simétrico presenta una estructura simple, con ramus a modo de pinzas, con el borde interno liso, sin dientes. Con cámara sub-basal que se extiende a lo largo del ramus, cámara basal lateral. Fulcrum corto,1/3 de los ramus y relativamente ancho. Unci con un diente grande y otros muy pequeños.

\section{Dimensiones}

Cuerpo contraído: 130-150, Trophi: 45-47, Fulcrum $10 \mu \mathrm{m}$.

\section{Distribución}

Probablemente cosmotropical ya que ha sido hallada en Sudamérica (Amazonas, Koste \& José de Paggi 1982), Africa y Asia (De Smet 1997).

\section{Comentarios}

Esta especie fue recientemente adjudicada a un nuevo género Dicranophoroides (De Smet \& Pourriot 1997). El mismo se caracteriza por el trophi, donde cada ramus presenta una cámara sub-basal que se extiende apicalmente, más larga que la cámara basal. Este carácter separa al género de los restantes de la familia. La especie fue registrada en la laguna $\mathrm{N}^{\circ} 15$, ubicada en la Isla Carabajal, $\mathrm{pH} 6,9$.

Dicranophoroides caudatus (Ehrenberg 1834) (Lám. 11, fig. 4)

Diglena caudatus, Ehrenberg 1834: 205

Digelena biraphis, Gosse 1851: 200

Dicranophorus caudatus, Wulfert 1936: 407-408 figs. 3, 3ac

Dicranophorus caudatus braziliensis, Koste 1972: 378, PI.18, fig.1

Los organismos presentaron un cuerpo contraido, en algunos apenas visible el palpo impar ubicado en la cabeza. Dedos afinados, largos, aproximadamente $1 / 4$ de la longitud total. Trophi muy pequeño, robusto, con un fulcrum corto y triangular. Cámara sub-basal ancha que se angosta distalmente terminando en tres dientes delgados que se proyectan hacia adentro, cámara basal o scapus terminando en dos dientes, que se ubican por detrás de los de la cámara sub-basal. Unci con un solo diente. Manubrio con una lamella triangular en el extremo anterior.

\section{Dimensiones}

Longitud cuerpo contraído 280-300, trophi 30 manubrio 25 fulcrum $8 \mu \mathrm{m}$. 


\section{Distribución}

Cosmopolita

\section{Comentarios}

Presente en Sudamérica (Koste \& José de Paggi 1982). Esta especie puede ser abundante en aguas con sedimentos orgánicos (De Smet \& Pourriot 1997) se la encontró en el litoral vegetado de la laguna $\mathrm{N}^{\circ} 13$, ubicada en la isla Sirgadero, $\mathrm{pH} 6,9$.

Dicranophorus prionacis Harring \& Myers 1928 (Lám. 11, fig. 5 )

Dicranophorus prionacis, Harring \& Myers 1928, 702-703, lám.25, figs 5,6

Dicranophorus prionacis, Pourriot 1966: 479-480, fig. 4

Dicranophorus prionacis, Kutikova 1970: 382, figs. $433 \mathrm{ab}$

Cuerpo alargado, se contrae con la fijación. Dedos cortos, (1/7 del cuerpo contraído). Trophi forcipado, robusto. Fulcrum, corto (1/2 del ramus aproximadamente), triangular en vista lateral. Ramus con álula triangular, margen interno con dientes, 10-12, decreciendo en tamaño hacia el fulcrum. Unci con un solo diente. Manubrios robustos, curvados distalmente, con una pequeña cámara en su extremo proximal, con lamella laterales bien desarrolladas.

\section{Dimensiones}

Longitud cuerpo contraído 250-300, trophi 55-59, manubrio 50-52, fulcrum 18-20 $\mu \mathrm{m}$.

\section{Distribución}

Cosmopolita

\section{Comentarios}

La especie fue registrada en el madrejón Pelón, isla Pelón ubicada aguas abajo próximas a la confluencia del Paraná con el Paraguay. Secchi $88 \mathrm{~cm}, \mathrm{pH} 7,3, \mathrm{~T} 25^{\circ} \mathrm{C}$, vegetada con Salvinia sp. y Eichhornia sp. Conforme los registros en la literatura está presente tanto en aguas ácidas como alcalinas (De Smet \& Pourriot 1997).

Euchlanis lyra Hudson 1886 (Lám. 11, fig. 6 )

Euchlanis lyra, Hudson 1886:89, fig 23:1

Euchlanis myersi, Kutikova 1959: 223 
Cuerpo ovoide, con un marcado ensanchamiento posterior. En vista transversal se observa la lámina dorsal fuertemente arqueada, convexa, dos surcos laterales y la lámina o placa ventral plana. Dedos de bordes paralelos que se afinan casi abruptamente. Trophi con cinco pares de dientes de desigual tamaño.

\section{Dimensiones}

Longitud Lámina dorsal:170-180 lámina ventral:150-160 ancho:100-110, longitud dedos: 70-75 $\mu \mathrm{m}$.

\section{Distribución}

Cosmopolita

\section{Comentarios}

La especie fue encontrada en una laguna del Paraná Inferior, Isla Cataneo frente a San Nicolás de los Arroyos. Los ejemplares hallados son más pequeños que los registrados en la literatura. 


\section{REFERENCIAS}

Adámoli, J. \& A. Pott. 1999. Las fuentes de diversidad en el Pantanal. p 317-360. En Matteucci, S.D., Solbrig, O.T.,Morello, J. \& G. Halffer (Eds). Biodiversidad y uso de la tierra. Eudeba, $580 \mathrm{p}$

Ahlstrom E.H. 1940. A revision of the Rotatorian genera Brachionus and Platyias with descriptions of one new species and two new varieties. Bulletin fo the American Museum of Natural History 77 (3):143-148.

Ahlstrom E.H. 1943. A revision of the Rotatorian genera Keratella with descriptions of three new species and five new varieties. Bulletin fo the American Museum of Natural History 80 (12): 411-457.

Amoros, C. \& A.L. Roux. 1988. Interaction between waterbodies within the floodplains of large rivers: function and development of connectivity. p 125-130. En Screiber, K (ed) Connectivity in Landscape Ecology. Munstersche Geographische Arbeiten 29.

Amoros, C. \& G. Bornette. 2002. Connectivity and biocomplexity in waterbodies of riverine floodplains. Freshwater Biology 47: 761-776.

Aparici, E., Carmona J.J. \& M. Serra. 1996. Polymorphism in bisexual reproductive pattern of ciclical parthenogenesis. A simulation approach using a rotifer growth model. Ecological Modelling 88: 133-142

Ardnt, H. 1993. Rotifers as predators on components of the microbial web (bacteria, heterotrophic flagellates, ciliates) a review. Hydrobiologia 255/256: 231-246.

Arnott, S.E., Yan, N.D, Magnuson J.J. \& T. Forst, 1999. Interannual variability and species turnover of crustacean zooplankton in Shield lakes. Canadian Journal of Fisheries and Aquatic Sciences, 56: 162-172.

Baltanas, A. 1992 On the use of some methods for the estimation of species richness. Oikos 65:484-492. 
Baribwegure D. \& H. Segers. 2001. Rotifera from Burundi: the Lepadellidae (Rotifera: Monogononta). Hydrobiologia 446/447: 247-254.

Bó, R.F. \& R.D. Quintana. 1999. Actividades humanas y biodiversidad en humedales: el caso del Delta del río Paraná. En Matteucci, S.D., Solbrig, O.T.,Morello, J. \& G. Halffer (Eds). Biodiversidad y uso de la tierra. Eudeba, 580 p.

Bonecker, C.C. \& F.A. Lansac-Toha. 1996. Community structure of rotifers in two environments of the upper River Parana floodplain (MS)-Brazil. Hydrobiologia 325: 137-150.

Bonecker, C.C., Lansac-Toha, F.A. \& L.M. Bini, 1998a. Composition of zooplankton in different environments of the Mato Grosso Pantanal, Mato Grosso, Brazil. Anais do VIII Seminario Regional de Ecologia. Vol.3: 1123-1135.

Bonecker, C., Lansac-Toha \& D.C.Rossa. 1998b. Planktonic and non-planktonic rotifers in two environments of the Upper Parana River floodplain. State of Mato Grosso do Sul, Brazil. Brazilian Archives of Biology and Technology 41: 447-456.

Bonetto, A.A. 1986. The Paraná River System. p. 541-556. En Davies B. \& K.F. Walker (eds) The Ecology of River Systems. Dr.Junk Publications, The Netherlands.

Bonetto, A.A. \& E. Drago, 1968. Consideraciones faunísticas en torno a la delimitación de los tramos superiores del río Paraná. Physis 75: 437-444.

Bonetto, A.A. y Corrales, M. 1985. Zooplancton del río Paraná medio: variaciones temporales y distribucionales en el área de confluencia con el río Para guay. Ecosur 12/13:1-23.

Bonetto, A.A. \& I. Wais. 1995. Southern South American streams and rivers. p.257-294. En Cushing, C.E., Cummins, K.W.\& G.W. Minshall (eds) River and stream ecosystems. 817p.

Brandorf, G., Koste, W. \& N.N. Smirnov. 1982. The composition and structure of Rotiferan and Crustacean Communities of the lower Rio Nhamundá, Amazonas, Brazil. Studies on Neotropical Fauna and Environment 17:69-121. 
Brown, J.H. 1990. Species diversity, p 57-89. En: Myers, A. \& Giller, P. (eds.) Analytical Biogeography.An integrate approach to the study of animal and plant distributions. Chapman \& Hall.

Chengalath, R., Fernando C.H. \& W. Koste 1973. Rotifera from Sri Lanka (Ceylon). II Further studies on teh Eurotatoria including new records. Bulletin of Fisheries Research Station Sri Lanka (Ceylon) 24: 29-62.

Ciros-Perez, J., Gomez, A. \& M. Serra, 2001. On the taxonomy of three sympatric sibling species of the Brachionus plicatilis (Rotifera) complex from Spain, with the description of B.ibericus n.sp. Journal of Plankton Research 23(12): 1311-1328.

Clarín, 2004. Atlas Mundial. Fascículo 32.

Connell, J. H. 1978. Diversity in tropical rain forest and coral reefs. Science 199: 1302310.

Connell J. H. \& E. Orias, 1964. The ecological regulation of species diversity. American Naturalist 98: 399-414.

Corrales, M.A. 1979. Contribución al conocimiento del zoo- plancton del río Alto Paraná. Ecosur 6: 185-205

Corrales de Jacobo, M. \& S. M. Frutos. 1985. Estudio preliminar del zooplankton de la laguna Sirena (Corrientes, Argentina). Physis 43(104): 43-48.

Crisci, J.V., Posadas, P., Katinas, L. \& D. Miranda Esquivel. 1999. Estrategias evolutivas para la conservación de la biodiversidad en America del Sur Austral. P 175-198. En Matteucci, S.D., Solbrig, O.T.,Morello, J. \& G. Halffer (Eds). Biodiversidad y uso de la tierra. Eudeba, 580 p.

Cyr, H. \& J. A. Dowing. 1988. The abundance of phytophilous invertebrates on different species of submerged macrophytes. Freshwater Biology 20: 365-337.

Daday, E. 1897. Uj-Guineai Rotatoriak. Math Termész Ertesito 15: 1-56. 
Daday, E. 1905.Untersuchungen uber die SuBwasser Mikrofauna Paraguays. Zoologica 18 (44): 1-374.

DeMott, W.R. 1986. The role of taste in food selection by freshwater zooplankton. Oecologia 69: 334-340.

DeMott, W.R. 1988. Discrimination between algae and artificial particles by freshwater and marine copepods. Limnology and Oceanograph 33: 397-408.

De Ridder, M. 1981. Rotiferes, En: Symoens, J.J. Exploration hydrobiolgique du bassin du lac Bangweolo et du Luapula. vol XI 4: 166 pp. Cercle hydrobiologique de Bruxelles.

De Ridder, M. 1984a. A review of the rotifer fauna of the Sudan. Hydrobiologia 110: 113-130.

De Ridder, M. 1984b. Peuplement des Rotiferes du Bassin du Bandama (Cote d' Ivoire). Revue d'Hydrobiologie tropicale 17: 287-294.

De Ridder, M. 1987a. Distribution of rotifers in African fresh and inland saline waters. Hydrobiologia 147: 9-14.

De Ridder, M. 1987b. Nieuwe gegevens betreffende de verspreiding der raderdieren in Afrika. Biologisch Jaarboek Dodonaea 55/1: 57-68.

De Ridder, M. 1991. Rotifers from Algeria. Journal of African Zoology 105: 473-483.

De Smet, W.H. 1988. Contributions to the Rotifer Fauna of the Bas Zaire. I The Rotifers from some small ponds and a river. Biologisch Jaarboek Dodonaea 56: 115-131.

De Smet, W.H. 1989. Contributions to the Rotifer Fauna of the Bas Zaire. 2 Composition and seasonal abundance of Rotifers in a shallow pond. Biologisch Jaarboek Dodonaea 57: 62-77.

De Smet, W.H. \& R. Pourriot. 1997. The Dicranophoridae (Monogononta) and the Ituridae (Monogononta), en Nogrady T.(ed) Rotifera 5, Vol.12 Guides to the identification of the Microinvertebrates of the Continental Waters of the World. Dumont H.(ed). SPB Academic, $344 \mathrm{p}$. 
Devercelli, M. 2000. Efectos de las fases de aguas altas y bajas sobre el fitoplancton de ríos de distinto tamaño (Paraná Medio, Argentina). Tesina de Licenciatura en Biodiversidad, Universidad Nacional del Litoral, 35 pp.

Depetris, P. \& S. Kempe. 1990. The impact of the El Niño 1982 event on the Parana River, its discharge and carbon transport. Palaeogeography, Palaeoclimatology, Palaeoecology 89: 239-244.

Dhert, P., Rombaut, G.,Suantika, G. \& P. Sorgeloos. 2001. Advancement of rotifer culture and manipulation techniques in Europa. Aquaculture 200: 129-146.

Dieguez, M.del C. \& B. Modenutti. 1996. Keratella distribution in North Patagonian lakes (Argentina). Hydrobiologia 321: 1-6.

Drago, E. 1973. Características de la llanura aluvial del Paraná medio y sus cuerpos de agua. Boletín Paranaense de Geociencias 31: 31-44.

Drago, E.1976. Origen y clasificación de ambientes leníticos en la llanura aluvial. Revista de la Asociación de .Ciencias Naturales del Litoral 7: 123-137.

Drago, E., 1980. Aspectos limnológicos de ambientes próximos a la ciudad de Santa Fe (Paraná Medio): comportamiento hidrológico y sólidos suspendidos. Ecologia 5: 31-48.

Drago, E. 1984. Estudios limnológicos en una sección transversal del tramo medio del río Paraná. Revista de la Asociación de Ciencias Naturales del Litoral 15 (1):1-6.

Drago, E. 1990. Geomorphology of large alluvial rivers: lower Paraguay and Middle Paraná. Interciencia 15 (6).

Drago, E.C. \& M.A. Amsler. 1988. Suspended sediment at a cross section of the Middle Parana River: concentration, granulometry and influence on the main tributaries. Sediment Budgets 174: 381-395.

Duggan I.C., Green, J., Thompson, K. \& R. Shiel. 1998. Rotifers in relation to littoral ecotone structure in Lake Rotomanuka, Nort Island, New Zealand. Hydrobiology 387/388: 179-197. 
Duggan, I.C., Green, J., Thompson, K. \& R. Shiel. 2001. The influence of macrophytes on the spatial distribution of littoral rotifers. Freshwater Biology 46: 777-786.

Dumont, H. 1983. Biogeography of rotifers. Hydrobiologia 104: 19-30.

Dumont, H. \& H. Segers 1996. Estimating lacustrine zooplankton species richness and complementarity. Hydrobiologia 341: 125-132.

Frutos, S.M. 1993 Zooplancton en cuerpos de agua isleños del Bajo Paraná. Ambiente subtropical 3: 87-121.

Fu, Y., Hirayama, K. \& Y. Natsukari. 1991. Genetic divergence between S and L type strains of the rotifer Brachionus plicatilis O.F.M. Journal of Experimental Marine Biology and Ecology 151: 43-56.

Gannon, E. \& R. Stemberg 1978. Zooplankton (specially crustaceans and rotifers) as indicators of water quality. Transactions of the American Microscopical Society 97: 1635.

García de Emiliani, M.O. \& M. Manavella, 1983. Fitoplancton de los principales cauces y tributarios del valle aluvial del río Paraná: tramo Goya- Diamante. II. Revista de la Asociación de Ciencias Naturales del Litoral 14 (2): 217-237.

Garcia de Emiliani, M.O. \& M. Manavella, 1989. Fitoplancton y variables ambientales en la cuenca del río Saladillo (Santa Fe, Argentina). Revista Brasilera de Biología 49(4): 957-967.

Giacosa R, Paoli, C. \& Cacik, P. 2000. Conocimiento del régimen hidrológico,p. 69-104. En: Paoli, C. \& M. Schreider (eds). El río Paraná en su tramo medio. Contribución al conocimiento y prácticas ingenieriles en un gran río de llanura. Centro de Publicaciones, Secretaria de Extensión Universidad Nacional del Litoral, Tomo I, 309 p.

Gilbert, J.J. 1995. Structure, development and induction of a new diapause stage in rotifers. Freshwater Biology 34: 263-270. 
Gillard, A.A.M. 1948. De Brachionidae (Rotatoria) van België met Beschouwingen over de Taxonomie van de Familie. Natuurwetenschappelijk Tijdschrift 30: 159-218.

Gillard, A. 1959. Contribution a I étude des Rotifères du Congo Belge et de Ruanda. Revue de Zoologie et de Botanique Africaines: 60:3-4.

Gliwicz, Z.M. 1969. Studies on the feeding pelagic zooplankton in lakes with varying trophy. Ekologia Polska17: 663-708.

Gliwicz, Z.M. 1977. Food size selection and seasonal succession of filter feeding zooplankton in an eutrophic lake. Ekologia Polska. 25: 179-225.

Gomez, A. 1998. Allozyme electrophoresis: its application to rotifers. Hydrobiologia 387/388: 385-393.

Gomez, A. \& M. Serra, 1995. Behavioral reproductive isolation among sympatric strains of Brachionus plicatilis Muller, 1786: insights into the status taxonomic species.

Hydrobiologia 313/314:: 111-119.

Gomez, A. \& T. W. Snell, 1996. Sibling species and cryptic speciation in the Brachionus plicatilis species complex (Rotifera). Journal of Evolutionary Biology, 9: 953-964.

Green, J. 1960. Zooplankton of the River Sokoto. The Rotifera. Proceedings and Transactions of the Zoological Society of London 137: 491-523.

Green, J. 1974. Parasites and epibionts on Cladocera. Transactions of the Zoological Society of London 32: 417-515

Green, J. 1994. The temperate-tropical gradient of planktonic Protozoa and Rotifera. Hydrobiologia 272: 13-26.

Green,J. \& S. Mengestou. 1991. Specific diversity and community structure of Rotifera in a salinity series of Ethiopian inland waters. Hydrobiologia 209: 95-106

Hamilton K., Sippel, S., Lewis, W.M. \& J. Saunders III. 1990. Zooplankton abundance and evidence for its reduction by macrophyte mats in two Orinoco flood plain lakes.- Journal of Plankton Research 12 :345-363. 
Hardy, E.R , Robertson, B. \& W. Koste. 1984. About the relationship between the zooplankton and fluctuating water levels of Lago Camaleao, a Central Amazonian varzea lake. Amazoniana 9: 43-52

Harring, H. 1914. Report on Rotatoria from Panama with description on new species. Proceedings of United States National Museum.

Harrinson, S., Ross, S.J. \& J.H. Lawton 1992. Beta diversity on geographic gradients in Britain. Journal of Animal Ecology 61: 151-158.

Hart, R.C. 1986a. Aspect of the feeding ecology of turbid water zooplankton. In situ studies of community filtration rates in silt-laden Lake Le Roux, Orange River, South Africa. Journal of Plankton Research, 8: 401-426.

Hart, R.C. 1986b. Zooplankton abundance, community structure and dynamics in relation to inorganic turbidity and their implications for a potential fishery in subtropical Lake Le Roux, South Africa. Freshwater Biology 16: 351-371.

Hart, R.C. 1988. Zooplankton feeding rates in relation to suspended sediment content: potential influences on community structure in a turbid reservoir. Freshwater Biology 19: 123139.

Hauer, J. 1953. Zur Rotatorienfauna von Nordostbrasilien. Archiv für Hydrobiologie 48 (2): 154-172.

Hauer, J. 1956. Rotatorien aus Venezuela und Kolumbien. Ergebnissen der Deutschen Limnologischen Venezuela-Expedition 1952 1: 277-312.

Hauer, J. 1965. Zur Rotatorienfauna des Amazonasgebeites. Internationale Revue of Hydrobiologie 50 (3): 341-389.

Heckman, C.W. 1998. The seasonal succession of biotic communities in wetlands of the Tropical wet-and dry climatic zone. V. Aquatic invertebrates communities in the Pantanal of Mato Grosso, Brazil. Internationale Revue der Gesamten Hydrobiologie 83(1): 31-63. 
Huespe, J. \& S. Ratto, 2001. Guía Hidrográfica del Río Paraná. Tramo Medio km 470680. Centro de Publicaciones, Secretaria de Extensión de la Universidad Nacional del Litoral, $10 \mathrm{p}$.

Hynes, HB.N. 1970 The ecology of running waters University of Toronto Press, 555p.

Iriondo, M. 1972. Mapa geomorfológico de la llanura aluvial del río Paraná desde Helvecia hasta San Nicolás. República Argentina. Revista de la Sociedad Geológica Argentina 27 (2): 155-160.

Iriondo, M. \& E, Drago. 1972. Descripción cuantitativa de dos unidades geomorfológicas de la llanura aluvial del Paraná Medio. Rep.Arg. Revista de la Asociación Geológica Argentina. 27: $143-160$

Jenkins D. G. \& M. O. Underwood. 1998. Zooplankton may not disperse readily in wind, rain, or waterflow. Hydrobiologia 387/388: 15-21.

José de Paggi, S. 1978a. First observations on longitudinal succession of zooplankton in main course of the Parana River between Santa Fe and Buenos Aires harbour. Studies on Neotropical Fauna and Environments 13: 143-156.

José de Paggi, S. 1978b. Observaciones sobre algunos rotiferos nuevos para la Fauna Argentina. Neotropica 24: 99-104.

José de Paggi, S. 1981. Variaciones temporales y distribución horizontal del zooplancton en algunos cauces secundarios del río Paraná Medio. Studies on Neotropical Fauna and Environment 16: 185-199.

José de Paggi, S. 1989. Rotíferos de algunas provincias del Noroeste de Argentina. Revue d' Hydrobiologie tropicale 22 : 223-238.

José de Paggi, S. 1990. Ecological and biogeographical remarks on the rotifer fauna of Argentina. Revue d'Hydrobiologie tropicale 23 (4): 297-311.

José de Paggi, S. 1993.Composition and seasonality of planktonic rotifers in limnetic and littoral regions of a floodplain lake (Parana river system). Revue d'Hydrobiologie tropicale. 26: 53-63. 
José de Paggi, S. 1996. Rotifera (Monogononta) diversity in subtropical waters of Argentina. Annales de Limnologie 32 (4): 209-220.

José de Paggi, S. 1997. Efecto de los pesticidas sobre el zooplancton de las aguas continentales: análisis revisivo. FABICIB 1: 103-114.

José de Paggi, S. 2001. Diversity of Rotifera (Monogononta) in wetlands of Río Pilcomayo National Park, Ramsar Site (Formosa, Argentina).Hydrobiologia 462: 25-34.

José de Paggi, S. 2002 a. Asplanchnidae, p 1-27. En: Nogrady T. \& H. Segers (eds) Rotifera 6. Vol. 18 Guides for the Identification of the microinvertebrates of continental waters of the world. Dumont H.(ed). Backhuys Publishers.

José de Paggi, S. 2002 b. New data on the distribution of Kellicottia bostoniensis (Rousselet, 1908) (Rotifera: Monogononta: Brachionidae): its presence in Argentina. Zoologischer Anzeiger 241 (4): 363-368.

José de Paggi, S. \& W. Koste. 1987 Rotifera from Saladillo River basin (Santa Fe province, Argentina). Hydrobiologia 157: 13-20.

José de Paggi, S. \& W. Koste. 1995. Additions to the Checklist of Rotifers of the Superorder Monogononta recorded from Neotropis. Internationale Revue der Gesamten Hydrobiologie 80: 133-140.

Junk, W. 1997. The Central Amazon Floodplain. Ecological Studies 126. Springer Verlag.

Junk, W., Bayley P. \& R. E. Spark. 1989. The Flood Pulse Concept in River-Floodplain Systems. Canadian Special Publication, Fisheries Aquatic Sciences 106: 110-125.

Junk, W. \& C. Da Silva. 1995. Neotropical floodplains a comparison between the Pantanal of Mato Grosso and the large Amazonian river floodplains. 195-218 p. En: Tundisi, J.G., Bicudo, C.E.M. \& T. Matsumura Tundisi. Limnology in Brazil. Brazilian Academy of Sciences -Brazilian Limnological Society 376 p.

Junk W. \& G. Weber. 1996. Amazonian floodplains: a limnological perspective. Internationale Vereinigung für Theoretische und Angewandte Limnologie 26: 149-157. 
Junk, W. \& B. Robertson. 1997. Aquatic Invertebrates, 279-298 pp. En Junk, W. (ed). The Central Amazon Floodplain. Ecological Studies 126. Springer Verlag.

Kalff, J. 2002. Limnology. Prentice Hall, 592 p.

Kirk, K.L. 1991. Inorganic particles alter competition in grazing plankton: the role of selective feeding. Ecology 72: 915-923.

Kirk, K.L. \& J.J.Gilbert 1990. Suspended clay and the population dynamics of planktonic rotifers and cladocerans. Ecology $71:$ 1741-1755.

Klopfer, P.H. 1959. Environmental determinants of fauna diversity. American Naturalist 93: 337-342.

Koch, L.P. 1957. Index of biotal dispersity. Ecology 38: 145-148.

Koste, W. 1972. Rotatoriens aus Gewässern Amazonies. Amazoniana III 3/4: 258-505.

Koste, W. (1974). Über Rotatorien aus einem Ufersee des unteren Río Tapajós, dem Lago Paroni. Gewässer und Abwässer 53/54: 43-68.

Koste, W. 1978. Rotatoria. Die Radertiere Mitteleuropas. Borntraeger, Berlin, 2 vols. 673 pp. 234 plates.

Koste, W. 1986. Über die Rotatorienfauna in Gewässern südÖstlich von Concepción, Paraguay, Südamerika. Osnabrücker Naturwissenschaftliche Mitteilugen 12 :129-155. 17 Abb.

Koste, W. 1988. Rotatorien aus Gewassern am Mittleren Sungai Mahakam, einem uberschwemmungsgebiet in E-Kalimantan, Indonesian Borneo. Osnabrucker naturwiss. Mitt. 14: $91-136$.

Koste, W. 1989. Über Rädertiere (Rotatoria) aus dem Lago do Macaco, einem Ufrsee des mittleren Rio Trombetas, Amazonien. Osnabrücker naturwiss. Mitt. 15 S.199-214. 15 Abb. 
Koste, W. 1999. Uber Radertiere (Rotifera) aus Gewässern des sudlichen Pantanal (Brasilien). Osnabrucker Naturwissenschaftliche Mitteilungen 25: 179-209.

Koste, W. 2000. Study of the Rotatoria Fauna of the Litoral of the Rio Branco, South of Boa Vista, Northern Brazil. International Review of Hydrobiologya 85: 433-469.

Koste, W. \& K. Bottger. 1992. Rotatorien aus Gewassern Ecuadors II. Amazoniana 12: 263303.

Koste, W. \& S. José de Paggi.1982. Rotifera of the Superorder Monogononta recorded from Neotropis. Gewasser und Abwasser 68-69: 71-102.

Koste, W., Robertson, B. \& E. Hardy. 1984. Further taxonomical studies of the Rotifera from Lago Camaleao a Central Amazonian varzea lake (Ilha de Marchantaria, Rio Solimoes, Amazonas, Brazil). Amazoniana 8: 555-576

Koste, W. \& R. J. Shiel. 1987. Rotifera from Australian Inland Waters II Epiphanidae and Brachionidae (Rotifera: Monogononta) Invertebrate Taxonomy 7: 949-1021.

Koste, W. \& R. J. Shiel. 1989a. Classical taxonomy and modern methodology. Hydrobiologia 186/187: 279-284.

Koste, W. \& R. J. Shiel. 1989b. Rotifera from Australian inland waters IV. Colurellidae (Rotifera: Monogononta). Transactions of the Royal Society of South Australia 113 (3): 119143.

Koste, W. \& R. J. Shiel. 1989c. Rotifera from Australian inland waters. III. Euchlanidae, Mytilindae and Trichotridae (Rotifera: Monogononta). Transactions of the Royal Society of South Australia 113, 1 \& 2: 85-114.

Koste, W. \& R.J. Shiel. 1990. Rotifera from Australien inland waters V. Lecanidae (Rotifera: Monogononta). Transactions of the Royal Society of South Australia 114 (1): 1-36.

Koste, W. \& R. J. Shiel 1991. Rotifera from Australian inlad waters. VII. Notomatidae (Rotifera: Monogononta). Transactions of the Royal Society of South Australia 115 (3): 111159. 
Koste, W. \& R. J. Shiel. 1992. Rotifera from Australian inland waters VIII. Trichocercidae (Monogononta). Transactions of the Royal Society of South Australia 116 (1): 1- 27.

Kreb, C.J. 1999. Ecological Methodology. Addison Wesley Longman, 620 pp

Kuczynski, D. 1991. Rotifers from Reconquista River, Argentina: the genus Brachionus with descriptions of new species. Hydrobiologia 215: 135-152.

Kuczynska-Kippen, N. 2003. The distribution of rotifers (Rotifera) within a single Myriophyllum bed. Hydrobiologia 506-509

Kuczynska-Kippen, N. \& B. Nagengast. 2003. The impact of the spatial structure of hydromacrophytes on the similarity of rotifera comunities (Budzynskie Lake,Poland). Hydrobiologia 506-509: 333-335.

Kutikova, L.A. \& C.H. Fernando. 1995. Brachionus calyciflorus Pallas (Rotatoria) in inland waters of tropical latitudes. Internationale Revue der Gesamten Hydrobiologie, 80(3): 429441.

Lampert, W. \& U. Sommer.1997. Limnoecology. The ecology of lakes and streams. Oxford University Press. 382 p.

Langley, J.M., Shiel, R., Nielsen, D.L. \& J. D. Green, 2001. Hatching from the sediment egg-bank, or aerial dispersing?.- the use of mesocosms in assessing rotifer biodiversity. Hydrobiologia 446/447: 203-211.

Lansac Toha, F.A, Costa Bonecker, C. Machado Velho, F. \& A. Fonseca Lima. 1997. Composicão, distribuicão e abundancia da comunidade zooplanctonica. 117-154. En Vazzoler, A.E. , Agostinho, A.A. \& N.S. (Hahn eds). A planicie de inundacão do Alto Rio Paraná: aspectos fisicos, biologicos e socioeconomicos. Ed. Univ. Estadual de Maringa.

Lewis, W.M., Hamilton, S. \& J.F. Saunders III. 1995. Rivers of northern South America. p 219-256.En Cushing, C.E., Cummins, K.W., Minshall, G.W. (eds). River and stream ecosystems. Amsterdam, Elsevier, 817 p. 
Lopes, R.M., Lansac-Toha, F., Vale, R. \& M. Serafim Jr. 1997. Comunidade zooplanctonica do reservatorio de Segredo. p: 39-60. In: Agostinho, A.A. \& L.C.Gomes, L.C. ( eds ) Reservatorio de Segredo, bases ecologicas para o manejo. 387 pp., EDUEM

Lynch, M. \& Shapiro J. 1981. Predation, enrichment, and phytoplankton community structure. Limnology and Oceanography 26: 86-102.

MacArthur, R. H. 1972. Geographical ecology: patterns in the distribution of species. Harper \& Row Publishers, New York, 269 p.

MacArthur, R. H. \& E. O. Wilson. 1967. The Theory of Island Biogeography. Princeton. Princenton University Press, 203 p.

Marchese, M. \& I. Ezcurra de Drago. 1992. Benthos of the lotic environments in the middle Parana River system: transverse zonation. Hydrobiologia 237: 1-13.

Marinone, M.C. 1994. A new and phylogenetically suggestive morphotype of Keratella lenzi (Rotifer, Monogononta), from Argentina. Hydrobiologia 299: 249-257.

Marinone, M.C. \& H. Zagarese 1991. A field and laboratory study on factors affecting polymorphism in the rotifer Keratella tropica. Oecología 86: 372-377.

Martínez C.C. \& S. José de Paggi. 1988. Especies de Lecane Nitzch (Rotifera, Monogononta) en ambientes acuáticos del Chaco Oriental y del valle aluvial del río Paraná (Argentina). Revue d'Hydrobiologie tropicale 21 (4): 279-295.

Menge, B. \& J.P. Sutherland, 1976. Species diversity gradients: synthesis of the roles of predation, competition, and temporal heterogeneity. American Naturalist 110: 351-369.

Miquelis,A., Rougier, C. \& R. Pourriot. 1998. Impact of turbulence and turbidity on the grazing rate of the rotifer Brachionus calyciflorus (Pallas). Hydrobiologia 386: 203-211.

Miracle, M. R. y M. Serra, 1989. Salinity and temperature influence in rotifer life history characteristics. Hydrobiologia 186/87: 81-102

Modenutti, B, Dieguez, M.C. \& H. Segers. 1998. A new Keratella from Patagonia. Hydrobiologia 389: 1-5. 
Morello, J. 1984. Perfil ecológico de Sudamérica. Características estructurales de Sudamérica y su relación con espacios semejantes del planeta. Ediciones Cultura Hispana $\mathrm{ICl}, 93$ p.

Moss,B. 2000. Biodiversity in fresh waters an issue of species preservation or system functioning. Environmental Conservation 27:1-4.

Murray, J. 1913. South American Rotiferan. Journal of the Royal Microscopical Society: 229246, 341-362, 449-454.

Neiff, J.J. 1990. Ideas para la interpretación ecológica del Paraná. Interciencia 15(6): 424441.

Neiff, J.J. 1997. El régimen de pulsos en ríos y grandes humedales en Sudamerica. En A.I. Malvarez \& P. Kandus (comps) Tópicos sobre Humedales Sudamericanos. Publicación ORCYT-MAB-UNESCO.

Neiff, J.J. 2002. Diversity in some tropical wetland systems of South America. pp 157-186. En Gopal, B., Junk W.J. \& J. A. Davis (eds) Biodiversity in wetlands: assessment function and conservation. Vol.2.

Nogrady, T, Wallace R.L. \& T.W. Snell, 1993. Biology, Ecology and Systematics, En Nogrady T.(ed) Rotifera I vol 4 Guides for the Identification of the microinvertebrates of continental waters of the world. Dumont H (ed) SPB Academic Publishing bv. 142 p.

Nogrady, T. \& R. Pourriot, 1995. The Notommatidae and the Scaridiidae, En Nogrady T.(ed) Rotifera 3 vol 8 Guides for the Identification of the microinvertebrates of continental waters of the world. Dumont H (ed) SPB Academic Publishing bv. 248 p.

Odum, E. 1982. Ecologia. Interamericana. 639 pp.

Oldani, N. \& A. Tablado. 1985. Dinámica temporal de pequeños peces de aguas libres en laguna La Cuarentena (Isla Carabajal, Paraná medio). Studies on Neotropical Fauna and Environment 20 (1): 49-58. 
Paggi, J.C. \& S.José de Paggi, 1973. Sobre algunos rotíferos nuevos para la Fauna Argentina. Revista de la Asociación de Ciencias Naturales del Litoral 4: 49-60.

Paggi, J.C. \& S.José de Paggi, 1990. Zooplankton of lotic and lenitic environments of the Middle Parana River. Acta Limnologica Brasiliensis 3: 685-719.

Paoli, C., Iriondo, M. \&. García, N. 2000. Características de las cuencas de aporte, p 2768, En: Paoli, C. \& M. Schreider (eds). El río Paraná en su tramo medio. Contribución al conocimiento y prácticas ingenieriles en un gran río de llanura. Centro de Publicaciones, Secretaria de Extensión Universidad Nacional del Litoral, Tomo I, 309 p.

Paoli, C. \& P.Cacik. 2000. Régimen de crecidas y análisis de caudales máximos. P 105171 En: Paoli, C. \& M. Schreider (eds). El río Paraná en su tramo medio. Contribución al conocimiento y prácticas ingenieriles en un gran río de llanura. Centro de Publicaciones, Secretaria de Extensión Universidad Nacional del Litoral, Tomo I, 309 p.

Pejler, B. 1962. On the taxonomy and ecology of benthic and periphytic Rotatoria. Investigations in northern Swedish Lapland. Zoologiska Bijdrag fran Uppsala 33: 327-422.

Pejler, B. 1977. General problems of rotifer taxonomy and global distribution. Archiv fur Hydrobiologie Beiheft 8: 212-220.

Pejler, B. \& B. Berzins, 1994. On the ecology of Lecane (Rotifera). Hydrobiologia 273: 7780.

Perez Garcia, A.P., Lansac-Toha, F. \& C. Bonecker. 1998. Species composition and abundance of Rotifers in different environments of the floodplain of the Upper Parana River, Brazil. Revista Brasilera de Zoologia 15(2): 327-343.

Pianka, E. R.1966. Latitudinal gradients in species diversity: a review of concepts. American Naturalist 100: 33-46

Pollard, A.I., González, M.J., Vanni, M.J. \& J.L. Headworth. 1998. Effects of turbidity and biotic factors on the rotifer community in an Ohio reservoir. Hydrobiologia 387/388: 215223. 
Pontin, R. \& R. Shiel. 1995. Periphytic rotifer communities of an Australian seasonal floodplain pool. Hydrobiologia 313/314: 63-67.

Pourriot, R. 1968. Rotiferes du lac Tchad. Bulletin de I'I.F.A.N. XXX,ser.A, n²: 472-496.

Quiros, R. 1990. The Paraná River basin development and the changes in the lower basin fisheries. Interciencia 15 (6): 442-451.

Quirós, R. \& S.Cuch. 1989. The fisheries and limnology of the lower La Plata Basin, En: D.P.Dodge (ed). Proceedings of the International Large River Symposium. Canadian Special Publication in Fisheries and Aquatic Sciences 106: 429-443.

Ramonell, C.G., Amsler, M. \& H. Toniolo. 2000. Geomorfología del cauce principal. En: Paoli, C. \& M. Schreider (eds). El río Paraná en su tramo medio. Contribución al conocimiento y prácticas ingenieriles en un gran río de llanura. Centro de Publicaciones, Secretaria de Extensión Universidad Nacional del Litoral, Tomo I, 309 p.

Rapoport, E.H. 1990. Contaminación por especies. En: Latinoamérica: Medio Ambiente y Desarrollo. IEIMA: 67-70.

Reynolds, P.S. \& J.-P. Descy. 1996. The production, biomass and structure of phytoplankton in large rivers. Archiv fur Hydrobiologie. Supplementband 113: 161-187 Ricci, C., Serra, M. \& T.Snell. 2000. Small, beautiful and sexy: what rotifers tell us about ecology and evolution. Tree 15 (6): 220-221.

Ricklefs, R. E. 1998. Invitación a la Ecología. Ed. Panamericana, 692 p.

Ricker, W.E. 1958. Handbook of computation for biological statistics of fish populations. Bulletin Fisheries Research Board of Canada 119, 300 p.

Rico-Martinez, R. \& T. Snell, 1995. Mating behavior and mate recognition pheromone blocking of male receptors in Brachionus plicatilis Muller (Rotifera). Hydrobiologia 313/314: 105-110.

Rico-Martinez, R. \& T. Snell, 1997 a. Comparative binding of antibody to a mate recognition pheromone on female Brachionus plicatilis and Brachionus rotundiformis (Rotifera). Hydrobiologia 358"71-76. 
Rico-Martinez, R. \& T. Snell 1997 b. Mating behavior in eight rotifer species: using crossmating test to study species boundaries. Hydrobiologia 356: 165-173.

Ringuelet, R. A. 1961. Rasgos fundamentales de la zoogeografía de la Argentina. Physis 22(63):151-170.

Robertson, B. A. \& E. Hardy. 1984. Zooplankton of Amazonian lakes and rivers. pp 337-352 En Sioli H.(ed). The Amazon: limnology and Landscape Ecology of a Mighty Tropical River and its Basin. Monogr.Biol. 56, Junk.

Rocha, O. Tundisi, T.M. \& I.G.Tundisi 1994. Latitudinal trends of zooplankton diversity in the Neotropical Region: present knowledge and future needs. Anais de Academia Brasileira de Ciencias. 66 (1): 41-47.

Ruttner-Kolisko, A. 1974. Planktonic rotifers biology and taxonomy. Die Binnengewasser (Supplement) 26: 1-46.

Ruttner- Kolisko, A. 1989. Problems in taxonomy of rotifers, exemplified by the Filinia longiseta-terminalis complex. Hydrobiologia 186/187: 291-298.

Samanez, I. 1988. Rotiferos planctonicos de la Amazonia Peruana. I. Rotiferos del departamento de Ucayali. Revista Peruana de Biología 3. (1): 141-167.

Saunders, J.F. \& W. M. Lewis. 1988. Zooplankton abundance in the Caura River, Venezuela. Biotropica 20(3): 206-214

Scheffer, M.1998. Ecology of shallow lakes. Chapman \& Hall, 355 p.

Segers, H. 1993. Rotifera of some lakes in the floodplain of the River Niger (Imo State, Nigeria). 1. New species and other taxonomic considerations. Hydrobiologia 250: 39-61.

Segers, H., 1995a. World records of Lecanidae (Rotifera, Monogononta). Studiedocumenten van Het K.B.I.N. p 114.

Segers, H., 1995b. The Lecanidae (Monogononta), En En Nogrady T. (ed) Rotifera 2 vol 6 Guides to the Identification of the Microinvertebrates of the Continental Waters of the World . Dumont H. (ed) SPB Academic Publishing bv, 226pp. 
Segers, H. 1995c. Nomenclatural consequences of some recent studies on Brachionus plicatilis (Rotifera, Brachionidae). Hydrobiologia 313/314: 121-122.

Segers, H. 1996. The biogeography of littoral Lecane Rotifera. Hydrobiologia 323: 169197.

Segers, H. 1997. Some Rotifera from the collection of the Academy of Natural Sciences of Philadelphia, including new species and new records. Proceedings of the Academy of Natural Sciences of Philadelphia 148: 147-156.

Segers, H. 2001. Zoogeography of the Southeast Asian Rotifera. Hydrobiologia 446/447: 233-246.

Segers, H. 2002. The nomenclature of the Rotifera: annotated checklist of valid family and genus group names. Journal of Natural History 36: 631-640.

Segers, H. 2003. A biogeographical analysis of rotifers of the genus Trichocerca Lamarck 1801 (Trichocercidae, Monogononta, Rotifera) with notes on taxonomy. Hydrobiologia 500: 103-104.

Segers, H. \& S.S. S. Sarma. 1993. Notes on some new or little known Rotifera from Brazil. Revue d'Hydrobiologie tropicale 26 (3): 175-185.

Segers, H., Nwadiaro, C.S. \& H. Dumont. 1993. Rotifera of some lakes in the floodplain of the River Niger(Imo State Nigeria). II Faunal composition and diversity. Hydrobiologia 250: 63-71.

Segers, H. \& L. De Meester. 1994. Rotifera of Papua New Guinea, with the description of a new Scaridium Ehremberg 1830. Archiv fur Hydrobiologie 131: 111-125.

Segers, H., N.L. Ferrufino \& L. De Meester, 1998. Diversity and zoogeography of Rotifera (Monogononta) in a floodplain Lake of the Ichilo River, Bolivia, with notes on little-known species. Internationale Revue der Gesamten Hydrobiologie, 83 (5-6): 439-448. 
Segers, H., Kotethip W. \& L. Sanoamuang (en prensa). Biodiversity of freshwater microfauna in the floodplain of the River Mun, Northeast Thailand: The Rotifera monogononta. Hidrobiología.

Sendacz, S. 1993. A study on the zooplankton community of the upper Parana and floodplain lagoons. PhD tesis. University of São Paulo.

Serra, M., Galiana, A. \& A. Gomez. 1997. Speciation in monogonont rotifers. Hydrobiologia 358:63-70.

Serra M. \& C.E. King 1999. Optimal rates of bisexual reproduction in cyclical parthenogenesis with densisty-dependent growth. Journal of Evolutionary Biology $12: 263-271$.

Shaden, R. 1977. Zur Zyklomorphose einiger Brachioniden (Rotatorian) Zentralamazonien. Amazoniana 6: 257-266.

Sharma, B. \& S. Sarma. 2001. Biodiversity of Rotifera in some tropical floodplain lakes of the Brahmaputra river basin, Assm (NE India) Hydrobiologia 446/447: 305-313.

Shiel, R.J. \& K. F. Walker. 1985. Zooplankton of regulated and unregulated rivers. The Murray Darling River System, Australia. En: Lillehammer L. \& S.J. Saltveit (eds):Regulated Rivers. Universitetsforlaget AS, Oslo, p.263-270.

Shiel, R.J. \& W. Koste. 1993. Rotifera from Australian inland waters VIII. Trichocercidae (Monogononta). Transactions of the Royal Society of South Australia 116(1): 1-27.

Shiel, R.J., Green J.D. \& D.L. Nielsen. 1998. Floodplain biodiversity: why are there so many species. Hydrobiologia 387/388: 39-46.

Sioli, H. 1984. The Amazon. Limnology and ladscape ecology of a mighty tropical river and its basin. Dr W.Junk Publishers. 763 p.

Sladecek, V., 1983. Rotifers as indicators of water quality. Hydrobiologia, 100: 169-201

Snell, T. \& R. Janssen. 1995. Rotifers in ecotoxicology: a review. Hydrobiologia 313/314: 231-247. 
Snell, T.W. 1998. Chemical ecology of rotifers. Hydrobiologia 387/388: 267-276.

Snelll, T.W., Rico-Martinez, L.S. Kelly, N. \& T.E. Battle 1995. Identification of a sex pheromone from a rotifer. Marine Biology 123: 347-353.

Sokal, R.R. \& C.D. Michener. 1958. A statistical method for evaluating systematic relationship. University of Kansas Scientifical Bulletin 38: 1409-1438.

Solbrig, O. 1991. Biodiversity: scientific issues and collaborative research proposals. UNESCO, $77 \mathrm{p}$.

Soldano, F. 1947. Régimen y aprovechamiento de la Red Fluvial Argentina: el río Paraná y sus tributarios. Editorial Cimera, vol.1, 217 p.

Sparks, R.E., Bayley, P., Kholer, S.L. \& L.L. Osborne. 1990. Disturbance and recovery of large floodplain rivers. Environmental Management 14: 699-709.

Stemberger, R.S., 1990. An inventory of rotifer species diversity of northern Michigan inland lakes. Archiv fur Hydrobiologie. 118:283-302.

Stemberger, R.S. \& J.J. Gilbert. 1987. Multiple species induction of morphological defenses in the rotifer Keratella testudo. Ecology 68: 370-378.

Sudzuki, M. 1977. Some puzzling problems in the taxonomy of Brachionus and Keratella Archiv fur Hydrobiologie 8: 230-231.

Systematics Agenda 2000. 1994. Systematics Agenda 2000: Charting the Biosphere. Technical Report. New York: Society of systematic Biologist, American Society of Plant Taxonomists, Willi Henning Society Association of Systematics Collections.

Tan, L. \& R. J. Shiel. 1993. Responses of billabong rotifer communities to inundation. Hydrobiologia 255/56: 361-369.

Tilman, D. 1982. Resource Competition and Community Structure. Princeton: Princenton University Press. 
Turner, P. \& C. Da Silva. 1992. Littoral rotifers from the State of Mato Grosso, Brazil. Studies on Neotropical Fauna and Environments 27 (4): 227-241.

Vannote, R.L., Minshall G.W., Cummins, K.W., Sedell, J.R. \& C.E. Cushing. 1980. The River Continuum Concept. Canadian Journal of Fisheries and Aquatic Sciences 37: 130137.

Vásquez, E. 1989. The Orinoco River: a review of hydrobiological research. Regulated rivers: Research \& Management 3: 381-392.

Vásquez, E. 1991. Variación morfológica del rotífero Keratella americana (Carlin, 1943) de una laguna de inundación del río Orinoco, Venezuela. Revue d'Hydrobiologie tropicale 24 (2): 83-90.

Vásquez, E. \& W. Koste, 1988. Form variation of the rotifer Brachionus variabilis (Hempel, 1896) from the Orinoco River (Venezuela). Annales de Limnologie 24 (2): 127-129.

Vásquez, E. \& J. Rey. 1989. A longitudinal study of zooplankton along the lower Orinoco River and its Delta. Annales de Limnologie 25: 107-120.

Vásquez, E. \& J. Rey. 1992. Composition, abundance and biomass of zooplankton in Orinoco floodplain lakes, Venezuela. Annales de Limnologie 28 (1): 3-18.

Vasquez, E. \& W. Wilbert. 1992. The Orinoco: Physical, biological and cultural diversity of a major tropical alluvial river. p 448-471, En: Calow P. \& G.Petts (eds.) The River Handbook . Hydrological and Ecological principles. Blackwell Scientific Publications.

Walz,N.H., Elster, J. \& M. Mezger. 1987. The development of the rotifer community structure in Lake Constance during its eutrophication. Archiv für Hydrobiologie. (Supplement) 74:452487.

Wantzen, K.M. \& W.J. Junk. 2000. The importance of stream-wetland systems for biodiversity: a tropical perspective. P.11-34.En Gopall,W., Junk, W. \& J.A. Davis (eds) Biodiversity in wetlands: assesment function and conservation. Vol 1.

Ward, J.V. 1989. The four dimensional nature of lotic systems. Journal of North American Benthology Society 8 (1):2-8. 
Ward, J.V. 1995. International Conference: sustaining the ecological integrity of large floodplain rivers. Regulated rivers: Research \& Management 11:1-2

Ward, J.V. \& J.A. Stanford. 1995. The serial discontinuity concept:extending the model to floodplain rivers. Regulated Rivers: Research and Management 10: 159-168.

Ward, J.V., Tockner K. \& F. Schiemer. 1999. Biodiversity of floodplain river ecosystems: ecotones and connectivity. Regulated Rivers: Research and Management 15: 125-139.

Ward, J.V. \& K. Tockner. 2001. Biodiversity: toward a unifying theme for river ecology. Freshwater Biology 46: 807-819.

Welch, J.L.M. \& Meselson, M. 1998. Karyotypes of bdelloid rotifers from three families. Hydrobiologia 387/388: 403-407.

Wetzel, R.G. 1999. Biodiversisty and shifting energetic stability within freshwater ecosystems. Archiv fur Hydrobiologie, Special Issues in Advanced Limnology 5419-32

Wetzel, R.G. 2001. Limnology. Lakes and Rivers Ecosystems. Academic Press.1006 p

Whittaker, R.H. 1960. Vegetation of the Siskiyou Mountains, Oregon and California. Ecological Monographs 30: 279-338.

Whittaker, R.H. 1972. Evolution and measurement of species diversity. Taxon 21: 213251.

Zagarese, H.E. y M.C. Marinone (1992). Induction and inhibition of spine development in the rotifer Keratella tropica: evidence from field observations and laboratory experiments. Freshwater Biology 28: 289-300.

Zar, J.H. 1996. Biostatistical Analysis. Prentice Hall, 121 pp.

Zurek, R. 1980. The effect of suspended materials on the zooplankton. I Natural environments. Acta Hydrobiologica 22: 449-471. 

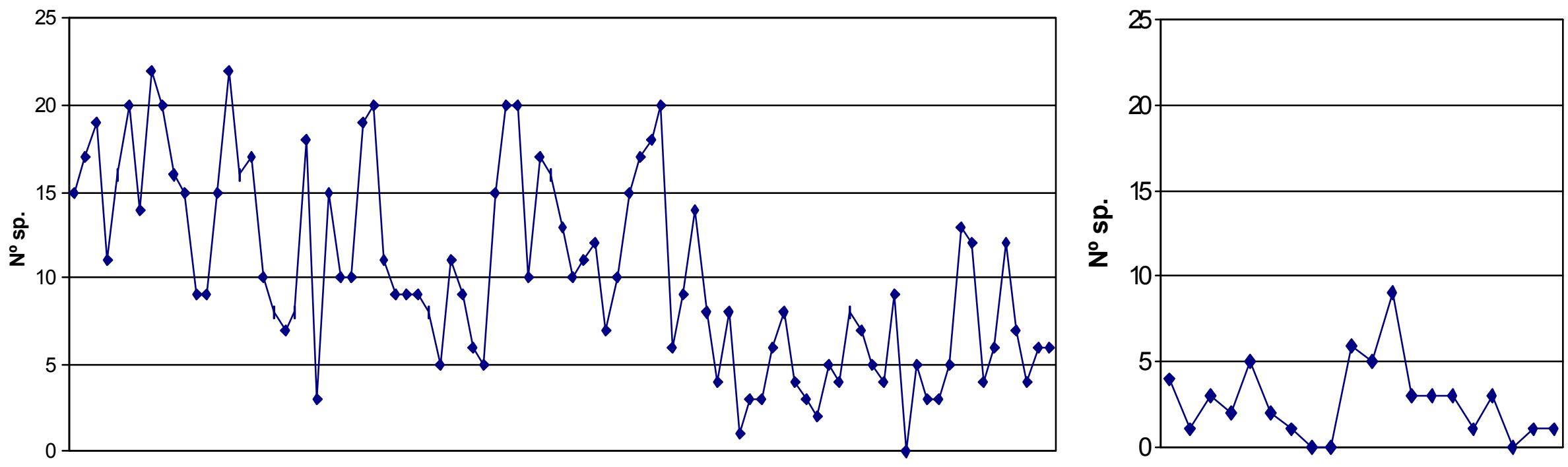

$\begin{array}{lllllllllllllllll}10 / 76 & 04 / 77 & 02 / 78 & 03 / 79 & 10 / 79 & 08 / 80 & 07 / 81 & 10 / 82 & 12 / 82 & 03 / 83 & 11 / 97 & 03 / 98 & 08 / 98 & 11 / 99 & 06 / 00\end{array}$
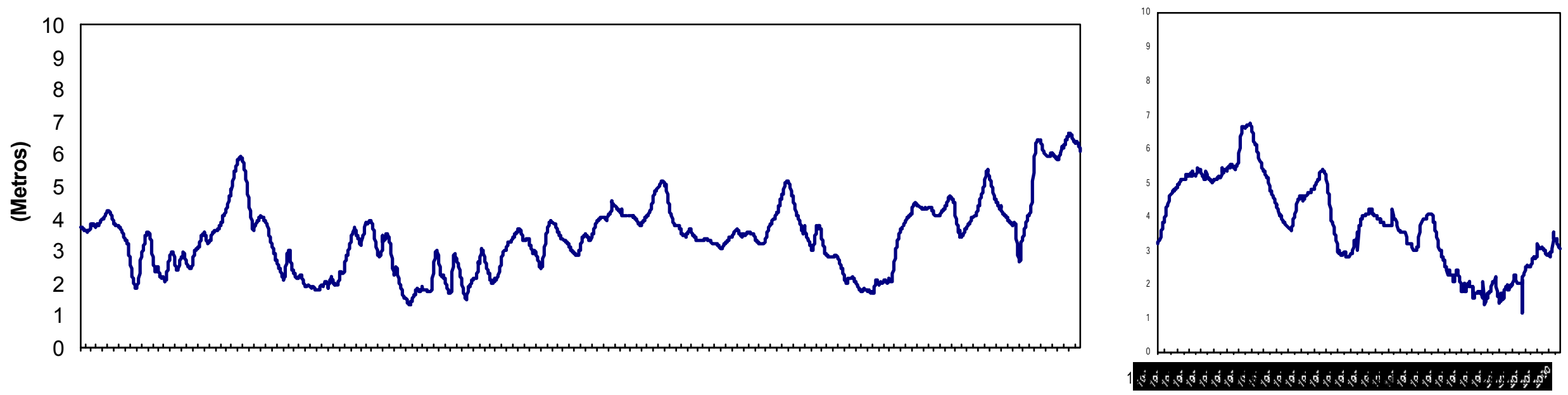

$\begin{array}{lllrrr}1976 & 1977 & 1979 & 1980 & 1981 & 1983\end{array}$

Fig. 1.5. Variaciones temporales de la riqueza de Rotíferos en el canal principal del Río Paraná, km 603 y niveles hidrométricos (Puerto de Paraná, E.Rios). 

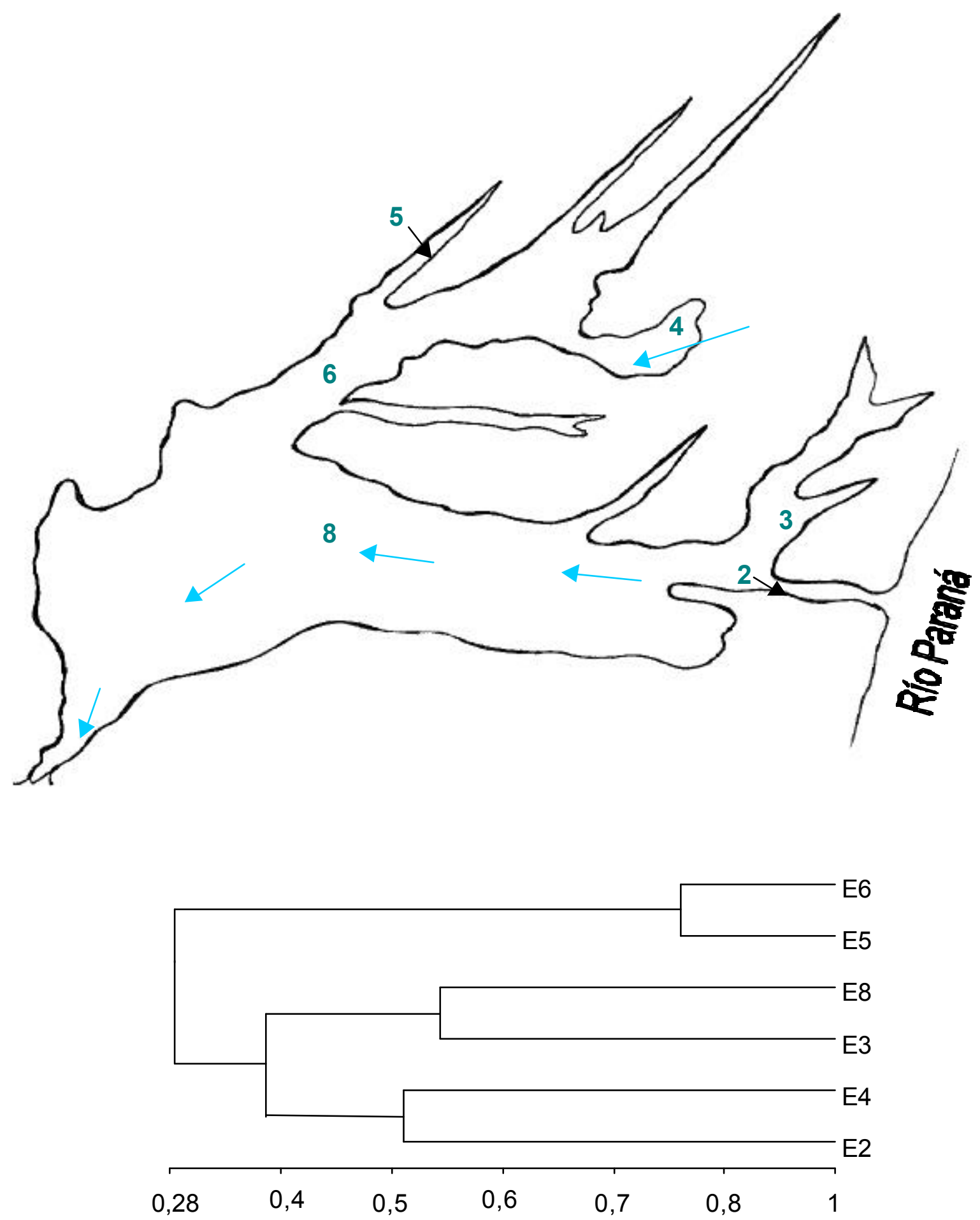

Fig. 2.6. La Cuarentena. Afinidad faunística entre estaciones (4/03/81) Las flechas azules indican el sentido de la circulación del agua en el interior de la laguna, ídem para las figuras 2.7, 2.8, 2.9. 

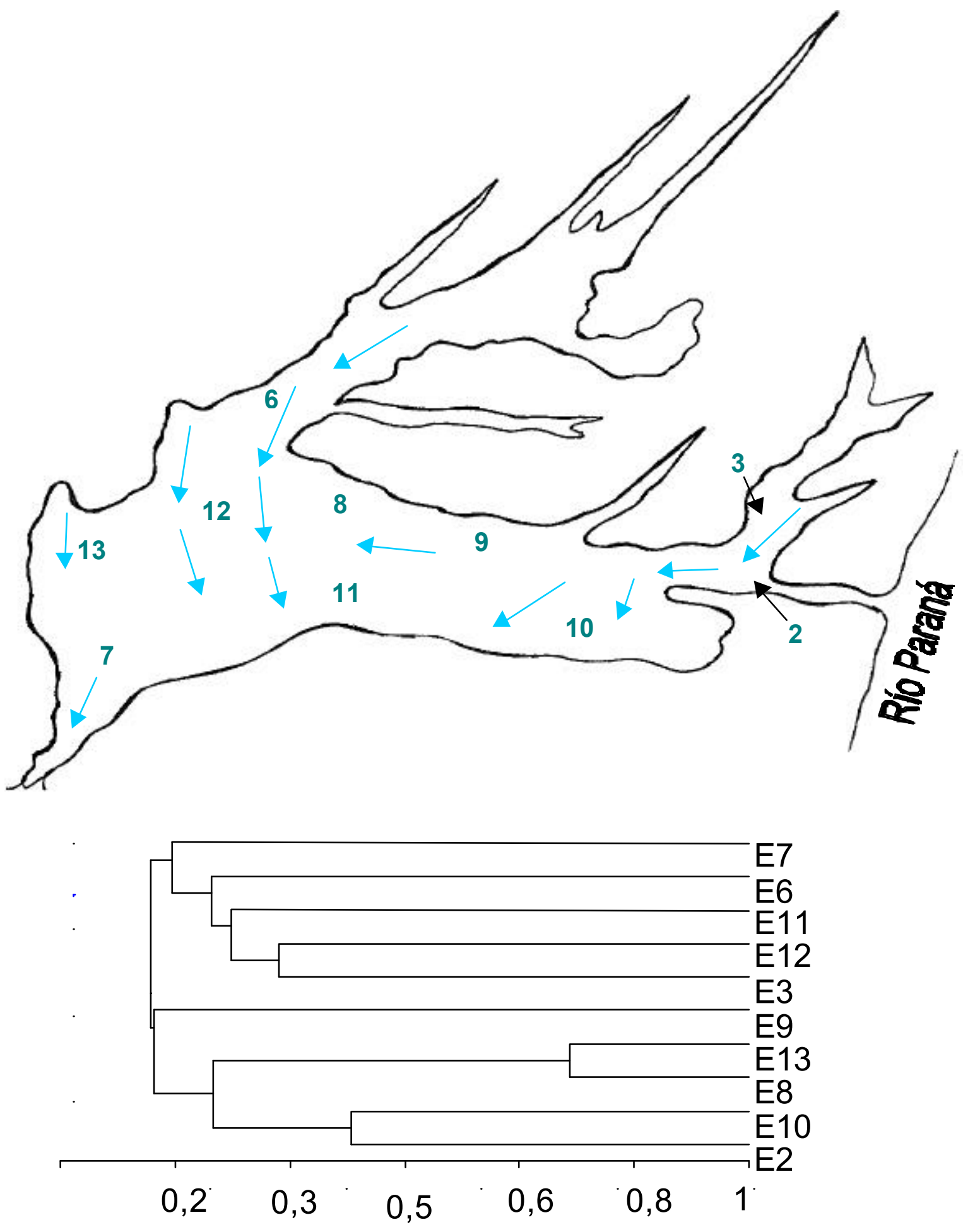

Fig. 2.7. La Cuarentena. Afinidad faunística entre estaciones (4/03/81). 

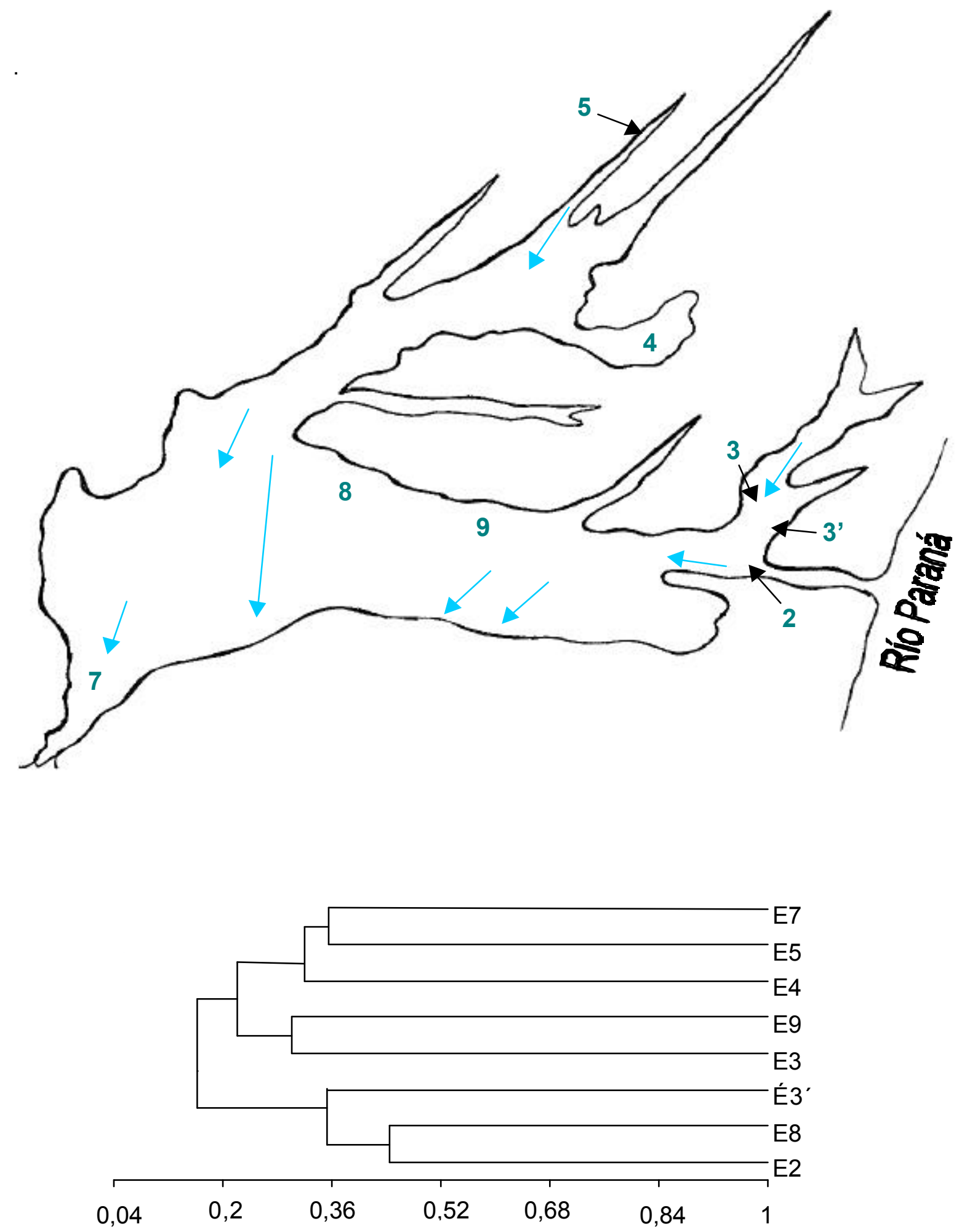

Fig. 2.8. La Cuarentena. Afinidad faunística entre estaciones (17/03/81) 

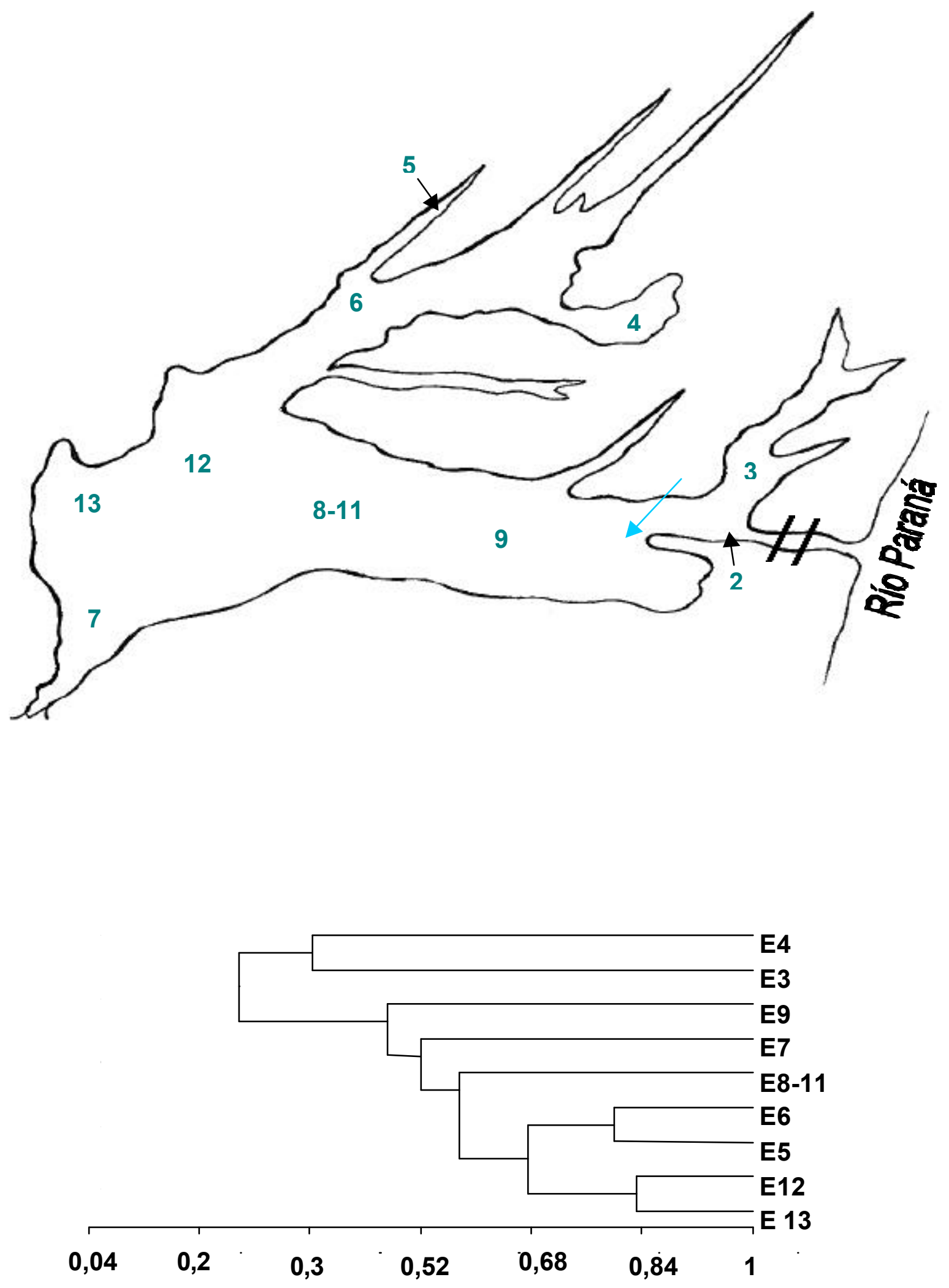

Fig. 2.9. La Cuarentena. Afinidad faunística entre estaciones (8/10/81) 


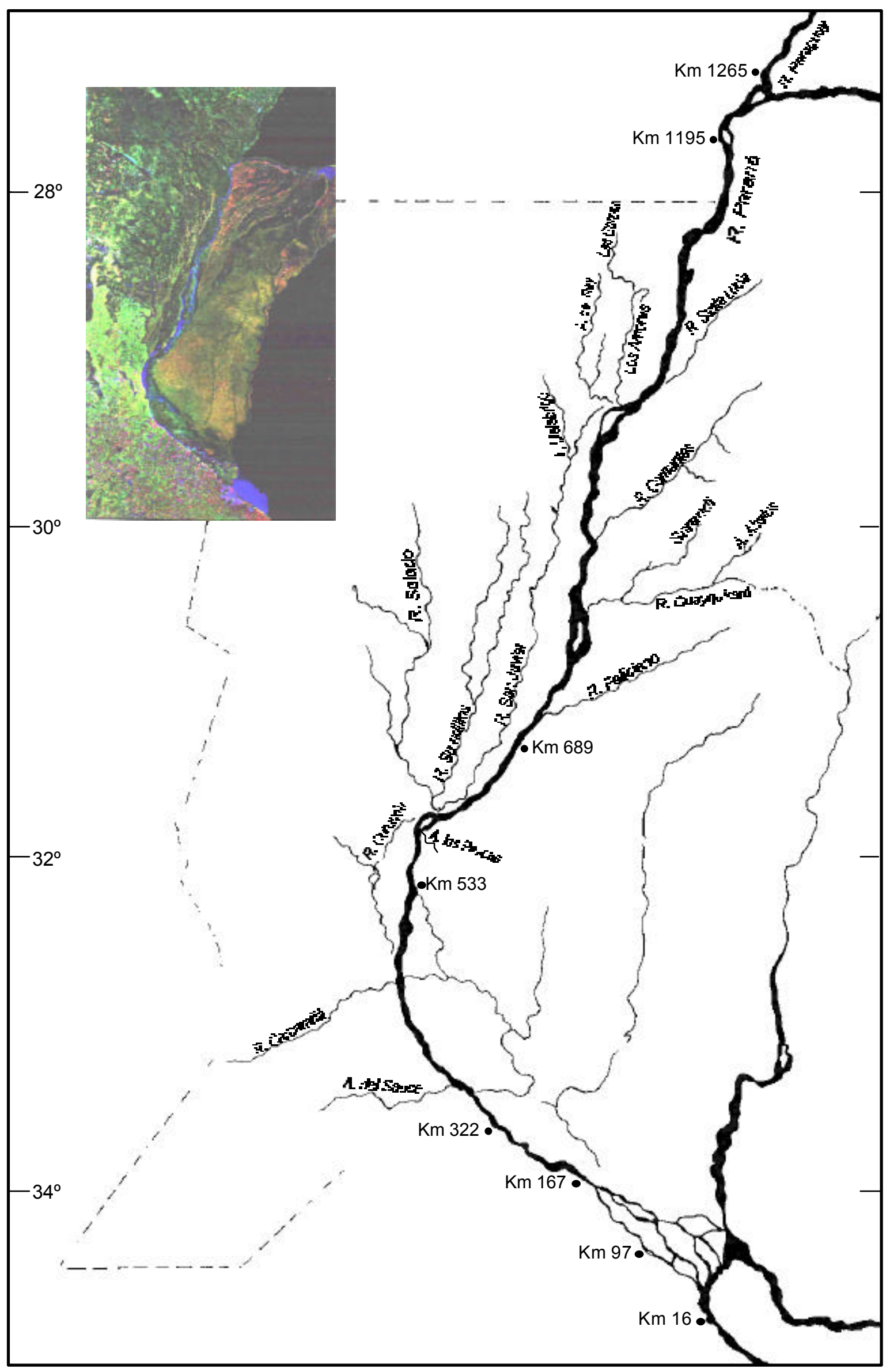

Fig I. Area de estudio: Río Paraná aguas abajo de su confluencia con el R. Paraguay. Los cauces de menor jerarquía nominados corresponden a los muestreados en este estudio. Imagen satelital tomada de Clarin 2004 (Atlas mundial) 


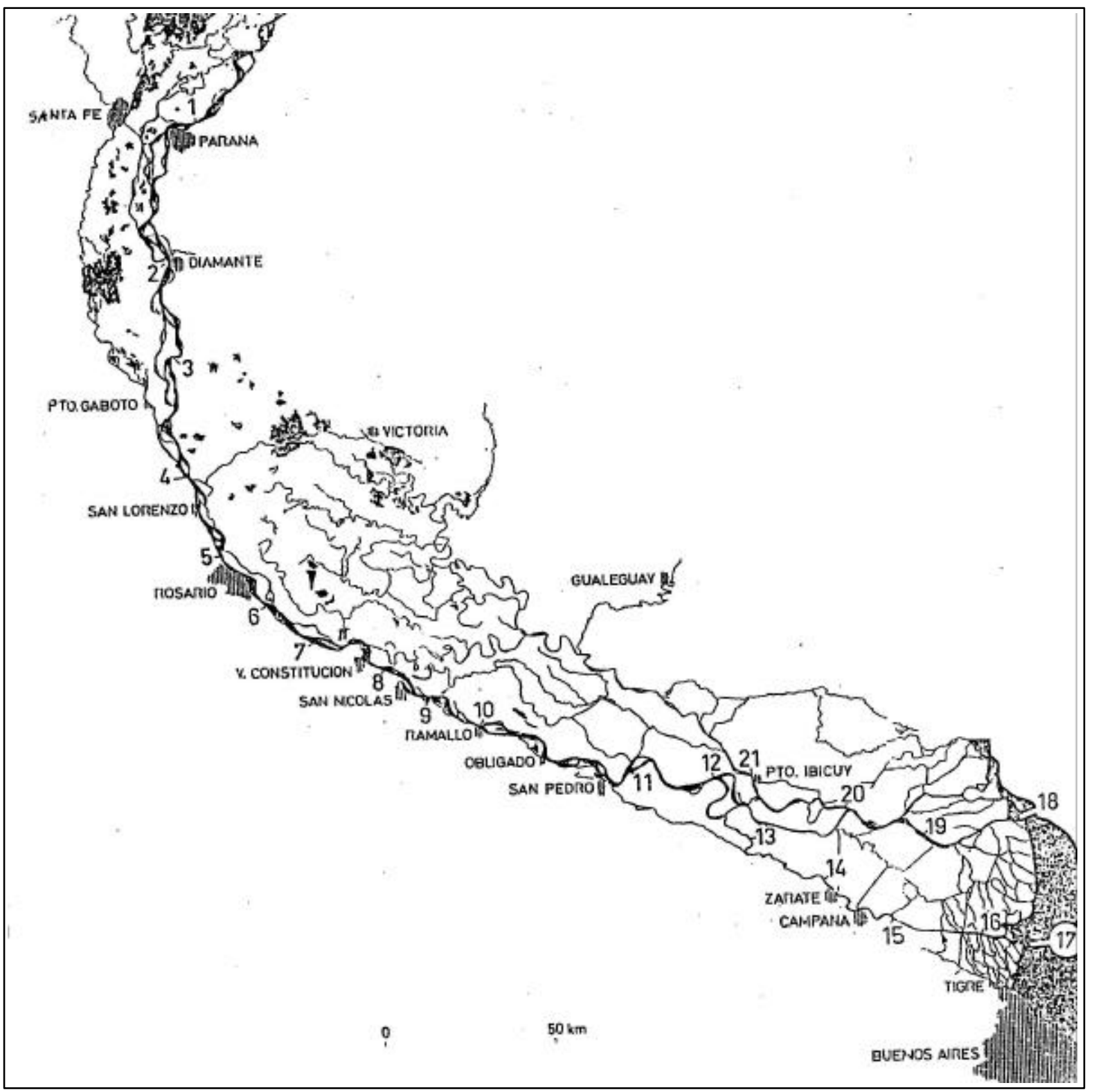

Fig. II. Río Paraná, tramo Santa Fe- Río de la Plata. Ubicación de las estaciones de muestreo en el período de aguas en bajante. 

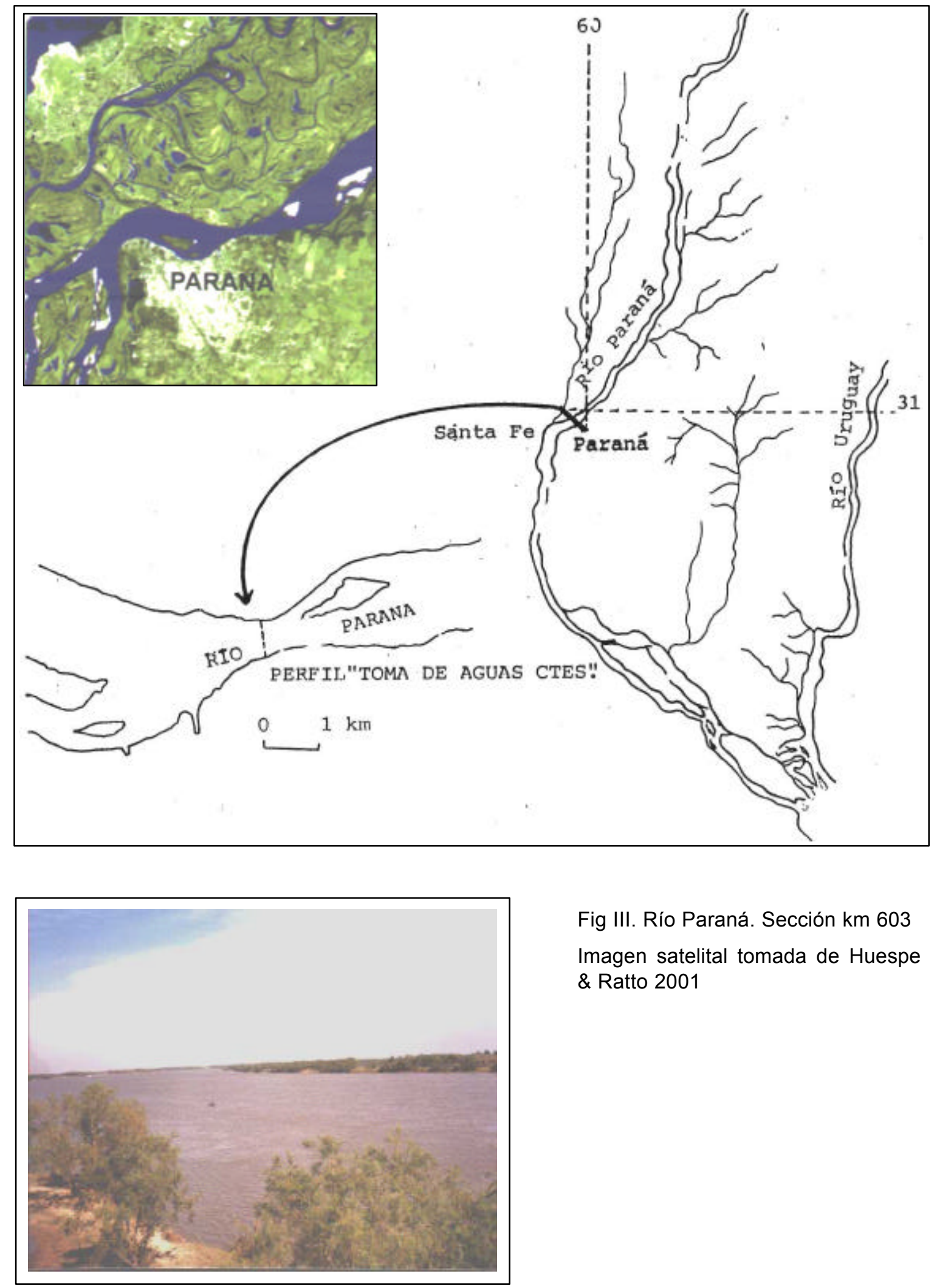

Fig III. Río Paraná. Sección km 603 Imagen satelital tomada de Huespe \& Ratto 2001 


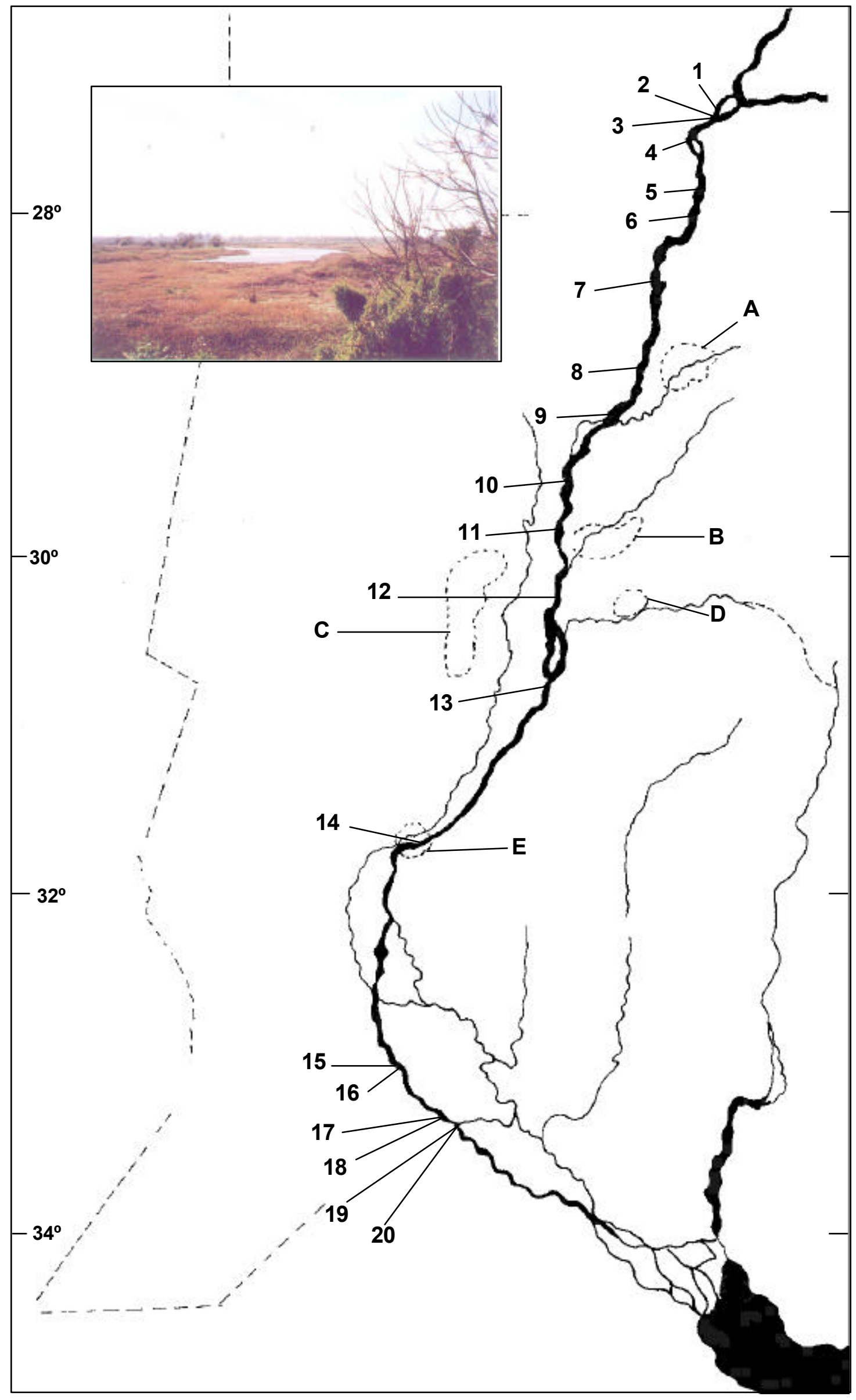

Fig.IV: Localización de los ambientes leníticos estudiados. Referencias aparte. 
Referencias de Lagunas $(\mathrm{L})$ y Madrejones (M) de la Fig. IV

\author{
1. L.en Isla Nogueras \\ 2. L. Pelón \\ 3. M. Pelón \\ 4. L. Nogueras \\ 5. L.La bella \\ 6. L.Sombrero \\ 7. L.Yuruatha \\ 8. L.Ñatiu \\ 9. M. San Jeronimo \\ 10. L. Malabrigo \\ 11. L. Gabriela \\ 12. L. Ingá \\ 13. L. Curuzu Chalí \\ 14. L. La Cuarentena \\ 15. L.1.en isla frente Rosario \\ 16. L. 2.en isla frente Rosario \\ 17. L.1. en isla Lechiguana \\ 18. L.2. en isla Lechiguana \\ 19. L.1. en isla Cataneo \\ 20.L.2. en isla Cataneo
}
A. Lagunas próximas al río Santa Lucia (7)
B. Lagunas próximas al río Corrientes (5)
C. Lagunas próximas al sistema Saladillos (8)
D. Lagunas próximas al Río Guayquiraró (2)
E. Lagunas en islas próximas a Santa Fe (25) 

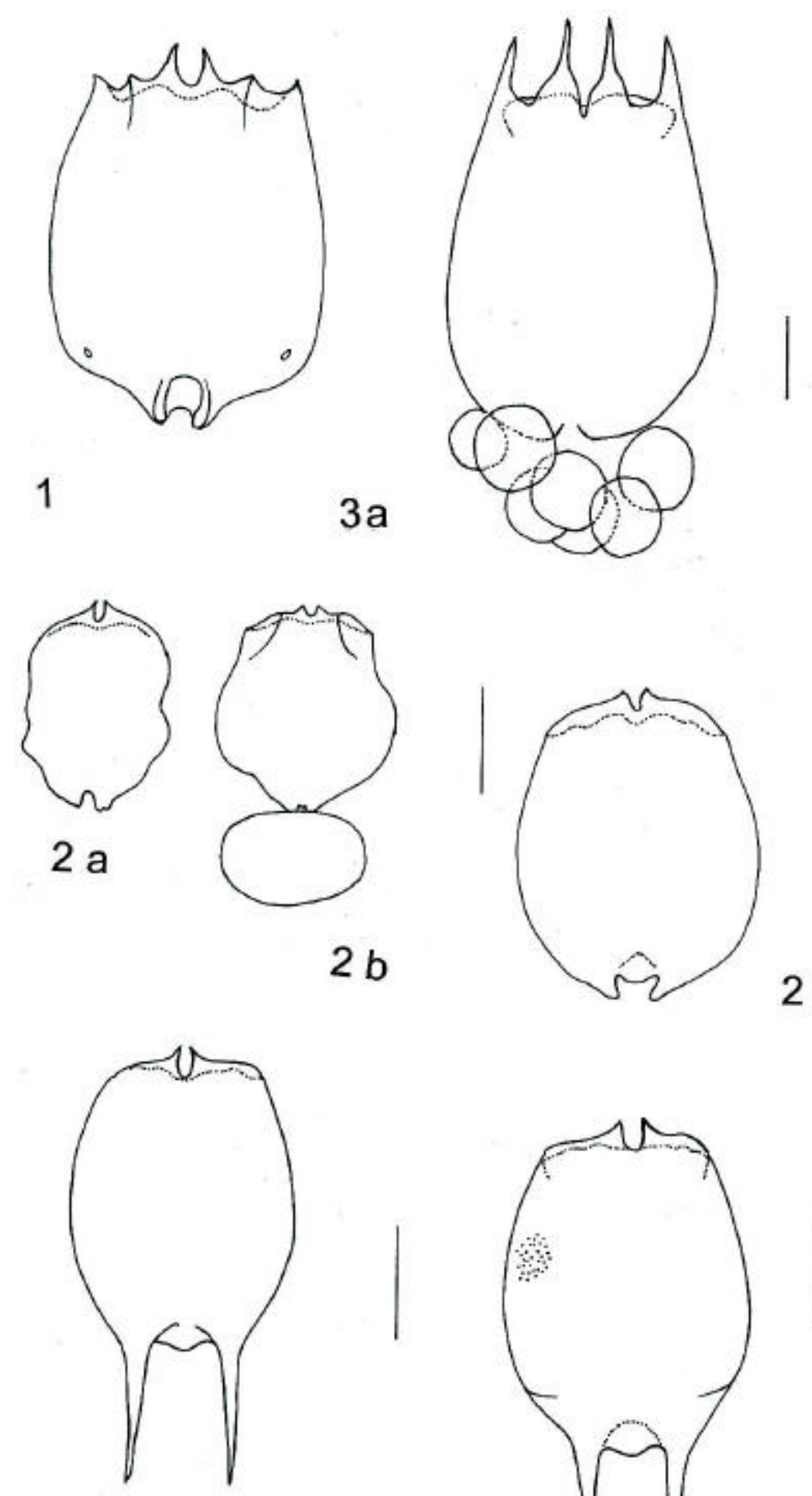

4 a
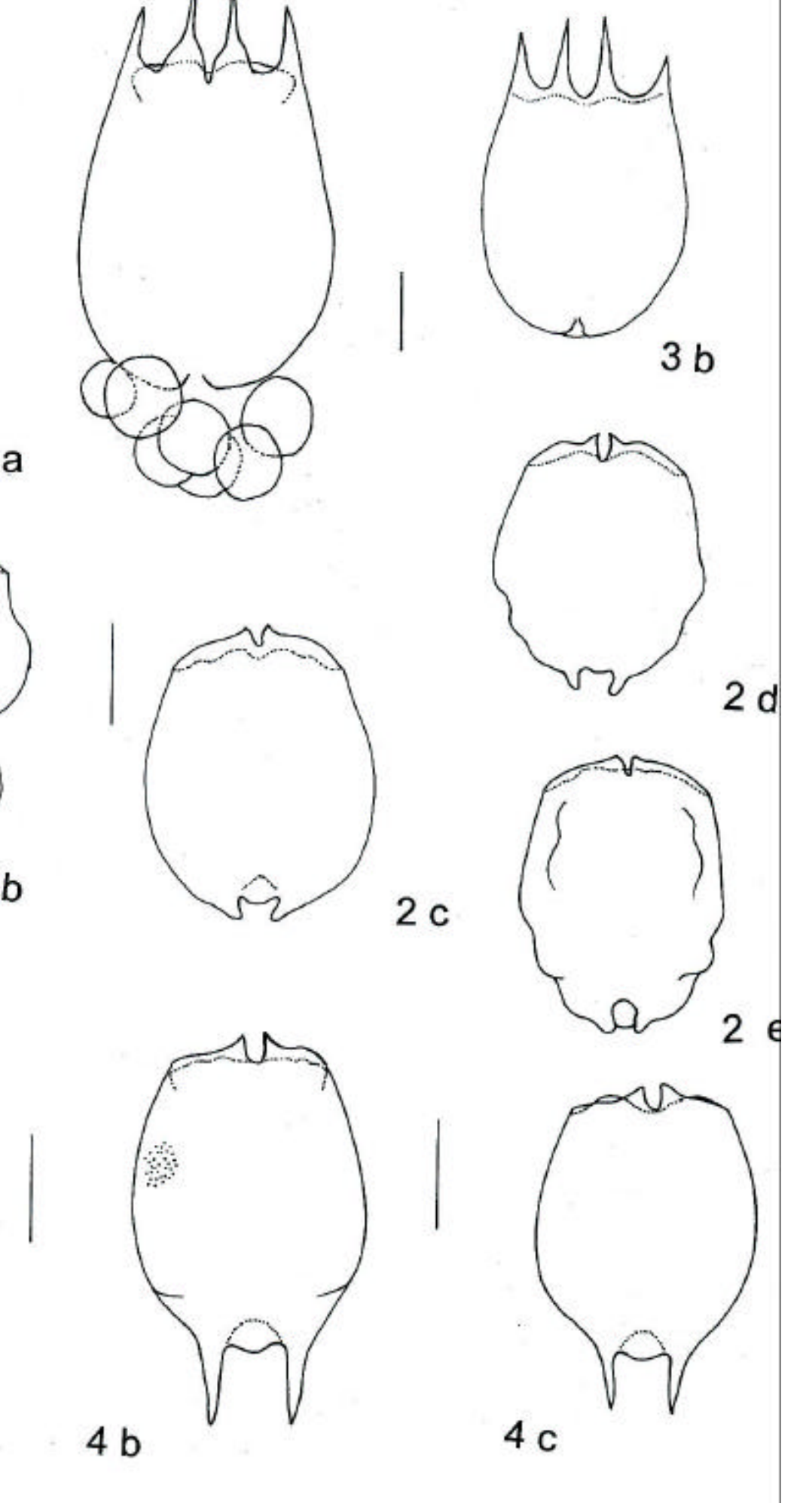

Lamina 1 


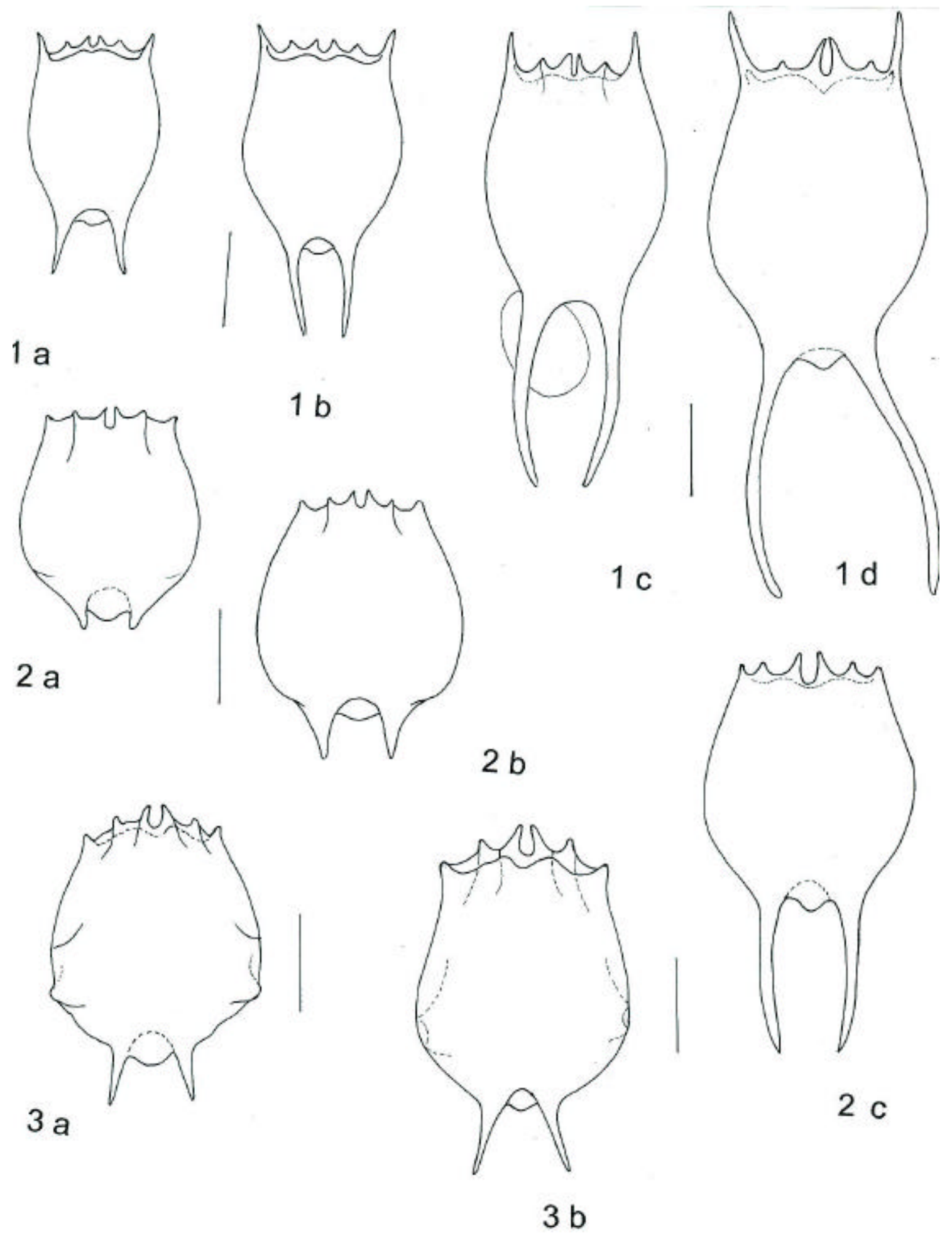

Lamina 2 


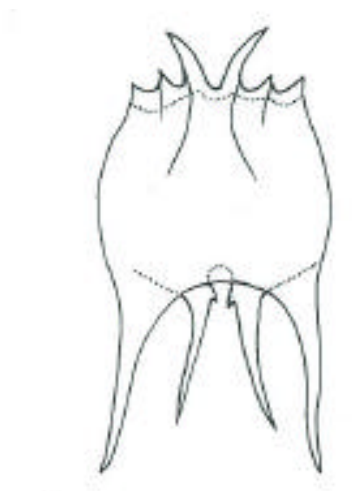

1
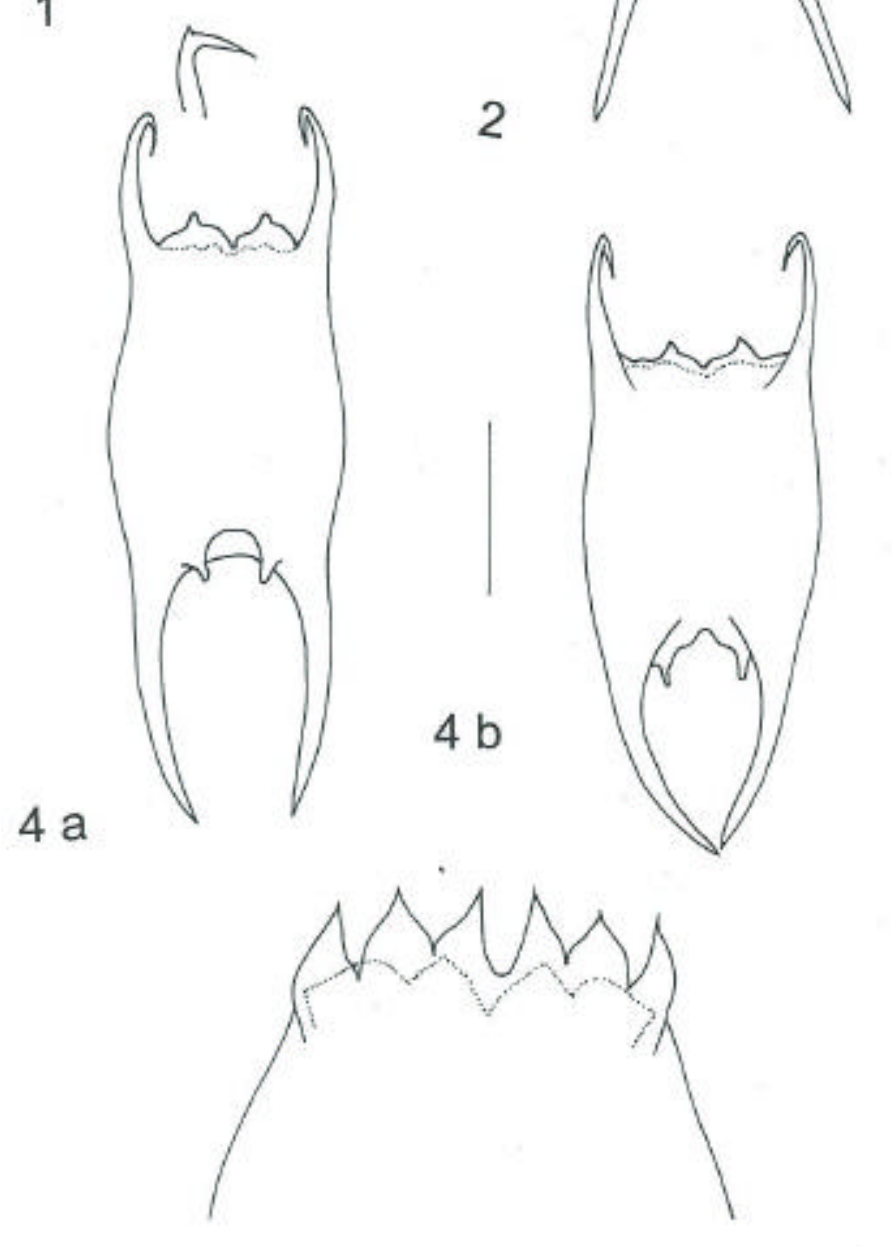

$5 b$
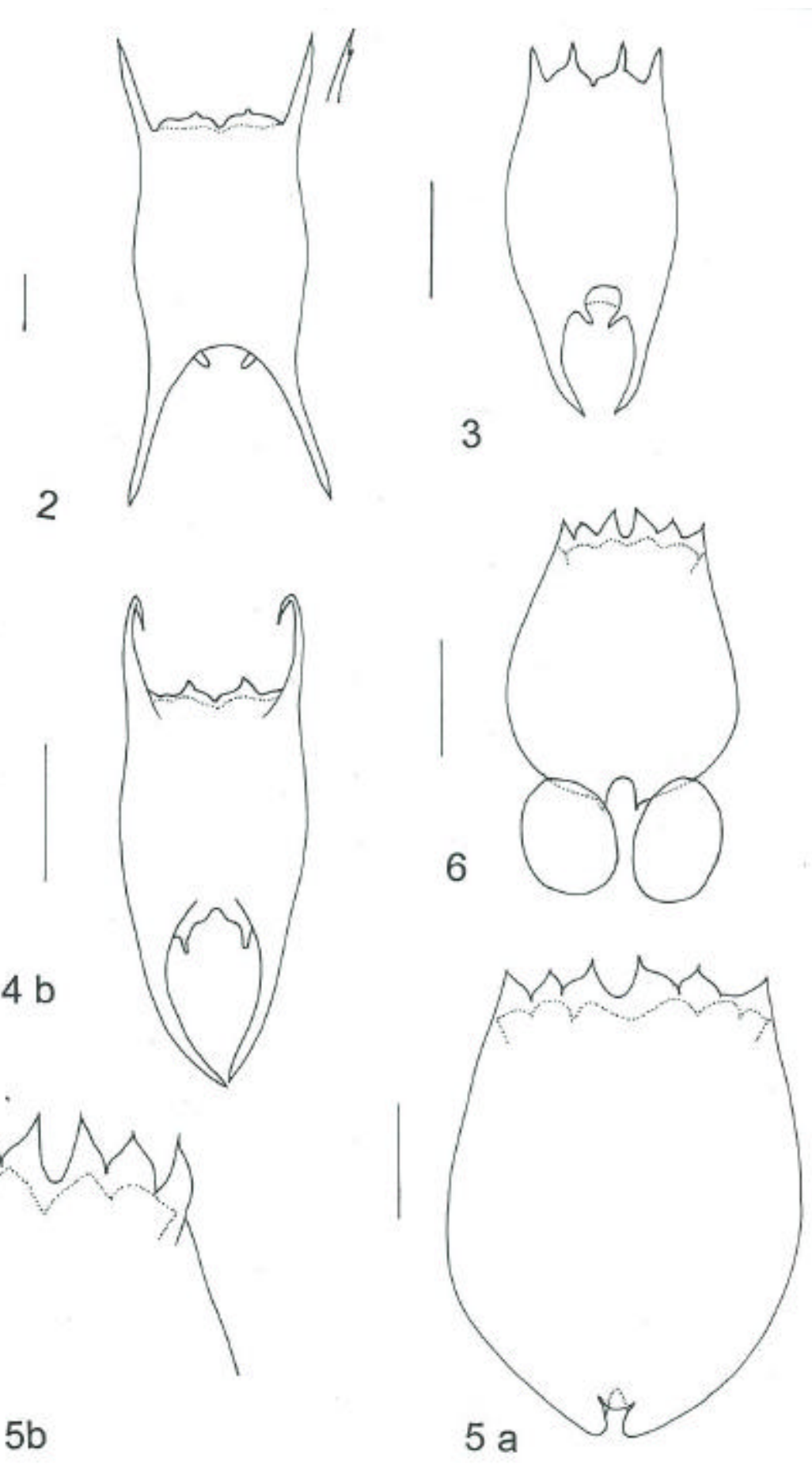

\section{Lamina 3}



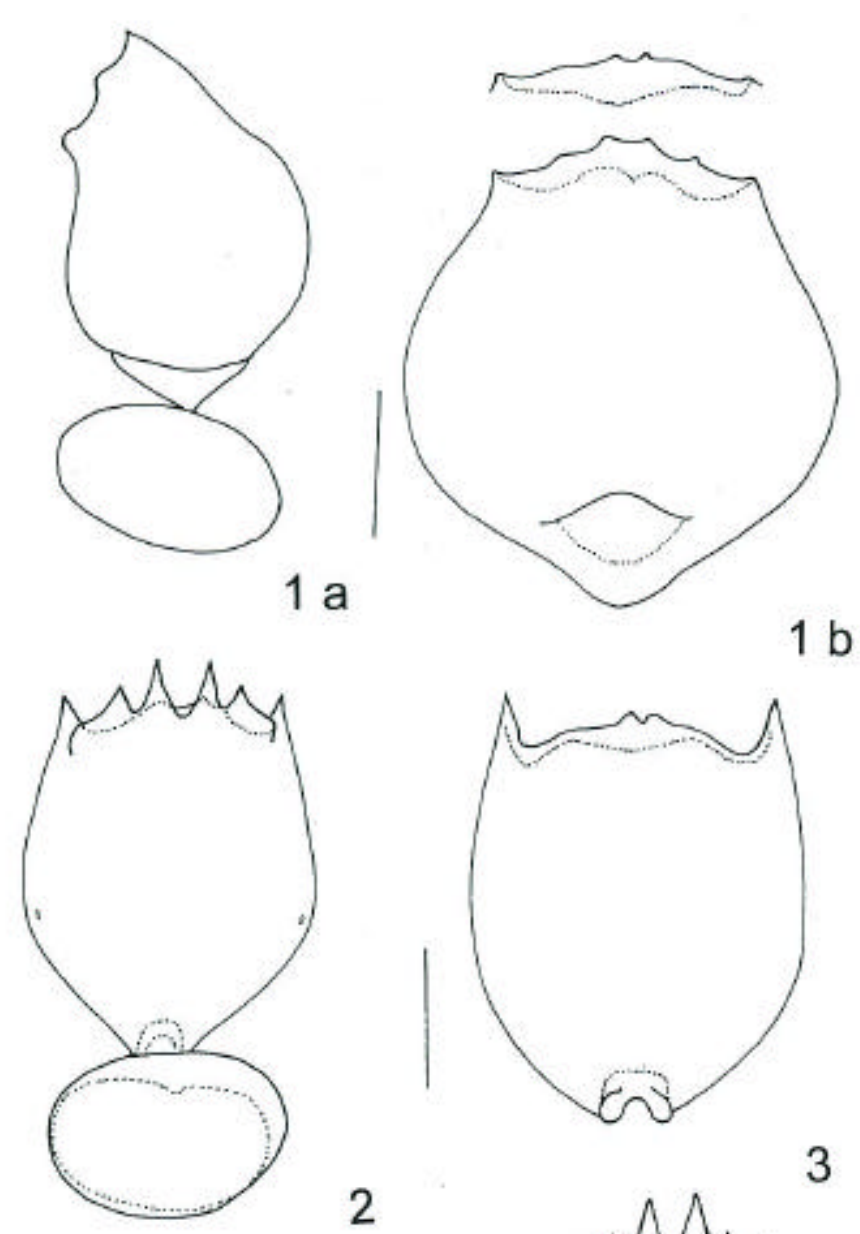

$1 \mathrm{~b}$

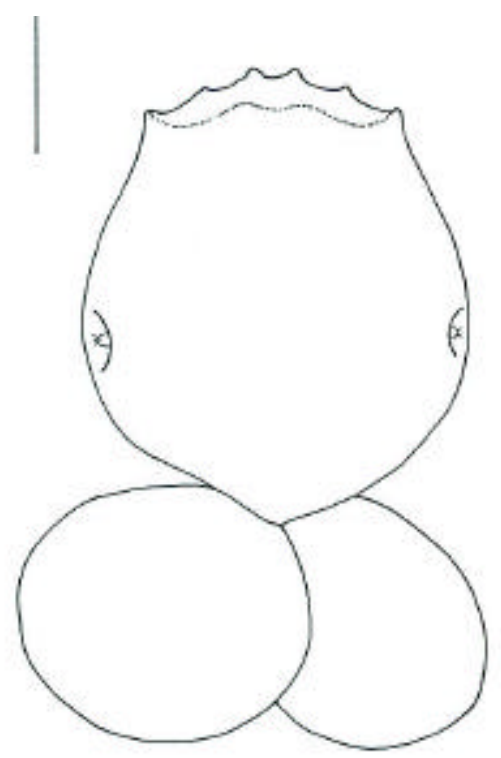

2

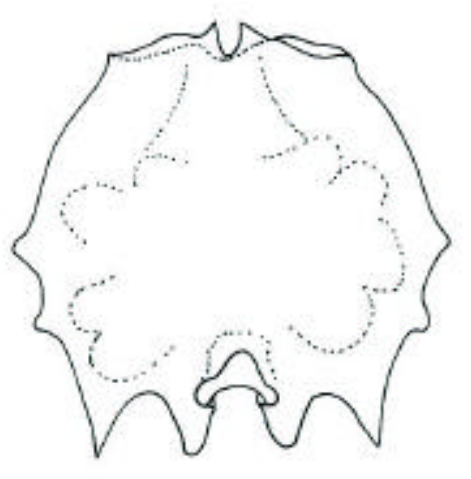

$6 a$

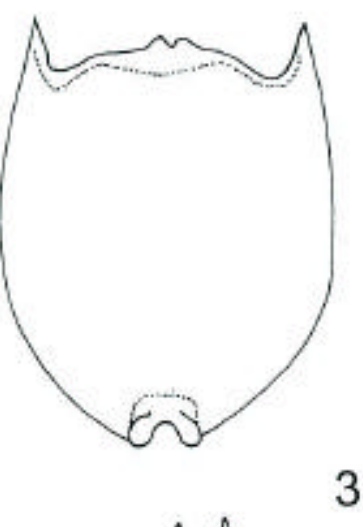

$1 \mathrm{c}$

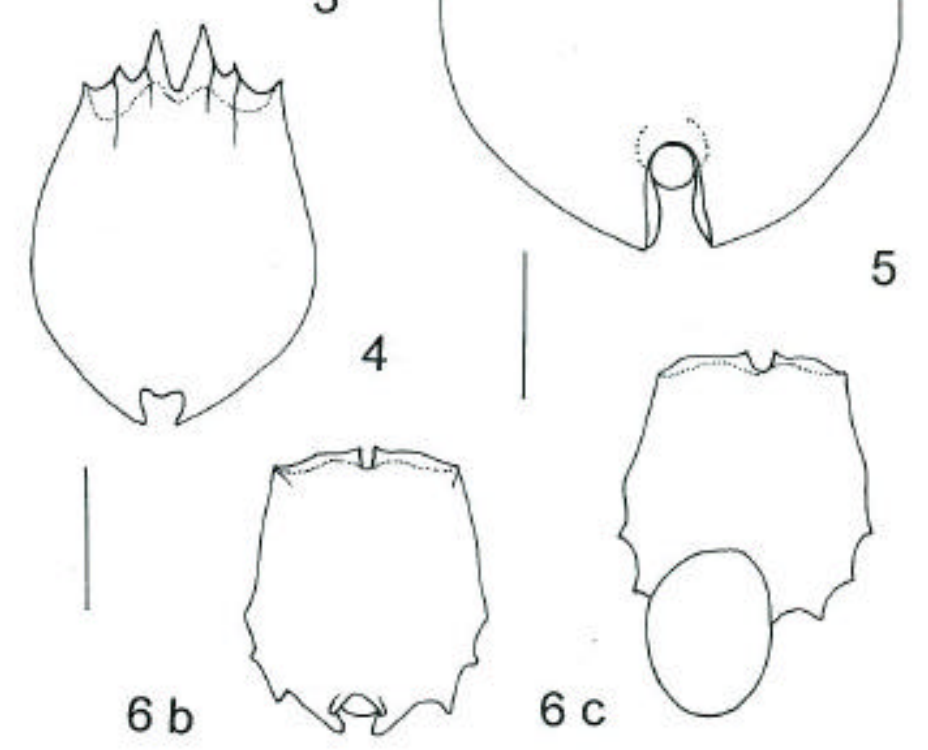

Lamina 4 

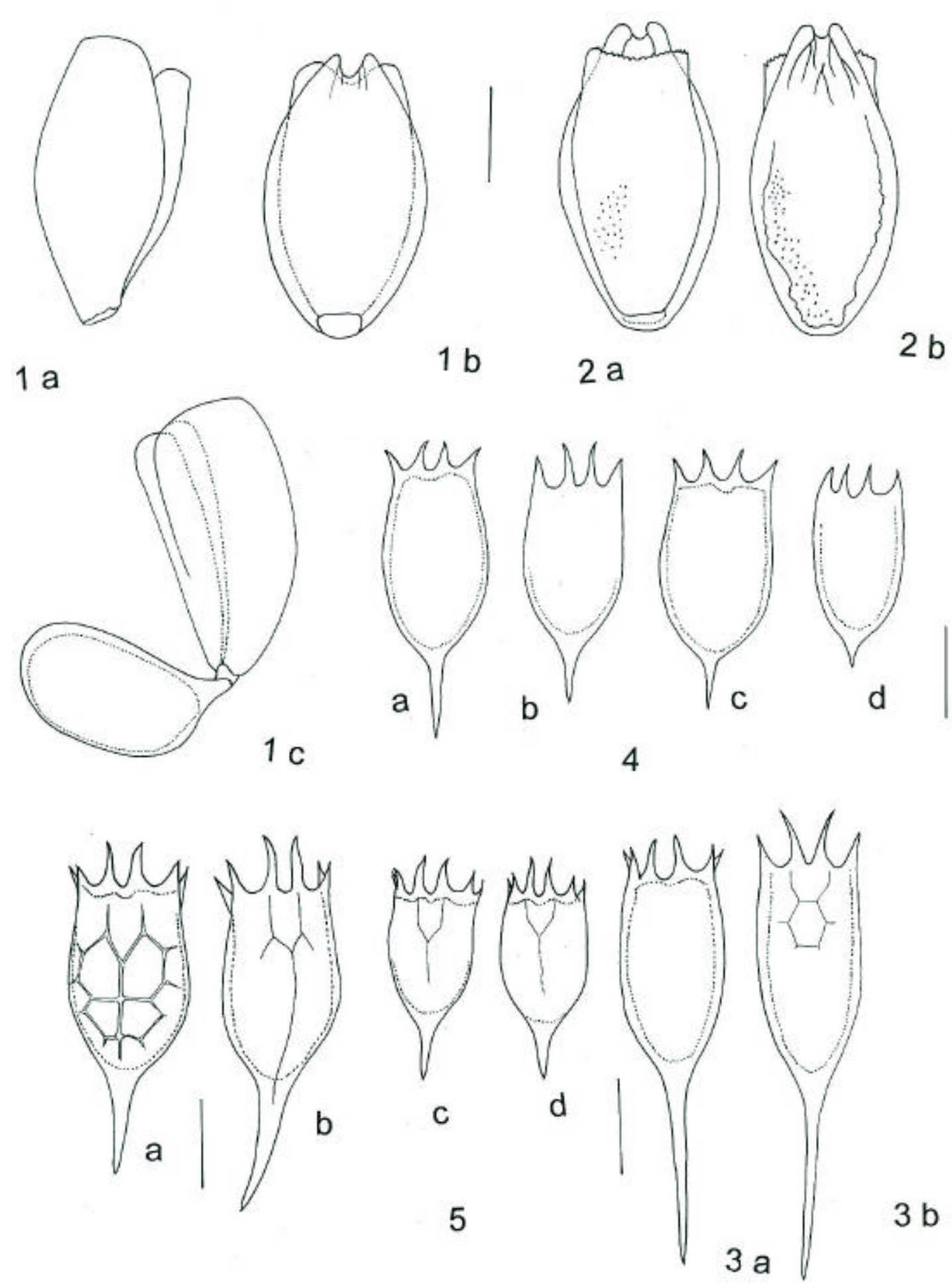

$3 b$

Lamina 5 

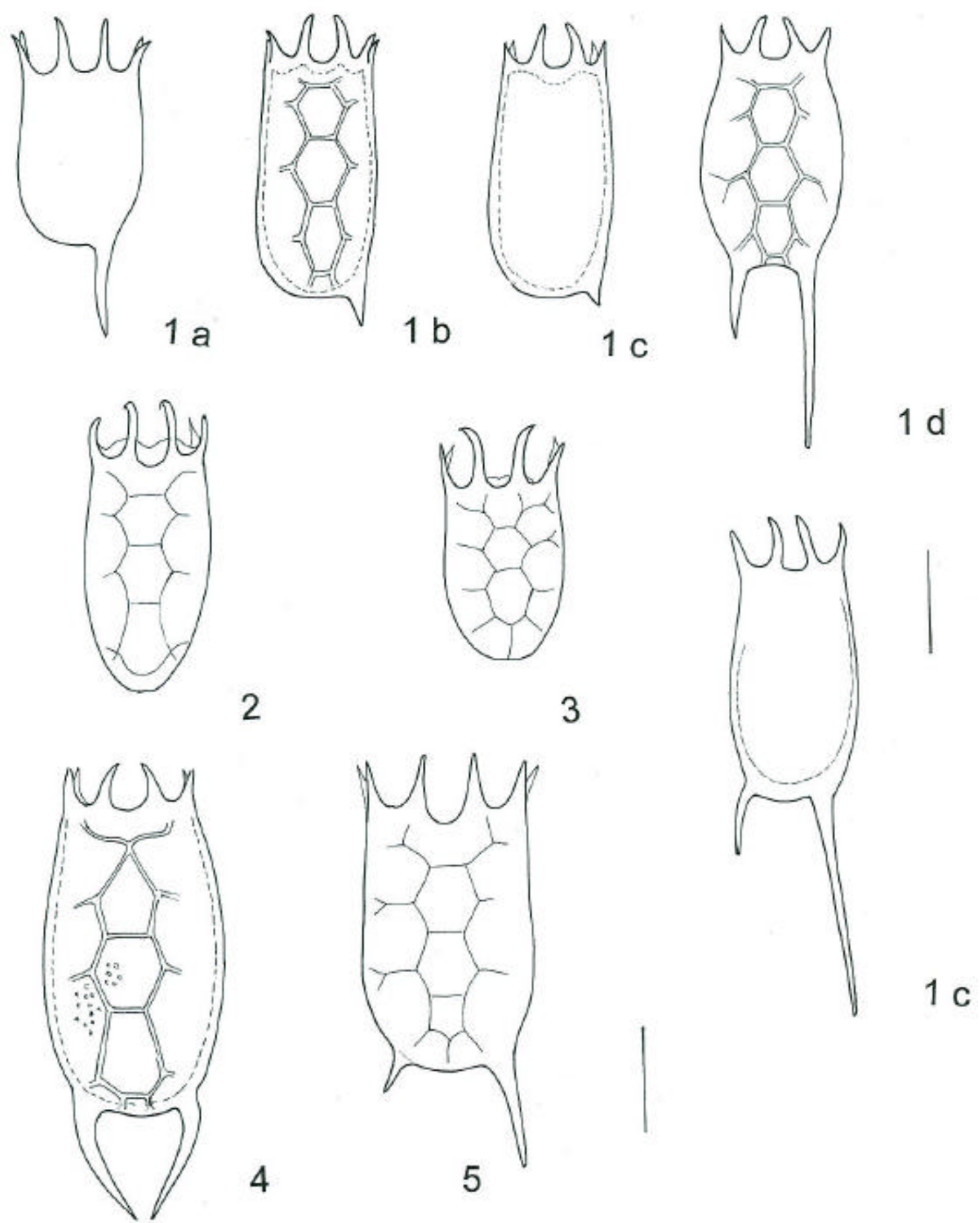

Lamina 6 

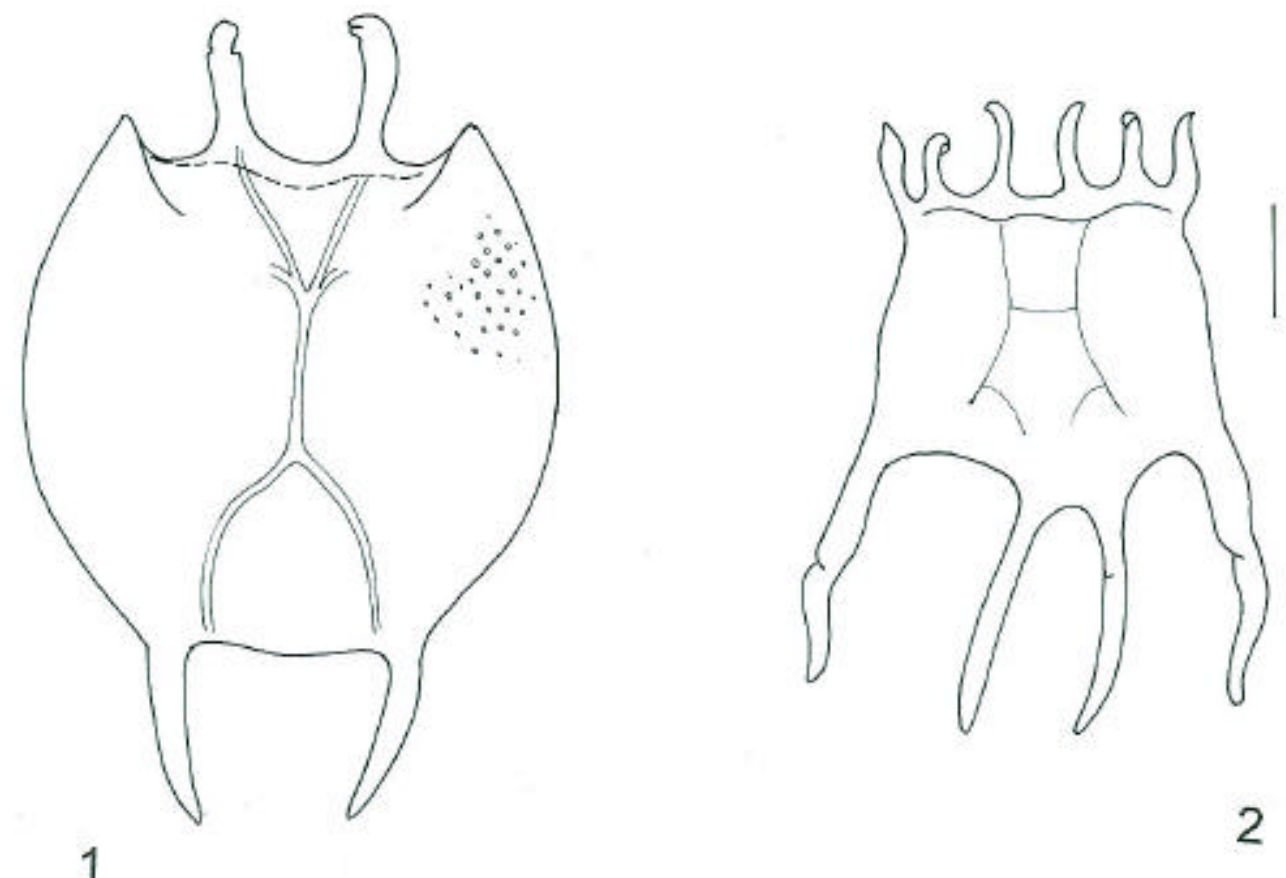

Lamina 7 

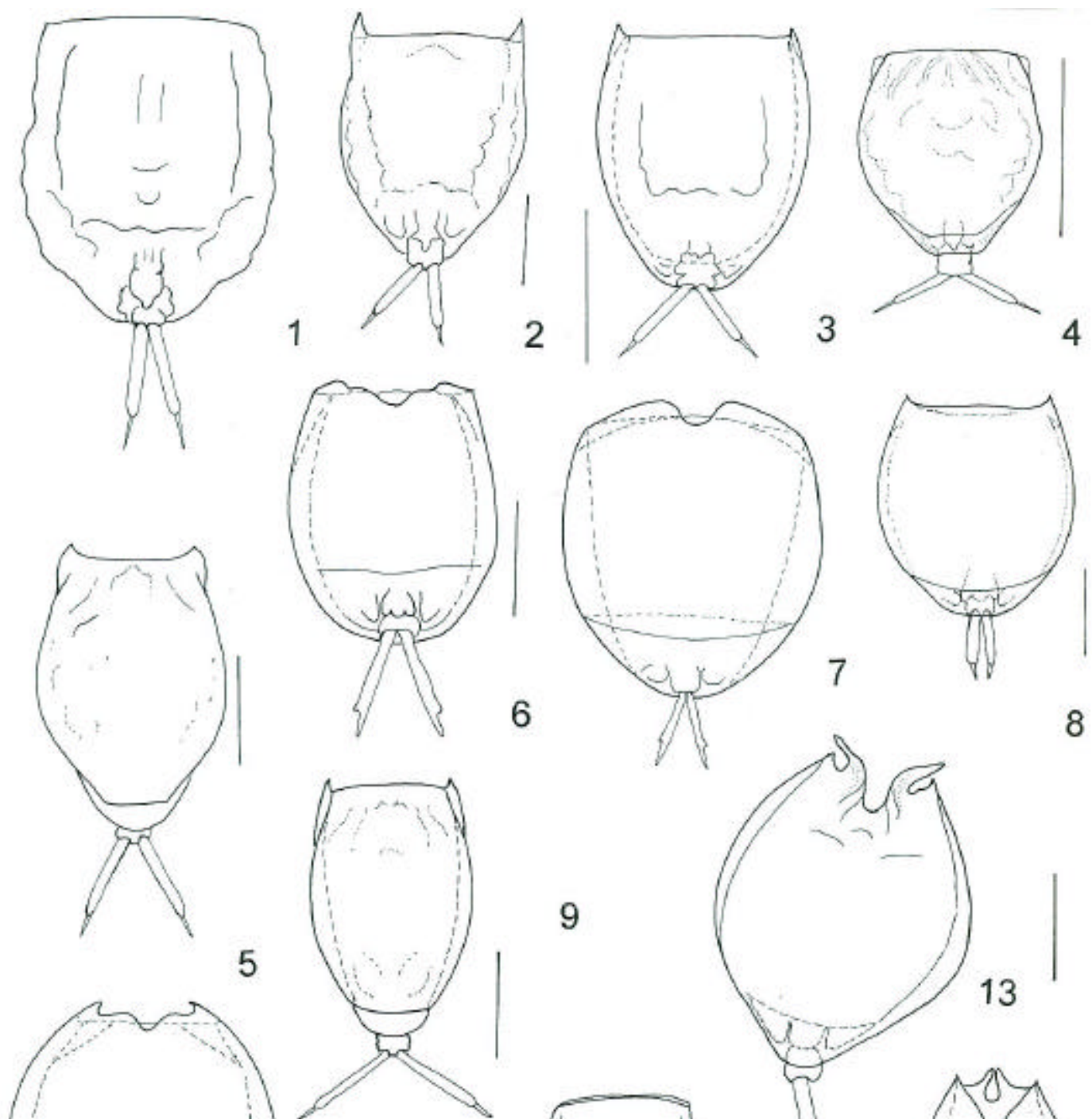

9

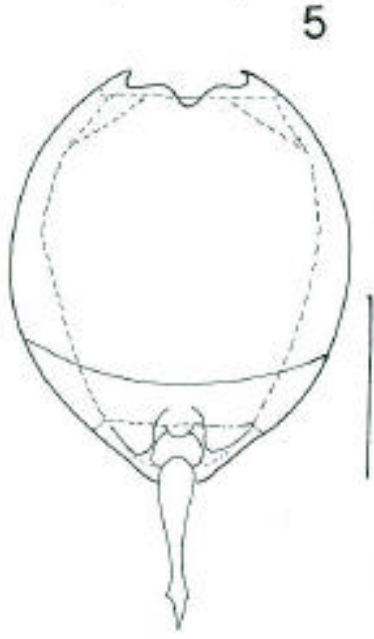

10
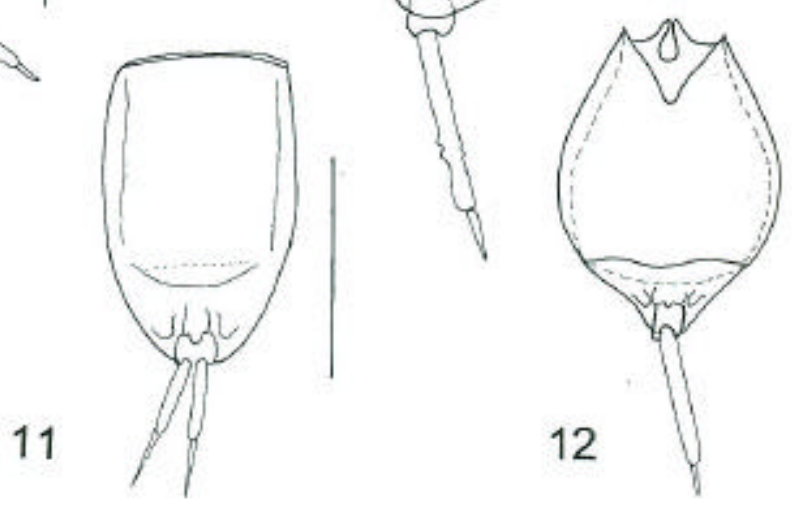

Lamina 8 

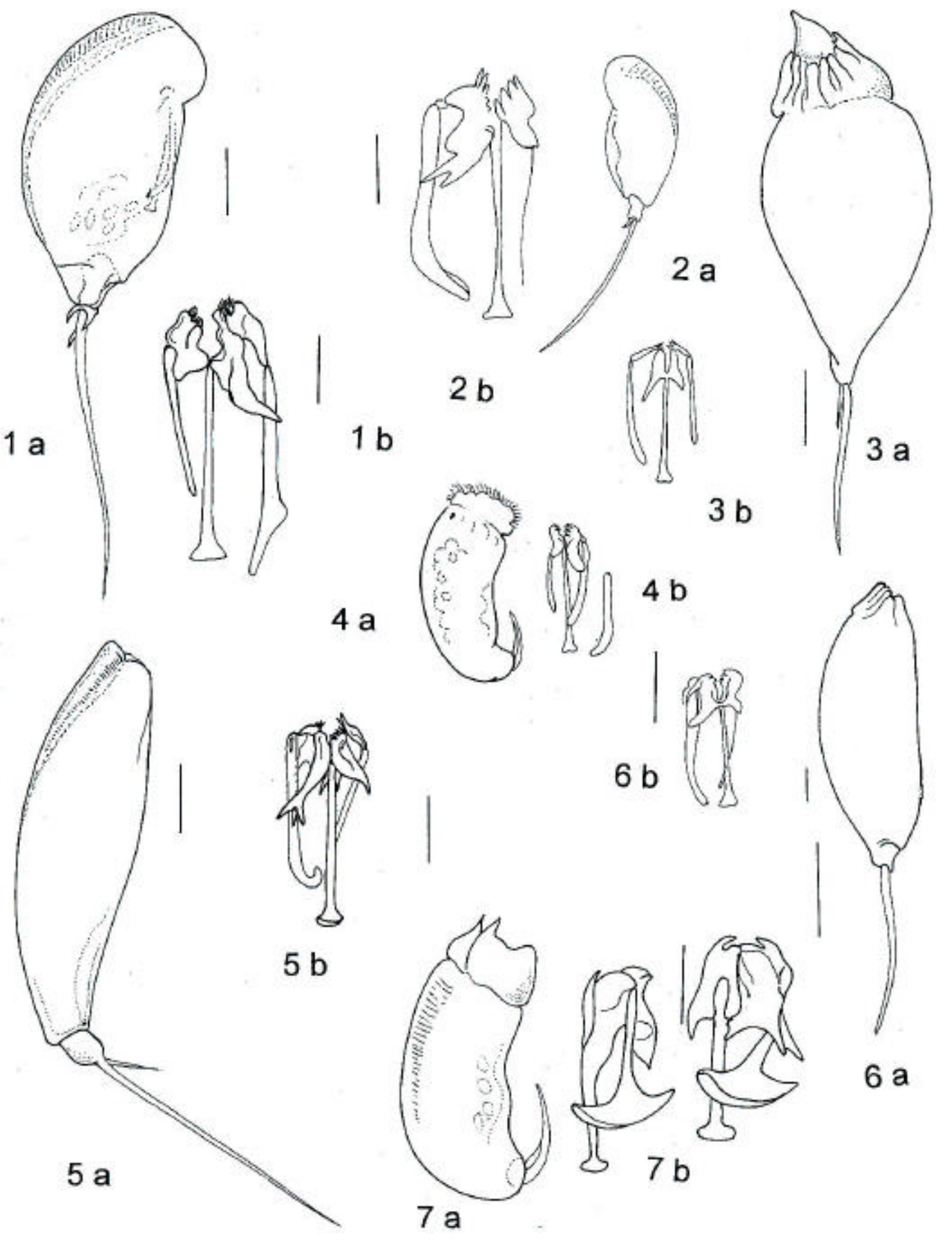

ivis

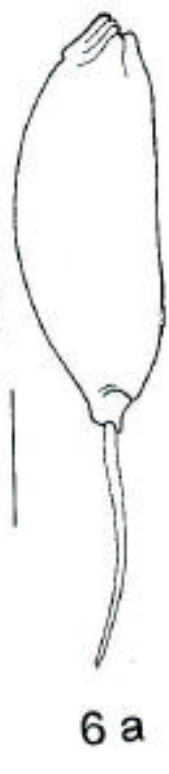

Lamina 9 


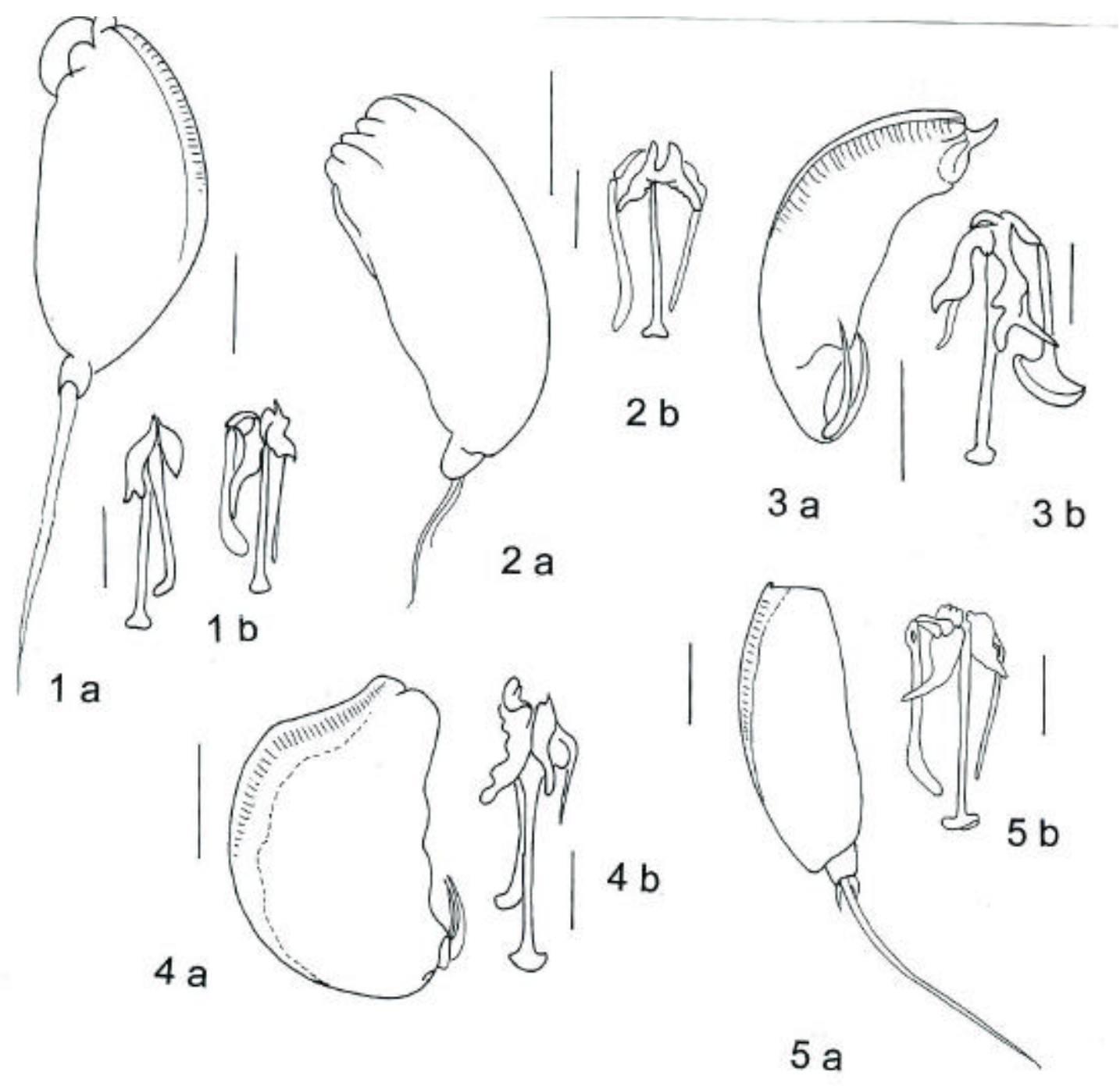

Lamina 10 

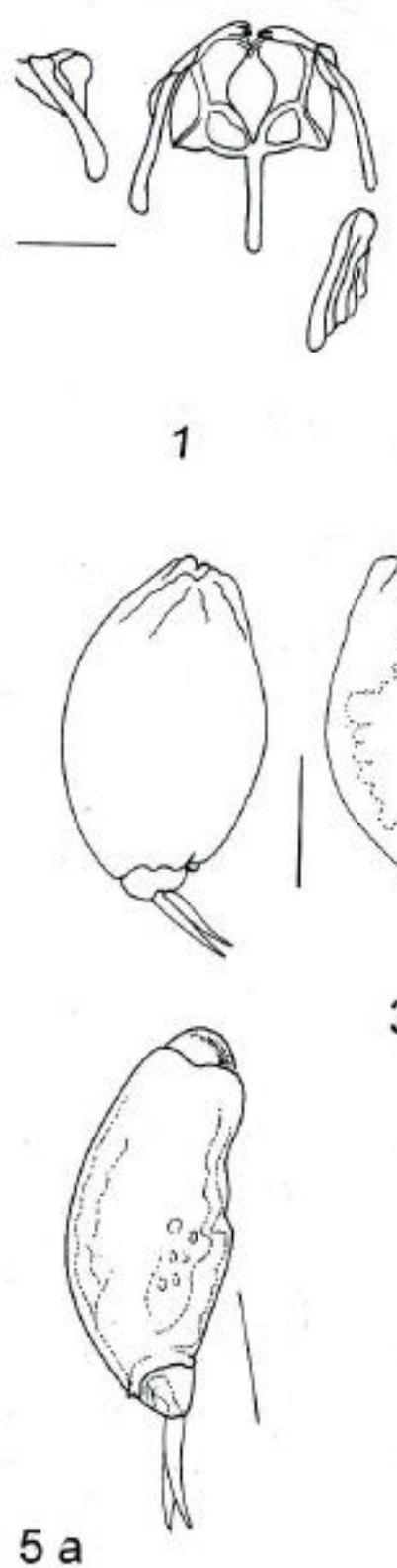
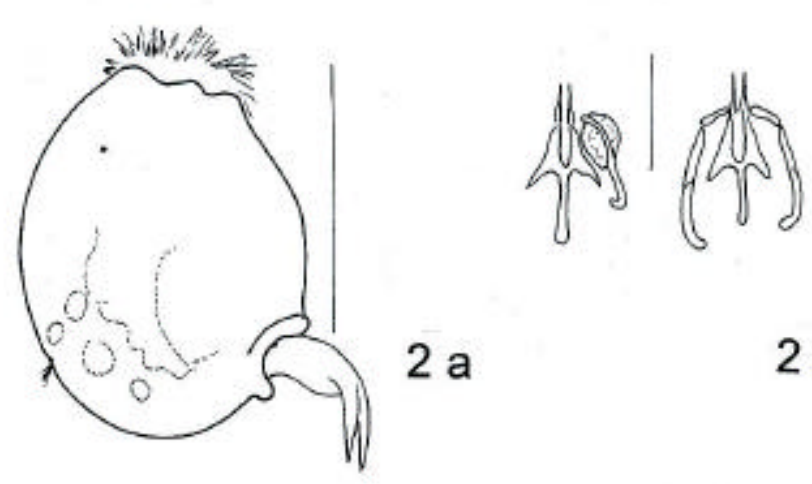

$2 \mathrm{~b}$

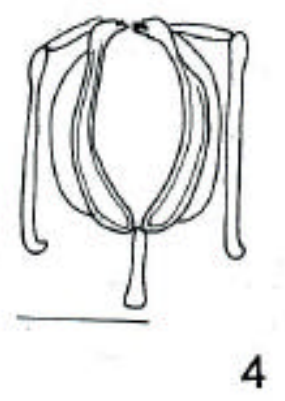

3 a
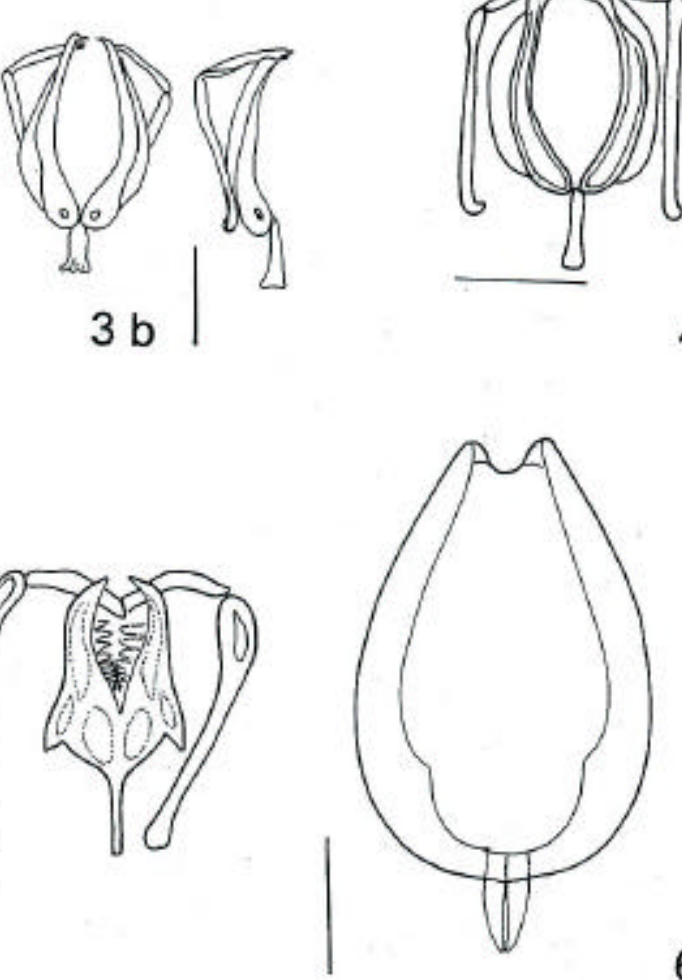

$5 \mathrm{~b}$

6

Lamina 11 


\section{LEYENDA DE LAS LAMINAS}

Lámina 1.- 1. Brachionus amazonica Lag. en isla Noguera, (2/10/71). 2. B.angularis, 2 a Los Matadores (10/03/77), 2 b-d Arroyo Cululú (21/03/96), 2c Lag. en isla Carabajal (6/04/72). 3. B. calyciflorus Palo Pelado (11/02/00). 4. B. caudatus, 4 a Los Matadores ( 23/03/77) 4 b Río Correntoso (12/04/00), 4 c Río Salado (7/12/93). Escala: $50 \mu \mathrm{m}$.

Lámina 2.- 1. Brachionus alh/stromi, El Tigre 1 a (26/01/88) 1 b. (23/03/88), 1 c ( 20/04/88) 1 d Los Matadores (14/07/77). 2. B. austrogenitus 2 a-b Río Salado (27/09/93), 2 c Lag. en isla Carabajal (8/04/72). 3. B. insuetus El Alemán, a-b (3/02/69). Escala: $50 \mu \mathrm{m}$.

Lámina 3.- 1. Brachionus mirabilis, El Tigre (23/03/88) 1. 2. B. mirus El Alemán (3/02/69). 3. B. laticaudatus, Lag. en isla Carabajal (02/72) 4 a- b B. voigti El Alemán (24/02/69). 5. B. plicatilis 5 a Palo Pelado (11/02/00), 5 b $A^{\circ}$ Calchaquí (19/03/96). 6. B. rotundiformis $A^{\circ}$ Las Garzas (10/02/00). Escala: $50 \mu \mathrm{m}$.

Lámina 4.- 1 a-c B. sessilis Río Paraná, km 603 (29/11/90). 2. B. rubens $A^{\circ}$ Cululú (21/03/96). 3. B. cheloni El Alemán (22/12/96). 4. B. nilsoni Río Paraná (22/11/78). 5. B. variabilis Río Salado (27/09/93). 6. B. dolabratus, 6 a Lag. 5 en isla Carabajal (8/04/72), 6 b-c El Tigre (26/01/88). Escala : $50 \mu \mathrm{m}$.

Lámina 5.- 1 a-b Anuraeopsis fissa Lag. Timbó ( 4/12/91), 1 c El Alemán ( 22/12/69) 2 a-b A. navicula La Cantera (9/12/92). 3. Keratella americana El Alemán (15/09/69), 4 a-d. Los Matadores (11/04/77), 5 K. cochlearis, 5 a-b Lag. Ingá (16/09/75), 5 c-d Madrejón Malabrigo (7/09/75). Escala: $50 \mu \mathrm{m}$.

Lámina 6.- 1 Keratella tropica 1 a. Río Paraná, km 403 (15/09/95), 1 b-c. Río Salado (27/09/93), 1 d. El Tigre (1/03/88) 1 c Los Matadores (10/08/77). 2. K. lenzi Río Paraná, km 603 (29/07/81). 3. K. serrulata, Río Paraná, km 440 (5/08/72). 4 .K. morenoi Río Paraná, km 50 ( $09 / 95$ ). 5. K. procurva Lag. en Isla Carabajal ( $6 / 04 / 72$ ). Escala: $50 \mu \mathrm{m}$.

Lámina 7.- 1.Platyias leloupi Lag. La Gabriela (09/75). 2. Platyonus patulus $f$. macracanthus El Alemán (22/12/69) Escala: $50 \mu \mathrm{m}$.

Lámina 8.- 1.Lecane aegana Lag. en isla Sirgadero (04/72). 2. L. arcula Lag. en isla Timbó (12/02/72) 3. L. aspasia Lag.en Saladillos (28/11/84). 4. L. doryssa Lag. La Cruz (6/12/92). 5. L. eutarsa Lag. en Saladillos (12/10/84). 6. L. papuana 7. L. proiecta Río Paraná, km. 603 (8/03/77). 8. L. rhenana Río Parana, km 603 ( 21/03/83). 9. L. robertsonae Lag. Eucaliptus (7/12/92) 10. L. stenroosi Lag. Los Matadores ( 3/06/77) 11. L tenuiseta Lag. Los Matadores (10/08/77). 12. L. quadridentata Río Paraná (28/08/80) 13.L. quadridentata f. gigantea Lag. Chajá (6/12/92) Escala: $50 \mu \mathrm{m}$.

Lámina 9. Trichocerca bicristata Lag. en isla Lechiguana (07/72). 2. T. brazilienis, La Cuarentena (10/12/80). 3. T. capucina Los Matadores (24/08/77). 4 T. dixon-nutalli Madrejón Ñatiu (10/09/75). 5 T. elongata ídem. 6. T. gracilis. Los Matadores (18/08/77). 7. T. porcellus Lag.La Bella (11/09/75). Escala: cuerpo $50 \mu \mathrm{m}$, trophi $20 \mu \mathrm{m}$.

Lámina 10. 1. Trichocerca rattus Río Paraná (30/03/81) 2. T. ruttneri . Los Matadores (10/08/77). 3. T. tigris Ingá (16/09/75). 4. T. voluta Pelón (12/09/75) 5. T. Scipio Los Matadores (23/03/77). Escala: cuerpo $50 \mu \mathrm{m}$, trophi $20 \mu \mathrm{m}$ 
Lámina 11. Eosphora ehrembergi lag. en isla Nogueras (09/75). 2. Gastropus minor lag. en isla Lechiguanas (07/72). 3.Dicranophoroides claviger lag. en isla Carabajal (11/02/72). 4. D. caudatus lag. en isla Sirgadero (13/02/72). 5. Dicronophorus prionacis madrejón Pelón (09/75). 6. Euchlanis lyra lag. Tembleque (02/00). Escala: cuerpo $50 \mu \mathrm{m}$, trophi $20 \mu \mathrm{m}$. 
Tabla 1.1. Lista de especies registradas en cursos de distinta jerarquía.Para las referencias de los números ver Material y Métodos.

\begin{tabular}{|c|c|c|c|c|}
\hline & C. Principal & C.Secund. & Trib. M.D. & Trib. M.Iz. \\
\hline 1 Anuraeopsis fissa (Gosse) & & 4,5 & & \\
\hline 2 A. navicula Rousselet & 8 & & & \\
\hline 3 Ascomorpha ecaudis (Perty) & $2,3,4,8$ & 1,3 & 1 & \\
\hline 4 Ascomorpha saltans Bartsch & & 2 & 5 & 2 \\
\hline 5 Ascomorpha klementi (Hauer) & 2 & & & \\
\hline 6 Asplanchna brightwelli Gosse & 1,2 & 4 & 1 & 1,2 \\
\hline 7 A. silvestrii Daday & & & 3 & \\
\hline 8 Beauchampiella eudactylota (Gosse) & 2 & 4 & & \\
\hline 9 Brachionus ahlstromi Lindeman & $1,2,5,6$ & 1.4 .5 & 1.3 & 1,2 \\
\hline 10 B. amazonica Koste \& Robertson & & & 5 & \\
\hline 11 B. angularis Gosse & $1,2,3,4,6,8$ & $1,2,3,4,5$ & $1,2,3,4,5$ & 1,2 \\
\hline 12 B. austrogenitus Ahlstrom & $1,2,4,6,7,8,9$ & $1,3,4,5$ & $1,2,3,4,5$ & 1,2 \\
\hline 13 B. bidentata Anderson & $1,2,4,8$ & 5 & 5 & \\
\hline 14 B. bidentata Anderson f. inermis (Rousselet) & & & 5 & \\
\hline 15 B. budapestinensis (Daday) & $1,2,4,6$ & $1,3,4,5$ & $1,2,3,4,5$ & 2 \\
\hline 16 B. calyciflorus Pallas & $1,2,4,6,7,8,9$ & $2,3,4,5$ & 2 & 1,2 \\
\hline 17 B. caudatus Barrois \& Daday & $1,2,4,8$ & 5 & & \\
\hline 18 B.c.Barrois \& Daday f. vulgatus Ahlstrom & & & 1,3 & 1 \\
\hline 19 B. insuetus Ahlstrom & $2,4,7,9$ & 5 & $1,2,3,5$ & 1 \\
\hline 20 B. chelonis Ahlstrom & & 4 & & \\
\hline 21 B. dolabratus Harring & $2,4,7$ & $1,3,4$ & & \\
\hline 22 B. falcatus Zacharias & $1,2,4,8$ & $1,2,3,4$ & 3 & 2 \\
\hline 23 B. havanaensis Rousselet & $2,4,6$ & $1,2,4,5$ & $2,3,5$ & 2 \\
\hline 24 B. leydigi Cohn & & & 3 & \\
\hline 25 B. mirabilis Daday & 2 & & 3 & \\
\hline 26 B. mirus (Daday) & $2,4,5$ & 3 & & \\
\hline 27 B. plicatilis (O.F.Müller) & $1,2,4,6$ & $1,2,3,5$ & $1,2,3,5$ & 1 \\
\hline 28 B. quadridentatus (Hermann) & $1,2,4,7,8,9$ & $2,3,4,5$ & $1,2,3,5$ & 1,2 \\
\hline 29 B. rotundiformis Tschugunoff & & & 7 & \\
\hline 30 B. rubens Ehrenberg & & 5 & 3 & \\
\hline 31 B.urceolaris (O.F.Müller) & 2 & 5 & 1,3 & 1 \\
\hline 32 B. nilsoni Ahlstrom & 1 & & & \\
\hline 33 B. variabilis Hempel & & & 1,3 & \\
\hline 34 B. zahniseri Ahlstrom & 2,4 & & & \\
\hline 35 Cephalodella catellina (O.F.Müller) & 1,2 & 4 & & \\
\hline 36 Collotheca cf campanulata (Dobie) & 2 & & & \\
\hline 37 Colurella colurus (Ehrenberg) & 2 & & 3 & \\
\hline 38 Conochilus coenobasis Skorikov & $1,2,4,8,9$ & $1,4,5$ & 1,3 & 1 \\
\hline 39 C. unicornis Rousselet & $1,2,3,4$ & 1 & 3 & \\
\hline 40 C. natans (Seligo) & 1,2 & & & \\
\hline 41 Dicranophorus robustus (Harring \& Myers) & 2 & & & \\
\hline 42 Dipleuchlanis propatula (Gosse) & 2,4 & 4 & 5 & \\
\hline 43 Epiphanes clavulata (Ehrenberg) & $1,2,4,8$ & 3 & 1 & 2 \\
\hline 44 Epiphanes clavulata (Ehrenberg) & $1,2,4$ & 1,3 & 5 & \\
\hline 45 Euchlanis dilatata (Ehrenberg) & $1,2,4,6,7,8$ & $2,3,4,5$ & 5 & 1 \\
\hline
\end{tabular}


46 E. incisa Carlin,

47 Filinia longiseta (Ehremberg)

48 F. opoliensis (Zacharias)

49 F. terminalis (Plate)

50 F. pejleri Hutchinson

$51 \mathrm{~F}$. saltator (Gosse)

52 Hexarthra intermedia Wiszniewski

53 Hexarthra intermedia braziliensis (Hauer)

54 H. mira (Hudson)

55 Keratella americana Carlin

56 K. cochlearis (Gosse)

57 K. c. (Gosse) f. tecta (Lauterborn)

$58 \mathrm{~K}$. lenzi (Hauer)

59 K. serrulata (Ehrenberg)

$60 \mathrm{~K}$. tropica (Apstein)

61 Lecane amazonica (Murray)

62 L. aspasia Myers

63 L. braziliensis Segers

64 L. bulla (Gosse)

65 L. closterocerca (Schmarda)

66 L. cornuta (O.F.Müller)

67 L. curvicornis (Murray)

68 L. decipiens (Daday)

69 L. elsa Hauer

70 L. elegans Harring

71 L. eutarsa Harring \& Myers

72 L. grandis (Murray)

73 L. hamata (Stokes)

74 L. halyclista Harring \& Myers

75 L. hastata (Murray)

76 L. hornemanni (Ehrenberg)

77 L. inopinata Harring \& Myers

78 L. leontina (Turner)

79 L. ludwigii (Eckstein)

80 L. ludwigii (Eckstein) f. ohioensis (Herrick)

81 L. luna O.F.Müller

82 L. lunaris (Ehrenberg)

83 L. monostyla (Daday)

84 L. papuana (Murray)

85 L. proiecta Hauer

86 L. pyriformis (Daday)

87 L. quadridentata (Ehrenberg)

88 L. rhenana Hauer

89 L. rhytida Harring \& Myers

90 L. scutata (Harring \& Myers)

91 L. signifera (Jennings) f. ploenensis (Voigt)

92 L. stenroosi (Meissner)

93 L. ungulata (Gosse)

94 Lepadella biloba (Hauer)

95 L. latusinus (Hilgendorf)

96 L. ovalis (O.F.Müller)
2,4

$\begin{array}{cccc}1,2,3,4,6,7,8,9 & 1,2,4,5 & 1,2,3,5 & 1,2 \\ 1,2,4,8 & 4 & 5 & 1 \\ 2,8 & & 2,4 & \end{array}$

$\begin{array}{cccc}8 & & & \\ 2,8 & & 3 & \\ & 4,5 & 1,5 & 1 \\ 2 & 4 & & \\ 1 \text { al } 9 & 1,2,3,4,5 & 1,23,5 & 1,2 \\ 1 \text { al } 9 & 1,2,3,4,5, & 1,2,3,5 & 1,2 \\ 2,4,8 & 1,3,4,5 & 1,3 & 1 \\ 1,2,4,6,7,8 & 1,2,3,4,5 & 1,2,3,5 & 1 \\ 1 & 3 & & \\ 1 \text { al } 9 & 1,3,4,5 & 1,2,3,5 & 1,2 \\ 2 & & & \end{array}$

6

2

$1,2,3,6,7,8$

2

1,4

$2,3,4$

$1,2,5$

1,2

1,2

$2,3,8$

8

2

2

4,5

3,5

2

3

2

5

4

4

2,8

4

5

6

5

6

2

8

2,3

$1,2,4,8$

$1,2,8$

$1,2,3,4$

3,5

1

5

$\begin{array}{llll}2,8 & 4 & 3 & 2\end{array}$

6,8

2,8

$1,2,7$

$1,2,4,5,6,7,8$

2,4

2

4

$2,3,4$

2,8

7

4,5

1,2

2

2,5

4

2,3

2

$1,2,3$

$3,4,5$

3 
97 L. patella (O.F.Müller)

98 Lophocharis salpina (Ehrenberg)

99 Macrochaetus longipes Myers

100 M. sericus (Thorpe)

101 Monommata longiseta (O.F.Müller)

102 Mytilina bisulcata (Lucks)

103 M. mucronata (O.F.Müller)

104 M. unguipes (Lucks)

105 M. ventralis (Ehrenberg)

106 Notholca acuminata (Ehrenberg)

107 Notommata copeus Ehrenberg

108 Plationus patulus (O.F.Müller)

109 P.p.(O.F.Müller) $f$ macracanthus (Daday)

110 Platyias quadricornis (Ehrenberg)

111 Ploesoma africana Wulfert

112 P. truncatum Levander

113 Pompholix complanata Gosse

114 P. sulcata (Hudson)

115 Polyarthra dolichoptera Idelson

116 P. vulgaris Carlin

117 P. major Burckhardt

118 Scaridium longicaudum (O.F.Müller)

119 Sinantherina spinosa (Thorpe)

120 S. cf ariprepes Edmondson

121 Synchaeta cf. jollyae Shiel \& Koste

122 Synchaeta stylata Wierzejski

123 S. oblonga Ehrenberg

124 S. longipes Gosse

125 Testudinella ahlstromi Hauer

126 T. greeni Koste

127 T. mucronata (Gosse)

128 T. patina (Hermann)

129 T. ohlei Koste

130 T. reflexa (Gosse)

131 T. tridentata Smirnov

132 Trichocerca capuccina (Kellicott)

133 T. bicristata (Gosse)

134 T. brachyura (Gosse)

$135 \mathrm{~T}$. gracilis (Tessin)

136 T. elongata (Gosse)

137 T. rattus (O.F.Müller)

138 T. similis (Wierzejski)

139 T. similis (Wierzejski) f. grandis Hauer

140 T. stylata (Gosse)

141 T. tigris (O.F.Müller)

$142 T$. weberis Jennings

143 Trichotria tetractis (Ehrenberg)

144 Trochosphaera aequatorialis Semper 145 Wolga spinfera (Western)

\section{2}

2

3,4

2,3

1,2

5

4

4

2

$2,3,8$

4

$\begin{array}{ccccc} & & 4 & 5 & \\ 2,3,4,5 & 3 & & & \\ 2 & & 1,2 & 1,3 & 1 \\ 1,2,7,8 & & & 3,5 & \\ & 2 & & & \\ 1,2,3,4 & & 1,4,5 & 1 & \\ 1,2,4,9 & 1,4,5 & 3 & 1 \\ 2,8 & & 5 & 1,2 \\ 2,4,6 & 1,5 & 3 & \\ 1,2,3,4,7,8,9 & 1,2,4,5 & 1,2,3,5 & 1,2 \\ 8 & & & \\ 2 & & & \\ 2 & & & \\ 2 & & & 3 & \\ & & 5,4,5 & 1 & 2\end{array}$

2,4

2

2

2,8

$1,2,4,7,8$

2

2,4

2

2,4

2,5

2

2

$\begin{array}{ccc} & 5 & \\ 2 & 4 & 5 \\ & 4 & 3 \\ & & 5 \\ 1,2,4,5,6,7,8 & 1,2,3,4 & 2,5 \\ & 4 & 3 \\ 2 & & \\ 1,8 & 5 & 3 \\ 2 & 2 & \\ 2 & & \\ 2,3,4 & 2,3,4,5 & 4 \\ & 4 & \\ 2,5 & 2 & 1\end{array}$


Tabla 2.1. Lista de especies de rotíferos registrados en ambientes leníticos 1: Los Espejos. 2:El alemán. 3:Don Felipe. 4:El Tigre. 5:Los Matadores 6: La Cuarentena. 7:Lagunas Isleñas Paraná Inferior. 8: Lagunas sector Confluencia-Diamante. 9:Lagunas isleñas, sector Santa Fe-Paraná. 10: Lagunas Pcia de Corrientes. 11: Lagunas subsistema Saladillos.

1 Anuraeopsis fissa (Gosse)

2 A. navicula Rousselet,

3 Ascomorpha ecaudis (Perty)

4 A. ovalis (Bergendahl)

5 Ascomorpha saltans Bartsch

6 Asplanchna brightwelli Gosse

7 A. girodi (De Guerne)

8 A. intermedia (Hudson),

9 A. sieboldi (Leydig)

10 Asplanchnopus multiceps (Schrank)

11 Beauchampiella eudactylota (Gosse)

12 Brachionus ah/stromi Lindeman

13 B. amazonica Koste \& Robertson

14 B. angularis Gosse

$15 \mathrm{~B}$. austrogenitus Ahlstrom

16 B. bidentata Anderson

17 B. budapestinensis (Daday)

18 B. calyciflorus Pallas

19 B. caudatus Barrois \& Daday

20 B. insuetus Ahlstrom

21 B. chelonis Ahlstrom

22 B. dolabratus Harring

23 B. falcatus Zacharias

24 B. havanaensis Rousselet

25 B. laticaudatus Paggi

26 B. mirabilis Daday

27 B. mirus (Daday)

28 B. plicatilis (O.F.Müller)

29 B. quadridentatus (Hermann)

30 B. rubens Ehrenberg

31 B.sessilis Varga

32 B.urceolaris (O.F.Müller)

33 B. voigti Hauer

34 B. zahniseri Ahlstrom

35 Cephalodella catellina (O.F.Müller)

36 C. gibba (Ehrenberg)

37 C. mucronata (Myers)

38 Collotheca cf coronatta (Cubitt)

39 C. cf. trilobata (Collins)

40 Colurella adriatica Ehrenberg

41 C. colurus (Ehrenberg)

42 C. denticauda Carlin

43 C. uncinata (O.F.Müller)

44 Conochilus coenobasis Skorikov

45 C. hippocrepis (Schrank)

46 C. unicornis Rousselet

47 C. natans (Seligo)

48 Dicranophoroides claviger (Hauer)

49 D. caudatus Ehrenberg

50 Dicranophorus cf. hauerianus Wiszniewski

51 D. grandis (Ehrenberg)

52 D. robustus Harring \& Myers

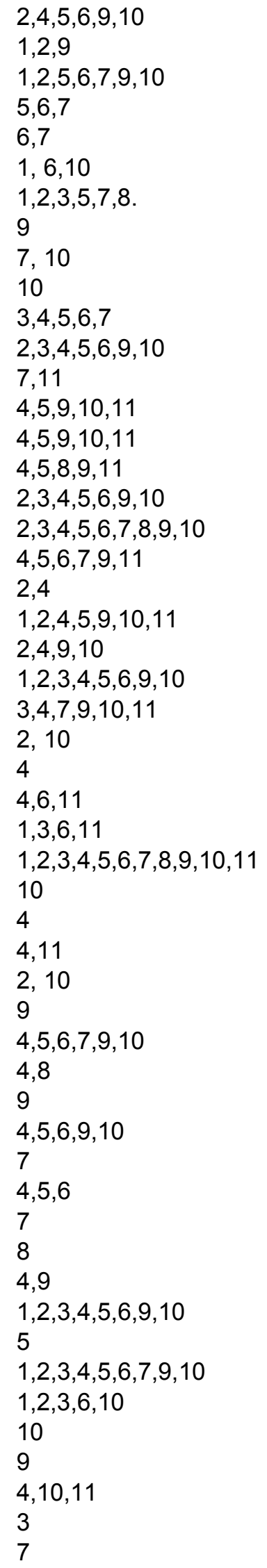


53 D. prionacis Harring \& Myers

54 Dipleuchlanis propatula (Gosse)

55 Eosphora ehrembergi Weber

56 Epiphanes clavulata (Ehrenberg)

57 E.macrourus (Barrois \& Daday)

58 Euchlanis deflexa Myers

59 E. dilatata (Ehrenberg)

60 E. incisa Carlin

61 E. lyra (Hudson)

62 E.cf. meneta Myers

63 E. parva Rousselet

64 Filinia longiseta (Ehremberg)

65 F. opoliensis (Zacharias)

66 F. terminalis (Plate)

67 F. pejleri Hutchinson

68 F. saltator (Gosse)

69 Gastropus minor (Rousselet)

70 Hexarthra intermedia Wiszniewski

71 Hexarthra intermedia braziliensis (Hauer)

$72 \mathrm{H}$. mira (Hudson)

73 Horaella thomassoni Koste

74 Keratella americana Carlin

75 K. cochlearis (Gosse)

76 K. c. (Gosse) f. tecta (Lauterborn)

77 K. lenzi (Hauer)

78 L. procurva (Thorpe)

79 K. serrulata (Ehrenberg)

80 K. tropica (Apstein)

81 Lecane aculeata (Jakubski)

$82 L$. aegana Harring

83 L. arcula Harring

84 L. arcuata (Jakubski)

85 L. amazonica (Murray)

86 L. aspasia Myers

87 L. braziliensis Segers

88 L. bulla (Gosse)

89 L. closterocerca (Schmarda)

90 L. cornuta (O.F.Müller)

91 L. crepida Harring

92 L. crepida Harring f. longidactyla (Koste)

93 L. curvicornis (Murray)

94 L. decipiens (Daday)

95 L. doryssa (Harring)

96 L. elegans Harring

97 L. elsa Hauer

98 L. flexilis Harring

99 L. furcata (Murray)

100 L. halyclista Harring \& Myers

101 L. hamata (Stokes)

102 L. hastata (Murray)

103 L. hornemanni (Ehrenberg)

104 L. inopinata Harring \& Myers

105 L. leontina (Turner)

106 L. ludwigii (Eckstein)

107 L. ludwigii (Eckstein) f. marshi Harring

108 L. Iudwigii (Eckstein) f. ohioensis (Herrick)

109 L. Iuna O.F.Müller

110 L. lunaris (Ehrenberg)
5,7

$3,4,5,11$

6,7

$1,2,4,6,10$

$4,10,11$

2,6

$3,4,5,7,8,9,10,11$

$4,5,6,8,9$

7

4

6

$1,2,3,4,5,6,7,9,10,11$

$1,2,3,4,5,9,10,11$

$1,2,3,4,5,6,7,9,10$

4,9

$8,6,10$

8

$2,3,4,6,7$

$4,9,10$

$4,5,11$

4,9

$1,2,3,4,5,6,7,8,9,10,11$

$1,2,3,4,5,6,7,8,9,10$

$3,4,6,7,9,10$

$1,2,4,5,6,7,8,9,10,11$

9

3,11

$1,2,3,4,5,6,7,8,9,10,11$

9

7,11

9

8

9

11

9

$1,3,4,5,6,7,8,9,10,11$

$4,5,6,7,8,9$

$1,4,5,6,9,10$

9

9

$1,3,4,5,7,8,9,10$

$4,5,7,9$

4,9

$4,5,7,9$

$4,9,10$

4,9

9

9

$4,5,6,7,8,9,11$

4

9

7

$1,3,4,5,6,7,9,10$

$4,5,6,7,9$

9

8

$4,5,6,7,9,10,11$

$4,5,6,7,9,11$ 
111 L. marchantaria Koste \& Robertson

9

112 L. monostyla (Daday)

113 L. nana (Murray)

114 L. obtusa (Murray)

$2,4,6,9,11$

115 L. papuana (Murray)

$4,5,6,9$

116 L. proiecta Hauer

$1,2,4,8,9,10,11$

117 L. pyriformis (Daday)

$1,5,6,9$

118 L. quadridentata (Ehrenberg)

$4,5,7,8,9$

119 L. rhenana Hauer

120 L. rhytida Harring \& Myers

121 L. robertsonae Segers

122 L. scutata (Harring \& Myers)

$7,6,9,10,11$

4

7,9

7,11

$5,6,9$

123 L. signifera (Jennings)

124 L. signifera (Jennings) f. ploenensis (Voigt)

125 L. stenroosi (Meissner)

$4,5,7,8,9$

126 L. stichaea Harring

6,9

$4,5,7,9$

7,9

127 L. tenuiseta Harring

$4,5,7,9$

128 L. ungulata (Gosse)

129 Lepadella acuminata (Ehrenberg)

130 L. benjamini Harring

131 L. biloba (Hauer)

132 L. costata Wulfert

133 L. cristata (Rousselet)

$4,8,9$

$4,5,8,9$

7,10

9

7,9

9

134 L. donneri Koste

4,9

135 L. ehrenbergi (Perty)

5,9

136 L. elliptica Wulfert

137 L. elongata Koste

9

138 L. latusinus (Hilgendorf)

139 L. mataca José de Paggi

140 L. ovalis (O.F.Müller)

141 L. patella (O.F.Müller)

142 L. rhomboides (Gosse)

143 L. rottenburgi (Lucks)

144 Lophocharis salpina (Ehrenberg)

145 Macrochaetus longipes Myers

146 M. subquadratus Perty

147 M. sericus (Thorpe)

148 Monommata longiseta (O.F.Müller)

149 Mytilina acantophora Hauer

150 M. bisulcata (Lucks)

151 M. lobata Pourriot

152 M. mucronata (O.F.Müller)

153 M. unguipes (Lucks)

$154 M$. ventralis (Ehrenberg)

155 Notholca acuminata (Ehrenberg)

156 N. squamula (O.F.Müller)

157 Notommata copeus Ehrenberg

158 Plationus patulus (O.F.Müller)

159 P.p.(O.F.Müller) f macracanthus (Daday)

160 P. leloupi (Gillard)

161 Platyias quadricornis (Ehrenberg)

162 Ploesoma africana Wulfert

$163 P$. lenticulare Herrick

$164 P$. truncatum Levander

165 Pompholix complanata Gosse

166 P. sulcata (Hudson)

7

$2,4,5,6,7,8,9,10,11$

$2,3,6,7,8,9,11$

$4,5,6,7,8,9$

6,9

$5,6,7,9,11$

$6,9,10$

7

$3,7,9,10$

$3,4,5,7,9,10$

8

$4,8,9$

8

6

$4,5,6,9,11$

$1,4,5,6,7,8,9,11$

5,11

3

7,9

$1,2,3,4,5,6,8,9,10,11$

4

9

$1,2,3,4,5,6,7,8,9,10$

9

7

$4,5,6,7$

$2,3,4,5,9,10$

6,7

4,9

3,4 ,

168 P. major (Burckhardt) 


\begin{tabular}{|c|c|}
\hline 169 P. remata (Skorikov) & 8 \\
\hline 170 P. vulgaris Carlin & $1,2,3,4,5,6,7,8,9,10,11$ \\
\hline 171 Ptygura kostei José de Paggi & 9 \\
\hline 172 P. libera Myers & 4,9 \\
\hline 173 Scaridium bostjan i Daems \& Dumont & 5 \\
\hline 174 S. elegans Segers \& De Meester & 5 \\
\hline 175 S. longicaudum (O.F.Müller) & $4,5,7,9$ \\
\hline 176 Sinantherina procera (Thorpe) & 1 \\
\hline 177 Squatinella bifurca (Bolton) & $4,7,9$ \\
\hline 178 S. leydigi Zacharias & 7,9 \\
\hline 179 S. lamellaris (O.F.Müller) & 7,9 \\
\hline 180 Synchaeta stylata Wierzejski & 4,6 \\
\hline 181 S. oblonga Ehrenberg & $5,7,8$ \\
\hline 182 S. longipes Gosse & 6,11 \\
\hline 183 Testudinella ahlstromi Hauer & $4,5,7,9$ \\
\hline 184 T. brevicaudata Yamamoto & 9 \\
\hline 185 T. brycei Hauer & 3 \\
\hline 186 T. emarginula (Stenroos) & 5,7 \\
\hline 187 T. incisa (Ternetz) & 6,9 \\
\hline 188 T. mucronata (Gosse) & 6,9 \\
\hline 189 T. ohlei Koste & 9 \\
\hline 190 T. parva (Ternetz) & 9 \\
\hline 191 T. patina (Hermann) & $1,2,3,4,5,6,7,8,9,10$ \\
\hline 192 T. patina (Hermann) f. intermedia Anderson & 10 \\
\hline 193 T. reflexa (Gosse) & 7 \\
\hline 194 T. tridentata Smirnov & 5 \\
\hline 195 T. cf. trilobata Anderson \& Stephard & $1,2,4$ \\
\hline 196 Trichocerca abilioi Segers \& Sarma & 4,9 \\
\hline 197 T. bicristata (Gosse) & $2,3,5,6,7,8,9,10,11$ \\
\hline 198 T. brachyura (Gosse) & 5 \\
\hline 199 T. braziliensis (Murray) & 9 \\
\hline 200 T. capuccina (Wierzejski \& Zacharias) & 5,6 \\
\hline 201 T. cylindrica (Imhof) & 4,9 \\
\hline 202 T. chattoni (De Beauchamp) & 5,6 \\
\hline 203 T. dixonnutalli Jennings & 7 \\
\hline 204 T. elongata (Gosse) & $7,9,10$ \\
\hline 205 T. gracilis (Tessin) & 5 \\
\hline 206 T. hollaerti De Smet & 9 \\
\hline 207 T. iernis (Gosse) & 2 \\
\hline 208 T. insignis (Herrick) & 7,9 \\
\hline 209 T. longiseta (Schrank) & 9 \\
\hline 210 T. porcellus (Gosse) & $5,6,7,9,10$ \\
\hline 211 T. pusilla (Lauterborn) & $5,7,9$ \\
\hline 212 T. rattus (O.F. Müller) & $4,7,9,11$ \\
\hline 213 T. ruttneri Donner & 5 \\
\hline 214 T.scipio (Gosse) & 5 \\
\hline 215 T. similis (Wierzejski) & $4,5,9,10$ \\
\hline 216 T. similis (Wierzejski) f. grandis Hauer & 5,6 \\
\hline 217 T. stylata (Gosse) & 6,9 \\
\hline 218 T. tenuior (Gosse) & 7 \\
\hline 219 T. tigris (O.F. Müller) & 7,9 \\
\hline 220 T. vernalis (Hauer) & 9 \\
\hline 221 T. voluta (Hauer) & 7 \\
\hline $222 T$. weberis Jennings & 6 \\
\hline 223 Trichotria tetractis (Ehrenberg) & $3,4,5,6,7,8,9$ \\
\hline 224 Tripleuchlanis plicata Levander & 3 \\
\hline 225 Trochosphaera aequatorialis Semper & $3,4,6$ \\
\hline 226 Wolga spinfera (Western) & 9 \\
\hline
\end{tabular}




\begin{tabular}{|c|c|c|c|c|c|c|c|}
\hline Tipos & $\mathrm{N}^{\circ}$ Lag. & $\begin{array}{c}\text { Superf. } \\
\text { has }\end{array}$ & $\begin{array}{c}\text { Prof. } \\
\mathrm{cm}\end{array}$ & $\begin{array}{c}\text { Transp. } \\
\mathrm{cm}\end{array}$ & Turb. & $\begin{array}{l}\text { Cond. } \\
\text { uS/cm }\end{array}$ & $\mathrm{pH}$ \\
\hline $\begin{array}{l}\text { Grandes } \\
\text { sin veget. }\end{array}$ & $\begin{array}{c}1 \\
2 \\
8 \\
11 \\
16 \\
19 \\
\end{array}$ & $\begin{array}{c}310,5 \\
38,2 \\
21,8 \\
82.2 \\
15,8 \\
252 \\
\end{array}$ & $\begin{array}{c}87 \\
80 \\
75 \\
30 \\
160 \\
120 \\
\end{array}$ & $\begin{array}{c}10 \\
30 \\
9 \\
2 \\
30 \\
8 \\
\end{array}$ & $\begin{array}{c}200 \\
70 \\
155 \\
\\
37 \\
301 \\
\end{array}$ & $\begin{array}{l}308 \\
234 \\
126\end{array}$ & $\begin{array}{l}7,5 \\
7,6 \\
7,9 \\
7,2 \\
7,3 \\
7,4 \\
\end{array}$ \\
\hline $\begin{array}{l}\text { Grandes } \\
\text { con veget. }\end{array}$ & $\begin{array}{c}3 \\
13 \\
\\
20 \\
\end{array}$ & $\begin{array}{r}7,5 \\
49,6 \\
79,5 \\
\end{array}$ & $\begin{array}{l}90 \\
80 \\
75 \\
\end{array}$ & $\begin{array}{l}35 \\
50 \\
\\
25 \\
\end{array}$ & $\begin{array}{l}44 \\
25 \\
56 \\
\end{array}$ & $\begin{array}{r}155 \\
112 \\
\\
206 \\
\end{array}$ & $\begin{array}{r}7 \\
6,9 \\
7,6 \\
\end{array}$ \\
\hline $\begin{array}{l}\text { Pequeñas } \\
\text { sin veget. }\end{array}$ & $\begin{array}{c}17 \\
7 \\
10 \\
21 \\
\end{array}$ & $\begin{array}{l}4,6 \\
1,6 \\
0,6 \\
1,6 \\
\end{array}$ & $\begin{array}{l}30 \\
30 \\
75 \\
65 \\
\end{array}$ & $\begin{array}{c}4 \\
5 \\
4 \\
10 \\
\end{array}$ & $\begin{array}{r}4,88 \\
888 \\
\\
250 \\
\end{array}$ & $\begin{array}{c}95 \\
252 \\
168 \\
\end{array}$ & $\begin{array}{l}7,2 \\
6,5 \\
5,4 \\
6,4 \\
\end{array}$ \\
\hline $\begin{array}{l}\text { Pequeñas } \\
\text { con veget. }\end{array}$ & $\begin{array}{c}4 \\
6 \\
9 \\
14\end{array}$ & $\begin{array}{c}5 \\
2,2 \\
1,6\end{array}$ & $\begin{array}{c}75 \\
125 \\
120 \\
65\end{array}$ & $\begin{array}{c}60 \\
30 \\
100 \\
60\end{array}$ & $\begin{array}{l}23 \\
51 \\
23 \\
22 \\
\end{array}$ & $\begin{array}{r}133 \\
143 \\
56,5 \\
71,1\end{array}$ & $\begin{array}{c}6,8 \\
6,9 \\
6,6 \\
6\end{array}$ \\
\hline Madrejones & $\begin{array}{r}5 \\
12 \\
15 \\
18 \\
22 \\
23 \\
24 \\
25 \\
\end{array}$ & $\begin{array}{c}15,6 \\
3 \\
6,3 \\
12,5 \\
3,5 \\
6 \\
7,3 \\
2,8 \\
\end{array}$ & $\begin{array}{c}65 \\
115 \\
110 \\
20 \\
75 \\
80 \\
60 \\
90 \\
\end{array}$ & $\begin{array}{c}9 \\
45 \\
110 \\
5 \\
25 \\
50 \\
60 \\
60 \\
\end{array}$ & $\begin{array}{c}40 \\
23 \\
380 \\
40 \\
17 \\
16 \\
29 \\
\end{array}$ & $\begin{array}{r}225 \\
96,9 \\
109 \\
135 \\
149 \\
149 \\
137 \\
140 \\
\end{array}$ & $\begin{array}{c}6,9 \\
6,9 \\
6,9 \\
7,1 \\
6,9 \\
6,9 \\
7 \\
7,2 \\
\end{array}$ \\
\hline
\end{tabular}

Tabla 2.5. Datos ambientales de 25 lagunas isleñas próximas a la ciudad de Santa Fe, definidas por su tamaño y existencia de vegetación litoral 


\begin{tabular}{|c|c|c|c|c|c|c|}
\hline Tipos de lagunas & Ubicación & $\mathbf{N}^{\circ}$ Laguna & $\mathbf{V}$ & $\mathbf{C V}$ & Total Spp & Total Gén. \\
\hline Grandes s/veget. & $\begin{array}{l}\text { I. Los Mellados } \\
\text { I. Sirgadero } \\
\text { I. Carabajal }\end{array}$ & $\begin{array}{c}1 \\
2 \\
8 \\
11 \\
16 \\
19\end{array}$ & & & $\begin{array}{c}3 \\
5 \\
3 \\
1 \\
17 \\
4 \\
\mathbf{5 , 5 0} \\
5,79\end{array}$ & $\begin{array}{c}3 \\
4 \\
2 \\
1 \\
9 \\
4 \\
3,83 \\
2,79\end{array}$ \\
\hline Grandes c/veget. & $\begin{array}{l}\text { I. Los Mellados } \\
\text { I. Sirgadero }\end{array}$ & $\begin{array}{c}3 \\
13 \\
20\end{array}$ & $\begin{array}{l}F \\
F \\
S F\end{array}$ & $\begin{array}{l}\text { III } \\
\text { I } \\
\text { IV }\end{array}$ & $\begin{array}{c}5 \\
10 \\
15 \\
10,00 \\
5,00 \\
\end{array}$ & $\begin{array}{c}3 \\
8 \\
11 \\
7,33 \\
4,04 \\
\end{array}$ \\
\hline Peq. s/veget. & $\begin{array}{l}\text { I. Sirgadero } \\
\text { I. Carabajal }\end{array}$ & $\begin{array}{c}7 \\
10 \\
21\end{array}$ & & & $\begin{array}{c}2 \\
6 \\
5 \\
4,33 \\
2,08 \\
\end{array}$ & $\begin{array}{c}1 \\
4 \\
2 \\
2,33 \\
1,53 \\
\end{array}$ \\
\hline Peq. c/veget. & $\begin{array}{l}\text { I. L os Mellados } \\
\text { I. Sirgadero } \\
\text { I. Carabajal }\end{array}$ & $\begin{array}{c}4 \\
6 \\
9 \\
14 \\
17\end{array}$ & $\begin{array}{c}F \\
S \\
S \\
F S \\
S\end{array}$ & $\begin{array}{c}\text { II } \\
\text { I } \\
\text { I } \\
\text { V } \\
\text { VI }\end{array}$ & $\begin{array}{c}15 \\
12 \\
13 \\
7 \\
8 \\
11,00 \\
3,40\end{array}$ & $\begin{array}{c}8 \\
6 \\
9 \\
6 \\
4 \\
7,25 \\
1,50 \\
\end{array}$ \\
\hline Madrejones & $\begin{array}{l}\text { I. Carabajal } \\
\text { I. Sirgadero } \\
\text { I. Carabajal } \\
\text { I. Timbó }\end{array}$ & $\begin{array}{c}5 \\
12 \\
15 \\
18 \\
22 \\
23 \\
24 \\
25\end{array}$ & $\begin{array}{c}\text { S } \\
\text { SF } \\
\text { S } \\
\text { SF } \\
\text { SF } \\
\text { S } \\
F \\
\text { S }\end{array}$ & $\begin{array}{l}\text { III } \\
\text { IV } \\
\text { IV } \\
\text { V } \\
\text { VI } \\
\text { VI } \\
\text { IV } \\
\text { IV }\end{array}$ & $\begin{array}{c}12 \\
16 \\
18 \\
16 \\
10 \\
9 \\
10 \\
12 \\
\mathbf{1 2 , 8 8} \\
3,36 \\
\end{array}$ & $\begin{array}{c}7 \\
9 \\
9 \\
12 \\
6 \\
7 \\
6 \\
8 \\
\mathbf{8 , 0 0} \\
2,00 \\
\end{array}$ \\
\hline
\end{tabular}

Tabla 2.6. Número total de especies de Rotíferos y de géneros, media y desvío estándar (en negrita e itálica respectivamente) en lagunas isleñas agrupadas por tamaño y presencia de vegetación. Vegetación (V) flotante $(\mathrm{F})$, sumergida $(\mathrm{S})$, sumergida + flotante $(\mathrm{SF})$. Cobertura de vegetación (CV): menos del 10\% (I), 10-20\% (II), 20-40\% (III), 40-60\% (IV), $60-80 \%$ (V), más del $80 \%(\mathrm{~V} / \mathrm{I})$ 
Tabla 3.1. Total de especies registradas. R: ambientes lóticos; L: ambientes lénticos.

1 Anuraeopsis fissa (Gosse)

2 A. navicula Rousselet

3 Ascomorpha ecaudis (Perty)

4 A. ovalis (Bergendahl)

5 Ascomorpha saltans Bartsch

6 Ascomorpha klementi (Hauer)

7 Asplanchna brightwelli Gosse

8 A. girodi (De Guerne)

9 A. intermedia (Hudson),

10 A. sieboldi (Leydig)

11 A. silvestrii Daday

12 Asplanchnopus multiceps (Schrank)

13 Beauchampiella eudactylota (Gosse)

14 Brachionus ahlstromi Lindeman

15 B. amazonica Koste \& Robertson

16 B. angularis Gosse

17 B. austrogenitus Ahlstrom

18 B. bidentata Anderson

19 B.bidentata Anderson $f$. inermis Rousselet

20 B. budapestinensis (Daday)

21 B. calyciflorus Pallas

22 B. caudatus Barrois \& Daday

23 B.c. Barrois \& Daday f. vulgatus Ahlstrom

$24 \mathrm{~B}$. insuetus Ahlstrom

$25 B$. chelonis A hlstrom

26 B. dolabratus Harring

27 B. falcatus Zacharias

28 B. havanaensis Rousselet

29 B. laticaudatus Paggi

30 B. leydigi Cohn

31 B. mirabilis Daday

32 B. mirus (Daday)

33 B. plicatilis (O.F.Müller)

34 B. quadridentatus (Hermann)

$35 B$. rotundiformis Tschugunoff

36 B. rubens Ehrenberg

37 B. nilsoni Ahlstrom

38 B.sessilis Varga

39 B.urceolaris (O.F.Müller)

40 B. variabilis Hempel

41 B. voigti Hauer

42 B. zahniseri Ahlstrom

43 Cephalodella catellina (O.F.Müller)

44 C. gibba (Ehremberg)

45 C. mucronata (Myers)

$\mathrm{R}$

$\begin{array}{ll}R & \text { L } \\ R & \text { L } \\ R & \text { L } \\ & \text { L } \\ R & \text { L } \\ R & \text { L } \\ \text { R } & \text { L } \\ & \text { L } \\ & \end{array}$

R

$\mathrm{R}$

$\mathrm{R}$

$\mathrm{R}$

$\mathrm{R}$

$R$

$\mathrm{R}$

$R$

R

$R$

$R$

$R$

$\mathrm{R}$

$\mathrm{R}$

R

R

$\mathrm{R}$

R L

R L

R L

R L

$\mathrm{R}$

R L

$\mathrm{R}$

R

$\mathrm{R}$

$\mathrm{R}$

R

L

L

L

L

L

L

L

L

L

L

L

L

L

L

$L$

$L$

L

L

$L$

L

L

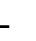

\section{L}

L

L

L

L

L 
46 Collotheca cf coronatta (Cubitt)

47 Collotheca cf campanulata (Dobie)

48 C. cf. trilobata (Collins)

49 Colurella adriatica Ehrenberg

50 C. colurus (Ehrenberg)

51 C. denticauda Carlin

52 C. uncinata (O.F.Müller)

53 Conochilus coenobasis Skorikov

54 C. hippocrepis (Schrank)

55 C. unicornis Rousselet

56 C. natans (Seligo)

57 Dicranophoroides claviger (Hauer)

$\mathrm{R}$

58 D. caudatus E hrenberg

59 Dicranophorus cf. hauerianus Wiszniewski

60 D. grandis (Ehrenberg)

61 D. robustus Harring \& Myers

62 D. prionacis Harring \& Myers

63 Dipleuchlanis propatula (Gosse)

64 Eosphora ehrembergi Weber

65 Epiphanes clavulata (Ehrenberg)

66 E.macrourus (Barrois \& Daday)

67 Euchlanis deflexa Myers

68 E. dilatata (E hrenberg)

69 E. incisa Carlin

70 E. lyra (Hudson)

71 E.cf. meneta Myers

72 E. parva Rousselet

73 Filinia longiseta (Ehremberg)

74 F. opoliensis (Zacharias)

75 F. terminalis (Plate)

76 F. pejleri Hutchinson

77 F. saltator (Gosse)

78 Gastropus minor (Rousselet)

79 Hexarthra intermedia Wiszniewski

80 Hexarthra intermedia braziliensis (Hauer)

$81 \mathrm{H}$. mira (Hudson)

82 Horaella thomassoni Koste

83 Keratella americana Carlin

84 K. cochlearis (Gosse)

85 K. c. (Gosse) f. tecta (Lauterborn)

86 K. lenzi (Hauer)

87 L. procurva (Thorpe)

$88 \mathrm{~K}$. serrulata (Ehrenberg)

89 K. tropica (Apstein)

90 Lecane aculeata (Jakubski)

91 L. aegana Harring

92 L. arcula Harring

93 L. arcuata (Jakubski)

94 L. amazonica (Murray)

95 L. aspasia Myers

$\begin{array}{ll} & \text { L } \\ & \text { L } \\ & \text { L } \\ & \text { R } \\ & \text { L } \\ \text { R } & \text { L }\end{array}$




\begin{tabular}{|c|c|c|}
\hline 96 L. braziliensis Segers & $\mathrm{R}$ & $\mathrm{L}$ \\
\hline 97 L. bulla (Gosse) & $\mathrm{R}$ & L \\
\hline 98 L. closterocerca (Schmarda) & $\mathrm{R}$ & L \\
\hline 99 L. cornuta (O.F.Müller) & $\mathrm{R}$ & $\mathrm{L}$ \\
\hline 100 L. crepida Harring & & L \\
\hline 101 L. crepida Harring f. longidactyla (Koste) & & $\mathrm{L}$ \\
\hline 102 L. curvicornis (Murray) & $\mathrm{R}$ & L \\
\hline 103 L. decipiens (Daday) & $\mathrm{R}$ & $\mathrm{L}$ \\
\hline 104 L. doryssa (Harring) & & $\mathrm{L}$ \\
\hline 105 L. elegans Harring & $\mathrm{R}$ & L \\
\hline 106 L. elsa Hauer & $\mathrm{R}$ & L \\
\hline 107 L. eutarsa Harring \& Myers & $\mathrm{R}$ & \\
\hline 108 L. flexilis Harring & & $\mathrm{L}$ \\
\hline 109 L. furcata (Murray) & & $\mathrm{L}$ \\
\hline 110 L. grandis (Murray) & $\mathrm{R}$ & \\
\hline 111 L. halyclista Harring \& Myers & $\mathrm{R}$ & $\mathrm{L}$ \\
\hline 112 L. hamata (Stokes) & $\mathrm{R}$ & $\mathrm{L}$ \\
\hline 113 L. hastata (Murray) & $\mathrm{R}$ & $\mathrm{L}$ \\
\hline 114 L. hornemanni (Ehrenberg) & $\mathrm{R}$ & $\mathrm{L}$ \\
\hline 115 L. inopinata Harring \& Myers & $\mathrm{R}$ & L \\
\hline 116 L. leontina (Turner) & $\mathrm{R}$ & $\mathrm{L}$ \\
\hline 117 L. Iudwigii (Eckstein) & $\mathrm{R}$ & $\mathrm{L}$ \\
\hline 118 L. ludwigii (Eckstein) f. marshi Harring & & $\mathrm{L}$ \\
\hline 119 L. Iudwigii (Eckstein) f. ohioensis (Herrick) & $\mathrm{R}$ & L \\
\hline 120 L. Iuna O.F.Müller & $\mathrm{R}$ & $\mathrm{L}$ \\
\hline 121 L. lunaris (Ehrenberg) & $\mathrm{R}$ & L \\
\hline 122 L. marchantaria Koste \& Robertson & & $\mathrm{L}$ \\
\hline 123 L. monostyla (Daday) & $\mathrm{R}$ & L \\
\hline 124 L. nana (Murray) & & L \\
\hline 125 L. obtusa (Murray) & & $\mathrm{L}$ \\
\hline 126 L. papuana (Murray) & $\mathrm{R}$ & $\mathrm{L}$ \\
\hline 127 L. proiecta Hauer & $\mathrm{R}$ & L \\
\hline 128 L. pyriformis (Daday) & $\mathrm{R}$ & L \\
\hline 129 L. quadridentata (Ehrenberg) & $\mathrm{R}$ & L \\
\hline 130 L. rhenana Hauer & $\mathrm{R}$ & $\mathrm{L}$ \\
\hline 131 L. rhytida Harring \& Myers & $\mathrm{R}$ & L \\
\hline 132 L. robertsonae Segers & & $\mathrm{L}$ \\
\hline 133 L. scutata (Harring \& Myers) & $\mathrm{R}$ & L \\
\hline 134 L. signifera (Jennings) & & L \\
\hline 135 L. signifera (Jennings) f. ploenensis (Voigt) & $\mathrm{R}$ & L \\
\hline 136 L. stenroosi (Meissner) & $\mathrm{R}$ & $\mathrm{L}$ \\
\hline 137 L. stichaea Harring & & $\mathrm{L}$ \\
\hline 138 L. tenuiseta Harring & & L \\
\hline 139 L. ungulata (Gosse) & $\mathrm{R}$ & L \\
\hline 140 Lepadella acuminata (Ehrenberg) & & $\mathrm{L}$ \\
\hline 141 L. benjamini Harring & & $\mathrm{L}$ \\
\hline 142 L. biloba (Hauer) & $\mathrm{R}$ & $\mathrm{L}$ \\
\hline 143 L. costata Wulfert & & $\mathrm{L}$ \\
\hline 144 L. cristata (Rousselet) & & L \\
\hline 145 L. donneri Koste & & \\
\hline
\end{tabular}


146 L. ehrenbergi (Perty)

147 L. elliptica Wulfert

148 L. elongata Koste

149 L. latusinus (Hilgendorf)

150 L. mataca José de Paggi

151 L. ovalis (O.F.Müller)

152 L. patella (O.F.Müller)

153 L. rhomboides (Gosse)

154 L. rottenburgi (Lucks)

155 Lophocharis salpina (Ehrenberg)

156 Macrochaetus longipes Myers

157 M. subquadratus Perty

158 M. sericus (Thorpe)

159 Monommata longiseta (O.F.Müller)

160 Mytilina acantophora Hauer

161 M. bisulcata (Lucks)

162 M. lobata Pourriot

163 M. mucronata (O.F.Müller)

164 M. unguipes (Lucks)

165 M. ventralis (Ehrenberg)

166 Notholca acuminata (Ehrenberg)

167 N. squamula (O.F.Müller)

168 Notommata copeus Ehrenberg

169 Plationus patulus (O.F.Müller)

170 P.p.(O.F.Müller) $f$ macracanthus (Daday)

171 P. leloupi (Gillard)

172 Platyias quadricornis (Ehrenberg)

173 Ploesoma africana Wulfert

174 P. lenticulare Herrick

175 P. truncatum Levander

176 Pompholix complanata Gosse

177 P. sulcata (Hudson)

178 Polyarthra dolichoptera Idelson

179 P. major (Burckhardt)

180 P. remata (Skorikov)

181 P. vulgaris Carlin

182 Ptygura kostei José de Paggi

183 P. libera Myers

184 Scaridium bostjani Daems \& Dumont

185 S. elegans Segers \& De Meester

186 S. longicaudum (O.F.Müller)

187 Sinantherina spinosa (Thorpe)

R

$\mathrm{R}$

$\mathrm{R}$

$\mathrm{R}$

$\mathrm{R}$

$\mathrm{R}$

$\mathrm{R}$

$\mathrm{R}$

$\mathrm{R}$

$\mathrm{R}$

$\mathrm{R}$

$\mathrm{R}$

$\mathrm{R}$

$\mathrm{R}$

$\mathrm{R}$

$\mathrm{R}$

$\mathrm{R}$

$\mathrm{R}$

$\mathrm{R}$

$\mathrm{R}$

$\mathrm{R}$

$\mathrm{R}$

$\mathrm{R}$

188 S. procera (Thorpe)

189 S. cf ariprepes Edmondson

190 Squatinella bifurca (Bolton)

191 S. leydigi Zacharias

192 S. lamellaris (O.F.Müller)

193 Synchaeta stylata Wierzejski

194 S. oblonga Ehrenberg

195 S. longipes Gosse

$\mathrm{R}$

$\mathrm{R}$

$\mathrm{R}$

$\mathrm{R}$

$\mathrm{R}$

$\mathrm{R}$

$\begin{array}{ll} & \text { L } \\ & \text { L } \\ & \text { L } \\ R & \text { L } \\ R & \text { L } \\ R & \text { L }\end{array}$


196 S.cf. Jollyae Shiel \& Koste

$\mathrm{R}$

197 Testudinella ah/stromi Hauer

$\mathrm{R}$

198 T. brevicaudata Yamamoto

199 T. brycei Hauer

200 T. emarginula (Stenroos)

201 T. greeni Koste

202 T. incisa (Ternetz)

203 T. mucronata (Gosse)

204 T. ohlei Koste

205 T. parva (Ternetz)

206 T. patina (Hermann)

207 T. patina (Hermann) f. intermedia Anderson

208 T. reflexa (Gosse)

209 T. tridentata Smirnov

210 T. cf. trilobata Anderson \& Stephard

211 Trichocerca abilioi Segers \& Sarma

212 T. bicristata (Gosse)

213 T. brachyura (Gosse)

214 T. braziliensis (Murray)

215 T. capuccina (Wierzejski \& Zacharias)

216 T. cylindrica (Imhof)

217 T. chattoni (De Beauchamp)

218 T. dixonnutalli Jennings

219 T. elongata (Gosse)

220 T. gracilis (Tessin)

221 T. hollaerti De Smet

222 T. iernis (Gosse)

223 T. insignis (Herrick)

224 T. longiseta (Schrank)

225 T. porcellus (Gosse)

226 T. pusilla (Lauterborn)

227 T. rattus (O.F. Müller)

228 T. ruttneri Donner

229 T.scipio (Gosse)

230 T. similis (Wierzejski)

$231 \mathrm{~T}$. similis $f$. grandis

232 T. stylata (Gosse)

233 T. tenuior (Gosse)

234 T. tigris (O.F. Müller)

$235 T$. vernalis (Hauer)

236 T. voluta (Hauer)

237 T. weberis Jennings

238 Trichotria tetractis (Ehrenberg)

239 Tripleuchlanis plicata Levander

240 Trochosphaera aequatorialis Semper

241 Wolga spinfera (Western)

R

$\mathrm{R}$

$\mathrm{R}$

$\mathrm{R}$

$R$

$\mathrm{R}$

L

$\mathrm{R}$

$\mathrm{R}$

$\mathrm{R}$

$\mathrm{R}$

$\mathrm{R}$

R

$\mathrm{R}$

$\mathrm{R}$

$\mathrm{R}$

R

R

R

R

R

$\begin{array}{ll} & \text { L } \\ & \text { L } \\ R & \text { L } \\ R & \text { L } \\ R & \text { L } \\ & \text { L } \\ R & \text { L } \\ & \text { L } \\ & \text { L } \\ R & \text { L } \\ R & \text { L } \\ R & \text { L } \\ R & \text { L } \\ R & \end{array}$

